\title{
In A Quest to Solve Information System Agility Problems \\ A SaaS Experience
}

\author{
By \\ Haibo Yang \\ A thesis \\ submitted to Victoria University of Wellington \\ in fulfilment of the requirements for the degree of \\ Doctor of Philosophy in Information Systems
}

Victoria University of Wellington

2018 


\section{Acknowledgements}

First and foremost, I must thank my brilliant supervisory team: Associate Professor Pedro Antunes, Dr. Mary Tate (HRA), Dr. David Johnstone, and Professor Sid Huff (HRA). Your extensive knowledge, great enthusiasm, infinite patience, and firm support have been invaluable in the creation of this thesis. I deeply appreciate the candid insights you have shared with me, regarding academia, life, and love.

My $\mathrm{PhD}$ has been a long and winding journey, many people have helped me along the way. My sincere thanks to all the admin staff in the School of Information Management and the School of Engineering and Computer Science, especially Usha, for your high efficiency, professionalism, and friendship. Thank Wiebke, Chiara, and Fang for all the inspiration, stimulation, and caring. Thank Hugo and Deon for those mind-blowing conversations and controversial jokes. Thank Richard and Brian for sharing the genuine joy in the pain of entrepreneurship. Thank Jimmy and Amy for looking after our animals and offering enjoyable distractions.

A special thanks to my thesis examiners: Dr. Markus Luczak-Roesch, Professor Alistair Barros, and Associate Professor Antonio Rito Silva. Thank you for the extraordinary scrutiny and fantastic recommendations.

Thank you, mum. I know this thesis is my "baby", not your grandchild. But I promise that you will be a grandma soon. Thank you, Lizzie, you are a true game changer and my life saver. Thanks for bringing me home.

Thank you, my late father. It's been more than 13 years since I last saw you, spoke to you, and hugged you. But your spirit still lifts me up in my darkest moments. Thank you for all the sacrifices. You are my hero.

Finally, a big THANK YOU to all my colleagues, teachers and students for the intellectual sparks you have passed on to me. Live long and prosper. 


\section{Abstract}

Change is endemic in modern business competition. In an age of globalisation, with the rapid development of information technologies (IT), changes occur at a much faster pace, and are also more unpredictable. Being agile in a turbulent environment has been ranked highly by executives in surveys of business issues conducted in past five years. Today nearly all organisations rely on information systems (IS) to operate. IS Agility is critical in achieving overall agility and performance in business. However, despite the strong interest from the practitioner community, IS Agility in academia has often been perceived as an overly abstract concept that is difficult to study. Resultantly, despite its importance, little has been published on how to systematically solve IS Agility problems with theoretical rigour and practical relevance. This "how to" question is a challenging one to researchers and is the major motivation of the present study.

A key difficulty to study IS Agility is the lack of a solid conceptualisation. In this thesis, based on a multidisciplinary literature review looking for a unified theory of IS Agility, we proposed the IS Agility Nomological Network (ISANN) as a holistic conceptualisation to be used for problem solving. Such a conceptualisation includes an IS Agility Cycle illustrating four stages (i.e. Sense, Diagnose, Select, and Execute) of the dynamic interactions between IS and its human agents (e.g. IS users and IS developers), a decision tree presenting four main IS Agility drivers (i.e. Change Frequency, Uncertainty, Information Intensity, and Time Criticality), and a pyramid incorporating four IS Agility Providers (i.e. Agile System-Development, Agile-System Architecture, Agile System-Operation, and Agile-System Configuration ). We classify IS Agility as having at least two sides, Dev Agility and Ops Agility. The former represents the agility of IS development function while the later refers to the IS operation function. We believe they are not the same, as agility in system 
development process doesn't necessarily translate to agility in the resulting system operation.

To be able to answer the "how to" question and design a systematic problem-solving approach, we then operationalised ISANN by developing data and task models in real-world settings. These models were used to investigate and analyse IS Agility problems faced by Software as a Service (SaaS) adopters. Such a SaaS environment, due to its multi-tenancy nature, provides a great opportunity to observe the interactions and trade-offs between Dev Agility (e.g. stories from engineers and developers) and Ops Agility (e.g. stories from operators and users), as well as an abundant source of IS Agility related business problems. Eventually, more elements and factors emerged from this SaaS practice and were merged into the final artefact created in this study: ISACAM (Information System Agility Causation Analysis Method). ISACAM incorporates all the dimensions and facts derived from the theoretical conceptualisation and the ongoing real-world problem-solving practice. The effectiveness of ISACAM in solving IS Agility problems has been observed through improved performance in real-life businesses. Furthermore, five technological rules have been synthesised to offer a prescription for designing solutions to improve IS Agility. 


\section{Table of Contents}

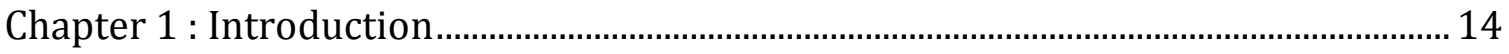

1.1 Research Problem / Motivation ............................................................................. 15

1.2 Research Goals / Objective / Questions ................................................................... 18

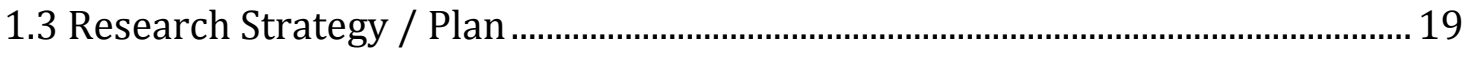

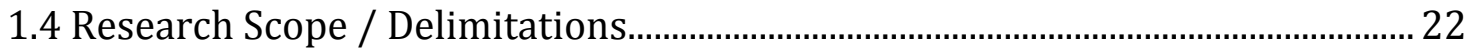

1.5 Major Outcomes / Contributions .......................................................................... 24

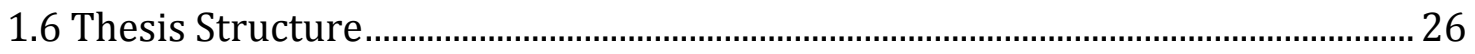

Chapter 2 : The Anatomy of IS Agility ………………………………………………... 28

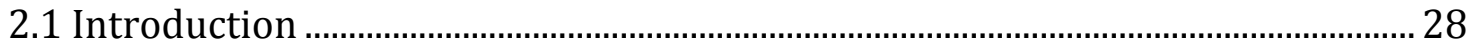

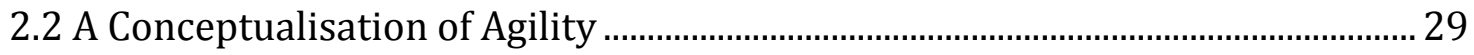

2.2.1 Agility vs. Flexibility: A Conceptual Clarification .............................................29

2.2.2 Agility in Business: A Conceptual Evolution ........................................................36

2.2.3 Sense and Respond Models: The Agility Cycle .................................................. 40

2.2.4 Main Categories of IS Agility Research .............................................................. 52

2.3 IS Agility Need vs. Supply - The Nomological Network ………............................... 68

2.3.1 IS Agility Drivers.........................................................................................................

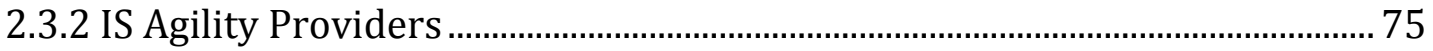

2.3.3 The IS Agility Nomological Network (ISANN) ……………………………... 78

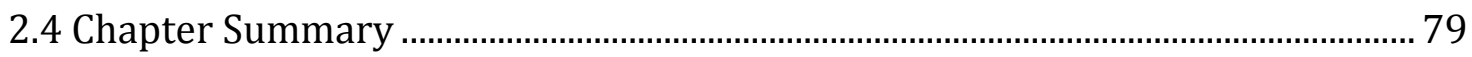

Chapter 3 : Operationalising ISANN …………………………………………………... 80

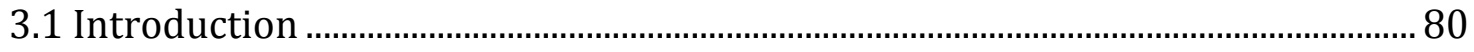

3.2 An Operational View of IS Agility: Illustrative Scenarios ………………………... 80

3.2.1 Dev S-R: Sensing and Responding Purely at Dev Level ................................... 84 
3.2.2 Ops S-R: Sensing and Responding Purely at Ops Level ................................... 94

3.2.3 On Interactions between the Dev and Ops Agility Cycles ...............................104

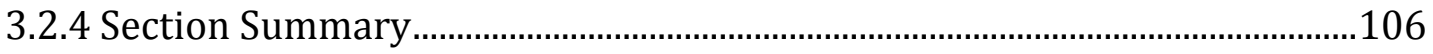

3.3 Applying ISANN: Descriptive Analysis of Cloud Services ………………………....109

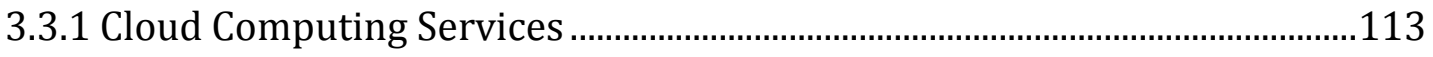

3.3.2 IS Agility Analysis of Cloud Services ……………………....................................117

3.3.3 Section Summary ..............................................................................................128

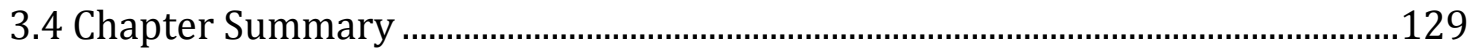

Chapter 4 : Design Science Research Methodology …………………………………...132

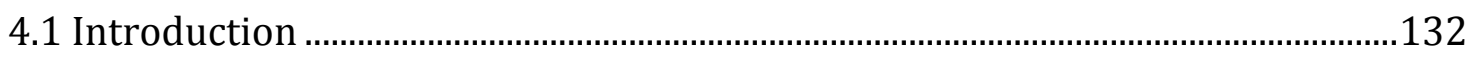

4.2 Problem formulation ..........................................................................................133

4.3 Philosophical Paradigm: Post-Positivism ..............................................................136

4.3.1 The Ontological Dimension ............................................................................137

4.3.2 The Epistemological Dimension ……………………………………………..139

4.3.3 The Methodological Dimension ......................................................................140

4.4 Design as a Scientific Research Method .................................................................141

4.4.1 Design? Science? Or both? .................................................................................141

4.4.2 Design Science Research in IS Field ..................................................................146

4.4.3 Design as a Reflective Practice.........................................................................149

4.5 Artefacts Design and Evaluation ……………………………………………......

4.5.1 The DSR Strategy and Process...........................................................................152

4.5.2 The Choice of Design Methods .........................................................................158

4.5.3 The Choice of Evaluation Methods ......................................................................164

4.6 Challenges of Design Science Research ................................................................170 
4.6.1 Danger of Self-Referential Paradox..................................................................170

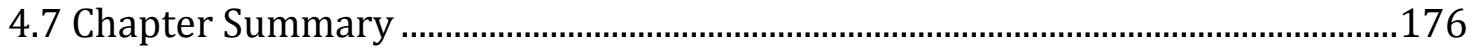

Chapter 5 : The Creation of ISACAM ………………………..............................................178

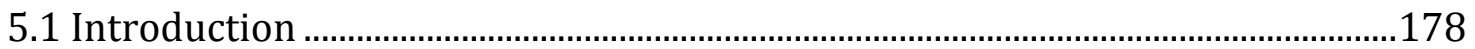

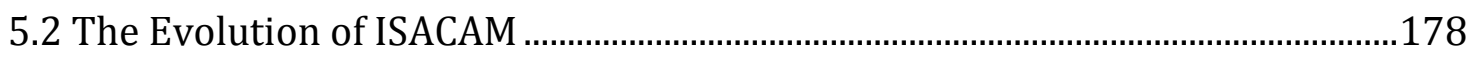

5.2.1 The DSR Environment........................................................................................179

5.2.2 Episode One - A “Sensing” Problem.....................................................................183

5.2.3 Episode Two - A "Diagnosing" Problem.............................................................205

5.2.4 Episode Three - A "Selecting" Problem .............................................................230

5.3 Ladders of Reflection .........................................................................................257

5.3.1 Reflection on Action - Some General Observations........................................257

5.3.2 Reflection on Technological Rules and ISACAM Artefacts ............................262

5.3.3 Reflection on the Success of "Agile Methodologies" ........................................273

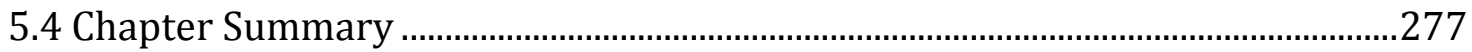

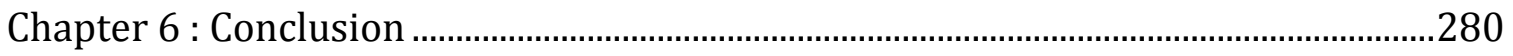

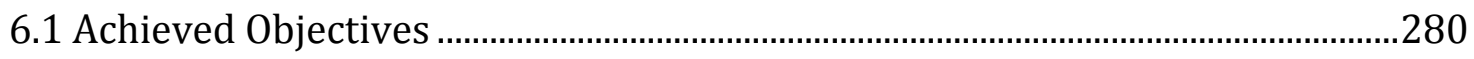

6.2 Main Contributions..................................................................................................281

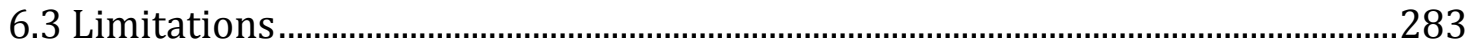

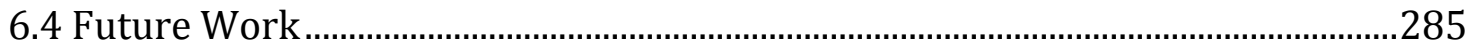

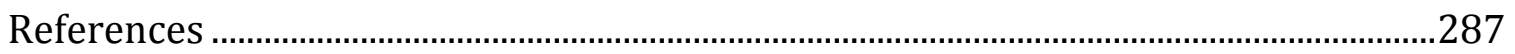

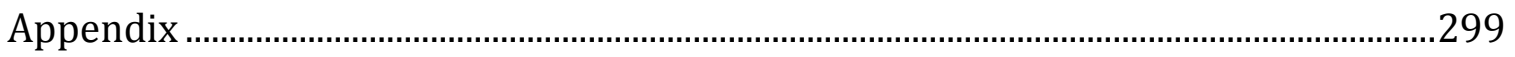




\section{List of Figures}

Figure 1: Components of Universal Agility in Sports Science......................................... 33

Figure 2: The Agility Cycle ………………............................................................................. 43

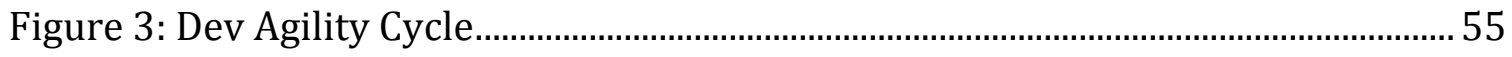

Figure 4: Ops Agility Cycle..................................................................................................6

Figure 5: IS Agility Pyramid ........................................................................................... 65

Figure 6: The Network of IS Agility ...............................................................................69

Figure 7: IS Agility Need Drivers - a decision tree .............................................................. 74

Figure 8: The Nomological Network of IS Agility (ISANN) ……………………………... 78

Figure 9: A Dynamic View of IS Agility ......................................................................... 82

Figure 10: The Steps for a Structured IS Agility Analysis of Cloud Services ...............118

Figure 11 A Strategic Framework of the Present DSR....................................................156

Figure 12 Design Process in General Design Theory ...........................................................163

Figure 13 FEDS Evaluation Strategies ………………………………………………….....165

Figure 14: A Recursive Function in Python ....................................................................172

Figure 15 A Self-Referencing Table Structure ................................................................173

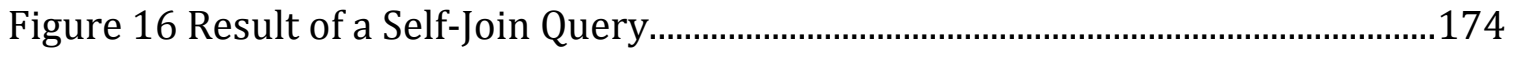

Figure 17: The Heinrich's Safety Triangle........................................................................185

Figure 18: The Initial Data Model of ISACAM Ver 1.0 ………………………………....193

Figure 19: The Task Model of ISACAM Ver 1.0 …………………………………………..195

Figure 20: The SDSE Mapping Table for Episode One.....................................................197

Figure 21: The Data Model of ISACAM Ver 1.1 ..............................................................215

Figure 22: The Task Model of ISACAM Ver 1.1 ……………………………………....216

Figure 23: The SDSE Mapping Table for Episode Two ......................................................218

Figure 24: The Data Model of ISACAM Ver 1.2 …………………………………….....240

Figure 25: The Task Model of ISACAM Ver 1.2 ………………………………………..242

Figure 26: The SDSE Mapping Table for Episode Three................................................24

Figure 27: Recap The SDSE Mapping Table....................................................................265

Figure 28: The Data Model of ISACAM Ver. 1.3 .................................................................271 
Figure 29: The Task Model of ISACAM Ver. 1.3 ...................................................................272

Figure 30: Scrum Software Development Process............................................................224

Figure 31: The SDSE Mapping Table for Scrum Methodology .......................................275 


\section{List of Tables}

Table 1: Research Strategy and Plan ......................................................................... 21

Table 2: Types of Agility in Sports Science .................................................................... 31

Table 3: Contrasting Agility and Flexibility ………………………………………….... 35

Table 4: Early Definitions of Agility in Business Literature ............................................. 38

Table 5: More Recent Definitions of Agility in Business Literature ................................ 39

Table 6: "Sense and Respond" Models .................................................................................. 41

Table 7: Cynefin Framework .......................................................................................... 51

Table 8: The Current Status of Key Research Areas of IS Agility.....................................66

Table 9: Drivers of IS Agility ……………………………............................................. 73

Table 10: Summary of Dev S-R vs. Ops S-R ...................................................................108

Table 11: Cloud Service Layers and Providers ................................................................114

Table 12: IS Agility Analysis of IaaS...................................................................................119

Table 13: IS Agility Analysis of PaaS...............................................................................122

Table 14: IS Agility Analysis of SaaS .............................................................................125

Table 15: Positivism vs. Post-positivism .......................................................................136

Table 16: Map of Design Science....................................................................................146

Table 17: Commonly Prescribed DSR processes .............................................................153

Table 18: Key Components of ISACAM and Design Methods used.................................162

Table 19: The Key Artefacts and Evaluation Methods.....................................................169

Table 20: Near Miss to Minor Injury Ration at E1 Company 2011 Q1 to 2012 Q2 ..187

Table 21: ADS Problem Solving of Episode One ............................................................189

Table 22: Near Miss to Minor Injury Ratio at E1 Company 2011 Q1 to 2012 Q4 .....191

Table 23: Near Miss to Minor Injury Ratio at E1 Company 2011 Q1 to 2014 Q1 .....201

Table 24: A Brief Summary of Episode One..................................................................201

Table 25: Number of Safety Events reported between 2012 Q1 and 2014 Q3..........206

Table 26: The Average Days Taken to Issue Corrective Actions 2012 Q1 to 2013 Q2

Table 27: ADS Problem Solving of Episode Two...............................................................211 
Table 28: The Average Days Taken to Issue Corrective Actions after Safety Incidents - 2012 Q1 to 2013 Q4. 213

Table 29: Number of Safety Events by Investigation types 2012-2013 .....................222

Table 30: The Average Days Taken to Issue Corrective Actions ....................................226

Table 31: A Brief Summary of Episode Two ………………….....................................227

Table 32: Number of Audits Started and Corrective Actions Issued at E3 in 2013.232

Table 33: ADS Problem Solving of Episode Three .........................................................236

Table 34: Number of Audits Started and Corrective Actions Issued at E3 Company

From April 2013 to March 2014 238

Table 35: Number of Audits Started and Corrective Actions Issued at E3 Company From April 2013 to August 2014 ……………………..................................................251

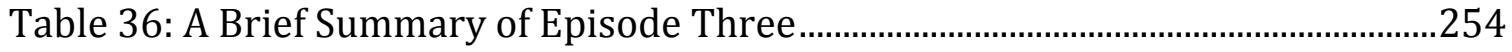

Table 37: ISACAM Technological Rules.......................................................................263

Table 38: Achieved Research Objectives ..........................................................................280 


\section{List of Publications (derived from this thesis)}

Resulted from Chapter 2:

Yang, H., Antunes, P. and Tate, M. (2016). Towards a unified conceptualisation of Agility: A design perspective. The 20th IEEE International Conference on Computer Supported Cooperative Work in Design (CSCWD) Nan Chang, China.

Resulted from Chapter 3:

Yang, H., Huff, S., and Tate, M. (2013). Managing the Cloud for Information Systems Agility. Cloud Computing Service and Deployment Models: Layers and Management. A. Bento and A.K.Aggarwal. Hershey, PA, USA, IGI Global: 70-93.

This book chapter has inspired and been cited in the first empirical studies towards the impact of Cloud Computing on IS Agility, e.g. (Sawas \& Watfa, 2015).

Yang, H. and Tate, M. (2012). "A Descriptive Literature Review and Classification of Cloud Computing Research." Communications of the Association for Information Systems 31(1/2): 35-60.

As at $1^{\text {st }}$ May 2018, this journal article has been cited over 200 times and remained on the "Most Popular Papers" list of the AIS since its inception. 


\section{Chapter 1 : Introduction}

For over a decade, becoming agile and able to thrive in a dynamic environment has been rated by executives as being at the top of their wish list. In an earlier global survey, 89 percent of over 1500 respondents indicated that agility is "very" or "extremely" important for business performance, while 91 percent perceived that the importance of agility has increased in the five years preceding the survey (McKinsey, 2006). Annual surveys conducted by the Society for Information Management (SIM) have consistently ranked agility at the high end among the top ten IT management concerns (Kappelman, McLean, Johnson, \& Gerhart, 2014; Luftman \& Ben-Zvi, 2010). More recently, agility has been again highlighted as a critical topic to both IS research and practice (Salmela, Tapanainen, Baiyere, Hallanoro, \& Galliers, 2015).

Given organisations nowadays rely extensively on IS (information systems) to operatate and to make business decisions, IS Agility has been emphasised as a crucial foundation for agile business by many researchers (Bhatt, Emdad, Roberts, \& Grover, 2010; Caswell \& Nigam, 2005; Goodhue, Chen, Boudreau, Davis, \& Cochran, 2009). As found in a survey of 660 CIOs conducted by HP, that the inability of the IT system to respond quickly to business changes is a genuine concern for these executives (HP, 2011).

This thesis, employing a Design Science Research paradigm, proposes a unified conceptualisation of IS Agility, and creates a generic IS Agility Causation Analysis Method (ISACAM) for design purposes. Both aim at empowering researchers and practitioners to clearly understand, analyse, and solve IS Agility problems with theoretical rigour and practical relevance. In the remainder of this chapter, we will discuss the research problem, motivation, goals, scope, research design, and major contributions of the study. 


\subsection{Research Problem / Motivation}

The present study was motivated by one grand problem observed in both the IT industry and the IS research field:

- RP0: The lack of prescriptive and systematic methods for solving IS Agility issues.

This grand problem can be divided into two sub problems:

- RP1: The lack of conceptual clarity and consistency of IS Agility as a notion

- RP2: The lack of prescriptive practice and method for designing IS Agility as a capability

Despite its importance, the concept of IS Agility tends to be taken at its face value thus seldom receives in-depth analysis from either researchers or practitioners (Mathiassen \& Pries-Heje, 2006). Systematic and rigorous examination of this concept has been rare. One reason that IS Agility is such an under-researched concept, despite the high industry demand, is that researching the concept has traditionally been difficult. Such difficulty lies in the complex and multifaceted nature of agility, which makes it hard to agree on how it should be investigated and from whose perspective (MacCormack, 2008).

Resultantly, the concept of IS Agility has been communicated in an ambiguous manner in both academic and practitioner literature. To the best extent, this concept is vaguely defined, using other abstract notions, as an ability of IS to produce nimble and speedy responses to business changes. Such conceptual vagueness is mostly caused by a lack of distinctiveness of the core concept of agility. Both IS researchers and IT practitioners tend to carelessly mix agility with other indefinite concepts, for example "flexibility" has often been loosely used in an interchangeable term of agility in both academic literature (Fullerton \& Ness, 2010; Ngo-Ye \& Ahsan, 2005) and in real-world IT projects. The indiscriminate use of "agility" and "flexibility" makes a literature review challenging. One has to delve into each article to seek a clear definition of its key concept -either "flexibility" or "agility"- before confidently 
including the article as a relevant reference. Achieving terminological distinctiveness and consistency is an important step for us to proceed further with research in this area.

We believe the conceptual vagueness (RP1) leads to the practical ambiguity (RP2). Without a solid conceptualisation, IS Agility as a notion, is bound to yield, diverse and disparate, interpretations and speculations, from both researchers and practitioners. For instance, in IS studies (i.e. studies published in IS journals or at IS conferences), when agility is referred to, the topics of interest can spread across the full spectrum what the IS field could possibly stretch. Researchers don't seem to have a consistent focus. Although they can reach as close to the presumed centre of our IS field, i.e. the design and development of IS artefacts, many times they can jump as far as to the boundaries, if any, between IS and other disciplines, e.g. organisational culture and climate. In the IT industry, agility, however, is mostly perceived as the equivalent to the adoption of agile software development methods, the scalability of computational resource, the modularity of system architecture, etc. Such diverse and inconsistent interpretations of IS Agility can make it difficult for both researchers and practitioners to find a common ground for knowledge sharing and problem solving.

Beginning with a general problem for research, and moving on to design and develop studies with clearly stated questions in specific contexts, has long been established as a reliable practice (T. J. Ellis \& Levy, June, 2010). However, not all problems are suitable for design science research (DSR). Gleasure (2015) argued that for a problem to be research-worthy to DSR, it should at least meet one of the three criteria:

1) the prescriptive aspect of the problem is less mature than the analytical, explanatory or predictive aspect,

2) effective solutions do not exist when an opportunity arises to engage with the class of design problems, 
3) important elements of a system may only become visible through the act of design (Gleasure, 2015).

The research problems, RP0, RP1 and RP2, tackled by the present study meet all three criteria, thus are suitable for DSR. First, IS Agility is not a mature field of study with rigorous and relevant prescriptions, thus many ambiguous and vague interpretations exist. Second, no existing methods have been established to solve IS Agility related problems. Third, to create a method for solving IS Agility problems, conventional behavioural research approaches cannot be more effective than the act of design through means-ends plus trial-and-error approaches. Before the present study, we simply didn't know what important factors should be taken into consideration to systematically solve IS Agility problems.

Furthermore, Ellis and Levy (2010) have recommended three types of problems that can drive DSR studies:

a) Lack of a product or a tool to correct a troublesome situation with emerging or evolving conditions

b) Lack of a workable method to conceptualise how to address a problem

c) Lack of instantiation in a new domain to address with unsolved conditions where similar problems were solved successfully in another domain (Timothy J Ellis \& Levy, 2010)

The three research problems (RP0, RP1 and RP2) driven this study fit in all three types listed above. Firstly, prior to the present study, there was no products or tools taking a holistic approach to help solving IS Agility related problems. Secondly, conceptualising IS Agility has been a challenging task and no workable conceptualisation was provided for problem-solving purposes before the present study. Thirdly, although not directly applicable, studies in other domains (i.e. sports science) that successfully address agility problems of athletes, can provide valuable insights to the present study, specifically in the creation of a systematic method for investigating and solving agility problems in the IS domain. 


\subsection{Research Goals / Objective / Questions}

Driven by the research problems identified from the previous section, we in turn identify two main research goals:

A. To generate a unified and holistic conceptualisation of IS Agility so that both researchers and practitioners can understand and utilise in their own specific contexts with clarity and consistency;

B. To design and develop a systematic method for investigating and solving IS Agility problems with which researchers and practitioners can follow prescriptive steps and rules to implement with clarity and consistency.

As a result of setting the above goals, this study explores the following research questions:

- RQ1: What are the constituents of IS Agility?

- RQ2: How do these constituents work together?

- RQ3: How to apply a conceptualisation of IS Agility in the form of a systematic method to investigate and solve IS Agility problems?

Consequently, our study established the following objectives:

a. To examine, synthesise, and refine existing theories/models of agility published in a broad range of literature;

b. To create a unified conceptualisation (i.e. ISANN) that explains why IS Agility is needed and how it can be achieved;

c. To justify and improve this unified conceptualisation and associated models through peer-review processes and/or scenario-based illustrations;

d. Based on the improved conceptualisation of IS Agility, to create a method for analysing and designing solutions to IS Agility problems (i.e. ISACAM); 
e. To evaluate and improve the relevance and effectiveness of the method through real-world applications.

\subsection{Research Strategy / Plan}

The research literature has suggested two main strategies for conducting DSR. The first, strategy 1 , is the deductive type examining theories in a context where an industrial partner may or may not be present (Gleasure, 2015). The second, strategy 2 , is the inductive/abductive type developing theories that are emerging from real-world projects. Gleasure urged there is a shortage of strategy 2 studies which is limiting the research field from generating new knowledge. One reason for such a shortage is that, engaging in industry projects can be too demanding for researchers with large volume of academic commitments. Another reason is that, not all industry projects can produce novel insights, especially with those merely routine consultancy projects. (Gleasure, 2015). Therefore, a key to effectively conduct strategy 2 DSR is that researchers need to identify the cutting edge of practice where mature artefacts may not yet exist.

The present study adopted strategy 2 DSR for two reasons. The first reason is that existing theories and models for explaining IS Agility are mostly too abstract and incomplete to be used in a strategy 1 type study. The second reason is that, as the researcher, I am also a "reflective practitioner" (Schön, 1983) working actively in the IT industry with direct access to real-life projects that are considered "cutting edge of practice" in terms of delivering agility in a Software as a Service (SaaS) environment. This SaaS solution has been adopted by over 100 client organisations ranging from large corporates in the energy industry to smaller entities such as regional or city councils. Such an environment offers abundant opportunities for IS Agility research, as almost all client organisations are expecting to improve IS agility (Hugos, 2010; Liu et al., 2007; Mullins, 2010; Oracle, 2010). 
Table 1 (in the next page) presents an overview of this study with four stages of research have been conducted to address all four research questions. RP1 (divided into RQ1 and RQ2) was first addressed in Chapter 2 and 3 before RP2, because when "the emerging or evolving condition is either very poorly understood or extremely complex", the conceptualisation of the problem supersedes the lack of a tool or product (Timothy J Ellis \& Levy, 2010). The real issue lies in "the absence of a workable method of conceptualizing how to address the problem...the lack of a way to model a siltation constitutes a worthy problem applicable to design research"(Timothy J Ellis \& Levy, 2010) (p.111). Addressing RP1 was mostly done through conceptualising and modelling IS Agility based on literature investigation and synthesis, as well as illustrations and analysis of industry examples (presented in Chapter 2 and 3). The results derived from addressing RP1 have been evaluated and published as a conference paper and a book chapter respectively (Yang, Antunes, \& Tate, 2016; Yang, Huff, \& Tate, 2013). 
Table 1: Research Strategy and Plan

\begin{tabular}{|c|c|c|c|c|c|c|c|}
\hline $\begin{array}{l}\text { Research } \\
\text { Problem }\end{array}$ & $\begin{array}{l}\text { Thesis } \\
\text { Segment }\end{array}$ & Purpose & $\begin{array}{l}\text { Research } \\
\text { questions }\end{array}$ & $\begin{array}{l}\text { Artefacts / } \\
\text { Outcomes }\end{array}$ & Design activities & $\begin{array}{l}\text { Evaluation } \\
\text { activities }\end{array}$ & Description \\
\hline \multirow[t]{2}{*}{ RP1 } & $\begin{array}{l}\text { Chapter } \\
2\end{array}$ & $\begin{array}{l}\text { To establish a } \\
\text { holistic } \\
\text { conceptualisation of } \\
\text { IS Agility }\end{array}$ & $\begin{array}{l}\text { RQ1: What are } \\
\text { the constituents } \\
\text { of IS Agility? }\end{array}$ & $\begin{array}{l}\text { The IS Agility } \\
\text { Nomological } \\
\text { Network (ISANN) }\end{array}$ & $\begin{array}{l}\text { Cross discipline } \\
\text { literature review } \\
\text { and synthesis } \\
\text { Conceptual } \\
\text { analysis and } \\
\text { modelling }\end{array}$ & $\begin{array}{l}\text { Artificial \& } \\
\text { Formative } \\
\text { Goal/Efficacy } \\
\text { Demonstration } \\
\text { (Peer Review) }\end{array}$ & $\begin{array}{l}\text { The main outcome of } \\
\text { Chapter } 2 \text { was published } \\
\text { as a CSCWD } 2016 \text { paper. } \\
\text { (Yang et al., 2016) }\end{array}$ \\
\hline & $\begin{array}{l}\text { Chapter } \\
3\end{array}$ & $\begin{array}{l}\text { To examine the } \\
\text { effectiveness and } \\
\text { usefulness of the } \\
\text { conceptualisation in } \\
\text { explaining and } \\
\text { analysing IS Agility }\end{array}$ & $\begin{array}{l}\text { RQ2: How do } \\
\text { these } \\
\text { constituents } \\
\text { work together? }\end{array}$ & $\begin{array}{l}\text { The Operational } \\
\text { View of Dev vs. } \\
\text { Ops Agility } \\
\text { A structured IS } \\
\text { Agility analysis on } \\
\text { Cloud Services }\end{array}$ & $\begin{array}{l}\text { Conceptual } \\
\text { analysis and } \\
\text { modelling }\end{array}$ & $\begin{array}{l}\text { Artificial \& } \\
\text { Formative } \\
\text { Illustrative } \\
\text { Scenarios(Peer } \\
\text { Review) } \\
\text { Goal/Efficacy }\end{array}$ & $\begin{array}{l}\text { Scenario-based analysis } \\
\text { and demonstrations in } \\
\text { Chapter } 3 . \\
\text { Punished CAIS article on } \\
\text { classification of Cloud } \\
\text { Computing research } \\
\text { (Yang \& Tate, 2012) } \\
\text { Published an IGI Global } \\
\text { book chapter explaining } \\
\text { how to manage Cloud } \\
\text { Services for IS Agility } \\
\text { (Yang et al., 2013) }\end{array}$ \\
\hline RP2 & $\begin{array}{l}\text { Chapter } \\
5\end{array}$ & $\begin{array}{l}\text { To operationalise the } \\
\text { conceptualisation } \\
\text { and apply it in real- } \\
\text { world problem- } \\
\text { solving situations. }\end{array}$ & $\begin{array}{l}\text { RQ3: How to } \\
\text { apply a } \\
\text { conceptualisation } \\
\text { of IS Agility as a } \\
\text { systematic } \\
\text { method to } \\
\text { investigate and } \\
\text { solve IS Agility } \\
\text { problems? }\end{array}$ & $\begin{array}{l}\text { ISACAM } \\
\text { (Information } \\
\text { System Agility } \\
\text { Causation } \\
\text { Analysis Method) } \\
\text { Technological } \\
\text { Rules }\end{array}$ & $\begin{array}{l}\text { Dimensional } \\
\text { modelling } \\
\text { Hierarchical Task } \\
\text { Analysis } \\
\text { Work domain } \\
\text { analysis } \\
\text { (Abstraction } \\
\text { Decomposition } \\
\text { Space) }\end{array}$ & $\begin{array}{l}\text { Naturalistic \& } \\
\text { Formative } \\
\text { Real-world } \\
\text { problem solving in } \\
\text { the form of } \\
\text { evaluation } \\
\text { episodes } \\
\text { Goal/Effectiveness }\end{array}$ & $\begin{array}{l}\text { Chapter } 5 \text { explains how } \\
\text { incremental changes } \\
\text { were made onto ISACAM } \\
\text { through processing real- } \\
\text { world problems. It also } \\
\text { demonstrates the } \\
\text { effectiveness of ISACAM. }\end{array}$ \\
\hline
\end{tabular}


RP2 (more specified in RQ3) was addressed through build-and-evaluate cycles (with methodology presented in Chapter 4, processes and outcomes presented in Chapter 5). Based on ISANN, data models and task models (essential components of ISACAM) were built, assessed, and evolved in real-world problem-solving settings. Models then were adopted in software prototypes.

As one of the first comers in this research direction, this study intends to maximise its contribution by embracing changes that happened during the investigation. Changes included emerging themes and relationships that were not found in the literature review and analysis but helped better understand and investigate the phenomenon of interest.

\subsection{Research Scope / Delimitations}

The research scope can be summarised into three key words:

- Adopters of Public Cloud

- IS Agility

- $\mathrm{SaaS}$

\section{Adopters of Public Cloud}

We chose public Cloud Computing as the research context for two reasons. Firstly, public Cloud Computing, which the term "cloud computing" commonly refers to, brings most impact to the traditional way of IT provisioning by providing the general public with off-site, on-demand, and pay-as-you-go computing self-services (Mell \& Grance, 2010). Secondly, compared to private cloud adopters who often are limited to internal users of a small number of organisations, public cloud adopters represent a much larger user base with significantly higher demographic diversity. In this study, the users subscribed to the NOHARM SaaS solution - that I have been directly involved in its fundamental activities such as designing, developing, training 
and consulting - are organisations of drastically different sizes, from different industries, stretching from public sector to private sector, yet all have a common intention, to reduce cost and improve agility by adopting the web-based multitenant SaaS approach.

\section{IS Agility}

The focus of this research is on IS Agility. This is based on the premise that IS Agility is important and has become a critical component of an agile business (Goodhue et al., 2009). Today's IS are often tightly coupled with business processes (especially in businesses requiring intensive information processing). Without agility, the IS may become an inhibitor rather than an enabler of business changes (SEO \& Paz, 2008). There are other factors that may impact the overall agility of an organisation, e.g. human resource strategy (Shafer, Dyer, Kilty, Amos, \& Ericksen, 2001). However, those other factors are not included within the scope of this study.

Besides agility, other pertaining concepts have been developed to explain business success in turbulent environments, such as absorptive capacity (Cohen \& Levinthal, 1990), strategic flexibility (Ansoff, 1980), dynamic capabilities (Tecce, Pisano, \& Shuen, 1997), and improvisational capabilities (Pavlou \& El Sawy, 2010). Nonetheless, these concepts largely zero in on strategic issues, whereas the concept of agility can apply to not only strategic issues, but more often it applies to tactical and operational issues. Strategic issues are distinct from tactical or operational issues (Porter, 1996). Therefore in alignment with other IS researchers, we have treated agility as a unique notion distinct from the aforementioned concepts (Overby, Bharadwaj, \& Sambamurthy, 2006; Pavlou \& El Sawy, 2010).

Moreover, the thesis is focused on analysing and solving IS Agility problems. This is done through designing an innovative method and applying it in real-world scenarios happened in the Cloud Computing ecosystem. The premise for such a study to be feasible is a well-established, stable cloud provider and adopter 
relationship where we can engage with the adopter's IS Agility problems on the provider's behalf. The adopters in such a context are mature cloud service users. Therefore other issues related to pre-adoption concerns such as data security, privacy, and "vendor lock-in" are considered beyond the scope of this thesis.

\section{SaaS}

This study was developed through real-world experiences in a cloud-based SaaS environment. Compared to the other two main layers of Cloud Computing services (i.e. IaaS and PaaS), SaaS seems to be the most problematic layer in terms of providing IS Agility to adopters, as changes and uncertainties occur at SaaS level tend to be much more diverse and complex. Such an observation was gained from a comprehensive review of Cloud Computing research literature and years of practical experience in the SaaS industry. The literature review was then published on CAIS (Yang \& Tate, 2012), followed by an IS Agility analysis on each layer of cloud services being published as a book section (Yang et al., 2013). An updated version of this analysis has been articulated in Section 3.3.2 of the thesis. Later an empirical study inspired by our book section also provided evidence to our observation that SaaS has significant problems with delivering IS Agility (Sawas \& Watfa, 2015). Therefore we see SaaS as an excellent field to study IS Agility problems as there is no lack of them.

\subsection{Major Outcomes / Contributions}

This study has four main contributions.

First, it has created the first IS Agility Nomological Network (hereafter ISANN, reported in Section 2.3.3) which brings a high level of clarity and consistency to the theoretical foundation of the concept of IS Agility. IS Agility as a notion has long suffered from a lack of consistency and distinctiveness in the literature. Such an 
issue can be a critical hinder for the IS research community to build up cumulative research culture (Keen, 1980). ISANN is considered the rigorous "kernel theory" for our further investigations and can be used by other researchers for new empirical studies as well. Part of ISANN has been published in a recently conference paper (Yang et al., 2016). The full version of ISANN will be published in the near future.

Second, based on the "kernel theory", this study offers in-depth analysis of the interdependencies between Agility components (reported in Section 3.2). Such analysis is practical and relevant to practitioners and can help them to make informed judgements by clarifying ambiguous agility notions. This contribution is in alignment with the call from Robey and Markus that IS research products need to be made simpler and consumable to thrive (Robey \& Markus, 1998).

Third, this study provides a structured IS Agility method to analyse cloud services. An earlier version of this method has been published as a book chapter (Yang et al., 2013) which then inspired one of the first empirical studies regarding the impact of Cloud Computing on IS Agility (Sawas \& Watfa, 2015). This empirical study has provided strong support to our analysis. An updated version of this method is reported in Section 3.3.2.

Finally, this study has designed and developed a structured and systematic method (ISACAM as the outcome of Stage Three, reported in Chapter 5 :) for investigating and solving IS Agility problems. ISACAM is based on solid theoretical analysis and reasoning yet evolves through series of real-world applications. Those major applications of ISACAM have yield successful results and are reported as three episodes in Chapter 5. 


\subsection{Thesis Structure}

The remainder of this thesis is structured as follows:

Chapter 2 surveys existing literature and synthesise a unified conceptualisation of IS Agility in the form of a conceptual framework (ISANN). Chapter 3 attempts to operationalise ISANN and demonstrates its efficacy through a series of illustrate scenarios. Particularly on the two key subcomponents of IS Agility, i.e. Dev Agility vs Ops Agility. Chapter 4 reviews the DSR methodology and provides justification for our choices of design and evaluation methods. Next Chapter 5 provides detailed description and reflections of the design and formative evaluations of ISACAM via a series of real-world applications. Finally, Chapter 6 concludes the research by elaborating on implications and limitations of the study and suggesting future directions. 


\section{Chapter 2 : The Anatomy of IS Agility}

\subsection{Introduction}

This chapter provides a literature review based on careful selection and examination of peer-reviewed studies on agility across multiple disciplines (sports science, military, business, and information technology).

IS appears to be a fertile field for popular but weakly defined concepts (Henri Barki, 2008). IS Agility is a good example, referred frequently by practitioners and researchers but often vaguely defined. Such vagueness has caused problems in differentiating the concept from other related ones and in establishing it as a legitimate and distinctive IS construct.

The development of a valid conceptualisation of IS Agility has been difficult (Maurer \& Goodhue, 2010). The difficulty in conceptualising IS Agility largely comes from the complex and multi-faceted nature of the general concept of agility (MacCormack, 2008). As such, agility in the business context has been made often indistinguishable from other similar notions and misused in academia and practice as an interchangeable term to other buzzwords such as flexibility and adaptability (Salmela et al., 2015; Yousif \& Pessi, 2016).

IS Agility can be viewed as a particular instance of the general concept of agility (Pankaj, Hyde, Ramaprasad, \& Tadisina, 2009). Establishing a good conceptualisation of agility in general is essential for providing a conceptual foundation for IS Agility. To understand the general concept, a broad review of related literature was conducted. Given the multidisciplinary nature of this concept, and the conceptual ambiguity existing in both academia and practice, the literature review extends to publications in the areas of sports science and military research where agility has long been studied with clearer and distinguishable conceptualisations. The purpose of this review is to elaborate on the essential 
meaning of agility, as well as to establish a proper theoretical foundation for the subsequent design and development of artefacts (Webster \& Watson, 2002).

This chapter starts by examining the general concept of agility and then extends to the specialised concept of IS Agility. This progression from generalisation to specialisation dominates the structure of the literature review. First, by comparing agility with other concepts, specifically, flexibility, we can provide more conceptual clarity to make the notion of agility distinguishable. Next we examine existing definitions and models of agility to identify the most valid ones. This is followed by further interrogation of the literature to synthesise the drivers and providers of IS Agility in the IS Agility Nomological Network (ISANN) for systematically describing and understanding the subcomponents of IS Agility.

\subsection{A Conceptualisation of Agility}

\subsubsection{Agility vs. Flexibility: A Conceptual Clarification}

Surveying both business related and IS related literatures suggests that the general concept of agility has suffered from the lack of a clear distinction between itself and other seemingly similar notions. Confusing agility with other concepts, especially flexibility, seems to be a common mistake in business and IS contexts. For instance numerous articles which include "flexibility" in their titles discuss the same concept to those with "agility" (Fink \& Neumann, 2007, 2009). Some papers even use these two terms in an interchangeable manner (Fullerton \& Ness, 2010; Ngo-Ye \& Ahsan, 2005; Sawas \& Watfa, 2015; Yousif \& Pessi, 2016).

Such terminological confusion can lead to perplexity not only in conceptualisation, but also in operationalisation of the potential constructs forming the notion of agility. Without a common terminology, studies are at risk of misleading each other, which makes it difficult for the IS research community to build up a cumulative 
research culture (Keen, 1980). Furthermore, Barki et al. (1993) have warned that "lacking a common research vocabulary" can make literature search less fruitful with low precision (i.e. a considerable number of articles found via keyword search in research databases can be of little relevance). The indiscriminate use of "agility" and "flexibility" makes a literature review unnecessarily troublesome, as the reviewer cannot rely on the title/abstract of an article to decide its relevance. One has to delve into each article to seek a clear definition or an explanation of its key concept - being either "flexibility" or "agility"- before confidently including the article as a relevant reference. Hence achieving terminological consistency is deemed critical to proceeding further with research in this area.

Exploring the origins of agility and flexibility also helps to clarify and differentiate these concepts. Business researchers have admitted that both agility and flexibility are "diverse concepts that are hard to grasp" (Gong \& Janssen, 2010). Part of the reason is that both were imported from other disciplines. Consequently, their distinctness is likely to be under-appreciated or lost in translation, hence misuses occur.

Both terms were originally used to describe physical capabilities of living beings and have been studied comprehensively in sports science as key predictors of athletic performance. Therefore, it is logical to look to the sports science literature as a source of developed knowledge about these two concepts and as a source of useful insights into the similarities and distinctions between the two.

In sports science, the agility concept is used to portray a desirable athletic capability which is critical to the athlete's performance in many competitive sports. Such capability is defined as a rapid whole body movement with change of velocity or direction accurately in response to a stimulus (Sheppard \& Young, 2006). Thus agility involves both reaction time and velocity. Reaction time is defined as the minimum time from the presentation of a stimulus to the onset of a response, and velocity is defined as the rate of change in position with respect to time (specifically 
referring to position) (Sheppard \& Young, 2006). Other underlying factors related to reaction time and velocity have been considered in sports, in particular the ideas of speed, coordination, reflex, and balance, all under one umbrella. But we will not delve into that level of detail in this thesis.

Agility is often used in the context of managing temporal and spatial uncertainties. Depending on the presence and absence of these uncertainties, agility in sports science has been classified into four categories: simple, temporal, spatial, and universal (as shown in Table 2 below ) (Sheppard \& Young, 2006).

Table 2: Types of Agility in Sports Science

\begin{tabular}{|l|l|l|}
\hline Types & \multicolumn{1}{|c|}{ Definition } & \multicolumn{1}{c|}{ Example of Sporting Skill } \\
\hline Simple & $\begin{array}{l}\text { No spatial or } \\
\text { temporal uncertainty }\end{array}$ & $\begin{array}{l}\text { Gymnast's floor routine: pre-planned activity, initiated when the } \\
\text { athlete desires, with movements that the athlete has pre-planned. } \\
\text { Stimulus is the athlete's own movement and the physical domain in } \\
\text { which they are executing the skill. }\end{array}$ \\
\hline Temporal & $\begin{array}{l}\text { Temporal } \\
\text { uncertainty, but } \\
\text { movement is pre- } \\
\text { planned (spatial } \\
\text { confidence) }\end{array}$ & $\begin{array}{l}\text { Athletics sprint start: pre-planned activity, initiated in response to a } \\
\text { stimulus (starter's pistol) wherein there is no certainty as to exactly } \\
\text { when the pistol will fire. }\end{array}$ \\
\hline Spatial & $\begin{array}{l}\text { Spatial uncertainty, } \\
\text { but timing of } \\
\text { movement is pre- } \\
\text { planned (temporal } \\
\text { confidence) }\end{array}$ & $\begin{array}{l}\text { Volleyball or racquet sport service receive: the umpire determines a } \\
\text { narrow window of time wherein the server must serve the ball to the } \\
\text { opponent. However, there is no certainty on the part of the receiver } \\
\text { as to where the service will be directed. }\end{array}$ \\
\hline Universal & $\begin{array}{l}\text { Spatial and temporal } \\
\text { uncertainty }\end{array}$ & $\begin{array}{l}\text { Ice hockey or football: during offensive and defensive plays, the } \\
\text { athletes cannot anticipate with certainty when or where opposition } \\
\text { players will move to. }\end{array}$ \\
\hline
\end{tabular}

Source: (Sheppard \& Young, 2006). 
Simple agility involves executing a series of pre-defined motions with the pace determined by the performer's own will meaning little temporal or spatial uncertainty is involved. However, most sports introduce either temporal uncertainties or spatial ones, or both, which require more complex types of agility.

Success in almost all contact sports requires universal agility. For instance, in a rugby game, a player carrying the ball knows a tackle will be initiated by the opponents, but he cannot predict when and where it will take place. However, once the tackle attempt occurs, the player needs to be agile enough to detect the signs and signals from the movement of his opponents and decide to either change direction to dodge the tackle, or quickly pass the ball to a teammate.

Examining the notion of agility in sports provides metaphorical insights in other contexts such as business. While "simple agility" may be less valued in business contexts which are characterised by uncertainties (H. Sharifi \& Zhang, 2001), the articulation of the "temporal" and "spatial" dimensions does provide an improved understanding of agility in business. More so if we regard spatial uncertainty as a specialisation of a related but more generic business concept: situational uncertainty. Situational uncertainty depicts uncertainty about the configuration of a system, a concept that can be more easily transferred to the business and IS contexts than spatial uncertainty ${ }^{1}$.

"Universal agility" is probably the most desirable form of agility businesses should aim for to prevail in today's competitive environments, since organisations need to accommodate environmental challenges by changing their situational context and doing it in reasonably short timeframes.

\footnotetext{
${ }^{1}$ Spatial Uncertainty still will be used hereafter throughout this thesis for the purpose of consistency.
} 


\section{Figure 1: Components of Universal Agility in Sports Science}

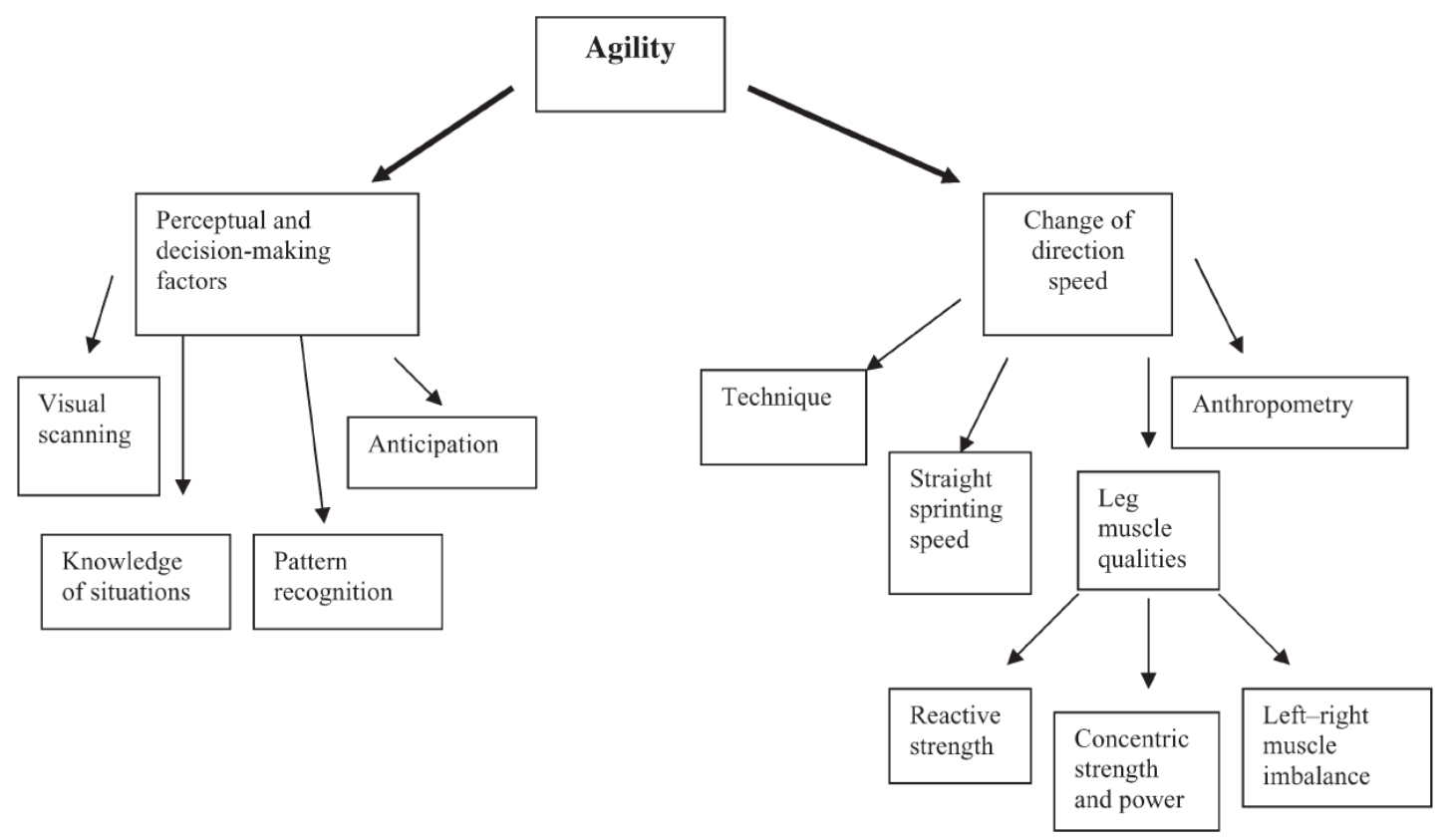

Source: (Sheppard \& Young, 2006).

According to the sports science literature, agility contains two major components (as shown in Figure 1 above): Decision making and change making (Sheppard \& Young, 2006). The decision-making part concerns perceptual activities. It includes scanning the environment for stimuli of change, recognising patterns, understanding the unfolding situations, and anticipating potential situational changes needed. All these perceptual activities should be done before the subsequent change of direction or speed can take place. The change making part refers to the actual execution of a decided response. The quality of the execution is determined by multiple factors such as technique, strength, balance, anthropometry, and so forth (Sheppard \& Young, 2006).

Measuring agility of individual athletes in the sports field is formal and quantitative in nature, for instance, the Illinois Agility Test. Such a test involves whole body moments in the form of multiple changes in direction and velocity in response to 
certain types of events, and the result is judged by the time taken for the testee to finish the test. The less time needed to complete the test, the more agility the testee is considered to have.

Flexibility is also a frequently mentioned concept in sports science, but in contrast to agility, it is considered less complex. Though it also relates to change, flexibility does not involve uncertainty nor the temporal dimension that characterises agility. Flexibility is often defined as the total "achievable excursion" of a body part through its potential range of motion (ROM) in a smooth, easy, unrestricted, and pain free manner (Alter, 2004).

Such emphasis on range means that flexibility can be conveniently evaluated by simple tests such as a "sit and reach" in which the testee is asked to reach both arms forward while sitting on the floor with straight legs. The maximum reach can be measured with a ruler. The further the maximum reach is, the more flexibility the testee is considered to have.

Depending on the particular sport, flexibility is often seen not as critical as agility to the athlete's performance. For instance, cricket players do not need to be as flexible as gymnasts, but they do need a higher level of universal agility to be able to hit and run in the right time to succeed in games.

In many sports, agility training is used to improve athletic performance, whereas flexibility training is considered a supportive conditioning for preventing injuries from sudden stretch of muscles and joints when performing agility-demanding tasks in competitions (Alter, 2004).

Table 3 below summarises the differences between the concepts of agility and flexibility derived from the sports science literature. Though both concepts relate to change, they are separate and distinctive to each other. Such conceptual distinctiveness helps us clarify the two notions in the business and IS contexts and gives insight into the true meaning of each. 
Table 3: Contrasting Agility and Flexibility

\begin{tabular}{|l|c|c|}
\hline \multicolumn{1}{|c|}{ Agility } & Flexibility \\
\hline $\begin{array}{l}\text { Emphasis on } \\
\text { Speed of motion }\end{array}$ & Yes & No \\
\hline $\begin{array}{l}\text { Emphasis on } \\
\text { Range of motion }\end{array}$ & No & Yes \\
\hline Uncertainty & Yes & No \\
\hline Measurement & Response Time & Capability Range \\
\hline Purpose & $\begin{array}{l}\text { Mostly for improving athletic } \\
\text { performance - increasing speed } \\
\text { of response }\end{array}$ & $\begin{array}{l}\text { Mostly for preventing } \\
\text { sports injury - } \\
\text { widening range of } \\
\text { response }\end{array}$ \\
\hline
\end{tabular}

Any good definition should include a genus and differentia. The former describes a broader category of the thing to be defined, and the latter is what distinguishes the thing from others in the same category (Pankaj et al., 2009). The definitions of agility and flexibility provided by sports science literature meet these criteria. They both concern the athlete's response in the form of motions, or changes of body positions, but one emphasises the time for completing the response while the other emphasise the range of the response.

In this study, the differentia summarised in Table 3 is used to guide the review and synthesis of the agility and flexibility concepts as drawn from the literature in the business and IS disciplines. On one hand, if a reference to flexibility includes notions of uncertainty (temporal and/or spatial) and speed of response, it will be treated as an agility reference and included in the review. On the other hand, if a study refers to agility but does not introduce the aforementioned notions, it will be excluded from the review. 
The foregoing review of the sports science literature has injected great conceptual clarity concerning the concepts agility and flexibility. With such clarity, next, we examine the definitions of agility in relevant business and IS literature.

\subsubsection{Agility in Business: A Conceptual Evolution}

\subsubsection{The History of Agility in Business Research}

For decades, business researchers have studied various approaches and capabilities for handling changes in organisations and their environments. Such changes used to happen at a relatively slow pace and often with limited level of uncertainty involved, hence the traditional approach for handling changes has been to increase flexibility which is essentially to expand the range of processes/products/services a business system can accommodate (Slack, 1993).

Today, however, simply building flexibility cannot cope with the changes faced in many industries (e.g. banking, finance, insurance, IT, manufacturing). The globalisation and development of technologies have introduced unprecedented levels of complexity and uncertainty, along with a much higher rate of change, into the internal and external environments of businesses. Building up agility has therefore been identified as a new approach replacing flexibility with the inclusion of speed for handling rapid and unanticipated changes in the business environment (Baskerville, Mathiassen, \& Pries-Heje, 2005; Kieran Conboy, 2009; Kieran Conboy \& Fitzgerald, 2004).

Agility, again, is an imported concept for business organisations. The earliest appearance of this concept in the business literature was probably the "corporate agility" brought in by Brown and Agnew in 1982 (Brown \& Agnew, 1982). However, the first time that agility entered the mainstream business literature was in a report named $21^{\text {st }}$ Century Manufacturing Enterprise Strategy (Goldman, Preiss, Nagel, \& 
Dove, 1991) within which the term agile manufacturing was coined. This report was a result of a joint study in the 1980s by the US government and the US business sector to discover new approaches for the US manufacturing industry to succeed in the global competition, with a special focus on its Japanese competitors.

Following this report, business agility was discussed more extensively in a subsequent book titled Agile Competitors and Virtual Organisations (Goldman, Nagel, \& Preiss, 1995) which defined four dimensions of agile competition: 1) enriching the customer, 2) cooperating to enhance competitiveness, 3) organising to master change, and 4) leveraging the impact of people and information. Businesses need to compete against rivals in handling changes in their customers, partners, and business operations to achieve desirable financial performance (Ngo-Ye \& Ahsan, 2005). Businesses must not only be capable to change, but to change quickly and gracefully (Baskerville et al., 2005).

The concept of agility has then been disseminated across various business disciplines. To describe such ability, researchers and practitioners have created a number of terms including "business agility" (Mathiassen \& Pries-Heje, 2006), "corporate agility" (Bradley \& Hood, 2003), "enterprise agility" (C.-Y. Huang \& Nof, 1999), "organisational agility" (Sull, 2010). Such vigorous creation of new terms for describing a common concept is a sign of increasing interest, but it is also a reflection of the lack of a common and concrete conceptualisation in the centre of such interest.

\subsubsection{The Development of Definitions of Agility in the Business Literature}

Various definitions of agility can be found in the business literature. Table 4 below summarises several early definitions of agility. These definitions commonly describe agility by its antecedents (e.g. unanticipated or unexpected changes, rapid change) and consequences (e.g. thrive, survive, and embrace change). Defining a concept by its antecedents and consequences is a useful practice for initial conceptualisations of a phenomenon of interest since such interest is often aroused by the need for 
effectively and efficiently articulate the antecedents and the need to articulate the desirable consequences. This is also a sign of the concept being premature and at a pre-science stage.

Table 4: Early Definitions of Agility in Business Literature

\begin{tabular}{|l|l|}
\hline Definitions (Agility defined by its antecedents and consequences) & Reference \\
\hline The ability to react quickly to changing circumstances. & $\begin{array}{l}\text { (Brown \& } \\
\text { Agnew, 1982) }\end{array}$ \\
\hline $\begin{array}{l}\text { Agility is the ability to thrive in a competitive environment of } \\
\text { continuous and unanticipated change and to respond quickly to } \\
\text { rapidly changing, fragmenting global markets that are served by } \\
\text { networked competitors with routine access to a worldwide } \\
\text { production system and are driven by demand for high-quality, } \\
\text { high-performance, low-cost, customer-configured products and } \\
\text { services. }\end{array}$ & \\
\hline $\begin{array}{l}\text { Agility is primarily concerned with the ability of enterprises to } \\
\text { cope with unexpected changes, to survive unprecedented } \\
\text { threats from the business environment, and to take advantage of } \\
\text { changes as opportunities. }\end{array}$ & Zhang, 2000) \\
\hline $\begin{array}{l}\text { The ability of an organisation to thrive in a continuously } \\
\text { changing, unpredictable business environment. }\end{array}$ & (Dove, 2001) \\
\hline $\begin{array}{l}\text { Agility is the successful exploration of competitive bases } \\
\text { (speed, flexibility, innovation pro-activity, quality, and } \\
\text { profitability) through the integration of reconfigurable resources, } \\
\text { and best practices in a knowledge-rich environment to provide } \\
\text { customer-driven products and services in a fast-changing } \\
\text { market environment. }\end{array}$ & $\begin{array}{l}\text { Kayakarni, \& } \\
\text { Jaknar, } \\
\text { 2001) }\end{array}$ \\
\hline $\begin{array}{l}\text { Agility is the continual readiness of an entity to rapidly or } \\
\text { inherently, proactively or reactively, embrace change, through } \\
\text { high quality, simplistic, economical components and relationships } \\
\text { with its environment. }\end{array}$ & $\begin{array}{l}\text { (Kieran } \\
\text { Conboy \& } \\
\text { Fitzgerald, } \\
\text { 2004) }\end{array}$ \\
\hline
\end{tabular}

Later conceptualisations tend to focus more on the core components or elements of the concept by removing antecedents and consequences from the definitions. 
Defining a concept by capturing its core primitives alone is essential for achieving conceptual maturity and theoretical parsimony. This in turn can enable further possible scientific operationalisation of the concept.

Table 5: More Recent Definitions of Agility in Business Literature

\begin{tabular}{|l|l|}
\hline Definitions (Agility defined by its core components) & Reference \\
\hline $\begin{array}{l}\text { The ability to detect and seize market opportunities with } \\
\text { speed and surprise. }\end{array}$ & $\begin{array}{l}\text { (Ngo-Ye \& Ahsan, } \\
2005)\end{array}$ \\
\hline $\begin{array}{l}\text { Agility is a response to the challenges posed by a business } \\
\text { environment dominated by change and uncertainty. }\end{array}$ & $\begin{array}{l}\text { (Zain, Rose, } \\
\text { Abdullah, \& Masrom, } \\
2005 \text { ) }\end{array}$ \\
\hline $\begin{array}{l}\text { The ability of firms to sense environmental change and } \\
\text { respond readily. }\end{array}$ & (Overby et al., 2006) \\
\hline $\begin{array}{l}\text { The ability to sense and respond to changes in an } \\
\text { organisation's internal and external environment by } \\
\text { quickly assembling resources, relationships and capabilities. }\end{array}$ & $\begin{array}{l}\text { (Gallagher \& } \\
\text { Worrell, 2008) }\end{array}$ \\
\hline
\end{tabular}

Table 5 above lists more recent definitions of agility found in the business literature, which focus more on core concepts. These definitions attempt to elucidate the internal composition of agility by describing forms of motion as the core components of agility, e.g., "sense" and "respond". The core components of agility have been added into these definitions over time and in an incremental manner, e.g. after "respond" has been well established as a core component of agility (Goldman et al., 1995), "sense" was incorporated into the definition (Overby et al., 2006).

Being able to respond to changes quickly has for long been mentioned as part of being agile (Goldman et al., 1995; Overby et al., 2006; H. Sharifi \& Zhang, 2001). "Responding" is the ability to leverage favourable changes or to develop defences against negative changes by adjusting one's course of action (Nazir \& Pinsonneault, 
2008). This could involve modifying existing products, services, processes, distribution channels, or creating new ones (Overby et al., 2006).

Early conceptualisations often stress the "responding" part and consider agility to be a reactive capability. This is in line with the COBIT (Control Objectives for Information and related Technology) framework (IT_Governance_Institute, 2007) which specifies agility as the capability of an IT function to respond to received changes in business requirements and strategy. Subsequent research work has suggested that agility should also be conceptualised as a proactive capacity in which sensing change should be the first action taken before responses can be made (Gallagher \& Worrell, 2008; Overby et al., 2006). In the business context, "sensing" is the ability of an organisation to track regulatory changes, competitor's actions, consumer preferences, technological advancements, and so forth (Overby et al., 2006).

The importance of this "sense and respond" lens in understanding business IS was argued by Sambamurthy in an influential MISQ paper (Sambamurthy, Bharadwaj, \& Grover, 2003) and used in subsequent studies to further develop theories. For instance, Overby et al. (2006) in an EJIS paper has proposed that the imbalance between sensing and responding capabilities can prevent firms from being agile and waste valuable resource (Overby et al., 2006). Since then, the capabilities of "sensing" and "responding" have been considered core components of agility and matching development should be done on both capabilities to achieve agility.

\subsubsection{Sense and Respond Models: The Agility Cycle}

The "sense and respond" lens provides some structural integrity regarding business agility. Such a structure roughly resonates with the components of agility in sports science literature, i.e. as shown in Figure 1 in Section 2.2.1, "sense" is more aligned with "perceptual and decision making", while "respond" more with "change of 
direction and speed". This rough alignment confirmed our approach in selecting literature and allowed us to review the literature with a better focus at a finer level of detail. Further investigation into the existing publications has suggested that "sense and respond" is not at all a brand-new notion in non-sport contexts and has been studied by other research communities besides business and IS. For instance, military researchers have long been developing models and theories to improve responsiveness in C2 (Command \& Control) operations based on sense and respond behaviour (Lawson, 1981).

Table 6: "Sense and Respond" Models

\begin{tabular}{|c|c|c|}
\hline Model & Components & Authors \\
\hline SDSE & Sense-Diagnose-Select-Execute & (Pankaj et al., 2009) \\
\hline SARI & Sense-Interpret-Analyse-Decide-Respond & $\begin{array}{c}\text { (J. Schiefer \& } \\
\text { Seufert, 2005) }\end{array}$ \\
\hline SIDA & Sense-Interpret-Decide-Act & $\begin{array}{c}\text { (Haeckel \& Nolan, } \\
1996)\end{array}$ \\
\hline SPCDA & Sense-Process-Compare-Decide-Act & (Lawson, 1981) \\
\hline SHOR & Stimulus-Hypothesis-Option-Response & (Wohl, 1981) \\
\hline OODA & Observe-Orient-Decide-Act & (Boyd, 1976) \\
\hline
\end{tabular}

Table 6 above provides a list of other representative "sense and respond" models we found across the literature of business, IS, and military. Among this set of models, the OODA model developed by military strategist Colonel John Boyd for the US Air Force is considered a seminal work. OODA, with "Observe and Orient" seen as subunits of "Sense" while "Decide and Act" as subunits of "Respond", was developed as a training program for fighter pilots to explicitly establish a dynamic learning habit. It is believed that pilots who learn to "cycle through" these mental stages faster than their opponents will prevail in dogfights where agility overtakes raw offensive power. Such a belief was derived from observations during the Korean War in the 1950s' 
when the US F-86 Sabres pilots achieved a 10 to 1 kill ratio over the pilots flying the more powerful Russian MIG-15 fighters. Compared to the mechanically more advanced MIG-15, the F-86 aircrafts allowed better visibility for fast sensing and easier control systems for rapid manoeuvre (Osinga, 2005).

The OODA model was first articulated as a tactical model for air-to-air combats in the 1960s' and later became a strategic model for command and control. The essence of OODA is a loop-like structure with Observe often being the default starting point. The following phases, Orient, Decide, and Act will in turn send feedback to the Observe phase for better informed observation. Such a model represents a philosophy of handling uncertainty and unpredictability through continuously refreshing one's perception of the reality and challenging the status quo.

The OODA model has been applied in business studies by Steve Haeckel and Richard Nolan who altered it to a SIDA loop (also in Table 6) to explain the transformation of modern businesses from "Make and Sell" to "Sense and Respond" in the information age (Haeckel \& Nolan, 1996). The OODA model has also been extended to the ECommerce context by John Canter as an "agility" model to explain the competition in business environments, which are seen as complex, non-linear, unpredictable and continuously changing (Canter, 2000). As argued by Canter, a competitive business marketplace is similar in many ways to a military battlefield (Canter, 2000).

Later on, more models have been published in business outlets, but share much in common with the OODA model. Examples include the SARI (J. Schiefer \& Seufert, 2005) and SDSE (Pankaj et al., 2009) models. SDSE is the most recent model used to describe the subcomponents of agility and has been assessed in an empirical IS study based on ten interviews with IS executives. In this study, Pankaj et al. (2009) verified that Sensing, Diagnosing, Selecting, and Executing are considered the four key capabilities enabling agility and concluded that each capability has its own distinct features which need to be developed individually. 


\subsubsection{The Agility Cycle}

All "sense and respond" models affirm a cyclic view of how agility should be achieved. Based on these models and following the recent terminology used in the literature (Pankaj et al., 2009), we propose the "Agility Cycle” (see in Figure 2, also called the "SDSE loop" in this thesis) as an abstract yet fundamental means to illustrate and consolidate the concept of agility. In this study, we posit that agility is not a one-off effort, rather, it is achieved though iterative loops which result in a continuous awareness and readiness for change in an ever-shifting and uncertain environment. An agile organisation needs to strive for refreshed perception of reality during each loop, as observations of the environment may be incomplete and imperfect.

In this Agility Cycle, we also introduce the concept of "Synchronicity" to highlight the time aspect of agility, as well as "Friction" and "Torque" to represent the forces that slow down and/or speed up the cycle. All these notions will be explained in the following pages.

\section{Figure 2: The Agility Cycle}

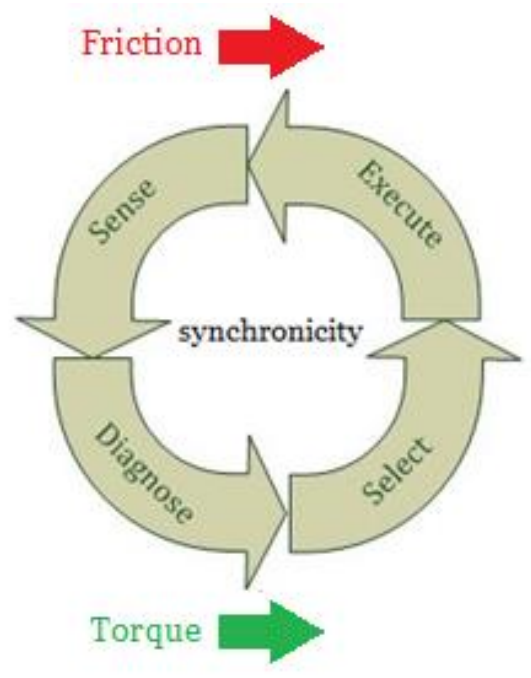

Sensing is about detecting and collecting signals from the business environment that suggest a need for change in the perception of reality and/or the course of 
action. This is arguably essential to initiate or continue a response, as the sensing capability of an organisation determines what changes can be observed (Ngo-Ye \& Ahsan, 2005; Overby et al., 2006). Today, physical and virtual sensors can be set up to monitor business signals such as customer shopping preferences, performance in order fulfilment, reputation on social media, etc. Sensors can also be used to capture signals from the IS and underlying technologies, such as security breaches of users, computing and storage resource, network traffic, etc.

If the sensing capability is flawed, the organisation may delay necessary changes. Even worse, it may initiate incorrect responses which can mislead the business to waste valuable resources. Given that most business organisations do not have unlimited resources, the consequences of flawed sensing, if not detected, can strain a business significantly ranging from cost increases to loss of market share and competitive advantages (Pankaj et al., 2009).

Diagnosing is about filtering and interpreting signals. Filtering involves separating valid signals from noise (Pankaj et al., 2009). Effectively and efficiently filtering out relevant and valuable data and discarding the rest is especially imperative for businesses operating in "globally wired", information intensive marketplaces (Canter, 2000). Such marketplaces are overloaded with data but much of it is noise rather than signals. With the explosive growth of data fuelled by further diffusion of Internet-based applications, the signal-to-noise ratio tends to wane thus distinguishing the two is becoming more important than ever (Silver, 2012). Without a proper filtering mechanism, businesses can be overwhelmed or even paralysed by the excessive amount of data received from internal, organisational, and environmental sources.

Interpreting is also a critical phase of diagnosing. Once a signal is sensed, it needs to be analysed and understood before any meaningful response can be made. Accurate diagnosis allows the organisation to gain more understanding towards the nature and cause of a change. An important objective of the diagnosis phase is to detect 
patterns and trends by collectively interpreting signals which individually may be too small to indicate an upcoming change in the environment (Pankaj et al., 2009). Today, many businesses have started to adopt techniques such as data-driven risk assessment and probabilistic analysis to help evaluating the likelihood and potential consequences of changes occurring in their organisations as well as from their environments.

Selecting is about deciding on a response to the diagnosed change. This is the process of choosing an hypothesis about a situation and making a response to it (Grant \& Kooter, 2005). A response can be as big as "change the whole working process" or as little as "keep an eye on it". Setting up criteria for selecting a response can help the decision making process. The four metrics-time, cost, predictability, and scope,-defined by Dove may be used as metrics to assess response proficiency (Dove \& LaBarge, 2014). Ideally, an agile business should be capable of continuously selecting responses within the time constrains and without compromise on other metrics (Pankaj, 2005). In situations where agility is critical, time should be prioritised but if there are several responses satisfying the time constraints, then other criteria need also be considered. This requires mastery in estimation to assess the available responses against the four metrics and the resources available. In reality, a "quick patch job" that can be done in time may be more valuable than a robust solution done too late (Pankaj, 2005).

Executing is the process of testing the chosen hypothesis by acting on the selected response (Grant \& Kooter, 2005). This stage is where flexibility can play a role. An inflexible business may find executing harder than a flexible one does. However, if an inflexible business senses a change way before the flexible one takes notice, it might start responding much earlier than the flexible one. Therefore, we note again that being flexible is not a sufficient condition to agility. Even though flexibility can help, a flexible organisation may not be agile if it is unable to detect and decide in a timely manner. 
Execution involves disseminating decisions and supervising actions through feedback (Canter, 2000). This stage is a critical part of the Agility Cycle, as a successful execution requires excellence in coordination between multiple aspects of the selected response (e.g. time, cost, scope, etc.). Being the last stage of the Agility Cycle, execution failure can effectively negate the results of the previous stages.

If a response is not executed within the time constrains, or it is executed in time but not as intended (e.g. of poor quality, at excessive cost) then it cannot be considered successful. The execution phase completes one loop of the Agility Cycle. As responses have been made, the situation is now changed, hence initiating a new loop that demands for new observations (Canter, 2000).

In a large business, multiple Agility Cycles may be processed concurrently within and between functions and business units. Reconciling these multiple cycles requires more effort in coordination and communication than does focusing on a single one. Therefore, an additional layer of orchestration or federation needs to be considered when designing an agile IS to support an agile organisation.

Synchronicity is used to describe the time aspect of the Agility Cycle. Dennis et al. (2008) in their MISQ article defines Synchronicity as "a state in which individuals are working together at the same time with a common focus" (p.581) (Dennis, Fuller, \& Valacich, 2008). Following this definition, by Synchronicity we mean that the individual steps in the Agility Cycle, i.e. "Sense", "Diagnose", "Select", and "Execute", should be working continuously without anyone lags behind and sharing a common focus of looping through the cycle.

Synchronicity characterises a synchronous and timely flow from one step to the next without any blockage. It demands for a desirable state of harmonious balance across the four steps of the Agility Cycle when continuously looping through iterations. In one single loop through the Agility Cycle, the output of a previous step (e.g. diagnose) 
should naturally become part of the input of the following phase (e.g. select) without delay. When looping through multiple iterations, however, a fast-moving Agility Cycle may have several steps (e.g. sense and diagnose) processing the next iteration already while the others (e.g. select and execute) still finishing the current one. This way, the capacity of each step on the Agility Cycle is fully utilised and not waiting in idle state. Such a full utilisation of capacity represents a high level of "Agility Alignment" described by Overby et al. (2006). This level of alignment indicates no material imbalance between the "sense" and "respond" capabilities of an enterprise through overdevelopment or underdevelopment.

Synchronicity also indicates that in any single loop of the Agility Cycle, the "respond" phase should occur within a certain acceptable period of time after the "sense" phase, and vice versa. Otherwise a response would be considered "out of sync" meaning outdated or even failed. Such an "acceptable time frame" between sense and respond hereafter is denoted by $\Delta \mathbf{S}$-R. In business, this $\Delta \mathrm{S}$-R can vary much vertically within an organisation, or horizontally across industries. For instance, along the vertical hierarchy, at the operational level, a business may need to set its $\Delta \mathrm{S}-\mathrm{R}$ as short as a matter of minutes (e.g. order fulfilment for online digital products), whereas at the strategic level, an acceptable $\Delta \mathrm{S}$-R can mean weeks if not months (e.g. acquisition of a smaller rival company). Horizontal contrast also exists among different industries, for example, in textile manufacturing, days or weeks are acceptable values of $\Delta \mathrm{S}$-R for changing colours and styles of products, whereas in high-frequency stock trading it often goes down to seconds if not milliseconds, meaning a few seconds late is considered a failure as the opportunities are already gone.

We argue that explicitly defining $\Delta S-R$ values at different organisational levels is essential for businesses to achieve agility. Being agile presupposes being timesensitive and acknowledge time constrains in business operations. This is a key property that differentiates agility from other concepts such as flexibility. Previously 
such time constrains have often been vaguely described as "quickly" (Gallagher \& Worrell, 2008; Goldman et al., 1995), "rapidly" (Kieran Conboy \& Fitzgerald, 2004; Goldman et al., 1995), "with speed" (Ngo-Ye \& Ahsan, 2005)," "in real time” (Pankaj et al., 2009), or "right-time and on-demand" (Knabke \& Olbrich, 2013). All these terms are attempts to capture the sense of urgency that inheres in agility. However, the terms "quickly, rapidly, with speed" can be too ambiguous to implement, whereas "real time" may be too radical and may only happen in an ideal world.

The notions of Synchronicity and $\Delta \mathrm{S}$-R can provide more conceptual clarity than the predecessors by articulating a particular state and depicting a specific and realistic time frame within which agile businesses should perform. Since modern businesses are defined by competition, it is not the absolute speed that matters, but rather the speed relative to one's customers and competitors (Canter, 2000). As long as a business can maintain a higher tempo of actions relative to customers and competitors, it is agile enough to cope with the challenges and reap the opportunities. To achieve this, a business must be able to loop through the Agility Cycle without disruptive delay or bottlenecks at any of the four phases.

Torque and Friction are two key forces commonly being studied in natural phenomena (e.g. Cyclone intensity (Smith \& Montgomery, 2015) ) or man-made artefacts (e.g. Helicopter rotor (Ferris \& Smith, 1978), Gear transmission (Fernandez-del-Rincon et al., 2017)) involving rotational and cyclic motions. In this thesis, the Agility Cycle is cyclic and rotational in nature. We have found that introducing the Torque and Friction notions into the mix brings higher conceptual clarity and helps gain insights into the inner workings of the Agility Cycle in a metaphorical fashion.

We define Torque as the force that drives forward the Agility Cycle to sense and respond to changes, whereas Friction is the counter-force to stop the forwarding movement. The stronger the "Torque" is, the more rapidly the Agility Cycle can loop forward, and shorter the $\Delta \mathrm{S}$-R will be. As a result of higher Torque, quicker decisions 
can be made, and faster actions can be taken. On the opposite, the higher "Friction" an Agility Cycle encounters, the slower it can cycle, and the longer $\Delta \mathrm{S}-\mathrm{R}$ will be. Or even worse, the cyclic motion may halt if Friction overpowers Torque. As a result, a business may be paralyzed into stagnation and become indecisive and unresponsive to changes. From an IS perspective, when agility is critical and a set of time constraints are given, the designers should favour features that add more Torque and be cautious with those bringing in more Friction.

However, one shall not hope to remove Friction completely and once for all. It is the nature of any cyclic and rotational systems (such as a complex decision support system) that Torque goes hand in hand with Friction (which is expressed in the concept of feedback from the environment). Often designers will need to continuously make trade-offs to keep a system evolving and tuned to support business agility. In some extreme cases where agility is the main desired outcome, identifying Torque and Friction should become part of the requirement engineering effort starting from the beginning of an IS development project. For example, MitoSystems.com ${ }^{2}$, which has designed and developed a ground-breaking knowledge discovery system called Mitopia, has explicitly defined Torque and Friction besides the OODA loop in their requirements documentation in order to keep development focused on agility throughout the whole Software Development Life Cycle (SDLC).

There is no doubt the proposed Agility Cycle is based on previous studies from multiple research disciplines, which we see as a strength. Such a proposal integrates the various models with concepts taken from sports science, military research, mechanical engineering, and business studies with the purpose to bring conceptual clarity and establish structural integrity of Agility as a critical concept. The Agility

2 http://mitosystems.com/how-to-write-requirements/ 
Cycle integrates the "perceptual and decision making" component of agility defined in sports science (as shown previously in Figure 1), while the execution of response parallels the "change of direction and speed" component (as shown in Figure 1). The Agility Cycle also explicitly depicts agility from a cyclic and rotational view, which is adopted from the OODA loop by John Ford (Osinga, 2005). The introduction of Synchronicity is influenced by the Theory of Media Synchronicity (Dennis et al., 2008). And finally, Torque, and Friction are included based on studies of cyclic and rotational motions in science and engineering (Fernandez-del-Rincon et al., 2017; Ferris \& Smith, 1978; Smith \& Montgomery, 2015).

\subsubsection{Other notions not to be confused with the Agility Cycle}

Besides agility, the business literature has seen other concepts being developed to describe business behaviour in turbulent environments, such as absorptive capacity (Cohen \& Levinthal, 1990), strategic flexibility (Ansoff, 1980), dynamic capabilities (Tecce et al., 1997), and improvisational capabilities (Pavlou \& El Sawy, 2010). However, these concepts largely zero in on strategic issues, whereas the concept of agility can not only describe strategic behaviours, but also tackle tactical and operational issues. Strategic issues are distinct from tactical or operational issues (Porter, 1996). Therefore, many IS researchers have urged to treat agility as a unique notion distinct from the aforementioned concepts (Overby et al., 2006; Pavlou \& El Sawy, 2010).

The Cynefin model (Snowden \& Boone, 2007), however, stands out on its own to be the most supportive concept to the Agility Cycle we defined. The Cynefin model was first developed by Dave Snowden in 1999 in the context of knowledge management and organisational strategy. Later in 2002, the model has absorbed complexadaptive systems theory into the mix. It was further developed and elaborated by Cynthia Kurtz at the IBM Institute of Knowledge Management, and by Mary Boone to extend the model to Leadership. The Cynefin model appeared as the 
cover feature in the Harvard Business Review in 2007 in the context of leadership and decision making (Snowden \& Boone, 2007).

Table 7: Cynefin Framework

\begin{tabular}{c|c} 
Complex & Complicated \\
Probe-Sense-Respond & Sense-Analyse-Respond \\
$\underline{\text { Emergent Practice }}$ & $\underline{\text { Good Practice }}$ \\
Enabling constraints \& Loosely Coupled & Governing Constraints \& Tightly coupled \\
\hline Chaotic & Simple \\
Act-Sense-Respond & Sense-Categorize-Respond \\
Novel Practice & $\frac{\text { Best Practice }}{\text { Tacking constraint \& De-coupled }}$ \\
& Treedom constrained \& Nogree of \\
\end{tabular}

Cynefin, although positioned itself as a framework for understanding and planning organisational strategy and leadership, highlights the critical value of "sense and respond" in all four quadrants representing four typical situations commonly faced by decision makers. Essentially, for any context defined by the model, (i.e. complex, complicated, chaotic, and simple), a business must go through the cycles of sense and respond. The four different contexts suggest different ways to approach the "sense and respond" cycle. In the "complex" and "chaotic" situations, Cynefin suggests to either probe or act first to gain initial feedback, and then proceed with "sense and respond". In the "complicated" or "simple" contexts, Cynefin suggests sensing first, and then either analyse or categorize, before the subsequence response.

We see the Cynefin model as a great supplement, not a rival, to the Agility Cycle described in Figure 2. The Agility Cycle, emphasises the cyclic nature of agility in business. This means that cycles after cycles of "sense, diagnose, select, and execute" stages performed in Synchronicity should be the nature of an agile business. We do not foresee, from an IS perspective and for the purpose of our study, that there is a 
need to differentiate which stage should be initiated first in different contexts. As long as the IS is designed properly to support and facilitate all these stages, the business and in particular the decision makers can choose where to start. Moreover, the steps proposed by the Cynefin model, namely, "act, probe, analyse, and categorise", are all activities covered by "diagnose" and "execute" in our Agility Cycle.

To sum up, this section has presented the agility theories and models derived from various streams of the research literature and integrated them in to one model - the proposed Agility Cycle. This Agility Cycle is comparable to the agility mechanism of natural living beings and of artificial control systems. Like rugby players in a competitive game or jet fighters in a dogfight, businesses which can execute the cycle faster, with better Synchronicity, higher torque and lower friction, than their competitors are more agile and will gain an ever-increasing advantage with going through each cycle. Such advantage can accumulate quickly so as to allow the more agile ones to overwhelm their opponents and to prevail (Canter, 2000).

\subsubsection{Main Categories of IS Agility Research}

The proposed Agility Cycle enables us to structure our inquiry into how the IS literature has been regarding the concept of agility. Among the published IS research, we have seen a diverse range of interests stretching from organisational culture and climate, to system design and development. Not all of these are directly related to the core Agility Cycle concepts (e.g. "sense and respond") we have elaborated. In this research, we specifically focus on IS Agility per se, which is defined as:

The ability to design, develop and use machine-based information systems to facilitate the "sense and respond" capabilities of human-based organisations.

Depending on the problems of interest, IS Agility can be studied from two perspectives, one is targeting at challenges from a system design standpoint studying 
the creation and construction of individual IS. This can include design patterns, development processes, and characteristics of IS, often in a generic term (Babb, Hoda, \& Norbjerg, 2014; Dove \& LaBarge, 2014; G. Lee \& Xia, 2010). The other is targeting at issues from an information design viewpoint studying the utilisation, configuration and organisation of a collection of information supporting a common business goal. This can include business decision making, event processing, workflow modelling, often in specific systems with explicit business missions (P.-Y. Huang, Pan, \& Ouyang, 2014; Nguyen, Schiefer, \& Tjoa, 2007; Rasouli, Ghazanfari, \& Eshuis, 2017; Rouse, 2007). The former, hereafter termed "Dev Agility", involves the interplay between the IS and its developers to make effective responses to changes in the technological components of the IS, whereas the latter, hereafter termed "Ops Agility", is mainly concerned with the interplay between the IS and its users ${ }^{3}$ on making effective responses to changes in the business components of the IS.

The "Dev vs. Ops" dichotomy provides a useful structure for us to organise the review of IS Agility literature. This structure fits well with the common classification scheme in IS research where studies make a clear distinction between IS development and IS operation (H. Barki, Rivard, \& Talbot, 1993). Such a dichotomous classification is also in alignment with the language used by IS practitioners, e.g. the recently popular notion of "DevOps" (Erich, Amrit, \& Daneva, 2014). "Dev Agility" can be seen as a joint capability of a system and its developers. It often refers to the "sense and respond" ability that an IS development function needs to create working systems, in situations where business requirements can be incomplete, uncertain and unarticulated, which in turn change frequently even when the coding phase has started (K. Conboy, Coyle, Wang, \& Pikkarainen, 2011). "Ops

\footnotetext{
${ }^{3}$ By users we mean those members who operate IS to achieve business goals within the limits and constrains inherited by the IS. This would include business users, super users, system administrators and so on, who can adjust the system within the boundary designed by IS developers. Users can create new content, reorganise existing functions and workflows, but are not responsible for creating new functionalities beyond the existing options of an IS.
} 
Agility" is more a joint capability of a system and its users. It is related to how well a system in operation is designed to allow easy and rapid changes on its own behaviours to support the "sense and respond" ability of its users to handle unpredictable changes in business processes and environments (Schatten \& Schiefer, 2007).

Fundamentally the focus of "Dev Agility" differs from that of "Ops Agility". The former is responsible for sensing and responding to changes in the systemengineering environment (e.g. to detect and act effectively and sustainably on changing demand on technological infrastructure and evolving functionalities/business requirements). On the other hand, the latter is mostly concerned with sensing and responding to changes in the system-operation environment which may or may not necessitate changes in the system-engineering environment (e.g. to monitor and respond effectively and sustainably to changes in online sales above/below different targets in different regions; this can mean capturing and analysing evolving product preferences of online customers, and adjusting online marketing approaches in a timely manner). Chapter3 will discuss the interplays between "Dev Agility" and "Ops Agility", as well as their inner workings in more detail.

\subsubsection{Dev Agility}

"Dev Agility" aims at improving the Agility Cycle of IS development. Such an agility is mostly about enabling IS developers to sense and respond to required technological changes, in the development mode of the IS being designed. The systems engineering literature has clearly identified Dev Agility as having two sides: agility of the system development process; and agility of the resulting system (Haberfellner \& Weck, 2005) (Dove \& LaBarge, 2014). The former inquiry, can be summed up as the title "Agile System-Development", analyses the agile engineering methodologies for developing IS, while the latter can be summed up by the title "Agile-System 
Architecture", examines common architectural arrangements and principles of agile systems.

Relating back to the Agility Cycle, studying and applying agile engineering methods and techniques are for increasing the desirable change-driven "Torque" of the IS development team when building new or modifying existing software components, while dissecting and extracting common design patterns from known agile systems are means for decreasing undesirable change-resistant "Friction" inherited in the integration of system subcomponents. Both are critical to the "Synchronicity" of the Dev Agility Cycle as they work together to reduce the $\Delta \mathrm{S}$-R of IS development teams. Such a dynamic interplay is illustrated in Figure 3 below.

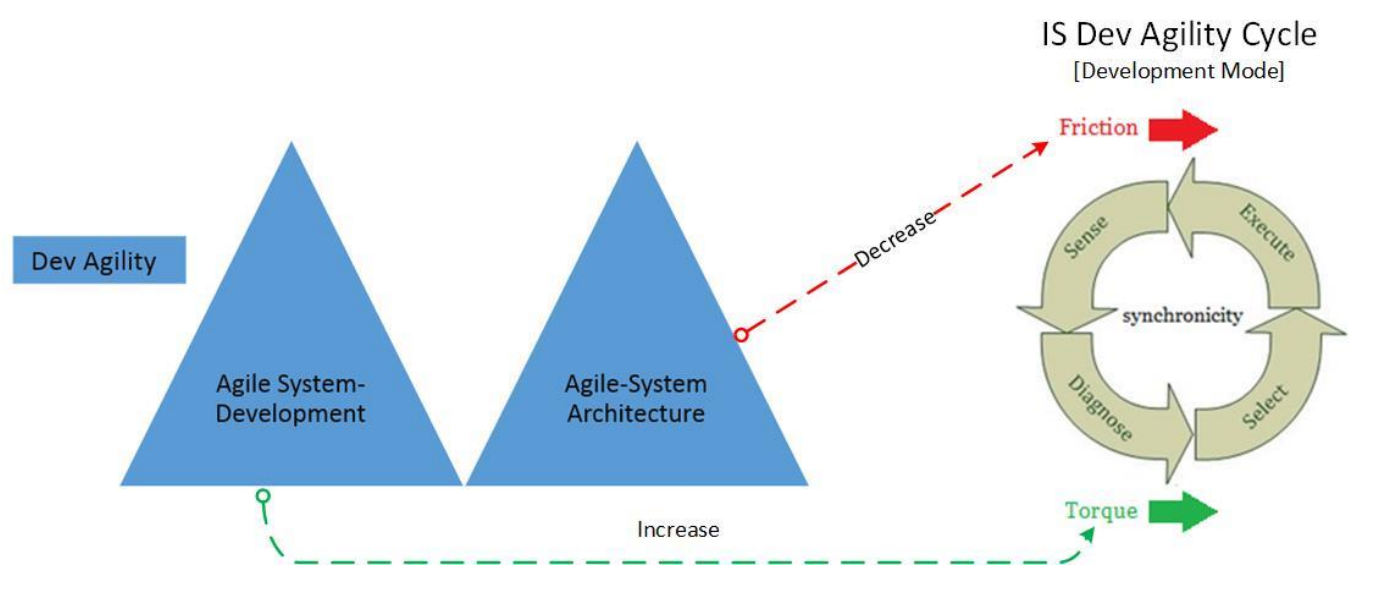

Figure 3: Dev Agility Cycle 


\section{Agile System-Development}

As shown in Figure 3 above, this category of research has a strong focus on increasing the "Torque" of IS development teams so they can cycle through the SDSE loop effectively by taking on new requirements frequently and delivering small chunks of functionality in much shorter iterations (often in weeks, if not days), when compared to traditional plan-driven or waterfall engineering approaches (Boehm \& Turner, 2003; Sommerville, 2010).

This category of literature concerns software-intensive engineering approaches to boost short iterative system development processes as well as to improve team capabilities and productivity. Such type of system-development methods is generally recognised as "short cycle time development" (Richard \& Jan, 2004). Methods examined in this category allow development teams to maintain a highlevel of responsiveness when faced with new/changed requirements. This research area has been highly prolific since the inception of The Agile Manifesto in 2001, and it zeroes in on Agile Software Development Methodologies (commonly known as Agile Methods) such as Extreme Programming, Scrum Project Management, and Adaptive Software Development etc. These methods suggest principles and practices emphasizing people over processes, working software over documentations, short iterative deliverables/prototypes over long planning phases, and close collaboration between development teams and clients over contract negotiation (AgileAlliance, 2001).

Agile Methods are believed to have revolutionized software development practice and have been passionately adopted by many business organisations across different industries. In academia, IS researchers have been studying the impact of these methods, e.g. in project success factors (Chow \& Cao, 2008), management approaches (Coram \& Bohner, 2005 ), leadership style (Yang, Huff, \& Strode, 2009), and so on. It would be impossible to discuss IS Agility without mentioning Agile Methods. The downsides of Agile Methods, however, as often criticised by 
conventionalists, are the lack of detailed documentation, the lower quality assurance due to fast iterations and the extensive dependence on individual capabilities of developers.

\section{Agile-System Architecture}

As shown in Figure 3, this category of literature concerns mostly with devising methods to improve the modifiability of IS, in development mode, by IS developers. Such methods aim to decrease the "Friction" of the Dev Agility Cycle to a degree that even unexpected new requirement changes are necessitated, the IS development team will be faced with minimal resistance entailed from the architectural arrangements of the existing system when making the decided technological changes. In other words, this category is about devising and evaluating means to minimise architectural rigidity in IS.

Researchers and practitioners have reported several key characteristics of AgileSystem Architecture, such as compatibility (Bhatt et al., 2010; Ngo-Ye \& Ahsan, 2005), interoperability (Hugoson, Magoulas, \& Pessi, 2009), scalability (Bhatt et al., 2010; Pankaj et al., 2009), modularity (Bhatt et al., 2010; Dove \& LaBarge, 2014; Ngo-Ye \& Ahsan, 2005), and standardisation (Bhatt et al., 2010; Gallagher \& Worrell, 2008; Nazir \& Pinsonneault, 2008). A detailed review of these characteristics is not the purpose of this section and can be found in our book chapter (Yang et al., 2013). Among the above architectural characteristics, modularity is often deemed to be a deciding factor for the level of re-constructability of a system (Camarinha-Matos, Afsarmanesh, \& Rabelo, 2003; Martensson, 2007) (Dove \& LaBarge, 2014). Other characteristics are more of prerequisites (e.g. standardisation and compatibility) or somewhat outcomes (e.g. scalability and interoperability) of high level of modularity. For instance, effective and functional modular design requires predefined standards (either globalised or localised) and sound compatibility to ensure connectivity across modules and components. These can then enable better interoperability across systems and services. Scalability is 
also a benefit of modularly designed systems as modularized resources and applications are easier to couple and decouple with each other. Advances in modularity should allow fast changes of the technological components of the IS (hardware infrastructure and software application) without major economic penalty (Nazir \& Pinsonneault, 2008).

Non-modular and tightly coupled architecture can become a major "Friction" since integrating new technological components can often become a whole-system reconstruction work which is slow and costly (Dove \& LaBarge, 2014). A highly modularised system, on the other hand, consists of reusable modules that are "selfcontained, encapsulated units, complete with well-defined interfaces which conform to the plug-and-play infrastructure..." (Dove \& LaBarge, 2014). Such an architectural design can also be found in those classic toy construction kits such as Erector Set, Bristle Blocks, and Marble Run which all allow kids to develop new toys and modify existing toys with ease and speed.

In general, Agile-System Architecture can be constructed to support effective and timely changes. This research area focuses extensively on software design patterns and architectural principles to accommodate functionality and technological changes. Many studies can be found on long-standing topics such as Objected Orientation (Singh \& Chana, 2012), Service-Oriented Architectures (A. Barros, Decker, Dumas, \& Weber, 2007; Ren \& Lyytinen, 2008), Aspect-Oriented Programming (F. J. Barros, 2015), Layered-Architectural Style (Babar, Brown, \& Mistrík, 2013), etc. These techniques are mainly concerned with creating loosely coupled, plug-and-play, system components and sub-functions that can be modified in isolation, in development mode, without significant time and cost penalties.

However, developing and following a reference architecture to map out all the key components/elements/interdependencies of an agile-system for a specific domain may require a significant amount of time and effort which can become costprohibitive to IS practitioners in the private sector expecting month-by-month new 
releases to compete and survive in a fast-paced marketplace. Not to mention that defining the degree of granularity for modularising a system is a difficult decision to be made upfront and has long been a critical challenge for system developers (Dörbecker \& Böhmann, 2015),

\subsubsection{Ops Agility}

The aforementioned two subcategories are the main pillars of "Dev Agility" found in the literature. However, with Dev Agility only, a business may find itself seeing new IS releases-with new features being implemented and old bugs being fixed-more effectively and frequently. But there is no guarantee that such releases and bug fixings will improve the "sense and respond" capabilities and quality of the very business. Being agile in the development mode of an IS doesn't suffice agility in its runtime mode. This is the fundamental issue addressed by "Ops Agility", which focuses on sensing and responding to the changes occurring in the IS-operation environment, in the runtime mode, regarding the business components of IS.

"Ops Agility" aims to improve the Agility Cycle of IS operation and utilisation (in business-focused functional groups such as production, distribution, sales \& marketing, etc.). We identified two main subcategories of "Ops Agility" in the literature: "Agile System-Operation" and "Agile-System Configuration". The former looks into approaches for increasing the change-driven "Torque" through technology-enabled "sensing and responding" driven by smart business sensors, analytics, and automation etc. The latter searches ways for decreasing changeresistant "Friction" via enabling system users to make effective and timely alterations of the business components of IS (e.g. risk classifications, product associations, operational workflows), through self-service parameter configurations, with minimal intervention from the original IS developers. Both are critical to the "Synchronicity" of the Ops Agility Cycle (shown in Figure 4 below) as they work together to minimise the $\Delta S$-R of IS users of non-IT business functions. 


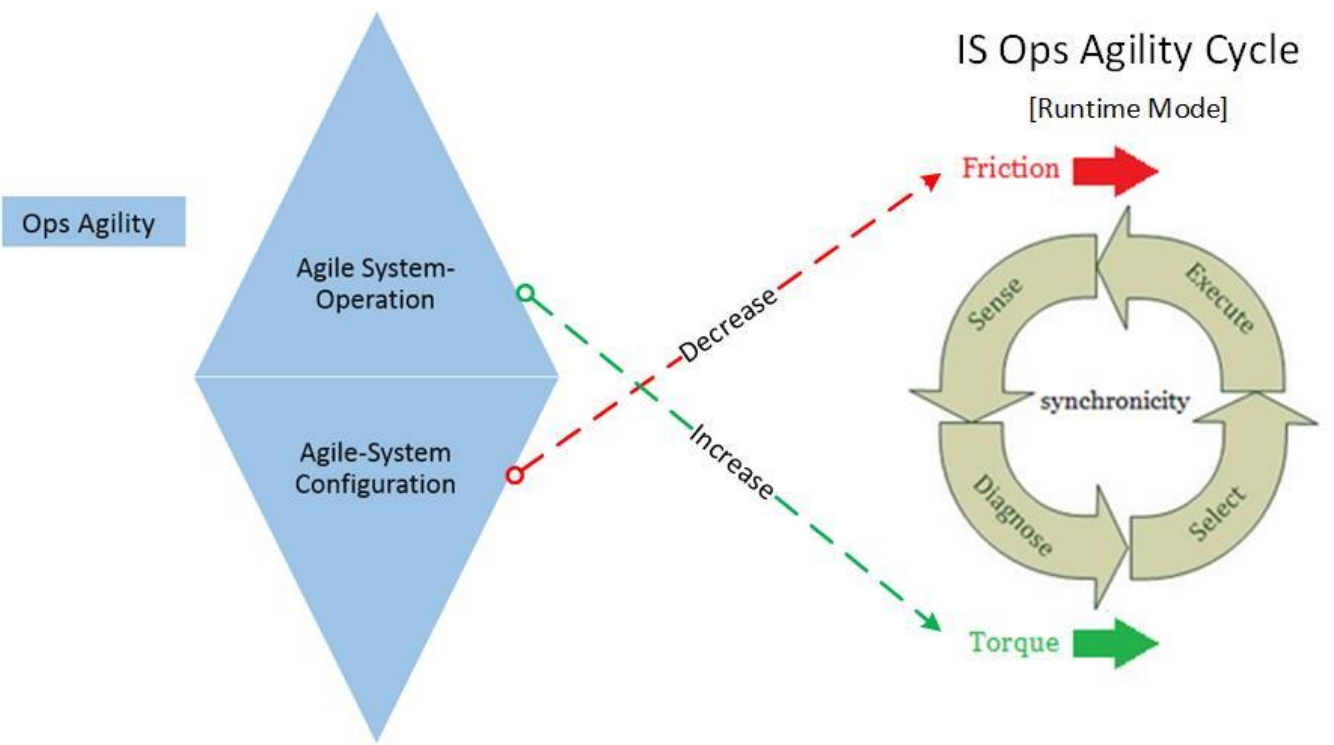

Figure 4: Ops Agility Cycle

\section{Agile System-Operation}

As shown in Figure 4, this category of research targets at increasing the "Torque" of IS users so that they can cycle through the SDSE loop effectively and efficiently by continuously sensing and responding to changes in the business environments where the IS are designed to operate during runtime. The essence of this category is to leverage advanced data integration, analytics, and human-computer interaction for system intelligence which can enable IS to automatically sense, diagnose, and even respond to changes in the business environment. For businesses providing pure digital services and products, a highly intelligent and responsive IS can become a key success factor of the business operation (e.g. Spotify).

Two main technological frameworks being investigated in this category are Complex Event Processing (hereafter CEP) and Information Fusion (hereafter Info Fusion). The underlying thesis is that changes in some business environments can happen at high frequency with high uncertainty and demand real-time responses which should be better handled automatically by the IS (predominantly autonomously) with 
assistance from human operators, rather than the other way around. In such environments, IS should have explicitly defined "sense and respond" functionalities for users to perform the initial setup and following adjustments (Zappia, Paganelli, \& Parlanti, 2012). With comprehensive event rule definitions, many responses can be automated based on the integration of multiple data sources for inference and decision making. IS users are allowed to define rules, add sensors and alerts, and create responses to events. Gradually many well-tested responses and reliable recommendations can be made automatic. Practical agile applications in specific areas include banking fraud detection (Nguyen, Schiefer, \& Tjoa, 2005), algorithmic stock trading (Acharya \& Sidnal, 2016), B2B eService recommendation system (Shambour \& Lu, 2012), traffic management (Dunkel, Fernández, Ortiz, \& Ossowski, 2011), etc.

Research in this category directly concerns the optimal balance of collaboration and coordination between IS and users that can help businesses to sense and respond to environmental changes (Josef Schiefer, Rozsnyai, Rauscher, \& Saurer, 2007). This involves utilising IS-enabled sensing capability to identify new threats and opportunities to the business, as well as to analyse and evaluate options in real time. This can be done by users setting up business sensors to automatically collect data/signals from the environment, integrating disparate data sources to collectively detect trends and patterns cannot be discovered through each individual source alone (Solano, Ekwaro-Osire, \& Tanik, 2012). Furthermore, IS can be operated in a way that helps the users perform inferences and make timesensitive decisions on appropriate courses of action (Paschke, Vincent, \& Springer, 2011; J. Schiefer \& Seufert, 2005), which can improve the speed of response to counter threats or reap opportunities. This can also include the actual execution of the decided actions, monitoring the progress of actions, and collecting feedback. More importantly, Agile System-Operation is about cultivating the ability to get all the aforementioned steps done in Synchronicity and within the constrained $\Delta S-R$ defined by the business environment. 
Established heavy-weight CEP and Info Fusion engines (e.g. TIBCO StreamBase) are expensive investments thus have not been universally adopted in business operations. Nonetheless in many business contexts, the "sense and respond" design logic and work mechanism of CEP and Info Fusion can still be adopted to create solutions that will deliver automated intelligence and make responses to business changes. Furthermore, light-weight solutions (Zappia et al., 2012) and open source options (e.g. WSO2, Esper) are also emerging which can potentially boost the adoption of such technologies.

\section{Agile-System Configuration}

As shown in Figure 4, the main purpose of this category is to look for approaches that can make the business-supporting features of IS more modifiable and manipulable, in runtime mode, by IS users, through configuration (often modelbased with adjustable parameters), if not construction. Such approaches aim for reducing the "Friction" on the Ops Agility Cycle to a degree that when unexpected new operational changes are necessitated, the business components of IS can be effectively and easily reconfigured by users or even the IS itself, during runtime, to support these changes, with minimal technological difficulties and business disruptions caused by rigid configuration design built into the IS.

Research topics in this category are relatively diverse but mostly represent the various aspects of dynamic configurability of sociotechnical systems, particularly adaptive Process-Aware Information Systems (PAIS) with which users can rely on to make easy and timely changes in business processes, using visual modelling tools. Historically, a major drawback of traditional PAIS has been the lack of adaptability in the implemented processes which then leads to rigid behaviours or gaps between real-world processes and implemented ones (Reichert, Rinderle-Ma, \& Dadam, 2009). PAIS promotes the separation of two important concerns: activity execution (e.g. workflow automation) and process modelling (e.g. BPMN) which were originally derived from the manufacturing industry where machine operations and 
assembly lines prevail. However, modern application of PAIS aim to support nonmanufacturing, service businesses and office operations which involve mostly human activities that are more complex and changeable than those on the factory floor. The operations that PAIS need to support in a modern business environment are far less standardised and repetitive, therefore difficult to fit in static process models and execution plans (Adams, 2010).

Many have reported systematic approaches for improving the dynamic configurability of PAIS so that processes execution instances can be adapted during runtime. To name a few, the Resilient BPM Framework based on the balance between "Control (prescribe vs. discretionary" and "Response (planned vs. unplanned" has laid out a high level conceptual model including five essential components: failure handling, exception handling, model adaptation, restricted adhoc changes, and unstructured interventions, as well as necessary services for detection, diagnosis, recovery, and escalation of changes at both model and process instance levels (Antunes \& Mourão, 2011). More technologically detailed solutions such as YAWL Worklet Services are based on Activity Theory and Ripple-Down Rule technique allow real-time launch or cancelation of smaller tasks which can be inserted to existing workflow instances upon execution (Adams, 2010). Also ADEPT2, leveraging Well-Structured Marking-Nets, can support process modifications (e.g. add, delete, change the sequence of tasks) during runtime both at the model and the instance levels through compliance to structural and behavioural criteria (Reichert et al., 2009).

Others focus more on specific techniques for solving particular issues associated with dynamically changing processes in IS. For instance, using partner synthesis to create configuration guideline capturing all feasible configurations which in turn improves the correctness and efficiency of process model configuration (Van der Aalst, Lohmann, \& La Rosa, 2012). More on configuration correctness includes event-based configuration guidance to ensure correct process variants and domain 
compliance (Boubaker, Mammar, Graiet, \& Gaaloul, 2016); automated extraction of configuration guidance from reusable business process repository to assist users creating and modifying effective business-driven IS (Assy \& Gaaloul, 2015); configuration optimisation through a binary linear program under a set of constraints (Rekik, Boukadi, Assy, Gaaloul, \& Ben-Abdallah, 2016). Furthermore, studies have proposed systematic methods for comparing and evaluating PAIS solutions, in terms of change patterns and change support features (B. Weber, Reichert, \& Rinderle-Ma, 2008), and workflow time patterns (Lanz, Weber, \& Reichert, 2010).

In a nutshell, the model-driven configurability of PAIS enables users to change the system to accommodate changing business processes with little intervention from IS developers (i.e. from the Dev Agility Cycle). These changes can be done fast, especially when compared with the more traditional software line-by-line coding. Agile-System Configuration is about empowering users with highly adaptable configuration allowing the IS to be reconfigured to support changing business processes, during runtime, with ease and speed. This can reduce the Friction on the Ops Agility Cycle where users not only know what changes are occurring in the business environment, but more importantly, have the capability to directly modify the IS behaviours to support these changes effectively and efficiently.

One historical critique is that process models often take a prescriptive role. That is, there is an engine that determines what information processing activities are required/allowed according to the prescribed model. However, research developments such as Coordination Theories (Cabitza \& Simone, 2013), Dynamic Workflow Management (Adams, 2010), and all the aforementioned studies on configurable PAIS have gone beyond prescriptive modelling to help IS users overcome model prescriptions, especially allow effective changes in process/model configuration when unexpected events occur during runtime. Furthermore, alternative approaches have also been proposed to take a paradigm shift by "moving 
away from model-based control flow" to context-based "dynamic activities defined by participants as processes unfold" (Antunes, Baloian, Zurita, \& Pino, 2018), as well as to make process modelling and execution more of a bottom-up social-collaboration among users (e.g. AGILIPO) (Silva et al., 2009)

\subsubsection{The IS Agility Pyramid}

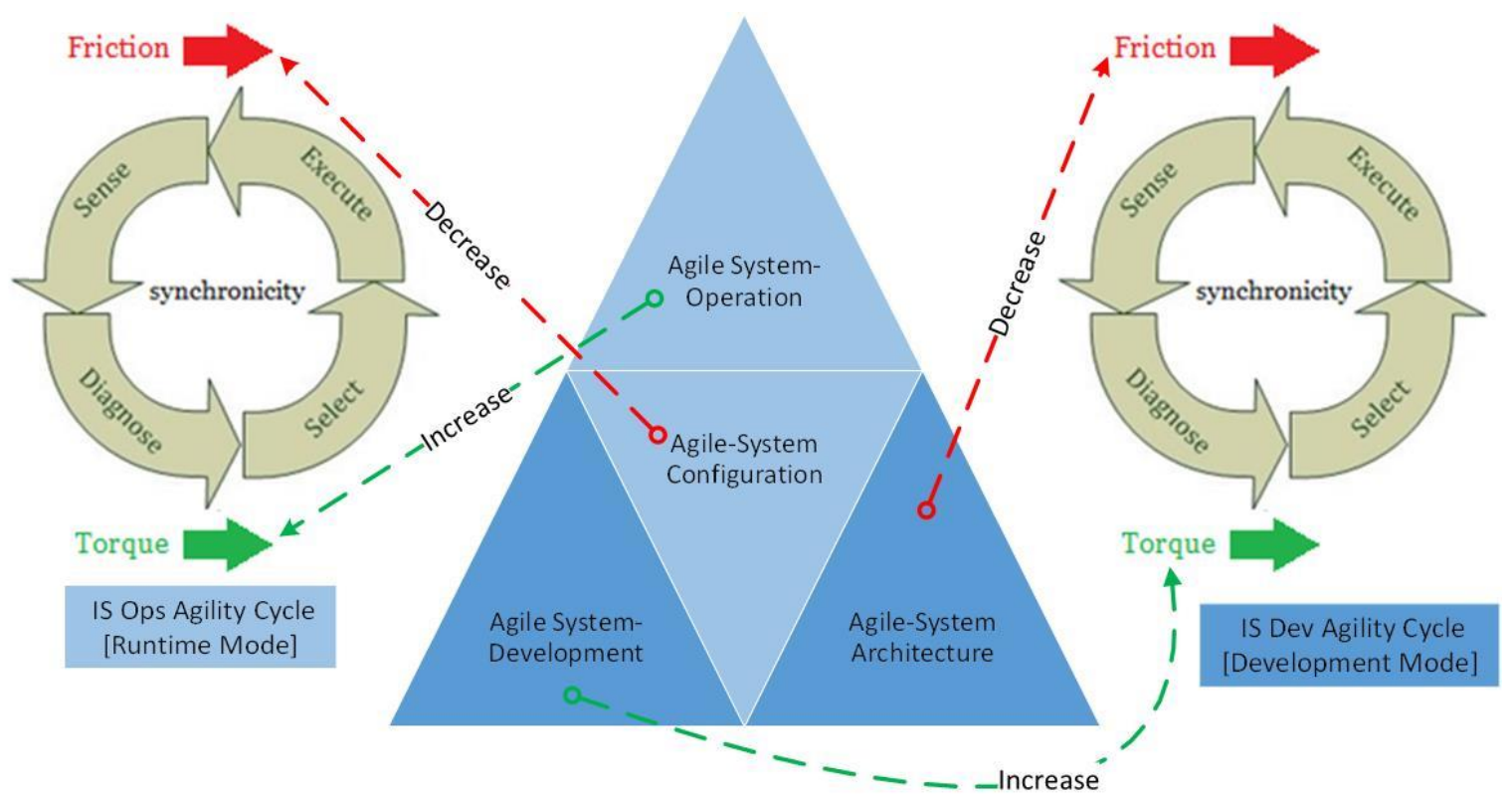

Figure 5: IS Agility Pyramid

Figure 5 above presents the "IS Agility Pyramid" integrating Dev Agility and Ops Agility into a unified model. Agile System-Development, Agile-System Architecture, Agile System-Operation, and Agile-System Configuration are the four key areas of IS Agility research we synthesised and labelled from our cross-discipline literature review. These categories can be seen as "key pillars" supporting the overall IS Agility with each playing a unique role in relation to the Dev Agility Cycle and Ops Agility Cycle. Based on our conceptualisation of IS Agility, each pillar of research facilitates either the increase of "Torque", or the decrease of "Friction" on the Agility Cycle, be it Dev or Ops. 
Our observation is that the intended impact of Dev Agility studies is mainly in the development mode of the IS life cycle and often at individual IS level, i.e. the development of a single IS, one at a time. The key stakeholders of concern are mostly IS developers, engineers, etc. The research focusing on the Ops Agility, on the other hand, is mostly focusing on the runtime mode of the IS life cycle and can cover a federation of IS and their collaborative behaviours.

Table 8: The Current Status of Key Research Areas of IS Agility

\begin{tabular}{|c|c|c|c|c|c|}
\hline & $\begin{array}{c}\text { "Key } \\
\text { Pillars" }\end{array}$ & To Support & $\begin{array}{c}\text { Benefits } \\
\text { to Agility } \\
\text { Cycle }\end{array}$ & Research Style & $\begin{array}{c}\text { Key } \\
\text { Stakeholders } \\
\text { \& Phase of IS } \\
\text { Life Cycle }\end{array}$ \\
\hline \multirow[t]{2}{*}{$\begin{array}{c}\text { Dev } \\
\text { Agility }\end{array}$} & $\begin{array}{l}\text { Agile } \\
\text { System- } \\
\text { Development }\end{array}$ & $\begin{array}{l}\text { Changes in } \\
\text { business/user } \\
\text { requirements \& } \\
\text { functionalities } \\
\text { etc. }\end{array}$ & $\begin{array}{l}\text { Increasing } \\
\text { Torque }\end{array}$ & \multirow{2}{*}{$\begin{array}{l}\text { Light-weight, industry- } \\
\text { agnostic approach, tends } \\
\text { to investigate abstract } \\
\text { principles, methods, } \\
\text { practice adopted in } \\
\text { smaller projects, } \\
\text { individual IS, and } \\
\text { development teams }\end{array}$} & \multirow[t]{2}{*}{$\begin{array}{l}\text { IS Developers, } \\
\text { Engineers etc. } \\
\text { In } \\
\text { Development } \\
\text { Mode }\end{array}$} \\
\hline & $\begin{array}{l}\text { Agile-System } \\
\text { Architecture }\end{array}$ & $\begin{array}{l}\text { Changes in } \\
\text { technological } \\
\text { structure \& } \\
\text { capacity of IS } \\
\text { etc., }\end{array}$ & $\begin{array}{l}\text { Reducing } \\
\text { Friction }\end{array}$ & & \\
\hline \multirow[t]{2}{*}{$\begin{array}{c}\text { Ops } \\
\text { Agility }\end{array}$} & $\begin{array}{l}\text { Agile } \\
\text { System- } \\
\text { Operation }\end{array}$ & $\begin{array}{l}\text { Changes in } \\
\text { business } \\
\text { operations \& } \\
\text { environments } \\
\text { etc. }\end{array}$ & $\begin{array}{l}\text { Increasing } \\
\text { Torque }\end{array}$ & \multirow{2}{*}{$\begin{array}{l}\text { Heavy-weight, industry- } \\
\text { specific approach, tends to } \\
\text { scrutinize effectiveness } \\
\text { and efficiency of large- } \\
\text { scale rule/flow engines via } \\
\text { simulation and real-life } \\
\text { implementation across a } \\
\text { federation of IS. }\end{array}$} & \multirow[t]{2}{*}{$\begin{array}{l}\text { IS Operators, } \\
\text { Users, etc. } \\
\text { In Runtime } \\
\text { Mode }\end{array}$} \\
\hline & $\begin{array}{l}\text { Agile-System } \\
\text { Configuration }\end{array}$ & $\begin{array}{l}\text { Changes in } \\
\text { business- } \\
\text { supporting } \\
\text { features of IS } \\
\text { etc. }\end{array}$ & $\begin{array}{l}\text { Reducing } \\
\text { Friction }\end{array}$ & & \\
\hline
\end{tabular}

Table 8 above summarises some main attributes of the four "key pillars" we discovered from the literature. Each of the four has a different purpose in terms of the nature of changes being facilitated, as well as the torque-increasing vs. frictionreducing benefits from an Agility Cycle viewpoint. The two "key pillars" of research under Dev Agility have seen a plethora of research from academic disciplines such 
as Computer Science and Software Engineering, which practically matches the strong interest from the IT industry. On the contrary, the two Ops Agility "key pillars" are less developed in an academic sense but tend to be driven from practitioners and large commercial entities (e.g. TIBCO's StreamBase and iProcess).

The reason might be that Dev Agility seems to be easier to study as it concerns mostly abstract principles, methods, and practice (e.g. Scrum, SOA) which can be introduced, observed, and measured in smaller sized IS development projects, with light-weight individual systems, and without strong attachment to any specific industry (Babb et al., 2014). Ops Agility studies, on the other hand, tend to require a lot more resources as they often involve design, simulation, and real-life implementation of heavy-weight rule/flow engines to test their efficiency and effectiveness in large industries such as finance (Saad \& Arakaki, 2014) and banking (Nguyen et al., 2005). This is reasonable, as for businesses operating in these industries, unexpected events and exceptions can result in catastrophic losses thus they tend to have large R\&D funds for improving IS Ops Agility.

However, we believe Ops Agility can also be studied following the light-weight approach used in Dev Agility studies, that it, focusing more on the generally abstract principles, methods, and practice that are applicable in wider industries for achieving Ops Agility. With a raised level of awareness, IS researchers can make more noticeable contribution to research in IS Ops Agility, due to our close relationship to business operations and systems, as well as organisation and management theories.

The IS Agility Pyramid not only illustrates the key research areas identified in the literature, but can also serve as the first articulation of the principle capabilities to achieve IS Agility in practice. It illustrates the main constituents of IS Agility and how they work together. This technically answers the first two research questions (RQ1 and RQ2) proposed in Chapter 1. Nevertheless, the IS Agility Pyramid is not sufficient to answer the third research question which concerns with method 
development for investigating and solving IS Agility problems. To formulate a problem-solving method, we will need to understand why IS Agility is needed in the first place. The next section discusses the Need vs. Supply of IS Agility.

\subsection{IS Agility Need vs. Supply - The Nomological Network}

Having dug deep into the essence of IS Agility and established desirable conceptual clarity, we extended our lens to see the fuller picture of agility. To effectively design agility in an IS context, one should not only be able to articulate what makes agility achievable but need to understand why and when agility is needed.

Early studies in agile manufacturing are no doubt the pioneers in searching the need for agility. Sharifi and Zhang (2001), in their well cited paper, proposed a conceptual model of agility in manufacturing within which two concepts "Agility Drivers" and "Agility Providers" were coined and used as the two key forces that make a firm agile.

The concept of "Agility Drivers" describes factors that necessitate a business to be agile to maintain its competitive advantage, while the concept of "Agility Providers" describes means by which the capabilities of being agile could be obtained (H. Sharifi \& Zhang, 2001). Sharifi and Zhang $(2000,2001)$ further validated these two concepts in industrial questionnaire surveys from some 1,000 companies followed by subsequence case studies based on two manufacturing companies.

Following the same route, as shown in Figure 6, we define "IS Agility Drivers" as the environmental and organisational factors that necessitate the needs for IS Agility. Such drivers in turn determine the "Need Level" for IS Agility. Meanwhile, "IS Agility Providers" can be defined as the means to enable the sensing, diagnosing, selecting, and executing capabilities of IS. Such providers will in turn decide the "Capability level" for IS Agility. Resultantly, the Need Level and the Capability Level will determine the actual status of IS Agility (IS Agility in use). 


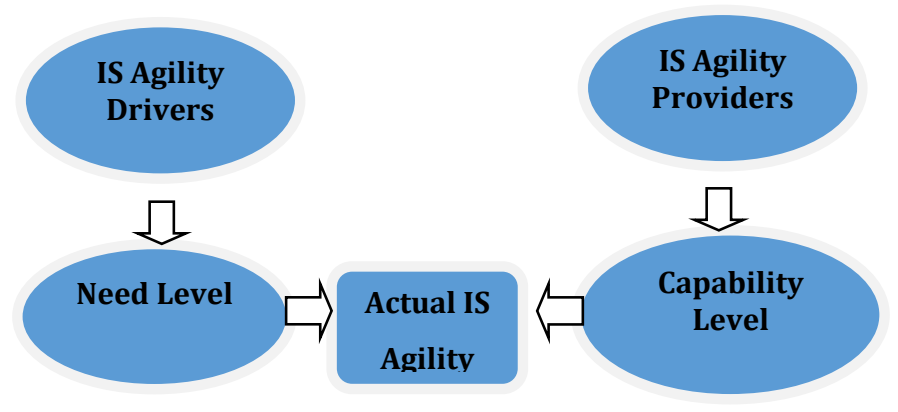

Figure 6: The Network of IS Agility

With strong drivers and high need level, but weak providers meaning low capability level, an IS needs to, but is unable to be agile. In such situation, an organisation is likely to fail in leveraging this IS to reap opportunities and counter threats in the business missions it was designed to support. For example, in the HP survey report mentioned earlier, an executive complained that the lack of IS Agility had made his company miss business opportunities. His company was unable to run a special pricing promotion to exploit a rival's mistake. The bottleneck wasn't the marketing department or the sales team, instead, it was the CRM system which was too rigid to configure and allowed pricing updates to be made only once a quarter (HP, 2011).

On the contrary, with weak drivers and low need level, but strong providers and high capability level - an IS can but doesn't need to be agile. This scenario may indicate a typical overprovisioning in IT. This could mean a serious waste of resource as building unnecessary agility capabilities in IS often involves extra cost and time on top of regular IT provision. For example, building a system with a modular design may allow easier and faster future changes of its technological structure, however this requires considerable extra effort (i.e. in structural analysis, communication and coordination of the sub-components) than merely building it in a monolithic fashion. 


\subsubsection{IS Agility Drivers}

\subsubsection{Change and Uncertainty}

Change and uncertainty have been widely identified as the drivers of agility in various disciplines such as sports training (Sheppard \& Young, 2006), HR (Shafer et al., 2001), system engineering (Dove \& LaBarge, 2014) and IS management (Gebauer \& Schober, 2006). In business context, these two drivers at times are joined together by researchers to form new notions such as "Environment/Market Dynamism" (Coronado, Lyons, \& Kehoe, 2004; Sengupta \& Masini, 2008). The increasing frequency of change and degree of uncertainty in today's business competition has introduced unprecedented market dynamism into many industries (e.g. finance, manufacturing, retailing, IT, etc.). To retain a leadership position in a dynamic marketplace, an organisation needs to be able to morph itself at will without significant cost and time, and do so faster than their rivals (Pankaj et al., 2009).

In general, organisations operating in a business environment characterised by uncertainties and changes have a much higher "need level" compared to those operating in a relatively stable markets with little turbulence involved (Coronado et al., 2004; Sengupta \& Masini, 2008; H. Sharifi \& Zhang, 2001. ). For example, firms producing cement will require much less agility, in contrast to firms producing computers (Coronado et al., 2004).

Uncertainty can have two dimensions, Temporal and Spatial (Sheppard \& Young, 2006) (previously listed in Table 2). "Temporal" uncertainty indicates the timing of change cannot be known upfront while "Spatial" uncertainty refers to the situation that "where" the change will occur is unknown. As discussed in previous sections, nowadays with the ever-increasing level of globalization and e-Commerce implementation, organisations often find themselves faced with both Temporal and Spatial uncertainties without knowing when and where changes would happen in their environments. The two-dimensional concept of uncertainty will be revisited and discussed with examples in the following sections. 


\subsubsection{Information Intensity and Time Criticality}

Uncertainty and change alone, may necessitate the need for business agility, however, do not guarantee the need for IS Agility. The degree of dependency on IS for organisations to perform mission-critical operations may vary largely across industries, e.g. firms manufacturing commodities do not depend on IS as much as firms producing automobiles do. Additional need drivers are required to justify the necessity of IS Agility.

Besides the uncertainty and change which are considered as two generic need drivers for agility, Information Intensity (Coronado et al., 2004) and Time Criticality (Gebauer \& Schober, 2006) are identified as two additional specific drivers of IS Agility need. Reportedly, the level of Information Intensity and Time Criticality involved in a business operation largely determines the dependency of this business on IS (Coronado et al., 2004; Gebauer \& Schober, 2006; Pankaj, 2005).

Time Criticality is more conspicuous in competitive environments than in the opposite (Gebauer \& Schober, 2006; Goldman et al., 1995). Although certain industries include a higher percentage of time-critical operations (e.g. operations of stock brokers are likely much more time-critical than those of shoe makers), business competition has been seen as another major catalyst for Time Criticality (Bhatt et al., 2010). Organisations operating in highly competitive marketplaces often cannot afford to be slow or late in making necessary changes in course of action, and have to move fast owing to pressures from rivals, customers, and suppliers ( $\mathrm{H}$. Sharifi \& Zhang, 2001). Therefore support from IS as communication infrastructure and automation platform becomes compulsory in order for the firm to be able to sense changes, make effective responses and timely implementations (Overby et al., 2006).

Information Intensity is greater in some industries than in others (Coronado et al., 2004). The amount of daily information processed by a bank is likely to be exponentially more than that processed by a breakfast cereal maker. In industries 
with high Information Intensity, the volume of data that organisations must process can easily outstrip traditional human capacity, hence using computer-based IS has become the norm for achieving effective and efficient information processing and decision making (Pankaj et al., 2009). In short, with high Information Intensity, IS can enable organisations to make sense out of what would otherwise overwhelm them (Overby et al., 2006).

In environments characterised by high Information Intensity and high Time Criticality, managing a business wherein timely sense making and action taking are impossible without IS. This phenomenon is referred as "managing by wire" (Haeckel \& Nolan, 1996). IS have been wired into organisations and become the backbone of many business operations, hence the ability of IS to sense and respond to change, is becoming crucial, as it can define the pace at which businesses can sense and respond to change (Pankaj et al., 2009). Rigid IS are often found hampering the business's ability to make changes (Oosterhout, Waarts, \& Hillegersberg, 2006; SEO \& Paz, 2008). The dependency of businesses on IS has further been tightened by the growth of E-Commerce implementations. Consequently many have argued that to certain degree, "managing IS" is essentially "managing business", and being agile in business first requires being agile in IS (Bhatt et al., 2010; Lyytinen \& Rose, 2006; Oosterhout et al., 2006; Weill, Subramani, \& Broadbent, 2002).

\subsubsection{Drivers of IS Agility and the Decision Tree}

Table 9 summarises the four environmental and organisational factors driving the need for IS Agility, namely Change Frequency, Uncertainty, Information Intensity, and Time Criticality. Indeed, IS Agility is a competitive advantage but not all organisations need to invest in it. For IS Agility to be relevant, first the very organisation should have the need to be agile (i.e. operating in a fast-changing environment with high level of uncertainty), second it should have the need to be agile in IS (i.e. entailed high level of Time Criticality and Information Intensity). 
Table 9: Drivers of IS Agility

\begin{tabular}{|l|l|l|l|l|}
\hline & Change & Uncertainty & $\begin{array}{l}\text { Information } \\
\text { Intensity }\end{array}$ & $\begin{array}{l}\text { Time } \\
\text { Criticality }\end{array}$ \\
\hline $\begin{array}{l}\text { (H. Sharifi \& } \\
\text { Zhang, 2001) }\end{array}$ & $\begin{array}{l}\text { Change } \\
\text { Frequency }\end{array}$ & Uncertainty & & \\
\hline $\begin{array}{l}\text { (Kieran Conboy \& } \\
\text { Fitzgerald, 2004) }\end{array}$ & $\begin{array}{l}\text { Change } \\
\text { Frequency }\end{array}$ & & & \\
\hline $\begin{array}{l}\text { (Gebauer \& } \\
\text { Schober, 2006) }\end{array}$ & $\begin{array}{l}\text { Business } \\
\text { Process } \\
\text { Variability }\end{array}$ & $\begin{array}{l}\text { Business } \\
\text { Process } \\
\text { Uncertainty }\end{array}$ & & $\begin{array}{l}\text { Business } \\
\text { Process } \\
\text { Time }\end{array}$ \\
\hline $\begin{array}{l}\text { (Pankaj, 2005) } \\
\text { Change } \\
\text { Frequency }\end{array}$ & Uncertainty & $\begin{array}{l}\text { Information } \\
\text { Intensity }\end{array}$ & \\
\hline $\begin{array}{l}\text { (Coronado et al., } \\
\text { 2004) }\end{array}$ & $\begin{array}{l}\text { Business Environment } \\
\text { Dynamism }\end{array}$ & $\begin{array}{l}\text { Information } \\
\text { Intensity }\end{array}$ & \\
\hline $\begin{array}{l}\text { (Sengupta \& } \\
\text { Masini, 2008) }\end{array}$ & Market Dynamism & & \\
\hline
\end{tabular}

Based on the four drivers identified from the literature, we propose a tool for organizations to assess their needs for IS Agility. Figure 7 below depicts a decision tree to evaluate if IS Agility is truly needed. With low level of Change Frequency in a business environment, there is no need for agility at all. With high level of Change Frequency, but low level of Uncertainty, responses to changes can be mostly defined in advance (such as emergency plans for fire evacuation in a warehouse). When both Change Frequency and Uncertainty are at high level, but Time Criticality is low, having the flexibility of being able to move parts/projects/operations around to alter the original course of action would be sufficient, even the process is not executed at a rapid pace. 


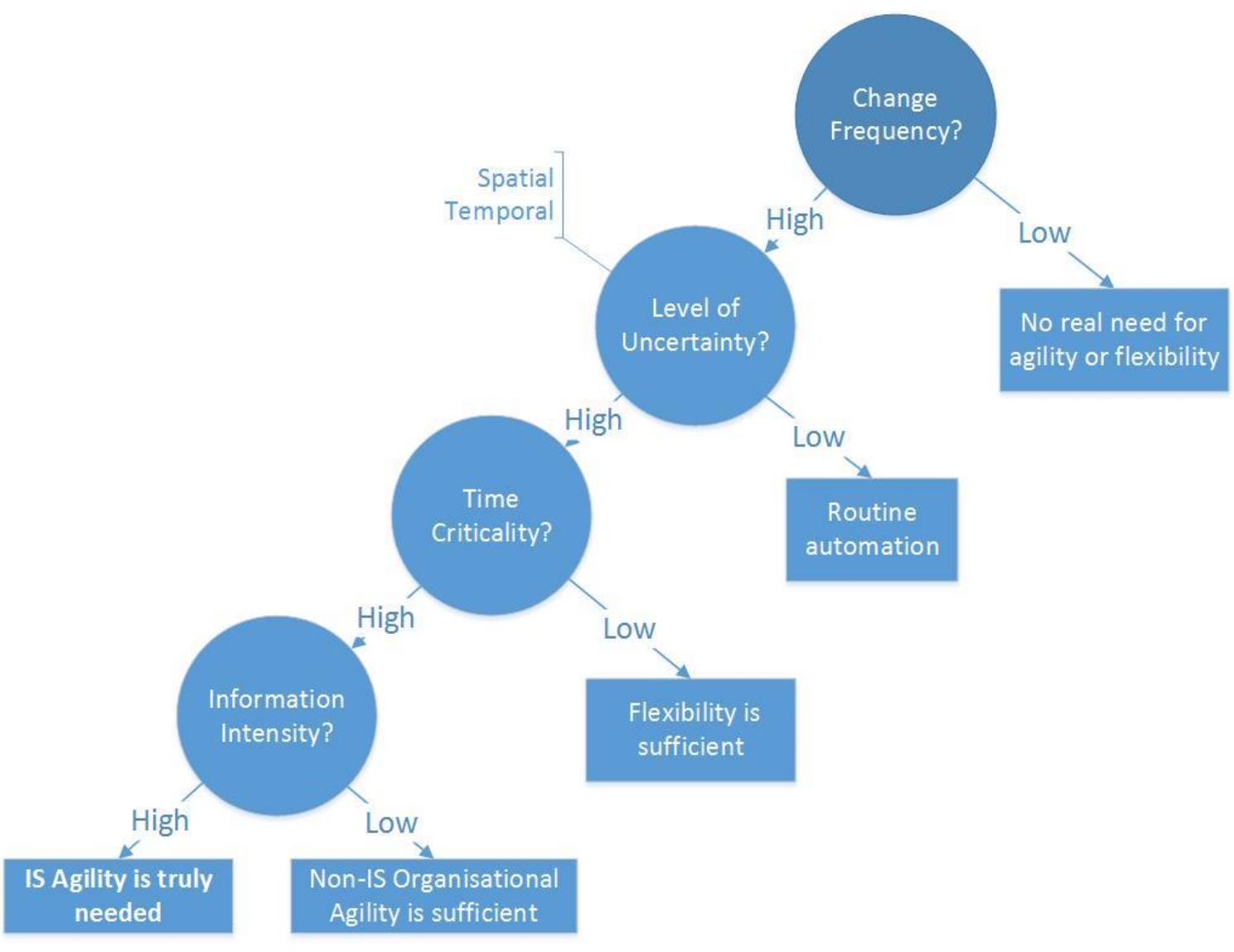

Figure 7: IS Agility Need Drivers - a decision tree

Finally, with high level of Change Frequency, Uncertainty, and Time Criticality, if Information Intensity is low, a business should focus on improving organisational agility 4 instead of investing heavily in IS Agility. After all, in a business with low Information Intensity, the IS implemented are unlikely to be a mission-critical game changer. Resultantly, we argue that only when all the four IS Agility drivers are presented at high level, a business should zero in on IS Agility to stay competitive and lead the field.

\footnotetext{
${ }^{4}$ Organisational agility is often achieved through strengthening leadership, strategy, culture and organisation structure etc. which has been well studied in management literature but is beyond the scope of this paper.
} 


\subsubsection{IS Agility Providers}

The four "key pillars" previously presented in the IS Agility Pyramid, are considered high-level IS Agility Providers. This level of detail is deemed sufficient for the purpose of this chapter - i.e. laying out the theoretical foundation of the following design science study. Although a finer level of classification for IS Agility Providers may exist, it is seen as beyond the scope of this chapter. Moreover, investigation into the IS Agility Drivers has brought about new insights for understanding the usefulness of IS Agility Providers, especially on the two dimensions of uncertainty introduced in the previous section, namely, "Temporal" uncertainty and "Spatial" uncertainty which make changes unpredictable.

In a turbulent marketplace, business requirements and system functionalities are changing more frequently. It is next to impossible to estimate when and where these changes will occur. The Dev Agility Cycle is dedicated for IS developers to handle such changes in the system environment. Extending from our understanding in Section 2.2.4.3, Agile System-Development focuses on increasing the Torque in Dev Agility Cycle, partly through establishing disciplined practice to handle Temporal Uncertainty. In reality, with the pervasive use of Internet based IS, system users may send through change requests of any nature and at any time. However Agile SystemDevelopment methods (i.e. Scrum, XP) are devised to establish Temporal Confidence by strictly defining fixed tempo for the development team to sense and respond with little ambiguity on the time dimension. For example, 15 minutes Daily Scrums (Or Stand-up meetings) to plan for the next 24 hours, Two-week Sprints, Biweekly Estimation meeting, Product Backlogs, and Sprint Backlogs are all artefacts designed to enforce regular and frequent development iterations with stable intervals and manageable workload. This way the development team will have a predefined period of time for diagnosing change requests and deciding on responses based on carefully selected, limited set of new requirements and bugs. Such an artificially defined temporal certainty can improve the development team's 
productivity and maximize throughput, as well as protect the team from being overwhelmed by the continuous change requests raised by client users.

"Agile-System Architecture" provides means to reduce Friction in the Dev Agility Cycle mostly through handling Spatial Uncertainty. Changes in business requirements and system functionalities are often not predictable, that is, the IS developers cannot know upfront which part of the IS will need to be changed and to what degree. Designing the technological structure of IS in a modular, plug-and-play manner helps establish Spatial Confidence. By intentionally dividing a complex system into loosely-coupled subsystems which exhibit limited interdependence (Tiwana \& Konsynski, 2010), developers can confidently add, remove, or modify individual modules and units knowing such changes will not affect other parts of the system. Take SOA as an example, it advocates encapsulating functionalities into services which can be invoked by others when needed. These services are reusable modules which can facilitate the speed in software system design and development (Setia, Sambamurthy, \& Closs, 2008). With appropriate granularity of each modular sub-unit, one can assure good spatial confidence as constructing an IS will become almost like building a Lego house.

The Ops Agility Cycle is for IS users to leverage IS to deal with changes in business environments which again often are uncertain in both temporal and spatial dimensions. "Agile System-Operation" is essentially a way of operating IS to detect changes as soon as they occur which in turn help improve Temporal Confidence. Such type of system operation can bring more Torque to the Ops Agility Cycle by assisting IS users in sensing and diagnosing, even automatically responding to business changes right after they occur. Instead of the traditional retrospective analysis of business events and transactional data, smart IS are built upon real-time data processing engines (often rule-based, such as TIBCO's StreamBase) that can be tuned by IS users to detect abnormities, unexpected incidents, potential risks, etc. in the business environment. Such a "real-time" focus makes the IS intelligent enough 
to sense and respond to frauds in transactions, to suggest optimised pricing, to promote cross selling and proactive inventory. In industries where products are fully digitized, companies are naturally becoming data-driven, such system operation style then should be considered a core competitive advantage to their businesses. For example, both Spotify and Pandora are relying on Apache Spark to generate dynamic online music recommendations to retain existing customers as well as attracting new ones. In short, "Agile System-Operation" can help IS users establish Temporal Confidence by offering a mentality of "we don't know when changes are going to happen, but we do know once they occur we will be notified immediately, and responses can then be made in real time."

"Agile-System Configuration" is concerned with reducing the "Friction" in the Ops Agility Cycle. When changes in business environments occur, users should be allowed to alter the business-supporting features of the IS (e.g. business process, workflow, company code, security rules) using abstract models during runtime, instead of having to request IS developers to make code-level changes in development mode. Spatial Confidence can be established for IS users knowing they have the control to add and modify the behaviours of the business components in their IS using visualised modelling approaches. In reality, Process Aware Information Systems represent a cluster of tools specialised in identifying, controlling, and executing business activities on the basis of process models (Van der Aalst, 2009). Dynamic workflow management and case handling systems are typical examples of PAIS. These systems can be configured and altered by IS users without a single line of code and often no intervention needed from the IS department. ProWorkflow and Zoho Creator are two examples of cloud-based platforms that business users can design and implement operational processes through drag-and-drop modelling and tap their solutions to existing enterprise IS through rapid wizard-driven data integration. 


\subsubsection{The IS Agility Nomological Network (ISANN)}

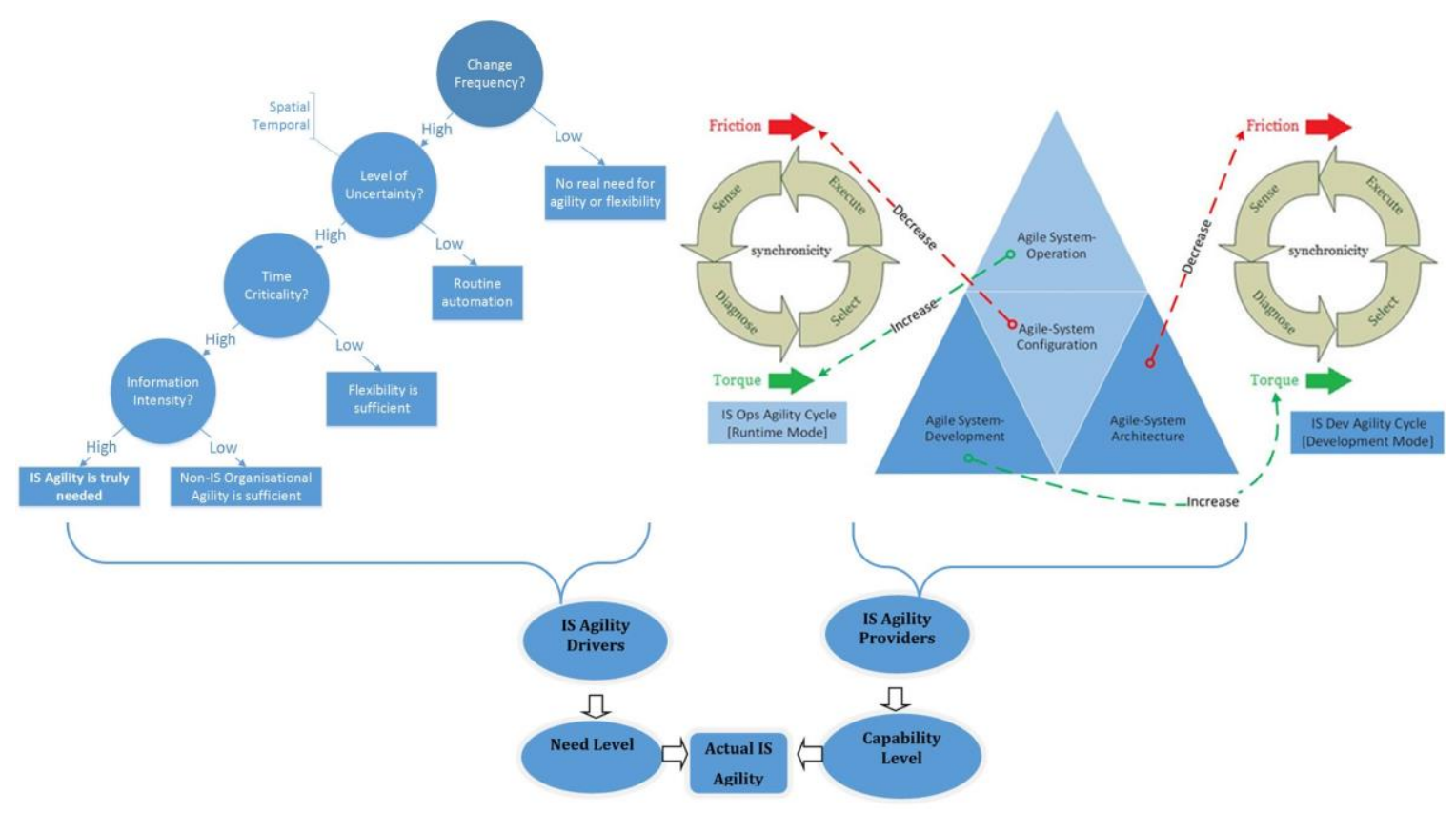

Figure 8: The Nomological Network of IS Agility (ISANN)

Gradually, with time, we formulated the IS Agility Nomological Network (hereafter ISANN) by integrating the IS Agility Drivers and Providers identified during our long-lasting iterative literature review and synthesis. As shown in Figure 8, the nomoligical network illustrate the mechanism of IS Agility as an ability as well as the current landscape of IS Agility as a research field.

We consider ISANN the most complete conceptualisation of IS Agility so far. It provides us with a guiding map for confidently further our inquiries and analysis into IS Agility related topics, in both the academia and the industry. As the first one of its own kind, this map provides the conceptual clarity, establishes the structural integrity, and acknowledges the contextual dependency of IS Agility. Such a map may not be extremely exhaustive, but it captures the critical crux of IS Agility. ISANN 
is informative enough to remove ambiguities as well as help both researchers and practitioners quickly grasp the nature and essence of IS Agility from a vantage point.

There are at least two types of balance need to be considered according to this ISANN. First is the balance between "Need Level" and "Capability Level" which has been discussed in detail in the previous sections. The second one, is the balance between "Dev Agility" and "Ops Agility" which will be discussed in the following sections using business scenarios.

\subsection{Chapter Summary}

In this chapter we have reviewed existing Agility literature across various disciplines and provided conceptualisation of general Agility as well as IS Agility. First, this chapter has established a clear conceptual boundary of Agility by clarifying the similarities and differences between Agility and Flexibly. Next it has reviewed the historical development of the definitions of Agility to solidify the core notion of "Sense and Respond". The major outcome is the creation of ISANN. Such a conceptual framework incorporates salient concepts and relationships such as the IS Agility Drivers and Providers, Dev Agility vs. Ops Agility, Torque and Friction, Synchronicity, etc. The following chapters will focus on business environments having high IS Agility Need Level. Chapter 3 will attempt to operationalise ISANN to demonstrate and evaluation its efficacy in describing and decomposing IS Agility phenomena. This is done through a series of illustrative business scenarios (specifically in the Cloud Computing context) to explain the demand, supply, and creation of IS Agility. 


\section{Chapter 3 : Operationalising ISANN}

\subsection{Introduction}

The purpose of this chapter is to demonstrate the application of ISANN in illustrative scenarios to generate insights into how and why IS Agility can be achieved, and to evaluate the efficacy of ISANN as a more complete conceptual framework for explaining the IS Agility phenomenon. This is done through real-life scenarios collected from different levels of Cloud Computing services.

Researchers have suggested that "the agility of IS is often studied through IT solutions that compose IS" (Izza, Imache, Vincent, \& Lounis, 2008, p.5). In fact, without a specific IT solution in mind, conceptually incorporating all the IS Agility elements introduced in the previous chapter can be convoluted and lack focus. Cloud computing 5 , as a common IT solution to today's businesses, has been promoted as an agility booster by vendors and service providers. A study of IS Agility simply cannot ignore the existence of Cloud Computing as it offers a great context for analysing and observing IS Agility delivered through technological innovations. This chapter provides a structured analysis on the IS Agility effects of the Cloud Computing at different service levels. Such an exercise helped us examine and demonstrate the efficacy of ISANN with regard to our goal of dissecting IS Agility.

\subsection{An Operational View of IS Agility: Illustrative Scenarios}

Articulating Dev Agility and Ops Agility is a difficult endeavour. Part of the difficulty comes from a lack of clarity regarding the underlying agility mechanism. This has

\footnotetext{
5 While there are several variants of deployment models for Cloud Computing (private, hybrid, etc.), this study focuses on the most common and influential type of these variants, public cloud computing.
} 
been a historical issue, but we have made a successful attempt to tackle it in Chapter 2. As a theoretical basis, Chapter 2 has established the conceptual clarity and structural integrity of IS Agility in the form of ISANN. This chapter proposes an operational view articulating IS Agility from an organisational perspective. This view provides a clear structure for examining the roles of Dev Agility and Ops Agility and their interplay. In particular, it shows Dev Agility Cycle and Ops Agility Cycle are parallel to yet dependent on each other.

As shown in Figure 9 below, we consider Dev Agility Cycle and Ops Agility Cycle as two parallel loops: with the inner SDSE loop representing Dev Agility while the outer SDSE loop concerning Ops Agility. These two SDSE loops (represented by solid lines in the diagram) can purely cycle on their own tracks respectively, namely, Dev $\boldsymbol{S}$ - $\boldsymbol{R}$ and $\boldsymbol{O} \boldsymbol{p} \boldsymbol{S} \boldsymbol{S}-\boldsymbol{R}$ (where "S-R" stands for "Sense and Respond") represented by solid single arrow lines. They can also interact or even intertwine with each other at any point when necessary. Such an interaction can be initiated from the inner loop hereafter called "Dev-initiated interaction", or from the outer loop - hereafter called "Ops-initiated interaction". In Figure 9 the Dev-initiated interactions are illustrated using red dashed lines while Ops-initiated interactions are represented by dark-blue dashed lines. There are also double arrow dashed-lines allowing free exchange of data, information, knowledge, and wisdom between the two loops. Moreover, the Torque and Friction arrows are also presented in Figure 9. 


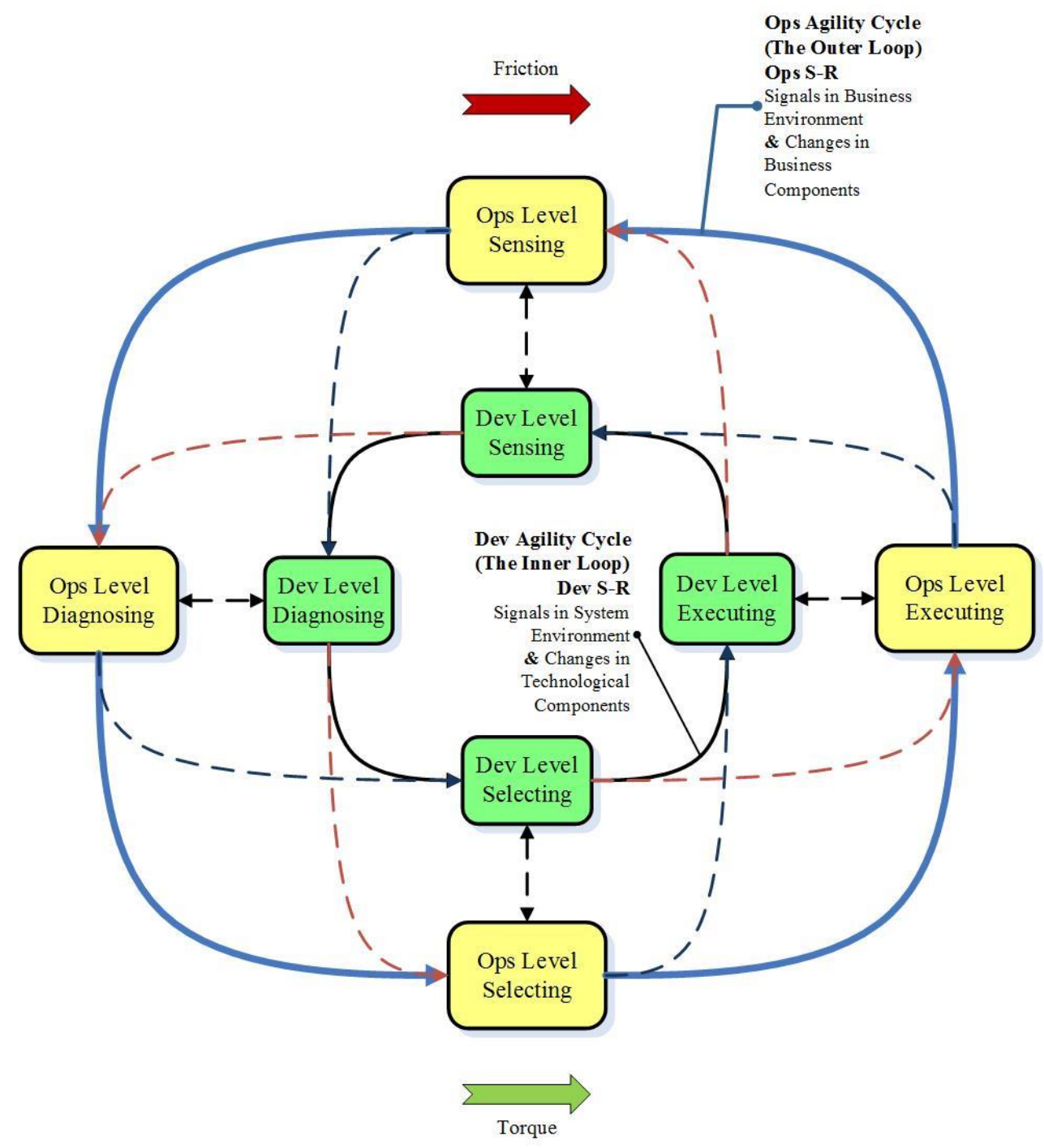

Figure 9: A Dynamic View of IS Agility

Change signals should be sensed and responded by business functions. Signals only related to potential changes in the technological components of the IS will be diagnosed and responded mainly by the Dev Agility Cycle which is often the responsibility of the internal IT function and/or an external IS provider (e.g. a SaaS or IaaS vendor). When cycling solely on the "Dev S-R" track, the inner loop works as a fully self-contained organ only sensing, diagnosing, and responding to necessitated technological component changes (e.g. this could be as fundamental as to sense the occurrence of deadlocks in an online flight booking system and respond with a 
hotfix). For organisations seeing themselves primarily operating on the Dev S-R track, the overall level of IS Agility depends predominately on the effectiveness and efficiency of the Dev Agility Cycle. Therefore, Dev Agility is critical and should be the focus of investment (e.g. strong expertise in system architecture, and productivityboosting automation tools for IS developers).

On the other hand, signals related to changes in the business components of the IS will be responded most often in the Ops Agility cycle and may be diagnosed collectively by one or multiple non-IT business functions (e.g. sales, marketing, and service quality management). When cycling solely on the "Ops S-R" track, the outer loop works as a self-sufficient unit sensing and responding to changes in the business environment, fully capable of making changes in business-supporting features of the IS (e.g. to sense inefficiency in the established inventory ordering processes and respond with optimised workflows and business rules to reduce customer complaints). For organisations operating mainly on the Ops S-R track, the level of overall IS Agility is mostly dependent on the effectiveness and efficiency of the Ops Agility Cycle, thus Ops Agility is essential and should be the focus of investment (e.g. intelligent tools to detect exceptions in business operations, smart workflows to support changing business processes).

Exclusively operating on the Dev S-R represents one extreme of a spectrum while solely cycling on the Ops S-R sits at the other end. The Dev Agility Cycle and Ops Agility Cycle can also be intertwined with and depending on each other, which makes the illustration of their relationships more complex. Organisations may see signals, diagnoses, decisions, and actions being bounced across these two cycles from time to time, following various tracks (e.g. as represented by the double arrow dashed lines in Figure 9). Such interactions can be initiated either by the Dev Agility Cycle or the Ops Agility Cycle, depending on the nature of the business (e.g. ITcentric vs. Non IT-centric). For the purpose of clarity, the next sections will first give 
clean examples of a pure "Dev S-R" and a pure "Ops S-R", and then elaborate on the intertwining relationships between the two cycles in more detail.

\subsubsection{Dev S-R: Sensing and Responding Purely at Dev Level}

As shown in Figure 9, operating on the "Dev S-R" track involves either the IS developers and/or the IS being signal sensors that detect changes needed. On this track, signals are proactively sensed to indicate and justify necessary changes in the technological components (Hobbs \& Scheepers, 2010). The subsequent actions including "diagnosing signals", "selecting and executing responses", are mainly handled within the IS development function. Depending on the dimensions of uncertainty involved (i.e. Temporal, Spatial, or both), the capabilities of the technologies, value vs. cost, and human performance consequences ${ }^{6}$ (Parasuraman, Sheridan, \& Wickens, 2000), cycling on the Dev S-R track may or may not require intensive human involvement meaning various levels of automation can be designed and implemented.

\subsubsection{Dev S-R with High Level of Automation}

With high Temporal Uncertainty and low Spatial Uncertainty, the nature of a change can be known to the IS developers but the timing for that change is unknown. In this situation, the IS can be programmed to follow known processes that will drive to expected outcomes. A response can be predefined and even made fully automatic by IS developers to maximise the "Torque" and drive the Dev Agility Cycle forward at high speed. The IS itself can be set up to demonstrate a high level of autonomy with sensing, diagnosing signals, selecting and executing responses, which may

\footnotetext{
${ }^{6}$ Parasuraman et. al. (2000) have provided a more detailed set of criteria for deciding the level of automation that can be achieved. However, we are not going to restate the ten levels of automation and the full list of criteria in this thesis which are beyond the scope of this thesis.
} 
involve changing its own technological behaviours automatically via adjustments on parameters, calculations and so on.

To take a simple example, consider Firm A, a China based SaaS company, providing its own B2C (Business to Consumer) e-Commerce web store solution to SMEs. Small business owners can sign up and pay a small monthly fee to open an online store on this platform in a self-service manner. However, a new trend is observed that an increasing number of business owners start to request dedicated e-Commerce solutions and are willing to pay for a premium service in order to build their own brands and customer bases. Such requests can come in anytime (convenient or not) and will require responses directly from the IS department of Firm A. Traditionally, deploying a dedicated e-Commerce solution would require weeks of laborious manual work coordinated by multiple IS technicians (e.g. implementing a standalone Linux virtual server with PHP and Apache installed, deploying a singletenant MySQL database and the online-store application, setting up the IP and DNS to make the store accessible to the public, integrating with payment channels, installing secure FTP).

Therefore, whether or not responding to these requests is mostly depending on the available capacity of Firm A's IS team. The lead time between sensing a request for a new standalone e-Commerce implement and responding with a functional solution to the customer, i.e. $\Delta S-R>$ two weeks, was unacceptable. The Dev Agility Cycle in such a circumstance was clearly out of Synchronicity by the Friction entailed in the manual implementation. From time to time, Firm A had to delay such types of implementation due to excessive demand on their already overloaded IS team. The manual implementation had clearly become a bottleneck. As a result, some larger business owners have turned to Firm A's competitors who either have more resources to handle manual implementations or apply different technologies to provide faster deployment of dedicated e-Commerce solutions. 
Seeing the loss of revenue from larger business owners, Firm A's IS department decided to speed up the implementation process for dedicated e-Commerce solutions. The IS development team was commissioned to automate those manual deployment and configuration steps as much as possible. Following the Scrum method, the Product Owner prioritised this implementation automation task in the product backlog (illustrative of Agile System-development), the IS development team then evaluated available technology options and decided to adopt Red Hat Ansible as a platform to construct the automation. They selected Ansible because it already contains various commonly needed modules for virtual server provisioning, configuration management, application deployment, intra-service orchestration and so on (illustrative of Agile System-Architecture). Developers are allowed to construct new and customised modules as well. All modules can be invoked sequentially as tasks executed through Ansible Playbook.

Within one Sprint, the alpha version of the automated standalone e-Commerce implementation was developed. In the following month, a fully tested stable version was launched and started to accept purchase orders online. Larger business owners now will only need to send their orders in, chose a business category and store template, decide the initial set of e-Commerce modules, make the payment, then their dedicated online store will be launched automatically and made ready for product data upload and layout configuration in a few hours - a much shorter $\Delta S$ - $R$ compared to the traditional manual method.

In this scenario, the implementation of a standalone e-Commerce solution has changed from slow (stretched into weeks), laborious, and manual processes to a fully automated machine-driven task (completed in hours). The IS development team of Firm A was leveraging both Agile System-Development and Agile-System Architecture to increase the Torque and reduce the Friction in the Dev Agility Cycle. The original high Friction imposed by the manual implementation has been reduced drastically via automation which closes the gap between the sensing and responding 
of the IS development team with regard to such user requests. In fact, most of the "sense and respond" responsibilities have shifted from the IS team to the IS itself. The changing user requirements can now be handled automatically on the Dev S-R track with high Synchronicity, responses are made right after changes being sensed, the $\Delta S-R$ has been shortened from weeks to just a few hours.

\subsubsection{Dev S-R with Moderate level of Automation}

In many business computing scenarios, the IS development team can control and minimise temporal uncertainty by following a known process with predefined timeframes but cannot do so with spatial uncertainty. As such, cycling purely on the “Dev S-R" track will still require considerable human effort. With spatial uncertainty being present, the nature of changes and the expected outcomes cannot be known in advance thus valid and reliable responses can hardly be highly automated. Such a spatial uncertainty has been exacerbated by the increasingly popular Cloud Computing business model having IS deployed and delivered on the Internet (i.e. SaaS) and shared by a huge number of different organisations. The average number of users of a traditional on-premises IS can range from hundreds to thousands, if not tens of thousands, whereas with a cloud-based multi-tenant IS, such a number can easily go up to millions. For an IS team developing and supporting such a SaaS type of IS, the diversity and the sheer volume of system changes requested by the IS users can be drastically higher than that with an on-premises IS.

For an online application with a small set of functionalities - often free with only tens, if not hundreds, of functional points, e.g. an Internet file sharing service such as Dropbox - the expansion of user base may not seem to be a major threat from a functionality perspective as a single focused application with simple features can legitimately keep user expectations within its original scope. However, with a complex IS offering a large set of functionalities and supporting critical business processes (e.g. ERP, CRM, LMS), client organisations need to pay a considerable subscription fee for using its sophisticated features involving thousands and more 
functional points, users would expect a lot more can be done in such a system. Resultantly, the tenfold, even hundredfold expansion of user base boosted by the SaaS model, to a complex IS, often means much higher rate new requirement changes bundled with higher diversity and spatial uncertainties.

With Agile System-Development methods (e.g. Scrum), however, an IS development team can establish a certain degree of "temporal confidence" to make the situation less overwhelming and even manageable. These methods mandate the need setting up disciplined mapping between tasks/processes and timing, often introduce a versatile tool set to facilitate the automation of information flow and task/process management, to make the sensing and responding processes partially automated. Such methods establish formal rules and tempo agreeable for both IS development team and IS user groups. This way, the IS team does not need to sense and respond in a 24/7 fashion, rather, it can have time for change aggregation, estimation, prioritisation, delivery, and reflection.

Firm B, for instance, as a New Zealand based SaaS provider, has adopted to manage the ever-changing user requirements towards its evolving cloud-based IS offering specialised in operational risk management. Firstly, an online tracking system called FogBugz (also a cloud-based solution) has been set up for all client users to send their change requests or bug reports in the form of "cases" via emails. This tracking system acts as the main sensor enabling the IS development team to keep "sensing" changes even when they are not at their workplace. Client users can send through requests any time and of any nature. All the "cases" recorded in Fogbugz will be read, classified, often rewritten as "user stories", and then assigned to a "Product Backlog" by the tier-one support team members on a daily basis, with duplicates removed.

Secondly, according to the Scrum methodology, the team has formally established a bi-weekly "Sprint" routine which can effectively control the level of temporal uncertainty (by the time this chapter was written, they had already gone through over 150 sprints, with some 12,000 cases recorded in the FogBugz). With such a 
routine, the team will do pre-defined tasks on certain days. On the second Thursday into a Sprint, the product owner (sometimes with client user representatives) will meet with the development team in a Sprint Review meeting to demonstrate what new features have been developed in the present Sprint. On the following Monday, at the beginning of a new sprint, the development team will have a Sprint Planning meeting with the top 10 priorities in mind to decide which cases from the Product Backlog should go into the Sprint Backlog. This is to limit the commitments for the planned Sprint and maintain a manageable workload. They will also need to discuss design decisions for the selected cases. On Wednesday the same week, the team will meet again to do some "Backlog Grooming" by aggregating user stories and estimating cases left in the Product Backlog to help the product owner make decisions for the upcoming Sprints. The rest of the time in a Sprint will be left for coding and testing with each team member being assigned to "just enough" number of "cases". Last but not the least, the newly developed features and fixed bugs during one Sprint will be automatically deployed from the development environment to the test environment in the following Sprint for quality assurance and testing, and then to the production environment in the third following Sprint with a Release Note being circulated among all system administrators at all client organisations.

Furthermore, to avoid being overwhelmed by the ever-expanding Product Backlog contributed by the increasing number of client users, the team also introduced other concepts such as "Half Life" and "Technical Debt" into the rules. "Half Life" means that after 30 days if a user story is not approved to be implemented then it should be considered half of the value to the original estimation. Such a concept helps the team with prioritisation of tasks. "Technical Debt" means the compromises have been made on system design due to time pressure or budget constraint. The development team often comes up with their own requirements - again in the form of user stories - to reduce Technical Debt. The product owner needs to take a balanced approach to handle Technical Debt and new requests from client users. 
After all, reducing Technical Debt, in the language used in this thesis, is a form of reducing Friction of the Dev Agility cycle.

Agile System-Development methods such as Scrum focuses on establishing a strict routine for the IS development teams to follow which intends to remove ambiguity and minimise Temporal Uncertainty. The team will know, in the face of everchanging user requirements, at least, which activities and tasks should be worked on and when, on a regular basis. Such a disciplined approach, when practised well, can generate high Torque to speed up the Dev Agility Cycle. Moreover, whenever a bottleneck is observed, or in the Scrum term, a "roadblock" is hit, team members can raise it at the daily "stand-up" meetings to seek help from others or reprioritise tasks in order to keep the Dev Agility Cycle moving forward.

Establishing some forms of Agile System-Development routine helps IS development teams improve confidence towards the temporal dimension of uncertainty. By following a regular "sense and respond" frequency with a high level of Synchronicity, a predefined, fixed value of $\Delta S-R$ can be agreed upfront. Such a regular frequency helps the team to manage expectations from IS users and maintain high responsiveness without being swamped or paralyzed by irregular, diverse, yet constantly changing user requirements. With a clearly defined and agreed $\Delta S-R$, the team will know precisely when to sense, diagnose, select, and execute on a day-to-day basis. Such regularity removes the burden of project coordination and helps IS development teams keep the momentum on their SDSE cycles, often voluntarily and autonomously

In this scenario, the Friction was not explicitly illustrated. However, as discussed previously, the Friction is decided by the difficulty in making changes on the technological components provoked by changing business requirements. Such difficulties can be reduced, as discussed in Chapter 2, by a carefully designed Agile System-Architecture to improve the changeability of the IS. Modern developer tools such as code generators (e.g. CodeCharge Studio) can also reduce the effort required 
for creating and modifying IS functionalities and features. In a SaaS context, establishing an ecosystem for IS developers to share their work in terms of customising and extending the IS of interest and creating new modules or add-ons. For example, Salesforce.com opens its development platform Force.com to developers to leverage the power of the crowd to help mitigating the pressure caused by ever coming new requirements from millions of system users.

\subsubsection{Dev S-R with Low Level of Automation}

Although equipped with modern smart tools for designing, developing, testing, debugging, and deploying, IS development teams can, from time to time, still find themselves cycling on the Dev S-R track with mostly manual effort. This often happens on occasions where no Spatial nor Temporal confidence is formally established in the system environment, particularly with those ad-hoc events where processes and outcomes cannot be known upfront.

For example, a New Zealand based IT consulting business, Firm C, provides OLAP (Online Analytical Processing) reporting services to its clients for operational performance management purposes. Firm $\mathrm{C}$ has developed as many as 800 automated online data reports and dashboards (either in tabular or graphical formats) for over 40 client organisations. Many of these reports are set up to execute and distribute to client users on predefined dates (such as weekly planning sessions, monthly board meetings, quarterly operational reviews, etc.). The rest are designed to be run by client users in real time during other important occasions. Hence the quality and performance of these reports are critical and closely monitored. Once the IS team and/or the IS itself detect an undesirable change (e.g. anomalies) in the quality or performance of these reports it must diagnose and respond to the change as soon as feasible. Such change can be sensed automatically by monitoring the execution of these reports and the CPU/Memory usage of the OLAP servers (Firm C uses a database performance analyser called SolarWinds to monitor and track server performance), or by manually receiving complaints from 
the clients. Although the managers at firm $\mathrm{C}$ don't like to see them, complaints do occur especially when client users trying to run their reports on an ad-hoc basis.

One day the support desk received a complaint from a client user experiencing extremely slow response-times and eventually timeout errors when running an adhoc management report and was worried as the report was required for an important meeting the next day morning. The source of the slowness could come from the virtual server being overly occupied at the time the report was running, or a malfunction of the underlying OLAP system, or the design of this particular report being flawed, or simply the client's network condition being poor, or some other unknown factors.

Such a scenario, with similarities to the previous one of Firm B (as reported in section 3.2.1.2), also involves both Temporal and Spatial uncertainties. However Firm B's scenario focuses on changes (i.e. business/user requirements), even though unpredictable and irregular, can be regulated and responded to at a regular pace (e.g. one Sprint every fortnight) which helps the IS development team build Temporal Confidence. On the other hand, in Firm C's scenario, changes initiated by the client user cannot be regulated on the temporal dimension due to strict time constraints - they need to be responded to immediately.

Although one could perhaps define formal procedures to handle situations like Firm C's scenario, automating the processes of diagnosing and responding to issues as such is next to impossible. Various IS technicians have to be involved and apply their knowledge and skills to find out the actual reasons for the error and initiate a quick response to satisfy the IS user. The diagnosing, selecting, and executing capabilities of IS team hence are critical. Most of the sensing and responding has to be done manually. First a complaint is manually received by the support desk, then the IS team has to manually diagnose the root cause of the issue and decide on how to react. In such a scenario, the capabilities of IS personnel largely decide how the agile response is made and what the outcome may be. 
In such a manual process, the complaining IS user is expecting an effective response immediately, but the actual $\Delta S-R$ is decided mostly by the available capabilities of the IS team that makes the response. A highly skilled and experienced expert, compared to a novice one, can achieve a higher level of Synchronicity in the SDSE cycle and represent a significant increase in Torque and shorten the $\Delta S$ - $R$. A novice IS team member, on the other hand, when operating alone, may hit multiple bottlenecks or "roadblocks" during the process of diagnosing and responding and end up bringing in more Friction and increasing the $\Delta S-R$.

For example, experienced IS expert would diagnose the nature of the issue first by scanning the OLAP server logs, the report execution logs, together with the helpdesk logs to find out when was the last time the report did not run well, what did the server usage look like, and were there any similar complaints from other clients. By collectively considering all these aspects, the expert could determine that the timeout error was not an issue about the report design nor the server capacity, but a bug associated with a recent update of the OLAP server which may cause a deadlock when certain queries were concurrently requested by multiple clients. The issue could be addressed by a hot-fix, and the complaining client can be reassured that the report would run properly in the next few hours.

However, without a comprehensive understanding of the technologies and systems in use, less experienced IS team members could have focused extensively on the particular slow report at first and spent hours in checking its design for flaws, without being able to reproduce the error experiences by the complaining client user. In the end, they might miss the window for fixing the problem in time which in turn would result in inconvenience for the client's meeting and damaged reputation of the company. 


\subsubsection{Dev S-R Summary}

To sum up, on the "Dev S-R" track, changes on the technological component of IS are detected and handled within the IS function (either an internal department or an external provider). Such handling can range from highly automatic by machines in real time (minimising $\Delta S-R$ ) to mostly manual by humans with context-based time constraints ( $\Delta S-R$ can be fixed or negotiable). The higher percentage of manual handling needed in the process, the more demand for highly skilled and experienced IS personnel to increase Torque and Synchronicity. In general, firms should aim at identifying those manual processes and convert them into more automated processes with higher efficiency and similar, if not higher, effectiveness, compared to the results of manual work. Although we admit, in reality, depending on the level of Spatial and Temporal uncertainties, efforts in automation may be found more expensive than having humans to sense and respond manually, we do believe, a systematic approach can be designed to help IS practitioners and researchers articulate the point where automation is most appropriate. ${ }^{7}$

\subsubsection{Ops S-R: Sensing and Responding Purely at Ops Level}

As shown in Figure 9, operating on the "Ops S-R" track involves the IS or the IS users being the signal sensors for detecting business changes needed. On this track, signals are proactively detected by the IS users and/or the IS to indicate and justify necessary changes in the business components of the IS. Hence the subsequent actions including "diagnosing signals", "selecting and executing responses", will be mainly within the relevant business functions relying the IS to operate.

\footnotetext{
7 Parasuraman et. al. (2000) proposed a set of criteria for deciding the level of automation can be achieved. We believe the dimensions of uncertainty and several other factors should be included to make the criteria more effective and practical. This will be demonstrated in our new publications.
} 
Again, similar to the Dev S-R track, depending on the dimensions of uncertainty involved (Temporal, Spatial, or both), as well as the capabilities of the IS and technologies, cycling purely on the Ops S-R track may or may not require intensive human involvement, thus various levels of automation can be observed.

\subsubsection{Ops S-R with High Level of Automation}

With the advance in system design and technologies, some signals indicating changes in the business environment can now be captured and responded autonomously by the IS itself, often when only Temporal Uncertainties are present. On the Ops S-R track, once Spatial Confidence can be established, the IS can be trained to follow certain rules and logic to infer and construct responses. The system itself can then automatically sense and diagnose signals and make responses to change its own business-supporting behaviours.

The same Firm A from section 3.2.1.1, for example, has implemented an intelligent recommendation system into its B2C e-Commerce web store platform. Such a system, can detect a user's browsing behaviour and analyse his/her preferences thus can dynamically and autonomously change the contents of the web page presented to that user with recommended products he/she will be interested in buying. All these operations are done in real time. Many customers are surprised yet pleased to see how relevant the recommended products can be, thus go ahead to add more into their shopping carts. In fact, over 30 percent of Firm A's online revenue (e.g. transaction fee) is believed to be generated by the recommendation system alone.

Such an intelligent recommendation system is built upon Apache Spark and modelled in a Complex Event Processing fashion (illustrative of Agile SystemOperation). Powered by large amount of transactional data with timestamps and smartly designed collaborative filtering based on user feedback (e.g. product ratings, reviews and comments), the recommendation system can discover relationships linking product to product, customer to product, and customer to customer. Using a 
consumer-based approach, the system will assume two consumers have a similar taste if they demonstrate alike preferences, namely, matching patterns can be found in their purchasing history, consumer surveys, browsing behaviour, etc. Using a content-based filtering approach, the system can compute similarities between products by comparing their attributes, consumer ratings, and so on. This way, when generating recommendations for a customer, the system can use the known preferences of other similar customers, plus products believed most relevant to those ones currently being viewed or already in the customer's shopping carts.

In this scenario, the IS can readily process through the SDSE cycle and change its business-supporting behaviours automatically and anonymously in real time. Surely the advancement in computational power and algorithms plays a significant role in fully automating the Ops S-R track, metaphorically, increasing the Torque and Synchronicity. However, we must acknowledge that the layered architecture and modularised presentation design (illustrative of Agile System-Architecture) of Firm A's web store platform also contribute to the success, as these allow the recommendation system to dynamically change the content on web pages without any difficulties and any support from human operators, in other words, minimising the Friction and $\Delta S-R$.

Moreover, as mentioned at the beginning of this section, we argue that such a fully automatic Ops S-R track can be achieved largely because Spatial Confidence can be established in advance, that is, Firm A knows where to make changes in the business components/behaviours of the IS and how to make them. Essentially the nature of responses produced by a recommendation system such as the one developed by Firm $\mathrm{A}$ is just modifying content of web pages and pushing relevant products information to users in real time. But the system does not know when such a response is needed and so Temporal Uncertainty is present.

The key challenge here is the requirement of minimised $\Delta S-R$ and high level of Synchronicity, that is, once the IS senses a customer begin to browse certain product 
information, it will need to make a response by computing and presenting recommendations instantly. If there is a noticeable delay and the recommended products cannot be calculated or presented on the web page in a timely manner, the customer may navigate to other pages or leave the web store without even seeing the recommendations. Resultantly customer shopping behaviours and purchase decisions will not be affected at all, due to delayed responses, which defeats the whole purpose of implementing the recommendation system.

\subsubsection{Ops S-R with Moderate Level of Automation}

Still, many changes in business environments can involve uncontrollable Spatial uncertainties and will require some form of human intervention. Similar to the Dev $\mathrm{S}-\mathrm{R}$ track, certain level of Temporal Confidence can be established by setting up a regular sensing and responding frequency, namely a constant $\Delta S-R$, for IS users to process through the SDSE cycle with a moderate level of automation.

Today many enterprise systems (e.g. ERP, CRM, SCM) with built-in KPIs and benchmarking functions can sense important business changes below or beyond a certain threshold (Trinh-Phuong, Molla, \& Peszynski, 2010). Firm D, for example, a New Zealand based energy company, has its own CRM and ERP system implemented for years and has established a routine for data reporting and analysis on a regular basis (Weekly, Monthly, and Quarterly). Such a routine establishes temporal confidence and is deemed critical for keeping Firm D's operational performance on track, as well as regularly looking for threats and opportunities. Users of such IS in Firm D (often business analysts and managers) can subscribe to relevant data analysis reports and have the results delivered to their email boxes automatically. In other words, users, with the assistance from the IS, are observing business changes at a regular frequency. Their responses to change are made at regular intervals, either every week, every month, or every quarter.

One week in the first quarter of the 2015 financial year, based on the integrated data reports automatically generated from the CRM and ERP systems, users in the sales 
department sensed that the growth rate of new customers from a recently developed region in the first quarter has dropped considerably below the target, compared to the same quarter a year before. This could indicate either an approaching market saturation, or a change in the intensity of competition in that region. Firm D then deployed market intelligence capabilities in that region, which suggested that there was a variety of comparable products and services pushed out to that region by rivals. Firm $\mathrm{D}$ then concluded that this region has become more competitive and a new strategy had to be designed for the next quarter.

At this point, although Firm D still did not know what the response should be to such a change (Spatial Uncertainty), it already knew when to decide the response (Temporal Confidence): at the monthly operational meeting coming up in a week's time. At that meeting, Firm D decided on what responses had to be made. The meeting participants came up with various solutions including changing pricing strategy, increasing marketing effectiveness, implementing a customer loyalty program, and so on. All these responses would represent changes in the businesssupporting features of Firm D's CRM and ERP systems. The firm needed to add an additional follow up call in the sales workflow, adjust new customer discount rates, modify unit prices, and alter the incentive-rewarding mechanism specifically for the targeted region to attract new customers and retain existing ones. From an IS perspective, all these adjustments were system configuration work thus were completed by IS users in the sales department within a week without involvement from the IS department (illustrative of the Agile-System Configuration). Being able to make these business changes so quickly and effectively through pure system configuration effort was largely attributed to the fact that the IS involved were designed and engineered in a highly configurable fashion. IS users were empowered to confidently change the business components of IS through defining/modifying process models and parameters without the need to understand the inner workings of the infrastructure. 
In this scenario, the Friction on the Ops S-R track was low due to the fact that the IS involved were leveraging Agile-System Configuration designs and technologies to allow IS users to add, modify, and delete business processes, rules, and workflows without intervention from the Dev Agility Cycle. Furthermore, by establishing a regular sensing and responding routine. a group of IS users can agree on a fixed $\Delta S$ - $R$ to ensure a rhythmic cycling on the Ops S-R track, with a certain level of automation in the sensing part. Without a regular routine, given today's level of market turbulence, IS users can be constantly exposed to signals from the business environment and easily fall into traps - either become paralysed by the overwhelming amount of business data, often containing large volume of noise, or get forced into a counterproductive fire-fighting mode leading to exhaustion and burnout. Similar to the Dev S-R discussion (i.e. the Scrum practice) in section 3.2.1.2, setting up a constant $\Delta S$ - $R$ can help IS users establish Temporal Confidence which in turn allows time for deciding priorities and designing effective responses. Having a regular "sense and respond" frequency can improve the level of Synchronicity as processing through the SDSE cycle becomes a rhythmic and graceful effort.

\subsubsection{Ops S-R with Low level of Automation}

Although empowered by modern IS for data gathering and processing, IS users can, at times, find themselves cycling through the Ops S-R track with much manual effort and low level of automation. This often happens on occasions where neither Spatial Confidence nor Temporal Confidence is formally established in the business environment.

Firm E, for example, a New Zealand based health service provider, over years, has implemented several IS to support staff training (custom built LMS), incidents and injuries management (WorkAon), workforce management (Kronos), and payroll processing (PayGlobal). For years, these IS were believed to be sufficient for the managers and staff members to report and record their health and safety related matters - such as hazards, risks, incidents, staff competency and training - upon 
occurrence. Despite Firm E's high-risk operation, a "management by exception" style was followed.

However, the environment was changing. Due to undesirably higher work-related injury and fatality rates in New Zeeland, significant legislation changes have been made along with a new Health and Safety Reform Bill that came in force on $4^{\text {th }}$ April 2016. Managers and directors (collectively called Officers in The Bill) can now be held primarily accountable for a breach of health and safety practice, even if the PCBU (the Persons Conducting a Business or Undertaking, or the persons in control of a place of work) is not going to be held responsible. This law change "...aims to ensure that those in governance positions will proactively manage health and safety and provides for some much-needed accountability." 8

Moreover, Officers are required to "...exercise a duty of due diligence to ensure the PCBU complies with its duties....Due diligence requires, among other things, an understanding of the nature of operations, hazards and risks and ensuring that the PCBU implements processes for complying with their duties....The Bill significantly increases the category of offences, with a three-tiered hierarchy being introduced, along with a range of other offending provisions. The Bill then imposes across all three tiers a six-fold increase in fines from the Act." ${ }^{9}$ For instance, Officers, if deemed "reckless conduct in respect of a health and safety duty", can face severe penalties up to five years in prison and/or a $\$ 600,000$ fine.

With such a radical change in legislation, Officers at Firm E sensed an urgent need to respond $(\Delta S-R=$ ASAP) by gaining high visibility to their health and safety risks and monitor the effectiveness of risk controls in order for making adjustments. However, as mentioned in the beginning of this section, data relevant to health and safety

\footnotetext{
${ }^{8}$ https://www.laneneave.co.nz/all-publications/70-employment-law-alert-no-8/

9 ibid.
} 
management was captured in several different systems and only patricianly integrated in monthly and quarterly reports prepared by health and safety advisors. Preparing these reports was time-consuming and prone to error as it required a collective effort from administrators (IS power users) of each system to pull data from the disparate systems into CSV files and send them to an analyst. That analyst then needed to reconcile and integrate the data into a unified dataset (in reality, a complex Excel spreadsheet) and to produce a standard set of calculations and charts. The health and safety advisors at Firm E would then work on this Excel spreadsheet and spend another week or so to plough through the data and look up for meaningful information so they can report to the Officers. After all the manual handling, a few weeks would be gone, thus the Officers at Firm E could never see the real-time updates how their health and safety management system was performing. They were always viewing their dated data and historical reflections.

Clearly, the traditional approach for data gathering, analysis and reporting used by Firm E on its health and safety matters presented a major bottleneck and was deemed too slow to produce the needed level of due diligence to the Officers (delayed sensing and diagnosing). It simply created too much Friction on the Ops SR track, which made the whole sense and respond cycle out of Synchronicity with reality. The Officers with a duty of due diligence needed the IS to be agile enough to provide timely feedback on the firm's health and safety decisions and actions.

Stressed managers initially planned to build a new safety management IS and integrate all health and safety related data into it for better data consistency, higher information visibility and real-time performance analysis. However, later this plan was dropped due to the estimated time and effort were unaffordable. It would take minimal eight months to design, develop, and implement the new system. This was nowhere near to the $\Delta S-R=$ ASAP expected by Firm E's Officers.

Under serious time pressure, Firm E called in external experts for help. Together they decided to adopt Microsoft Power BI as a replacement for the old data 
integration and analysis approach. Such a tool has the capacity to discover relationships across scattered datasets which can considerably improve the speed and accuracy of data reconciliation. It allows visualised data modelling to cleanse and transform the integrated data for higher quality. Within a few days, system administrators and safety analysts have got Power BI installed on their work computers. One week later, some were sitting in tutorials learning how to use a model-driven approach to define their datasets and tap into different data sources including all Firm E's exiting IS.

Within three weeks, new health and safety management reports and data analysis results started to come out. Based on the integrated data models built using Power $\mathrm{BI}$ and regular data refresh from source systems, Firm E has now become able to monitor its critical health and safety risks daily with most of the manual data processing work being replaced by automation. Next step the Officers want to build a real-time dashboard to track the effectiveness of designed risk controls. They are much assured that due diligence can be achieved, and their health and safety risks are in check.

In this scenario, cycling on the Ops S-R was mostly manual by the IS users. The IS in question were merely scattered data recording systems with little intelligence built in. The IS users had to put in tedious work to integrate the data needed for "sensing and responding" to changes in their operational safety practice. This work involved both Temporal and Spatial uncertainties. Temporal uncertainty came from the unpredictable availability of needed personnel to perform the manual data handling work. Spatial uncertainty came from the unforeseeable errors and discrepancies in the various versions and copies of CSV files and Excel spreadsheets. There was a major lag on the Ops S-R track due to Friction caused by the slow process of detecting and diagnosing signals from disparate data sets. The Ops S-R track in this context was out of Synchronicity with an unacceptably long $\Delta S-R$. 
Due to undesirable performance, eventually more automation was introduced onto the Ops S-R track of Firm E's health and safety management team. The advance in intelligent data analysis tools (i.e. Power BI in this scenario) helped the IS users establish Temporal Confidence by automatically and autonomously performing all the tasks needed to refresh the data and calculations daily, as well as monitoring the whole process and keep the users updated on unexpected events (illustrative of Agile System-Operation and Torque Boost on Ops S-R). The model-driven data integration and analysis approach embedded in such tools can help establishing Spatial Confidence by providing a single version of the truth with high level of accuracy and certainty. Instead of Firm E's originally error-laden process of having multiple IS users handling various versions and copies of data files, data from different sources can be visually organised into one unified semantic model. Along building this model, an automated workflow can be configured to execute data extracting, cleansing, transforming, and loading into the model. When data sources/sets change, the workflow can be modified quickly and easily by adding, altering, or removing detailed data manipulation steps to accommodate the changes (Illustrative of Agile System-Configuration and Friction Reduction on Ops S-R).

\subsubsection{Ops S-R Summary}

To sum up, on the "Ops S-R" track, changes in business environment and the business supporting-feature of IS are detected and handled predominantly by IS users with minimal intervention from the IS function (either an internal department or an external provider). Such type of handling can range from high to low level of automation. The higher percentage of manual handling is needed, the more dependency on the skills, experiences, and availability of IS users to maintain desirable $\Delta S-R$ and Synchronicity. In general, firms should aim at identifying those manual processes and gradually, through learning and reflection, convert them into automatic yet effective processes. Intelligent tools and technologies are becoming more available to help IS users reduce Friction and increase Torque while performing "sensing and responding". Again, we admit that, in reality, the mix of 
Spatial and Temporal uncertainties may make the effort of automation more expensive than having humans to sense and respond manually. Organisations will need to be able to evaluate automation options and make trade-offs. One starting point could be gaining insights from human-automation interaction research (Hancock et al., 2013). In addition, we believe articulating the Temporal and Spatial dimensions of uncertainty and establishing some form of context-based confidence in at least one dimension would improve the feasibility of automation.

\subsubsection{On Interactions between the Dev and Ops Agility Cycles}

Although the Ops Agility Cycle and the Dev Agility Cycle can operate separately on their own tracks in parallel, at times, they also intertwine with each other. Such an intertwining relationship can be complex and dynamic in reality. The diagram in Figure 9 intends to graphically capture this cross-loop interrelationships. As represented in dashed lines which allow a free flow between the two loops. In the real world, organisation may find themselves having to cycle through some parts of the outer loop and then other parts of the inner loop (or vice versa) in order to effectively and efficiently sense and respond to changes.

The interaction between the inner and outer loops can take in many forms as both loops can communicate and collaborate with each other at any stage if required. With a great deal of simplification, we classify the types of interaction into two: Devinitiated vs. Ops-initiated, with each represents a deviation from the pure and clean Dev S-R and Ops S-R tracks. In both types of interactions, actions and decisions can be bounced between the Dev Agility Cycle and the Ops Agility Cycle with each contributes its own portion to keep cycling forward.

\subsubsection{Dev-Initiated Interaction}

The Dev-initiated interaction means the Dev Agility Cycle takes lead in sensing signals and detecting potential changes in the business environment which need to 
be forwarded to the Ops Agility Cycle to diagnose and decide on responses. The responses could include a modification of the technological components of the IS or an adjustment of the business components instead.

For instance, the Dev Agility Cycle can sense threats presented by abnormal user transactions and then report to the Ops Agility Cycle to decide if a more restricted access to system/data should be enforced. This way, the signals for change are sensed on the Dev Agility Cycle and decisions on responses are being made on the Ops Agility Cycle, yet the execution of the decision is done back on the Dev Agility Cycle.

Dev Agility Cycle may intentionally or unintentionally capture signals suggesting changes in business components of the IS. These signals then get forwarded to the Ops Agility Cycle to diagnose and respond. For example, a data integrity issue sensed by the Dev Agility Cycle may need to be responded by the Ops Agility Cycle to alter the business workflow and classification rules. This time, the selecting and executing capabilities on the Dev Agility Cycle are not required.

Such a Dev-initiated interaction represents an emerging view of the role of IS function in organisations. The IS function is, to a lesser extent, just a passive unit that solves technical problems such as infrastructure glitches and bugs in software applications. Instead, with more business operations turning into highly digitalised products and services, the IS function can serve as a scout in detecting business problems, identifying risks, and making innovations. This is especially true with organisations having Internet based services as their core businesses.

\subsubsection{Ops-Initiated Interaction}

The Ops-initiated interaction, on the other hand, depicts a situation where the Ops Agility Cycle detects signals for potential changes in the business environment which require the Dev Agility Cycle to make responses. For instance, through analysing historical sales data, an online book selling business has discovered a 
clear trend that old customers are moving away. The business then intends to add a smarter cross-vendor loyalty program into their online store. Such a program cannot be implemented without help from IS developers/engineer, as in involves adding new technological structures and functionalities into the underpinning IS to retrieve and integrate customers' points accumulated via historical purchases done with other collaborating vendors. Signals for changes are observed and interpreted on the Ops Agility Cycle yet decisions for response (e.g. technologies and techniques to be used for the development of such cross-vendor loyalty program) are made and executed collectively with the Dev Agility Cycle.

In such a situation, the Dev Agility Cycle acts more as a reactive responder to signals sensed and diagnosed on the Ops Agility Cycle. The IS users may first detect signals indicating necessary changes in the technological components of the IS which they cannot implement. Then IS developers are called in to make the changes by either constructing new features or modifying existing functionalities of the IS. Such Opsinitiated interaction represents a traditional view of the role of the IS function in organisations, i.e. being a supportive and reactive function to other business operations. However, given the transformational role of technologies in modern businesses, lesser organisations can afford purely operating in this manner and ignore the sensing capabilities on the Dev Agility Cycle.

\subsubsection{Section Summary}

This section elaborated on an operational view of the IS Agility Cycles from an organisational standpoint. Conceptually, the two Agility Cycles (Dev vs. Ops) can operate on their own tracks (Dev S-R vs. Ops S-R) in parallel and/or intertwine with each other at the same time. Table 10 below summarises the key elements emerging from this elaboration. In this table we present only the pure form of Dev S$\mathrm{R}$ and Ops S-R which are essential to understand the IS Agility concept. The intertwining relationships between the two are more like variations with no 
fundamental deviation from the core conceptualisation thus not presented in the table for simplicity and readability.

As shown in Table 10 below, Dev S-R and Ops S-R have different responsibilities in terms of sensing signals and responding to changes. Both can have various levels of automation, although for to simplify the presentation we classified only three levels (high, moderate, and low). More extensive classification of automation can be found in the work of Parasurman et al. (2000), even though it does not address issues of uncertainty. We will not discuss automation any deeper as it involves complex context-based design and decisions thus would take us far apart from the primary purpose of this thesis. 
Table 10: Summary of Dev S-R vs. Ops S-R

\begin{tabular}{|c|c|c|c|c|c|c|}
\hline & Sense & Respond & $\begin{array}{c}\text { Level of } \\
\text { Automation }\end{array}$ & $\Delta S-R$ & Temporal & Spatial \\
\hline \multirow{3}{*}{$\begin{array}{l}\text { Dev } \\
\text { S-R }\end{array}$} & \multirow{3}{*}{$\begin{array}{l}\text { Changes in } \\
\text { System } \\
\text { environments }\end{array}$} & \multirow{3}{*}{$\begin{array}{l}\text { Changes in } \\
\text { technological } \\
\text { components } \\
\text { of IS } \\
\text { (Structure, } \\
\text { Functionality, } \\
\text { Capacity, } \\
\text { etc.) }\end{array}$} & High & Instant & Uncertain & Confident \\
\hline & & & Moderate & $\begin{array}{l}\text { Pre-defined } \\
\text { regular } \\
\text { intervals }\end{array}$ & Confident & Uncertain \\
\hline & & & Low & Unguaranteed & Uncertain & Uncertain \\
\hline \multirow{3}{*}{$\begin{array}{l}\text { Ops } \\
\text { S-R }\end{array}$} & \multirow{3}{*}{$\begin{array}{l}\text { Changes in } \\
\text { business } \\
\text { environments }\end{array}$} & \multirow{3}{*}{$\begin{array}{l}\text { Changes in } \\
\text { business } \\
\text { components } \\
\text { of IS } \\
\text { (Workflow, } \\
\text { Company } \\
\text { Codes etc.) }\end{array}$} & High & Instant & Uncertain & Confident \\
\hline & & & Moderate & $\begin{array}{l}\text { Pre-defined } \\
\text { regular } \\
\text { intervals }\end{array}$ & Confident & Uncertain \\
\hline & & & Low & Unguaranteed & Uncertain & Uncertain \\
\hline
\end{tabular}

The needed $\Delta S$ - $R$ values, as listed in the table, can vary largely depending on the nature of changes in the IS and business environments. We argue that being able to identify a satisfying value of $\Delta S-R$ is critical to achieving IS Agility in a business context. However, the actual $\Delta S-R$ values can be maintained may be determined by the dimensions of uncertainties involved, the process and outcome expected, the level of automation can be implemented, and other contextual factors not presented here. Designing the IS to meet the expected $\Delta S-R$ value requires careful considerations of these factors. Chapter 5 will discuss this in more detail.

In short, the two tracks summarised in previous sections are a simplification of reality for separation of concerns. As expected in any representation or abstract models, the reality is more complex. One may find these two tracks can blend into each other and become an almost integral function at times (especially for those businesses providing IS development as their core services). For instance, within one cycle, the Dev Agility Cycle may sense signals relevant to both technological and 
business components of the IS. Then it will go on to respond to signals related to the technological side and pass the signals related to the business side onto the Ops Agility Cycle. Hence "Dev S-R" and "Ops S-R" can both be present in one cycle. In the same fashion, the Ops Agility Cycle may proceed by itself while passing signals down to the Dev Agility Cycle.

Depending on the business models and technologies in use, some firms may value one track over the others. For instance, firms with their own e-Commerce implementations which require responsiveness, reliability, and easy recovery to support smooth and secure online transactions, may find that the "Dev S-R" track deserves much investment. On the contrary, firms purely relying on third-party solutions to conduct online retail and maintaining little in-house IS capability, may have no interest in developing "Dev S-R" at all, rather, they would focus their investment on "Ops S-R" and adopt more low-maintenance cloud-based smart applications to satisfy their customers.

This section has brought about more detailed understanding and a holistic view concerning IS Agility and its positioning within the organisation. This view has injected higher level of conceptual clarity into this study. Yet again, without a specific IS solution in mind, conceptually incorporating all the discussed IS Agility elements together may seem to lack focus. More technology-specific analytical elements will be provided in the following sections.

\subsection{Applying ISANN: Descriptive Analysis of Cloud Services}

To achieve agility in IS, IT practitioners have devoted considerable effort to bring about innovations in technical architectures and frameworks. In particular, the service-oriented paradigm has become increasingly popular in recent years (Chang, He, \& Castro-Leon, 2006). This paradigm proposes that IT systems should be built 
based on loosely coupled and reusable modular services which can be quickly constructed and deconstructed to support changing requirements in IS and business requirements (Setia et al., 2008). Such a popular paradigm in the IT industry is in alignment with the "Agile-System Architecture" identified in ISANN. Out of the notion of service orientation has emerged a new approach for converting conventional IT resources into public online services - an approach commonly called cloud computing.

Cloud computing delivers IT resources in a service-oriented model and is marketed as a new approach to provide agile and responsive computational power to businesses. The necessary underlying infrastructure is provided by large data centres located in distant areas offering cheap electricity, with each operating tens of thousands of servers (Katz, 2009), which brings about economies of scale. Plus the advancement in server virtualisation and administration automation, Cloud Computing providers can rent out their computing resources and software services to clients at a low price in a pay-as-you-go subscription fashion. These resources and services are delivered via the Internet, often in a self-service model with which users can initiate, configure, and terminate virtual servers and systems remotely without intervention from vendors (Mell \& Grance, 2010). Therefore, Cloud Computing adopters no longer need to maintain and manage local IT infrastructures and systems to support their business activities. For an organisation, this means the "Dev Agility Cycle" becomes mostly the responsibility of the cloud provider. Resultantly, the business can focus more on their core business operations and the "Ops Agility Cycle" by leaving many IT-related activities such as server installation, maintenance, and software updates to be handled by remote specialised vendors who are dedicated in managing such technologies and infrastructures.

Cloud computing, as a unified IT delivery model with a focus on agility gains, provides a valuable context for us to better understand issues surrounding IS Agility. The following sections further the elaboration of ISANN and use it as a conceptual 
framework to descriptively analyse the agility impact of Cloud Computing services (i.e. IaaS vs. SaaS). Through this chapter, we are able to justify that ISANN is not only a theoretically robust conceptualisation, but more importantly, a practically relevant model for inspecting and designing IS Agility in real-world businesses. Subsequently, ISANN is deemed capable to provide a solid foundation for designing a systematic method to dissect and solve IS Agility problems.

Today, when discussing IS Agility, Cloud Computing is perhaps among the top-cited technology terms. Cloud Computing providers and proponents often highlight "agility" as a key benefit to promote adoption. For instance, Oracle has organised an online seminar titled "Cloud Computing enables IT agility" (Oracle, 2010), while Microsoft has promised that adopting cloud services brings "more agility, more freedom, and more choice" (Microsoft, 2010). Some technology commentators even suggest that it is "agility, not savings, may be the true value of the cloud" (Mullins, 2010). CIO magazine has been recommending "business strategy based on Cloud Computing and agility" (Hugos, 2010). All these promises and efforts have made Cloud Computing an unprecedented phenomenon when researching IS Agility.

Despite the large supply of marketing materials and white papers, to date there has been limited academic research explaining if cloud-based services really enable IS Agility, and if so, how it may happen (Sawas \& Watfa, 2015). This section takes our refined understanding of IS Agility to the Cloud Computing context and "drills down" into a deeper analysis of the potential effects of cloud services. Through a structured assessment, using the concepts and insights generated from previous literature and synthesis (e.g. ISANN), we have reasoned and discovered that different levels of cloud-based services have different impacts on IS Agility which can vary drastically from high Synchronicity with minimised $\Delta S-R$, to low Synchronicity with $\Delta S-R$ mostly unguaranteed. Such a structured analysis, again, can help us evaluate the usefulness and effectiveness of ISANN (and those more detailed elements and inner workings discussed in Section 3.2) in the real-world business context. 
An earlier version of this analysis has been published ${ }^{10}$ and cited as part of the theoretical foundation by one of the first empirical studies into the impact of Clout Computing on IS Agility (Sawas \& Watfa, 2015). This empirical study provided evidence to support the outcome of our structured analysis, that is, the agility claim made by cloud service providers is only partially valid. SaaS is mostly a cost-saving option allowing light-weight implementations, but appears to have no guaranteed impact on IS Agility (Sawas \& Watfa, 2015). IaaS and PaaS can address some aspects of the agility issues related to technology infrastructure and software development (Sawas \& Watfa, 2015), but are not sufficient to achieve the full scope of IS Agility we conceptualised in the previous sections. Nevertheless, Sawas and Watfa (2015), from an organisational capability point of view, applied a "reflective measurement" approach to survey the perceived IS Agility effects among CIOs and IT managers of 78 companies have adopted some form of cloud service for unspecified business applications. By contrast, our structured analysis in the next section is predominantly "formative" based on the subcomponents constituting ISANN and performed from a system design viewpoint.

In general, we view that Cloud Computing is more of a facilitator than an enabler, to IS Agility Cycles. In other words, business adopters should expect Cloud Computing to help eliminate or mitigate bottlenecks in their consciously established IS Agility Cycles, instead of hoping it to be an "Agility Injection" that can miraculously turn a rigid business operation into an agile one. Among the three levels of cloud services, we still consider a genuine SaaS delivery model has the most potential to facilitate a fuller scope of IS Agility (i.e. both Dev Agility and Ops Agility), provided it is

\footnotetext{
${ }^{10}$ This structured analysis has been published as a chapter in the IGI Global book titled "Cloud Computing Service and Deployment Models: Layers and Management" edited by Al Bento and Anil Aggarwal (Yang et al., 2013). We are very pleased to see this book chapter later inspired one of the first empirical studies surveying the impact of Cloud Computing on IS Agility (Sawas \& Watfa, 2015).
} 
designed to incorporate the sensing and responding capabilities needed by the business and is built on top of automatically scalable infrastructures such as native PaaS or IaaS. However, many self-claimed SaaS offerings on the market today don't meet such criteria. Therefore, we intend to provide the following analysis as a guiding principle for SaaS vendors to examine the design and development of their solutions/services if IS Agility should be delivered to the business users/customers. This analysis will also be informative to Cloud Computing adopters to review which level of cloud services can meet their agility needs and to evaluate service providers more effectively.

\subsubsection{Cloud Computing Services}

Cloud Computing offers a competitive alternative to traditional IT provisioning. Instead of operating servers and applications in an on-premises fashion, Cloud Computing provides on-demand computing power and storage via the Internet, with rapid implementation, pay-as-you-go subscription, little maintenance, and less local IT staffing (Truong, 2010). Such a "rent-based" IT provisioning model is promised to reduce cost and improve agility for its business adopters, according to leading providers such as (Microsoft, 2010) and (VMware, 2011).

Formally, the National Institute of Standards and Technology (NIST) of the U.S. defines Cloud Computing as a "model for enabling convenient, on-demand network access to a shared pool of configurable computing resources (e.g., networks, servers, storage, applications, and services) that can be rapidly provisioned and released with minimal management effort or service provider interaction" (Mell \& Grance, 2010). Despite the emphasis on computing infrastructure at its early stage, Cloud Computing has now grown into a full-fledged service stack. Such a stack offers a spectrum of rental services ranging from hardware-intensive to software-intensive. These generally include three layers: IaaS (Infrastructure-as-a-Service), PaaS 
(Platform-as-a-Service), and SaaS (Software-as-a-Service). Table 11 below illustrates some representative cloud providers by service layers.

Table 11: Cloud Service Layers and Providers

\begin{tabular}{|l|l|}
\hline Cloud Services & \multicolumn{1}{|c|}{ Examples of Cloud Providers } \\
\hline IaaS & $\begin{array}{l}\text { Amazon AWS EC2 \& S3, DigitalOcean, IBM Blue Cloud, Microsoft Azure } \\
\text { IaaS, RackSpace, HP FlexDC }\end{array}$ \\
\hline PaaS & $\begin{array}{l}\text { Google App Engine, Microsoft Azure PaaS, IBM BlueMix, LongJump, } \\
\text { Amazon AWS Elastic Beanstalk, Apache Stratos, OpenShift, Heroku, Cloud } \\
\text { Foundry, Engine Yard }\end{array}$ \\
\hline SaaS & $\begin{array}{l}\text { Salesforce CRM, Oracle SaaS platform, Google Apps, NetSuite, Workday } \\
\text { Human Capital Management, Zoho CRM, Xero Accounting, GitHub, } \\
\text { ZenDesk }\end{array}$ \\
\hline
\end{tabular}

Source: Extended from (Leavitt, 2009 )

IaaS is the basic form of Cloud Computing and provides the backbone of the cloud service stack. It offers rental service of computing infrastructures, such as processors, memory, storage, networking and other forms of hardware resources in a virtual, on demand manner via the Internet (Leavitt, 2009 ). Developments in server virtualization and network management have enabled cloud infrastructures to scale up and down dynamically according to demand. Infrastructure utilisation is monitored and measured by the cloud management system (e.g. hypervisor). The IaaS tenants are charged for the resources they have consumed and/or occupied. Tenants do not manage or control the underlying hardware infrastructure but have control over operating systems, deployed applications, and some networking components (e.g., host firewalls) (Mell \& Grance, 2010).

Typical IaaS examples include Amazon EC2 (Elastic Cloud Computing) and S3 (Simple Storage Service) where computing and storage infrastructure are open to public access in a utility fashion. For a fee, a service subscriber can gain access to thousands of virtual servers from EC2 to run a business simulation and then release them as soon as the computational work is done. Some researchers further divide 
IaaS into HaaS (Hardware as a Service) and DaaS (Data as a Service) (Wang et al., 2008 ), but it is more common that IaaS is referred to as a whole concept.

PaaS moves one step further than IaaS by providing programming and execution environments (i.e. Integrated Development Environment, hereafter IDE), database and web servers, and middleware, etc. A PaaS acts as an integrated platform for software developers to support the full SDLC of design, development, testing, deployment, and maintenance. Just by clicking through the setup wizard, PaaS tenants can create identical environments (e.g. development, test, and production) and integrate their web applications with common middleware in the matter of minutes. Software applications can be developed using programming languages and APIs supported by the provider, and then directly deployed onto the same infrastructure. The PaaS tenants do not need to manage or control the underlying hardware infrastructure including networking, virtual machines, operating systems, or storage, but has control over the deployed applications and some needed configurations of the application hosting environment (Mell \& Grance, 2010). PaaS can reduce the burden of system administration traditionally carried by software developers who can now concentrate on more creative tasks. PaaS provides a complete set of development tools, from the interface design, to process logic, and to integration (Lawton, 2008). Some other appealing features of PaaS include built-in instruments for measuring the usage of the deployed applications for billing purposes, dynamic resource allocation to ensure the QoS and SLAs of the deployed applications and established online communities for collaboration and problem solving among developers.

An example of PaaS is Google's App Engine, which allows subscribers to build applications on the same scalable system architecture that power Google's own applications (Foster, Yong, Raicu, \& Lu, 2008 ). PaaS offerings tend to lower the entry level for software development. WaveMaker, recently acquired by VMware, is providing an easy and intuitive way of building web sites, enabling non-expert 
developers to build their own online applications in the cloud. Such platforms comprise a modern instantiation of the End User Computing (EUC) paradigm which has long been envisioned by generations IS researchers (Huff, Munro, \& Martin, 1988). PaaS tenants will likely become providers of SaaS once their applications deployed become mature. However, unlike the general-purpose IaaS, PaaS providers may choose to focus on a vertical market and support specialised development in certain industry segments. For example, Long-Jump's platform is only for developing CRM systems for newspapers.

SaaS provides complete, turnkey, hosted software applications, sometimes even complex enterprise information systems, such as CRM and ERP, through a web browser via the Internet (Leavitt, 2009 ). This approach is not completely new. From a service user's perspective, similar to the previous ASP model (Application Service Provider), SaaS can eliminate the need to install, run, and maintain the application on local servers. However, instead of ASP's single-tenant arrangement, i.e. each application is customised and hosted for just one client, SaaS is known for its multi-tenant architecture in which all the service users share the same single code base maintained by the provider. Authentication and authorization security policies are used to ensure the separation of tenant data. Such a sharing mechanism reduces the cost of resource and maintenance; thus SaaS providers can still profit while offering their services at a lower price than ASP vendors.

A prominent example of SaaS is Salesforce's online CRM system, Salesforce.com. This service provides subscribers with complete CRM functionalities as well as a customization options based on its PaaS by-product Force.com. There are two types of customizations available, one is "point-and-click configuration" that requires no programming, the other is "customize with code" that allows user developers to create new functionalities beyond the constraints of configuration, with Apex Salesforce.com's own native programming language. 
IaaS, PaaS, and SaaS reflect a full spectrum of cloud services available to the public. IaaS providers are the most independent as they operate their own datacentres (e.g. Amazon AWS EC2, IBM Blue Cloud). PaaS providers may build their platforms upon third-party IaaS (e.g. LongJump), or they may have their own IaaS offerings, and extend those services by providing software development environments (e.g. Microsoft Azure). A SaaS provider can either use the PaaS layer to develop and run its applications, or directly use the IaaS layer to deploy already built applications.

\subsubsection{IS Agility Analysis of Cloud Services}

The IS Agility analysis is conducted mainly from a business adopter's perspective, not a cloud provider's point of view. This is because that cloud providers have been promising IT/IS Agility to business adopters, not the other way around. The analysis is to examine the key characteristics of each cloud service layer against our IS Agility conceptualisation for a concrete understanding of the contributions the former can make to the latter via a direct mapping between these two. To perform the structured analysis, a simple flowchart was developed and followed through step by step. This is to ensure a consistent structure that the key elements constituting our IS Agility conceptualisation are being assessed against the core characteristics of each layer of cloud services. 


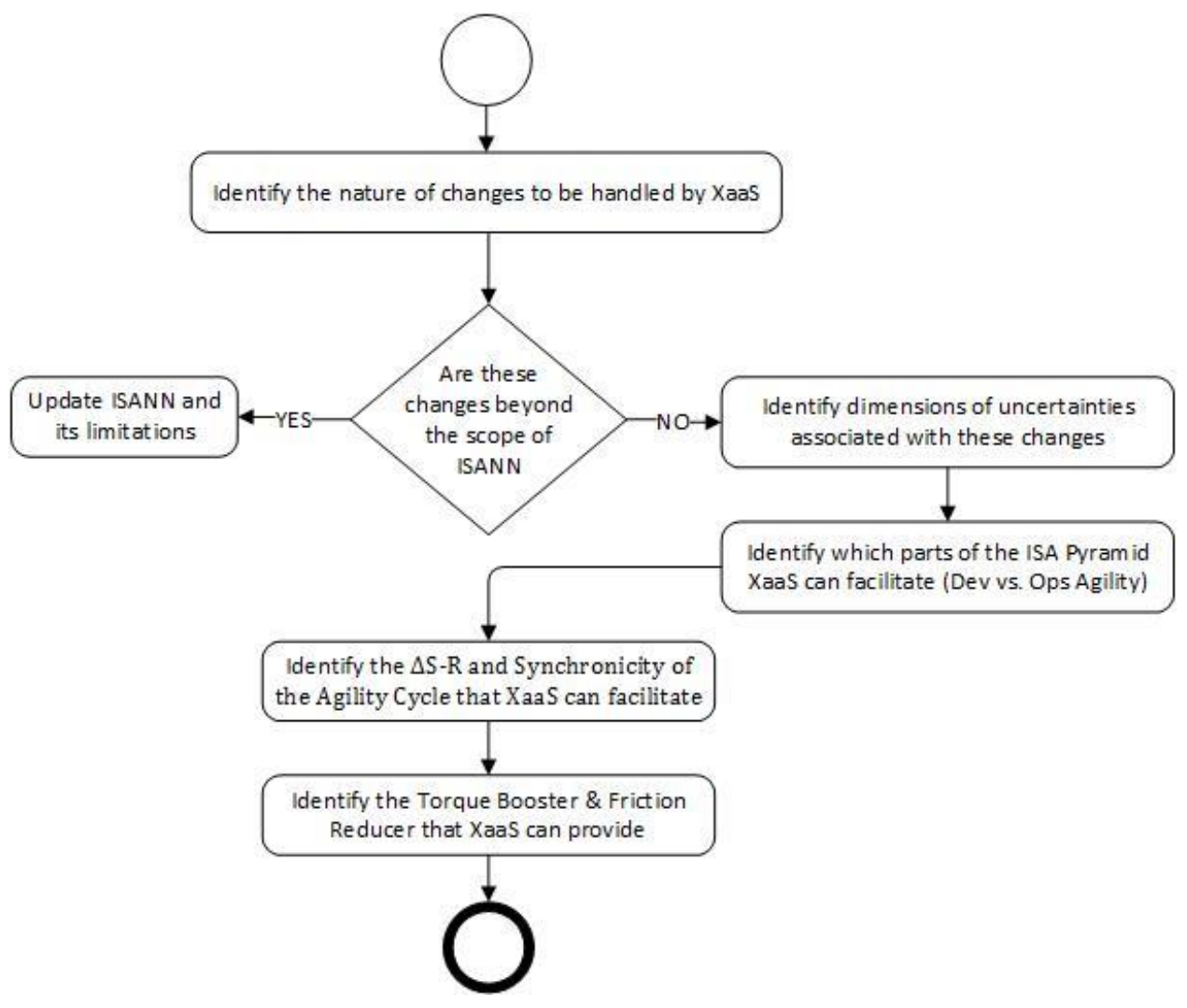

Figure 10: The Steps for a Structured IS Agility Analysis of Cloud Services

\subsubsection{IS Agility Analysis of IaaS}

Among the three layers of cloud services, IaaS is the most basic and original form of Cloud Computing. It is also the most straightforward service offering with least ambiguity about its features and capabilities documented by providers and reported by service users. Our analysis shows that IaaS has genuine capability to facilitate IS Agility, specifically on the Dev Agility Cycle, due to its native ability to dynamically sense and respond to changing capacity requirements in the technological infrastructure - which is the key selling point of IaaS and is widely delivered as promised. 


\section{Table 12: IS Agility Analysis of IaaS}

\section{Mapping IS Agility Elements to IaaS}

\begin{tabular}{|l|l|}
\hline $\begin{array}{l}\text { Nature of } \\
\text { Changes } \\
\text { Supported } \\
\text { Specifically } \\
\text { by IaaS }\end{array}$ & $\begin{array}{l}\text { Concentrated mainly on technological components of IS. } \\
\text { Basic and straightforward automated provisioning allows rapid } \\
\text { expansion and shrinkage of computing, storage, and networking } \\
\text { capacity, in according to changing user workload }\end{array}$ \\
\hline $\begin{array}{l}\text { Uncertainty } \\
\text { Dimensions }\end{array}$ & $\begin{array}{l}\text { Spatial Confidence can be established due to nature of changes } \\
\text { predictable, i.e. variation of capacity, thus mainly Temporal } \\
\text { Uncertainty - unknown timing of such changes }\end{array}$ \\
\hline $\begin{array}{l}\text { IS Agility } \\
\text { Providers } \\
\text { Facilitated } \\
\text { Specifically } \\
\text { by PaaS }\end{array}$ & $\begin{array}{l}\text { Mainly on Agile System-Architecture thus supporting Dev Agility } \\
\text { Cycle }\end{array}$ \\
\hline $\begin{array}{l}\text { Synchronicity } \\
\text { Higher than traditional hosting service, with minimal gap } \\
\text { between Sensing and Responding to changes in the technological } \\
\text { environment due to automated resource allocation can be } \\
\text { triggered by predefined threshold } \\
\text { AS-R } R \text { real time, nearly instant }\end{array}$ \\
\hline $\begin{array}{l}\text { Friction } \\
\text { Reducer vs. } \\
\text { Torque } \\
\text { Booster }\end{array}$ & $\begin{array}{l}\text { Mostly reducing Friction via dynamic resource allocation enabled } \\
\text { by virtualisation and modularisation }\end{array}$ \\
\hline
\end{tabular}

Following steps illustrated in Figure 10, we first identified the nature of changes that IaaS is designed to handle. This is done through analysing the service descriptions ${ }^{11}$, formal definitions (e.g. the NIST version in Section 3.3.1), tutorials

11 For example: Amazon EC2 https://aws.amazon.com/ec2/details/ and IBM Blue Cloud https://www.ibm.com/cloud/products/ 
and demos, and several trial experiences of major laaS offerings (e.g. Amazon EC2, IBM Blue Cloud, and RackSpace). The nature of changes IaaS can handle is essentially the growth and decline of capacity at the technological infrastructure level. Given the advancement in virtualisation, modularisation, and resource scheduling algorithms, such capacity changes can be automatically monitored and managed by hypervisors in a seamless manner (Lunsford, 2009). Therefore, there is little Spatial Uncertainty involved. The IaaS knows how to scale up and down virtual resources and can do so rapidly and autonomously once metrics and conditions are defined (e.g. Amazon's CloudWatch). The uncertainty we identified at IaaS level is mostly at the Temporal dimension, meaning the timing of workload changes demanding increase or decrease capacity is unknown upfront. This is in alignment with the previous discussion in Section 3.2, automation is more practical when Spatial Confidence can be established in advance while Temporal Uncertainty still presents.

Due to the high level of automation, there is little gap between sensing changes of workload and responding with dynamic capacity and resource allocation. IaaS can maintain a sustainably low $\Delta S-R$ and high Synchronicity. For business adopters using IaaS to develop, run and test their applications, at least they can expect agility when faced with unexpected changes in IT infrastructure capacity requirements, or referred to by some as "rapid elasticity" (Mell \& Grance, 2010). As such, IaaS is mapped into the Agile-System Architecture category and considered a Friction Reducer to the Dev Agility Cycle due to its ability to completely remove the burden of installing, upgrading, and maintaining physical machines and networking equipment in a local server cluster. From a business adopter's perspective, IaaS represents a new generation of automation in capacity scaling and load balancing (Böhm, Leimeister, Riedl, \& Krcmar, 2010) and can deliver far more responsive and dynamic capacity than traditional hosting services. To save time, IaaS users can set up separate QoS criteria for each application deployed to have its own capacity plan 
through a web-based self-service portal without needing to talk to a server technician.

In addition, some well-established IaaS providers (e.g. Amazon EC2) can offer user choices of easy switching between various types of computing capacity to support specialised computational tasks. This is particularly handy for R\&D intensive businesses who tend to have different computational workloads for different projects. These will require different computing infrastructure for optimal performance and cost balance. For example, data-intensive computing tasks upon massively-parallel architecture can be assigned to GPU clusters for better performance, those process-control applications built on sequential architecture would be more suitable for CPU clusters.

Despite the widely-tested dynamic capacity of IaaS that can contribute to users' Agile System-Architecture, our analysis identified no intended contribution of IaaS to Agile System-Development. This is understandable because that changes and uncertainties need to be sensed and responded in software development activities are beyond the scope of infrastructure services. Moreover, IaaS seems to have no intended contribution to users' Ops Agility Cycle. After all, this is depending on the nature of IaaS users' business operations and the applications they deploy on IaaS. The applications deployed by users may be just an archive management system for staff members and have little to do with improving the sensing and responding capabilities of their own businesses.

\subsubsection{IS Agility Analysis of PaaS}

PaaS can facilitate the processes of IS development by enabling developers to build, test and publish their web applications in a much easier and quicker way compared to the traditional approach of developing applications in local IDE (Lawton, 2008). A genuine PaaS provider (e.g. Microsoft Azure PaaS, IBM BlueMix) can provide specialized tools/services besides a web-based IDE to make their platforms a onestop shop for software development, test automation, middleware integration (e.g. 
identity management, message queuing), version control, application publication, and performance monitoring (e.g. Azure’s Application Insights). Our analysis shows that these special capabilities of PaaS can support IS Agility, particularly on the Dev Agility Cycle.

Table 13: IS Agility Analysis of PaaS

\begin{tabular}{|l|l|}
\hline \multicolumn{2}{|c|}{ Mapping IS Agility Elements to PaaS } \\
\hline $\begin{array}{l}\text { Nature of } \\
\text { Changes } \\
\text { Supported } \\
\text { Specifically } \\
\text { by PaaS }\end{array}$ & $\begin{array}{l}\text { Concentrated mainly on technological components of IS: } \\
\text { Common changes in software development environment, generic } \\
\text { software functionalities, generic features and components }\end{array}$ \\
\hline $\begin{array}{l}\text { Uncertainty } \\
\text { Dimensions }\end{array}$ & $\begin{array}{l}\text { Both Spatial and Temporal Uncertainties - PaaS can improve } \\
\text { confidence on both dimensions when faced with changes in the } \\
\text { generic functionalities and features of applications }\end{array}$ \\
\hline $\begin{array}{l}\text { IS Agility } \\
\text { Providers } \\
\text { Facilitated } \\
\text { Specifically } \\
\text { by PaaS }\end{array}$ & $\begin{array}{l}\text { On both Agile System-Development and Agile-System } \\
\text { Architecture thus supporting Dev Agility Cycle }\end{array}$ \\
\hline Synchronicity & $\begin{array}{l}\text { Higher than application development in traditional local IDE, } \\
\text { reduced gap between Sensing and Responding due to easy and } \\
\text { direct integration with common middleware, as well as } \\
\text { automation of system administration tasks } \\
\end{array}$ \\
$\begin{array}{l}\Delta S-R \text { : shorter than using traditional local IDE yet still defined by } \\
\text { capabilities of PaaS adopters (e.g. IS developers) }\end{array}$ \\
\hline $\begin{array}{l}\text { Friction } \\
\text { Reducer vs. } \\
\text { Torque } \\
\text { Booster }\end{array}$ & $\begin{array}{l}\text { Improve Torque via task automation and reduction of system } \\
\text { admin effort, reduce Friction by easy coupling and decoupling } \\
\text { with common application building blocks }\end{array}$ \\
\hline
\end{tabular}

Following the same steps used in our analysis of IaaS, we first identified the nature of changes that PaaS specifically can handle. This is done predominantly through 
analysing official tutorials and workshops, demonstrations, technical documents, and trial experiences from several key PaaS providers (e.g. Microsoft Azure PaaS, IBM BlueMix). As shown in Table 13, our observation is that a general-purpose PaaS can facilitate more generic changes in the technological components of an application. For instance, IBM BlueMix allows developers to call on an arsenal of prebuilt services (known as "application building blocks") to construct their applications with a wide range of features such as security, mobile, integration, and analytics. Within each feature, there are often various options for developers to choose (e.g. The Data and Analytics category of services includes Apache Hadoop, Apache Spark, Elasticsearch, Insights for Twitter, and a dozen more choices).

Given the availability of a large set of common "application building blocks", when faced by changes in generic functionalities and features, PaaS can reduce the level of uncertainty and help developers establish confidence on both Temporal and Spatial dimensions. This is a good illustration of Agile-System Architecture which in turn facilitates Agile System-Development. As such, the Synchronicity on the Dev Agility Cycle of PaaS adopters should be higher than what they could achieve with traditional local IDEs. In the same fashion, the $\Delta S$ - $R$ should be shorter for the same developers migrated from local IDE to PaaS. Some particular changes (e.g. adding an live chat feature for the sales representatives to communicate directly with online customers) used to need days of manual handling to implement, can be done on PaaS in the matter of hours due to the automation of admin tasks (Torque Booster) and directly usable application building blocks (Friction Reducer).

However, despite all the task automation and building blocks facilitating generic changes in software development, adopters may not be able to leverage the power of PaaS to handle their business-specific changes. PaaS is essentially an all-in-one web-based software development and deployment platform. As discussed in previous sections, software development, as a human activity, inevitably faces changes in user requirements, functionalities and features. Some changes are 
generic ones that can fully leverage the agility of PaaS for rapid implementation (e.g. adding a SMS text messaging functionality to an existing web application). Other changes are more business-specific and may be even unique to the particular group of users with no immediate solutions can be articulated. This type of changes are not rare and will not be directly supported by the building blocks on PaaS. The PaaS adopters (e.g. application developers) will need to dissect the problems based on their domain knowledge and probably implement some ad-hoc custom-built solutions.

Furthermore, from an adopter's viewpoint, PaaS doesn't necessarily contribute to Ops Agility Cycle. Similar to our analysis of IaaS, whether or not PaaS can have an impact on the adopter's Ops Agility Cycle is depending on the nature of the adopter's business operation and the application being developed and deployed on PaaS. If the application developed and deployed on PaaS is an online product catalogue for sales representatives and customers, it is difficult to make a case that such an application can boost the sensing and responding capabilities of the PaaS adopter's own business operation as a real estate developer.

\subsubsection{IS Agility Analysis of SaaS}

Unlike IaaS and PaaS, we have found SaaS offerings highly diverse and divergent, which makes our analysis difficult. After all, there are only tens of IaaS and PaaS providers in the market offering consistent, general-purpose services, whereas thousands of SaaS providers are already in business for assorted purposes and the number is still growing. This is understandable as the entry barrier and upfront investment for becoming an IaaS and/or PaaS provider is generally quite high as they normally need to establish industry-strength, large-scale data centres to ensure the resource pool is big enough to accommodate the maximum capacity required by customers. A typical cloud data centre would reportedly contain tens of thousands of physical servers plus all the networking, security, cooling, and facilitates needed to stabilise the computing environment (Katz, 2009). On the contrary, SaaS in 
general has a significantly lower entry barrier and upfront investment as many new providers can start serving customers by rapidly deploying a low-budget prebuilt application on an IaaS and paying per use.

\section{Table 14: IS Agility Analysis of SaaS}

\begin{tabular}{|c|c|}
\hline \multicolumn{2}{|r|}{ Mapping IS Agility Elements to SaaS } \\
\hline $\begin{array}{l}\text { Nature of } \\
\text { Changes } \\
\text { Specifically } \\
\text { Supported by } \\
\text { SaaS }\end{array}$ & $\begin{array}{l}\text { Divergent and unclear, provider dependent and application- } \\
\text { dependent } \\
\text { Some established SaaS providers can offer customisation and } \\
\text { configuration, others cannot. }\end{array}$ \\
\hline $\begin{array}{l}\text { Uncertainty } \\
\text { Dimensions }\end{array}$ & $\begin{array}{l}\text { Both Spatial and Temporal Uncertainties - diverse yet unclear } \\
\text { how they are managed by SaaS }\end{array}$ \\
\hline $\begin{array}{l}\text { IS Agility } \\
\text { Providers } \\
\text { Facilitated }\end{array}$ & $\begin{array}{l}\text { Unguaranteed } \\
\text { Provider-dependent and application-dependent }\end{array}$ \\
\hline Synchronicity & $\begin{array}{l}\text { Unclear - Some SaaS solutions may improve business adopters' } \\
\text { "sensing and responding" capabilities, other may not. } \\
\Delta \mathrm{S}-\mathrm{R}=\text { unguaranteed }\end{array}$ \\
\hline $\begin{array}{l}\text { Friction } \\
\text { Reducer vs. } \\
\text { Torque } \\
\text { Booster }\end{array}$ & $\begin{array}{l}\text { Unclear } \\
\text { Provider-dependent and application-dependent }\end{array}$ \\
\hline
\end{tabular}

As discussed in previous sections, the changes facilitated, and uncertainties controlled by IaaS (or PaaS) are convergent and can be clearly identified. With SaaS however, we cannot do the same. For example, changes and uncertainties dealt with by Citrix GotoMeeting and SAP Concur are apparently not alike, although they both are representative SaaS offerings. Even when we narrow our scope by examining strictly only management information systems, still, Salesforce.com CRM is obviously different from Xero accounting tool (even though these two can now be 
integrated via "Trigger and Action" configuration). Without a convergent set of changes and uncertainties being supported, we cannot perform IS Agility analysis on SaaS as a whole. To reason and appreciate the impact of SaaS on IS Agility, we would need to analyse the providers and services in a case-by-case manner. Such an effort is considered impractical and beyond the scope of the present study, yet it can be a candidate for future research if a SaaS classification schema can be developed to enable a group-by-group analysis.

Table 14 above sums up our general observations on SaaS from an IS Agility standpoint. No assured findings can be presented there. Having said that, depending on the ambition and capabilities of a SaaS provider, some IS Agility supporting features can be found among those well-established SaaS offerings. Take the superstar SaaS Salesforce.com for an example, founded in February 1999, had initial public offering (IPO) in June 2004, has invested heavily in R\&D to improve the capabilities of its SaaS CRM system, with its stock price gone from the original 3.95 USD to 122.82 USD (as at 20 $0^{\text {th }}$ April 2018) in 14 years. We see Salesforce.com is a non-typical SaaS as it also opens its own system development platform as a PaaS offering (i.e. Force.com) in 2007 to allow both developers and users to customise the standard CRM package through Apex code and Point-and-Click App building tool. Such a move has largely improved Salesforce adopters' ability to handle technological and business changes in their requirements. Prior to launching Force.com, Salesforce.com has already opened a marketplace in 2006 called AppExchange where developers and users can share the Apps they developed with each other. These Apps can be directly plugged in to the Salesforce CRM to make system adaptions and extensions convenient to adopters. There are currently almost 3,000 Apps in this marketplace with customer reviews and recommendations. Furthermore, all these customisation options are offered despite the fact that the Salesforce CRM is already a highly configurable system with inbuilt engines to support workflow and business rules. 
The whole Salesforce ecosystem built around Force.com and AppExchange can provide unconventional yet effective support to the IS Agility we conceptualised. This ecosystem can facilitate changes in both technological and business aspects of the Salesforce CRM system. The workflow and rule engines built in the system are in alignment with the Agile-System Configuration we conceptualised by allowing dynamic changes in business processes. The Force.com and AppExchange are supporting the Agile-System Architecture by enabling easy and fast modifications of the technological structure of the system. However, we cannot state the same on Agile System-Development and Agile System-Operation as the former is more concerned with how developers handle changing business requirements while the latter is more about how users operate the system to sense and respond to business changes. Both are not identifiable in the features and characteristics of the IS in question (i.e. Salesforce CRM), and would be mostly depending on the individual level practice of the SaaS adopters. Still, we can conclude that Salesforce CRM can facilitate both Dev Agility Cycle and Ops Agility Cycle of its adopters in the part of business this system is designed to support.

Nevertheless, again, Salesforce.com is a uniquely special case among thousands of SaaS providers. To say every SaaS provider has the same level of capability and investment to enable adopters IS Agility, is almost like saying all software development companies can become Microsoft. The majority of SaaS providers do not have their development platforms open to adopters like Salesforce does. Many smaller providers with less mature systems have to take the full responsibility of developing new features upon adopters' requests. The provider-adopter relationship then could become a more traditional outsourcing form with which considerable time and effort will be needed to merely manage communication and collaboration. In such a case, support to the Dev Agility Cycle is more dependent on the Synchronicity can be achieved between the SaaS adopter and the provider, as well as on the IS development capabilities of the provider. The $\Delta S-R$ will not be guaranteed. The provider can reject a proposal from the adopter to make certain 
system changes that are not directly beneficial to or may even cause issues for other adopters sharing the same multi-tenant SaaS instance. Support to the Ops Agility Cycle is also unguaranteed. A SaaS solution, meaning a single code base with shared multi-tenant database and process engines, tends to set limitations on the adopters' ability to adjust the IS for optimised sensing and responding capabilities specifically relevant to their own business environments. These observations have been supported by the empirical study from (Sawas \& Watfa, 2015).

Finally, we can, however, envisage the possibility of a SaaS adopter's Ops Agility Cycle being supported by SaaS, not from a single provider, but from a selection of providers. These providers can each offer a narrow yet focused set of businesssupporting functionalities. A masterfully selected group of interoperable SaaS can form a federation of applications that specifically strengthen the adopter's "Sensing, Diagnosing, Selecting and Executing" capabilities. This will require a deep understanding of the adopter's business operation as well as a broad knowledge of the capabilities and functionalities of SaaS offerings on the market.

\subsubsection{Section Summary}

Using the concepts, logic, and relationships established in ISANN, this section has analysed Cloud Computing services with regard to their capabilities in facilitating IS Agility. Such an analysis has demonstrated the usefulness of our IS Agility conceptualisation in terms of dissecting a complex phenomenon, structuring the analysis, and organising the findings (i.e. Table 12). An earlier version of this analysis, as mentioned at the beginning of Section 3.3, has been published and cited by one of the first empirical studies into Cloud Computing's impact on IS Agility, as part of the foundation (Sawas \& Watfa, 2015). We consider this a recognition of the usefulness and effectiveness of our conceptualisation work in terms of explaining and analysing IS Agility. 
For Cloud Computing, our analysis indicated that future research in this area should carefully differentiate each layer of the Cloud services. Each layer does exhibit notably different characteristics and capabilities, and distinct impact on IS Agility. Again, such a finding has been supported by empirical evidence published by (Sawas \& Watfa, 2015). To leverage Cloud Computing for IS Agility, organisations must recognise and understand these differences between the three layers of cloud services. Each layer needs to be analysed and evaluated against the adopter's "sensing and responding" requirements. ISANN can be used as a tool to structure such an analysis.

\subsection{Chapter Summary}

Chapter 3 has demonstrated that the concepts, logic, and relationships integrated in ISANN are powerful means for analysing and explaining the IS Agility phenomenon. Through a series of business scenarios, we illustrated an operational view of Dev Agility Cycle, Ops Agility Cycle, and their interplays. We then furthered the analysis to a specific IT provisioning model, Cloud Computing, which is closely associated with agility in today's business environment. The structured analysis and explanations provide valuable insights for business practitioners and researchers who are seeking to leverage Cloud Computing for IS Agility, and for researchers seeking to conceptualise relationships between IS Agility and Cloud Computing. The analysis presented in this chapter can serve as a basic framework for furthering research in this area.

In a nutshell, the value of the analysis work done in this chapter is twofold. Firstly, it articulates the IS Agility effect of each key layer of Cloud Computing services in a systematic and structured manner with concrete examples and conceptual clarity. Secondly, it demonstrates the usefulness of ISANN in decomposing and analysing IS Agility phenomena which justifies that an innovative, yet formal tool can be 
designed based on ISANN to solve IS Agility problems systematically with theoretical rigour and practical relevance. Next chapter will discuss the methodological aspects of the design and development of such a tool. 


\section{Chapter 4 : Design Science Research Methodology}

\subsection{Introduction}

As stated in Chapter 1, the research goals of this study are twofold and include:

A. To generate a unified and holistic conceptualisation of IS Agility so that both researchers and practitioners can understand and utilise in their own specific contexts with clarity and consistency;

B. To design and develop a systematic method for investigating and solving IS Agility problems with which people can follow prescriptive steps and rules to implement with clarity and consistency.

The earlier stage of this study (reported in Chapter 2 and 3) have fulfilled the first goal. The later stages aim to achieve the second goal through a Design Science Research (DSR) approach. This chapter reports and discusses the rational, processes and reflections of the journey crafting the following DSR. It includes discussions on Design Science as an academic field of inquiry on its own, as a scientific study approach in IS research, and as a rich knowledge base guiding the creation of artefacts. In this thesis, we take a broader view of the term "artefact". The artefacts created during this research can include tools, methods, rules, software applications, as well as the publications yielded, and finally, the thesis itself.

The DSR part of this study was conducted in real-world business settings. Instead of working in a laboratory with university students. I, as the researcher, have been involved in the development and implementation of cloud-based SaaS solutions for over six years, and worked with many client organisations (mostly New Zealand based businesses and government departments) to solve their problems with data processing, information analysis, decision making, and of course, agility with IS. Such a client base offers abundant examples and opportunities for studying IS Agility and finding common patterns and trends which make it possible to design an 
analytical method that is applicable and useful for investigating and solving IS Agility problems.

Following Schön's theory on design as a reflective practice (Schön, 1983), I, the researcher, have positioned myself as a reflective practitioner throughout the whole research project. Actions and reflections were continuously interleaving with each other during problem formulation, solution design and evaluation. Given the indepth theoretical synthesis and analysis I have completed in Chapter 2 and 3, it is in fact inevitable and natural for me to apply the knowledge and insights gained from my study into my day-to-day job and evaluate their relevance and usefulness to practical problems and issues in the real-world.

This chapter explains and justifies the selection of the research design used in this study. A research design should address research questions, philosophical paradigms, methodological considerations regarding challenges and issues. The following sections are to address these aspects and to provide justification and practical guidelines.

This chapter is constructed as follows: first, the research problems and questions are recapped (as they have been introduced in Chapter 1 already) and their implications are discussed. Next the choices of philosophical paradigm and methodological approach for this study are explained. Then the DSR approach is reviewed and assessed as a scientific method for conducting academic research. Finally, the strategies and techniques for designing and evaluating research artefacts are articulated.

\subsection{Problem formulation}

Chapter 1 has already elaborated on the justification of choosing a DSR approach to address the research problems motivating this study. This section provides more details about how the problems were formulated at the first place. 
Since 2008, I, as the researcher, also as an IS practitioner, have been working closely with agile software development teams in different organisations in New Zealand. I have developed a strong interest towards the concept "agility" in an IS context. I studied the differences between agile software development projects and traditional ones, and later published the results at the American Conference of Information Systems in 2009 (Yang et al., 2009).

During my years of working with and within agile software development teams, I have observed that the "agility" focus of these teams is consistently on delivering new features and modifications on working software frequently and regularly. These software development teams tend to believe agile methods (e.g. XP, Scrum) make them agile in sensing and responding to changes in user requirements. This is unsurprising as agile methods have been much popular in software engineering for the past decade (Babb et al., 2014). Since the inception of Agile Alliance ${ }^{12}$, the word "agility" has often been associated with "agile methods" by software practitioners (illustrative of Agile System-Development in the IS Agility Pyramid).

However, in recent years I have worked more closely with IS users to solve their issues and problems with IS implementations and operations. I have been able to frequently conduct "reflection on action" and "reflection in action" (Schön, 1983) during my problem investigations to study the discrepancies in problem definition between IS users and developers. Particularly, I have seen IS Agility as a concept being described as having different meanings to the two groups. For instance, instead of receiving monthly new releases from IS developers demonstrating new changes in technological components of the system (e.g. system reliability being improved through bug fixing, system performance being enhanced via infrastructure upgrade), IS users would rather focus on improving the business components of the system in a way they could effectively and efficiently sense and

\footnotetext{
${ }^{12}$ https://www.agilealliance.org/
} 
respond to changes in the business environment. In fact, IS users tend to hope such a "sensing and responding" cycle related to the business components of the IS could go without intervention from IS developers or experts, as "getting the IT department involved will mean extra time and complexity" - according to one business operation manager from a New Zealand based energy company.

Therefore, my observation in the industry, as well as in the IS academia, is that agility as a concept lacks a unified, clear, and workable conceptualisation that can reconcile the view from IS developers with the view from IS users. This is disturbingly counter-productive in both IS research and practice as merely forming a common ground for the definition and measures of IS Agility can become a struggle, especially for problem solving purposes.

In such a background, this study set to address the following research problems (stated first in Chapter 1 but recapped below):

- RP0. The lack of prescriptive and systematic methods for solving IS Agility issues.

This grand problem can be divided into two sub problems:

- RP1. The lack of conceptual clarity and consistency of IS Agility as a notion.

- RP2. The lack of prescriptive practice and method for designing IS Agility as a capability.

This study is concerned with how to systematically solve IS Agility related problems. These problems are often difficult to articulate due to the ambiguity and obscurity posed by the complexity of the messy concept of "IS Agility". We can choose to either just live with messy problems and work around them as black boxes, or face them and thrive through innovations (Denning, 2007). This study takes the latter path. 


\subsection{Philosophical Paradigm: Post-Positivism}

Research is concerned with contributing to knowledge. In any knowledge production process, the philosophical paradigm plays a critical role by guiding the way in which the researcher bridges the truths and beliefs, and by deciding the research outcomes.

The two major paradigms in IS field are positivism and interpretivism. Positivist researchers seek objective realism whereas interpretivist researchers see reality as socially constructed (A. S. Lee, 1991). Positivism has been traditionally the dominant paradigm in IS field hence a large proportion of extant IS literature is based on positivist research.

Table 15: Positivism vs. Post-positivism

\begin{tabular}{|l|l|l|}
\hline Ontology & Positivism & $\begin{array}{l}\text { Post-positivism } \\
\text { apprehensible }\end{array}$ \\
\hline Epistemology & $\begin{array}{l}\text { Dualist/objectivist (knowledge is a phenomenon } \\
\text { that exists external to the observer; the observer } \\
\text { maintains a distance and studies the } \\
\text { phenomenon, sometimes referred to as } \\
\text { empiricism); findings are true and context-free } \\
\text { universal knowledge. }\end{array}$ & $\begin{array}{l}\text { Modified dualist/objectivist; critical } \\
\text { tradition/ community; findings are } \\
\text { probably true and contextualised } \\
\text { probabilistically apprehensible }\end{array}$ \\
\hline Methodology & $\begin{array}{l}\text { Experimental/manipulative; verification of } \\
\text { hypotheses; chiefly quantitative methods. } \\
\text { Interventionist seeks to control variables and } \\
\text { neutralise contexts. The goal is to explain how } \\
\text { something "really works" in order to predict and } \\
\text { control. }\end{array}$ & $\begin{array}{l}\text { Modified experimental / } \\
\text { manipulative; critical multiplism; } \\
\text { falsification of hypotheses; may } \\
\text { include qualitative methods }\end{array}$ \\
\hline $\begin{array}{l}\text { Nature of } \\
\text { Knowledge }\end{array}$ & \begin{tabular}{l} 
Verified hypotheses established as facts or laws. \\
\hline
\end{tabular} & $\begin{array}{l}\text { Non-falsified hypotheses that are } \\
\text { probably facts or laws }\end{array}$ \\
\hline
\end{tabular}

Source: (Guba \& Lincoln, 2005) p. 195-196

This study is developed under the modern successor to positivism, namely, the postpositivism paradigm. A philosophical paradigm can be seen as a combination of the ontological, epistemological and methodological premises of a researcher and 
determine the research actions (Denzin \& Lincoln, 2005). This section aims to explain why post-positivism is better-suited to this study by analysing and comparing positivism and post-positivism with regard to ontology, epistemology, and methodology (as shown in Table 15).

\subsubsection{The Ontological Dimension}

Ontology refers to the assumption about what is reality and deals with the nature of being (Guba \& Lincoln, 2005). Positivists and post-positivists both believe that an objective reality is "out there" independent of the researcher's mind. Therefore the researcher and the subject (the phenomena in the world that are their focus of the research) are two separate, independent things. Both paradigms have an underlying assumption that the research subject has inherent qualities existing independently of the researcher (R. Weber, 2004).

The subtle ontological difference between these two paradigms lies in the apprehensibility of reality. Positivists contend that the objective reality is fully apprehensible and there is a unique, best description of any chosen aspect of the phenomenon. Reality operates according to immutable natural laws that often take the form of cause and effect. Under positivist paradigm, truth is defined as the set of statements that accurately describe reality. With a belief that "if appropriate general laws are known and relevant initial conditions are manipulable, we can produce a desired state of affairs natural or social" (Wanda J. Orlikowski \& Baroudi, 1991 ,p.11), positivist studies often set off to seek for universal laws for prediction and control. However the quest of universal laws and the disregard of contextual factors have limited the problem-solving capability and development of positivist studies in the social world where human behaviours are often not rational and predictable (Wanda J. Orlikowski \& Baroudi, 1991). 
Post-positivists admit that the objective reality can never be fully apprehended (Guba \& Lincoln, 2005). Reality is merely apprehensible on a probabilistic basis and contextual factors should be taken into consideration and critically assessed. Given the same objective reality, individual researchers may observe it differently in different contexts. This is especially the case in the social world. IS research and practice can be largely influenced by contextual factors. For example, a same ERP system with same implementation procedure may succeed in one organisation but fail in another, owing to the differences in organisational structure, business processes, IT capabilities, user expectations, level of uncertainties, and so forth. Positivist approaches focusing on "discover unilateral causal relationships that are the basis of generalised knowledge that can predict patterns of behaviour across situations" (Wanda J. Orlikowski \& Baroudi, 1991) tend to ignore contextual factors and leave unexplainable gaps in the research findings. On the other hand, postpositivists urge that research findings are contextual in nature and there is no research outcome that can claim to be the absolute truth. Hence research efforts help humans approach the reality closer, but not necessarily achieve it.

This study aims at advancing knowledge towards IS Agility and how it can be generated in a certain technological context, i.e. Cloud Computing and SaaS. The literature analysis and synthesis in Chapter 2 have enabled us to establish a systematic and structured conceptual view of IS Agility (i.e. ISANN). However, the pre-specified knowledge derived from the literature is neither seen as absolute truth, nor adequate to cover the whole domain of the studied subject. Rather, such knowledge is considered merely a summary of collective understandings produced from previous research efforts done by us humans.

Taking a post-positivist stance is believed beneficial as it keeps the investigation open for potentially new and influential contextual factors which help portray a more complete picture of the phenomenon of interest. Moreover, post-positivism also represents how the researcher appreciates knowledge acquired via IS research. 
The majority of IS research is largely based on human perceptions and experiences with technologies/systems hence should be treated as a "reflection of the absolute truth" rather than the "absolute truth" itself.

\subsubsection{The Epistemological Dimension}

Epistemology refers to the assumption about how knowledge can be obtained, in plain words, it is about the philosophy of how we humans come to know the world (Creswell, 2009). The major difference between positivist and post-positivist lies in the objectivity of the researcher. Positivist epistemology believes that a researcher can be absolutely objective and put aside personal biases and beliefs and see the world as it really is. A positivist research would often claim its description of the reality as the absolute truth.

On the contrary, post-positivists reject the idea that ultimate objectivity and valuefree judgements can be achieved by any researcher. Therefore knowledge is conjectural and there can be no absolute claims about truth (Creswell, 2009). This view recognises that we humans are all biased and all of our observations are affected by such biases. As a result, human knowledge is based on not unchallengeable, rock-solid foundations, but rather upon human conjectures and curiosities. Any research can only produce imperfect understanding towards the reality owing to the cognitive limitations of humans and other influential factors such as capabilities of instruments and fullness of datasets. Consequently, even top scholars in "hard-science" fields such as Physics still have doubts regarding the nature of modern science, that is, either scientific theories truly are "discoveries" or merely "human inventions" (Von Foerster, 2003).

Furthermore, post-positivists argue that even though objectivity can never be achieved perfectly, the best hope for approaching objectivity is to triangulate across multiple fallible perspectives, which encourages researchers to criticise each other's 
work. Therefore, post-positivist in philosophy is also called critical realism. In IS research which human subjects and artefacts are often involved, even in the best case where the researcher can claim to be value-free and absolutely detached from the phenomenon, the objectivity of the participants is yet no way to be guaranteed.

Taking a post-positivist stance, researchers can admit that the knowledge acquired via studies is contextualised thus need not to make universal claims. Post-positivists should stay critical to investigate the multiple facets of reality. In this study, the literature reviewed, and artefacts developed are not context-free and would not exist without "human inventions". Such inventions are deeply contextualised (e.g. ISANN would become meaningless and of no use if taken out of its original context and placed into an environment having no reference to IT or IS), yet they help us gain better understandings towards the phenomenon of interest.

\subsubsection{The Methodological Dimension}

Methodology deals with the practical process of research. The two major methodological schools are quantitative approach and qualitative approach. Quantitative approach originated in the field of natural sciences and was first used to numerically study natural phenomena. Qualitative approach originated in the social sciences and was developed to study social and cultural phenomena based on non-numeric data (Myers, 1997).

Any research is based on some underlying assumptions about what methods are valid and appropriate. Positivists aim to replicate the methods of natural science, which was developed for analysing conditions and forces in the material world, most often using quantitative methods. The prowess of quantitative approaches has been well demonstrated all the way through the contemporary evolution of science and technology. The dominance of quantitative approaches can be observed across a wide range of scientific disciplines from conventional "hard science" (e.g. Physics, 
Chemistry) to relatively recently established "soft science" (e.g. Management, Sociology). However, post-positivist epistemology rejects that quantitative approach should be the only choice especially when the social world is studied. This view has led an increasing subscription to qualitative approach in social research which makes the situation today is less "qualitative versus quantitative" and more how research practices lie on a continuum between the two (Creswell, 2009, p.3-4). Rather than commonly working in a deductive manner as their positivist counterparts, post-positivist researchers utilise both deduction and induction in their studies and embrace qualitative approaches as well as quantitative ones.

There is a common misunderstanding that qualitative approaches are always related to interpretivism (Wanda J. Orlikowski \& Baroudi, 1991). Guba and Lincoln (2005) suggest that the underlying philosophical paradigm for qualitative research can vary and is mainly dependent upon the philosophical assumptions of the researcher. Therefore, it is not unreasonable for post-positivist studies to employ qualitative methods.

In this post-positivist study, both qualitative and quantitative approaches have been utilised. Qualitative techniques were adopted for formulating and investigating IS Agility problems as well as designing solutions to solve the problems. Quantitative techniques were used to measure the usefulness and effectiveness of the designed solutions. Detailed applications of both approaches are reported in Chapter 5.

\subsection{Design as a Scientific Research Method}

\subsubsection{Design? Science? Or both?}

Although some may still debate whether design is an art or a science, scientific design activities have been well observed and acknowledged for decades. At the centre of any design endeavour lies a human-made so-called "artefact". Design as an 
artificial phenomenon is distinct from things occurring in the nature without human intervention. A few hundred years ago, design effort was still considered more of an art, not much of a science. Indeed, in most of the history of human civilisation, the majority of visible work done by engineers was mostly associated with architectures and objects that changes the surroundings of humans to improve aesthetical value more than functional efficiency (e.g. temples and monuments from ancient times).

However, along with the advancement of technologies and industrialisation, especially the dawn of modern computing starting from the 20th century, more and more engineers have established their roles dealing with predominantly functional efficiency and scientific theories. For instance, integrated chip engineers would value interconnectivity, testability, controllability, and observability over aesthetic characteristics of the chips being designed. In fact, to be able to design such "artefacts", engineers must first acquire extensive amount of scientific knowledge and training which effectively presents a significant shift from the traditional "art" view of design.

Today, artistic design and scientific design coexist and collaborate in many ways. On classic example is the relationship between industrial design and design engineering (Eder, 2011). According to Eder, the former focuses on the artistic elements, appearance, ergonomics, customer appeal, and other observable properties. Industrial engineers intend to produce "visually attractive and user-friendly" artefacts following more intuitive design processes by defining the "envelope" first and then working from the outside to inwards, meaning the internal constituents and actions will need to bear the constrains set from the outside (Eder, 2011). The engineering approach to design, on the other hand, focuses on functioning and operation of artefacts, hence needs to be aware of the whole range of uses of an artefact and their complex interactions. Engineers are particularly equipped with scientific knowledge and processes in order to systematically create and test their designs, optimise their methods and tools to improve efficiency and effectiveness, as 
the artefacts they create should work and fulfil a purpose by helping to perform a process (Eder, 2011).

Scientific design, as argued by Cross, should refer to "modern, industrialised design - distinct from pre-industrial, craft-oriented design - based on scientific research but utilising a mix of both intuitive and non-intuitive design methods" (Cross, 1993). Therefore, in this thesis, we believe, when deciding if a design effort is more of an art or more of a science, one may evaluate the "artefact" first. If the artefact being designed requires mostly artistic appreciation and experience (e.g. garden landscaping), then the designer in action would probably be recognised as "creative artists". On the other hand, if the artefact being designed demands largely scientific knowledge and skills (e.g. unmanned spacecraft), then the designer involved would likely be referred to as "scientific researchers".

With the ever-increasing demand on the design of modern technologies, undoubtedly more attention and investment have been given to "scientific" design efforts. The first conference on Design Methods, held in London in 1962 was an iconic event launching Design Science as an academic field of enquiry with a strong focus on novel and scientific design methods (Cross, 1993). Soon after, design method books and conferences were appearing at an unprecedented speed with knowledge and experiences being shared frequently across previously separated design disciplines such as architecture planning, mechanical engineering, software development, and so on.

After the "scientifically designed" artefacts started being rapidly adopted in the modern world, the term "Design Science" began to be recognised and accepted in academic institutions worldwide. Cross pointed out that Design Science includes "both process and product knowledge and theory thus refers to an explicitly organised, rational and wholly systematic approach to design; not just utilisation of scientific knowledge of artefacts, but design in some sense as a scientific activity itself" (Cross, 1993). However, such a statement was considered controversial by 
some, thus design researchers started to contemplate on the differences and commonalities between the long-lasting conventional natural science and the newborn fashionable design science.

To clarify the distinction between design science and natural science. Herbert A. Simon, a Nobel Prize laureate and a Turing Award winner, one of the most cited authors in design methods, has for long advocated design as "the science of the artificial" which did not exist in the nature before being produced by humans. He further explained the differences between design science and natural science, in terms of the purpose of inquiry, are that the former deals with the "contingent" how things ought to be, whereas the latter deals with the "necessary" - how things are (Simon, 1996). From a methodological point of view, Cross later added that the critical distinction between the two is that method may be vital to natural science due to the necessity of validating results, but not to design science as results may not have to be repeatable (Cross, 1993).

At the same time, many have tried to articulate the common ground between design science and natural science. Archer urged that both are essential ways for humans to observe and structure the world (Archer, 1981). Levy later claimed that natural science itself has been evolving and no longer means " $a$ fixed methodology focused on a specific view of the world" but more of "an expanded rationality for problemidentifying, -structuring, and -solving activities" (Levy, 1985). Cross later commented that Levy's view suggested the indistinguishable characteristics between natural science and design science which share "a complex recognition of the web of interdependencies between knowledge, action and reflection" (Cross, 1993).

In fact, as observed by John R. Pierce in his book on Information Theory, many of the most powerful scientific discoveries have derived "not through the study of phenomena as they occur in nature", instead, have arisen from studying phenomena "in man-made devices...in products of technology" (Pierce, 2012)(p.19). An explanation to such an observation is that human-made artefacts are "simplified and 
ordered in comparison with those occurring naturally" (ibid.). For example, the development of the general science of thermodynamics was driven heavily by the creation of the steam engine which forms "phenomena involving heat, pressure, vaporisation and condensation occur in a simple and orderly fashion" (ibid.).

Design Science, since its inception, has seen a strong drive from the engineering design field. Unsurprisingly, engineering design researchers, specifically Hubka and Eder, were the first to provide a definition of Design Science as "a collection of logically connected knowledge in the area of design, and contains concepts of technical information and of design methodology...addresses the problem of determining and categorizing all regular phenomena of the systems to be designed, and of the design process...concerned with deriving from the applied knowledge of the natural science appropriate information in a form suitable for the engineer's use" (Hubka \& Eder, 1987).

Hubka and Eder (2012) further elaborated on four key categories of statements of Design Science: Design knowledge about objects (systems), Design process knowledge (e.g. Design methodology), Theory of technical systems, Theory of design processes. As shown in Table 16, these four were positioned in a quadrant with "Practice (branch, domain) Knowledge" to "Theory" on the vertical axis, and "Object knowledge" and "Process knowledge" at the horizontal axis. Although a more detailed version of this quadrant was later refined to be specific on Engineering Design Science, we have found the generic version shown in Table 16 more applicable to the present study which is hosted in, not an engineering, but a business school. 


\section{Table 16: Map of Design Science}

\section{Practice (Branch, Domain) Knowledge}

Prescriptive statements

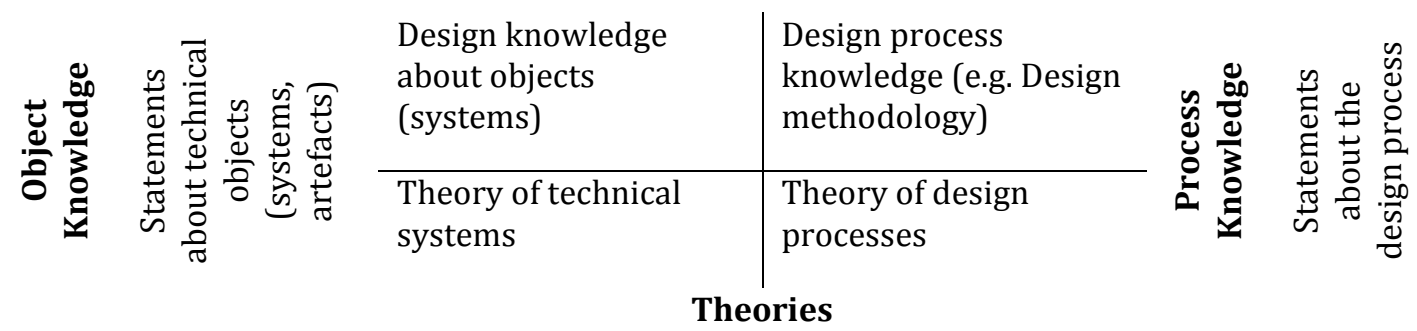

Descriptive statements

Source: adapted from (Hubka \& Eder, 2012)

The present study is deemed to bring salient understanding mostly towards the Practice knowledge and Object Knowledge ends. In Chapter 2 and 3, we have brought new depth in the practice knowledge of the IS Agility domain through the creation of ISANN. In Chapter 5, we explore and explain the nature of another designed artefact, namely, ISACAM, a first of its own kind method for analysing and solving IS Agility problems. The creation and evaluation of this artefact will in turn contribute to the object knowledge by promoting new insights into how IS Agility can be designed.

\subsubsection{Design Science Research in IS Field}

Since the inception of the IS field manifested by the first International Conference in Information Systems (ICIS) in 1980, "Behaviour Science Research" has gained dominance in IS schools and publication outlets. Early IS researchers, likely due to the anxiety with the "new-born" status, were preoccupied with justifying and proving IS as a "scientific" and "rigorous' research discipline that should be respected, recognised, and cited by other scientific communities. Such a preoccupation, however, had resulted in an overly self-conscious attitude and desperate attempts to establish IS as a quasi-natural science by mimicking 
philosophies, methods, techniques, and presentation styles from hard sciences such as Physics and Mathematics.

For a while, the legitimacy of the IS field was endangered by the lack of practical relevance and guidance to practitioners as well as the weak contribution to other neighbouring academic disciplines. One key reason being identified was that IS researchers tended to focus much on the theoretical significance of the context where IT artefacts are being used. Such IT artefacts are taken as granted and treated as an separable item from their context with "discrete processing capabilities" thus often disappear from view (Wanda J Orlikowski \& Iacono, 2001). Excessively focusing on the research context instead of the core matters (the IT artefacts), makes IS studies hard to stand out and differentiate themselves from works produced by researchers from other well-established business disciplines (e.g. Management, Marketing, Accounting, Finance, etc.) who are interested in understanding the broad impact of IT to their own fields and practices. Resultantly the IS field has been suffering from a lack of respect and recognition from other academic communities as well as setbacks when seeking funding for research.

Leading researchers in the IS field have warned there would be "nothing at the centre" of the IS discipline due to much of the past research development being focused on "intellectual periphery" drawing "intellectual capital" from outside the field (Lyytinen \& King, 2004). The centre of IS field, was supposed to be grounded primarily in praxis, specifically on the human made, information intensive, "IT artefacts". However, earlier IS studies predominately treated the "IT artefacts" as "black boxes" without looking inside (Iivari, 2007). The "IT artefacts" were often conceptualised as a variable with its presence or absence being observed to test its organisational, social, and or cultural impact (e.g. technology driven behavioural changes) as well as to identify factors affecting its adoption and diffusion of technologies. Numerous statistical IS studies have been published, with a common practice treating "IT artefacts" as a primary independent variable, to assess the 
dependant variables such as communication behaviour and effectiveness at organisation, team, and individual levels. Nevertheless, the statistical studies and findings have been often criticised for the lack of details on how theories/models can be turned into implementation in real world practice.

Over 25 years ago, Nunamaker and the colleagues, in a JMIS (Journal of Management Systems) essay, have already challenged the "black box" view towards IT artefacts in the IS field. They urged "system development" should be accepted as a research method to promote the focus on analysing, designing, and developing IT artefacts (Nunamaker Jr, Chen, \& Purdin, 1990), instead of focusing solely on the "intellectual periphery". Indeed, technologies are not equivalent to each other in terms of capacities, capabilities, purposes, and behaviours. More importantly, technologies are changing all the time, thus should not be treated as mysterious black boxes.

However, seeing little improvement but more diversion from the centre in IS research, Hevner et al. (2004), in a thoughtful and highly influential MISQ (Management of Information Systems Quarterly) article, urged the strong need for Design Science Research (DSR) in the IS field and suggested a conceptual framework for designing artefacts as a means of conducting scientific research towards the end goal of efficient and effective management of information (Alan R. Hevner, March, Park, \& Ram, 2004). So far this article has been cited over 10,000 times (according to Google Scholar). It has forcefully driven the DSR movement forward and resulted in a series of developments including the first International Conference on Design Science Research in Information Systems and Technology (DESRIST) in 2006.

Hevner et al. (2004) further argued the dominant "Behavioural Science Research" should give space to DSR as these two should complement rather than compete against each other. The former should provide "truth" to the latter in the form of theories whereas the latter should offer "utility" to the former in the form of artefacts. Such a complementary view has effectively eased the tension between the two schools of thought. New generations of IS researchers started adopting a 
pragmatic approach and focus on understanding and solving problems instead of spending excessive amount of time debating with each other the academic justification or philosophical stances of their research. After all, we human beings, ought to learn to live and let live in the real world.

DSR has been gradually adopted in the IS field and helped us to restore our focus on the "core", namely, the human-made IT artefacts. Still, senior researchers are calling for more DSR studies in the years beyond and deem that the IS field is no longer modelling itself "on the research disciplines found in the natural and social sciences, but instead charts a course for its future development by modelling itself on the research disciplines found in the professions, such as medicine, engineering, architecture., and law" (A. Lee, 2010).

The present study is a typical project based on the profession of IS development and services. In such a profession, IS Agility issues have been frequently encountered but often ill defined, partially understood, and roughly handled on an ad-hoc basis. The processes, solutions and outcomes can vary greatly depending on the expertise and experiences of the people assigned to solve the problems. With the artefacts created in this study (e.g. ISACAM), however, we have introduced a high level of theoretical clarity and structure which can systematically reduce the need for adhoc practices. This in turn makes the investigation and problem-solving processes more consistent, systematic, and effective.

\subsubsection{Design as a Reflective Practice}

Allen S. Lee's proposition of modelling the IS field on the research disciplines found in the more design-oriented professions (A. Lee, 2010), is significant and can be traced back to the days when Design Science attempted to establish itself as an academic discipline. Donald A. Schön has long been arguing that practitioners in 
design professions, with systematic reflections, become researchers themselves (Schön, 1983).

In Donald A. Schön's classic book “The Reflective Practitioner: How Professionals Think in Action" (Schön, 1983), design is articulated as a reflective practice meaning professional engineers are consciously aware of their implicit knowledge base and learn from their experiences. He explores the idea that we, as designers, tend to know more than we can say thus often rely on "tacit knowledge" to make informed guesses and act on hunches to solve problems. Therefore design practice "triggers awareness of new criteria for design: problem solving triggers problem setting." (Schön, 1988)

Schön defines the key notion in his book: reflection in action which refers to reflecting while performing an action as a way to optimise the immediately subsequent actions. He believes that when a practitioner starts to reflect-in-action, he/she then becomes a researcher in a practice context. Such a researcher will adjust his/her actions according to iterative reflections which in turn create a mental "Iadder of reflections", namely, action is followed by reflection and every reflection is followed by action. In such a ladder, the outcomes of reflections can also become the sources for further reflections (Schön, 1983).

Furthermore, Schön argues that design, as a "reflection in action", occurs naturally when engineers are handling a "situation of uncertainty, instability, uniqueness and value conflict" and trying to change the situation to a preferred state. He suggests "reflection in action hinges on the experience of surprise" (p.56) meaning reflections occur mostly when our actions do not yield results as expected in a way that surprises us (Schön, 1983)

An engineer may stop reflecting when he/she becomes too acquainted with a particular field of expertise, in other words, "over-learned". An over-learned engineer, can become narrow-minded and rigid with a set of own theories-in-action 
- which Schön referred to as "knowing-in-action" - based on previous experiences. The engineer will find his/her own practice to become increasingly repetitive and routine. This way his/her knowing-in-action will turn into a tacit and spontaneous form. The engineer, may develop a symptom that is "selectively inattentive to phenomena that do not fit the categories of his/her knowing in action" which in turn can result in boredom and burn-out (Schön, 1983).

According to Schön, consciously practice reflection-in-action can correct the negative consequences of becoming "over-learned" and help us to "surface and criticise the tacit understanding that have grown up around the repetitive experiences of a specialised practice, and can make new sense of the situations of uncertainty or uniqueness which he/she may allow him/herself to experience" (Schön, 1983) (p.61).

In this study, I have carried dual identities throughout the journey. One is the IS practitioner specialised in designing Business Intelligence solutions. The other one is the Design Science researcher interested in learning how to solve real-world IS Agility problems. The practitioner, as informed by Schön, has been fully aware of his reflection-in-action and made great use of it in his daily practice with clients and colleagues while solving IS-related problems. Such reflection-in-action, has informed the other identity, namely the Design Science researcher, to map a theoretically grounded academic artefact (i.e. ISANN) into a practically relevant method (i.e. ISACAM) for improved understanding and solution design (i.e. for investigating and solving IS Agility problems).

Comprehension of the role of a reflective practitioner in research setting has naturally led to reflective analysis on the design activities and outcomes. Reflective analysis has been used in innovative design studies as a means for evaluation (Antunes, Simes, \& Pino, 2013). Because innovative artefacts at the early development stage may have to be continuously assessed by the experts who designed the artefacts at the first place. Due to the salient nature of innovative artefacts, often non-experts or the general public cannot fully apprehend and 
appreciate the value and the problems such artefacts can solve. Not to mention there would be no comparable artefact to benchmark against. In this study, adjustments and improvements were then made based on reflections and feedback gained through real-world applications of the artefact (e.g. ISACAM). Such reflections are also considered a type of formative evaluation in this study which is discussed in Section 4.5.3.

\subsection{Artefacts Design and Evaluation}

\subsubsection{The DSR Strategy and Process}

Methodologists in the IS field, when prescribing methodological guidance for DSR, tend to confine themselves at an abstract level without elaborating on the detailed design and evaluation activities. This makes a stark contrast to the circumstantial and specific prescription given to Behavioural Science Research (Alturki, Gable, \& Bandara, 2011) which often gets explained at a low level of granularity, for instance, interviewing techniques (Myers \& Newman, 2007), survey development (Pinsonneault \& Kraemer, 1993), and the overall qualitative research method (Myers, 1997). A general consensus is that to conduct DSR, one needs to go through certain generic stages listed below (Timothy J Ellis \& Levy, 2010; A. Hevner \& Chatterjee, 2010; Peffers, Tuunanen, Rothenberger, \& Chatterjee, 2007):

- Identify Problem

- Define Objective

- Design and Development

- Test and Evaluation

- Communication

These stage-based research processes have been frequently referred to by Design Science researchers as the basic steps to follow when conducting DSR in the IS field. Table 17 below provides a summary of previous studies iterating on these steps, 
either partially or fully, in the hope of establishing rigour and discipline in the conduct and execution of DSR.

Table 17: Commonly Prescribed DSR processes

\begin{tabular}{|c|c|c|c|c|c|}
\hline & \multicolumn{5}{|c|}{ Generic DSR Activities } \\
\hline & $\begin{array}{l}\text { Identify } \\
\text { Problem }\end{array}$ & $\begin{array}{c}\text { Define } \\
\text { objective }\end{array}$ & $\begin{array}{c}\text { Design and } \\
\text { Development }\end{array}$ & $\begin{array}{c}\text { Test and } \\
\text { Evaluation }\end{array}$ & Communication \\
\hline $\begin{array}{l}\text { (Nunamaker Jr } \\
\text { et al., 1990) }\end{array}$ & $\begin{array}{l}\text { Construct a } \\
\text { conceptual } \\
\text { framework }\end{array}$ & & $\begin{array}{l}\text { Develop system } \\
\text { architecture \& } \\
\text { Analyse , design, } \\
\text { and build system }\end{array}$ & $\begin{array}{l}\text { Experiment, } \\
\text { Observe, and } \\
\text { evaluate the } \\
\text { system }\end{array}$ & \\
\hline $\begin{array}{l}\text { (Walls, } \\
\text { Widmeyer, \& El } \\
\text { Sawy, 1992) }\end{array}$ & $\begin{array}{l}\text { Meta } \\
\text { requirement \& } \\
\text { Kernel theories }\end{array}$ & & Build & Evaluate & \\
\hline $\begin{array}{l}\text { (March \& Smith, } \\
\text { 1995) }\end{array}$ & & & Build & Evaluate & \\
\hline $\begin{array}{l}\text { (Alan R. Hevner } \\
\text { et al., 2004) }\end{array}$ & $\begin{array}{l}\text { Identify } \\
\text { relevant } \\
\text { problems }\end{array}$ & & $\begin{array}{l}\text { Design as a } \\
\text { search process }\end{array}$ & $\begin{array}{l}\text { Design } \\
\text { evaluation }\end{array}$ & $\begin{array}{l}\text { Communication } \\
\text { of research }\end{array}$ \\
\hline $\begin{array}{l}\text { (Peffers et al., } \\
\text { 2007) }\end{array}$ & $\begin{array}{l}\text { Problem } \\
\text { identification } \\
\text { and motivation }\end{array}$ & $\begin{array}{l}\text { Define the } \\
\text { objectives } \\
\text { of a } \\
\text { solution }\end{array}$ & $\begin{array}{l}\text { Design and } \\
\text { development }\end{array}$ & $\begin{array}{l}\text { Demonstration } \\
\text { Evaluation }\end{array}$ & Communication \\
\hline $\begin{array}{l}\text { (Kuechler \& } \\
\text { Vaishnavi, 2008) }\end{array}$ & $\begin{array}{l}\text { Awareness of } \\
\text { problem }\end{array}$ & Suggestion & Development & Evaluation & Conclusion \\
\hline $\begin{array}{l}\text { (Offermann, } \\
\text { Levina, } \\
\text { Schnherr, \& Bub, } \\
\text { 2009) }\end{array}$ & $\begin{array}{l}\text { Identify } \\
\text { problem, } \\
\text { Literature } \\
\text { research, }\end{array}$ & $\begin{array}{l}\text { Expert } \\
\text { Interviews, } \\
\text { Pre- } \\
\text { evaluate } \\
\text { relevance }\end{array}$ & $\begin{array}{l}\text { Design artefact } \\
\text { Literature } \\
\text { research }\end{array}$ & $\begin{array}{l}\text { Refine } \\
\text { hypothesis, } \\
\text { Expert survey, } \\
\text { Laboratory } \\
\text { experiment, } \\
\text { Case } \\
\text { study/action } \\
\text { research, }\end{array}$ & $\begin{array}{l}\text { Summarise } \\
\text { results }\end{array}$ \\
\hline $\begin{array}{l}\text { (Timothy J Ellis } \\
\text { \& Levy, 2010) }\end{array}$ & $\begin{array}{l}\text { Identify the } \\
\text { problem \& } \\
\text { Describe the } \\
\text { objectives }\end{array}$ & & $\begin{array}{l}\text { Design \& } \\
\text { Develop the } \\
\text { artefact }\end{array}$ & $\begin{array}{l}\text { Test the artefact } \\
\text { \& Evaluate } \\
\text { testing results }\end{array}$ & $\begin{array}{l}\text { Communicate } \\
\text { the testing } \\
\text { results }\end{array}$ \\
\hline $\begin{array}{l}\text { (A. Hevner \& } \\
\text { Chatterjee, } \\
\text { 2010) p.28-30 }\end{array}$ & $\begin{array}{l}\text { Problem } \\
\text { identification } \\
\text { and motivation }\end{array}$ & $\begin{array}{l}\text { Define the } \\
\text { objectives } \\
\text { for a } \\
\text { solution }\end{array}$ & $\begin{array}{l}\text { Design and } \\
\text { Development }\end{array}$ & $\begin{array}{l}\text { Demonstration } \\
\text { Evaluation }\end{array}$ & Communication \\
\hline
\end{tabular}


These five steps, essentially are strategic-level guidelines with limited operationallevel instructions. Repetitively prescribing high level abstract view of DSR is a manifestation of a pragmatic approach emphasising ends over means. Such an emphasis has both benefits and risks. One key benefit is that researchers following these guidelines will have room to improvise with their imagination and be creative. This is reasonable given the enormous diversity of topics being studied in the IS field, DSR in IS may result in artefacts that are drastically distinct in nature, e.g. from software applications, to organisational policies. On the other hand, the missing of finer level guidelines will risk reproducibility and reliability of the design process as well as the resulting artefacts. Every researcher can have his/her own preferred, maybe even unique approaches to design and develop artefacts while others may not be able to comprehend and duplicate.

Discontented by the lack of specification in those high-level guidelines, a group of researchers from QUT (Queensland University of Technology), after reviewing and analysing some 60 DSR articles, "distilled" key activities/steps/tasks involved in DSR and synthesised fourteen finer processes in a model called the "Overall DSR roadmap". The roadmap was published at the DESRIST 2011 conference (Alturki et al., 2011) and is a considerable improvement from previous DSR guidelines in terms of practical clarity.

1. Document the spark of an idea/problem

2. Investigate and evaluate the importance of the problem idea

3. Evaluate the new solution feasibility

4. Define research scope

5. Resolve whether within the Design Science paradigm

6. Establish type (IS design sciences vs. IS design research)

7. Resolve theme (Construction, Evaluation, or both)

8. Define requirements

9. Define alternative solutions

10. Explorer knowledge base support of alternatives

11. Prepare for design and/or evaluation

12. Develop (construction)

13. Evaluate: "Artificial "Evaluation

14. Evaluate: "Naturalistic" Evaluation 
This roadmap introduced considerations regarding feasibility, scope, methodological fit of the research problem to DSR, requirements, and alternative solutions (Alturki et al., 2011). The authors, citing March and Smith's work, stated that "acceptable research need not extend to evaluation if the design solution is particularly novel." (Alturki et al., 2011; March \& Smith, 1995). They further argue that both construction research and evaluation research should be promoted but such a separation is a key decision to be made as evaluation often require "different expertise and entail substantial resources" (Alturki et al., 2011).

Nonetheless, similar to those previous guidelines listed in Table 17, this roadmap still remains silent on how artefacts should be designed, what design decisions should be made, and which techniques should be used. The design and development phase is yet unclear and abstracted which leaves much tolerance to deviation and improvisation. The underlying assumption seems to be that researchers will determine design processes and techniques during the development process in accordance with the research problems and objectives. Such an assumption may be right but only to a certain degree when the artefacts being designed are drastically different from each other thus design decisions would/should be different.

After reviewing these DSR guidelines offered in the IS literature, we concluded that they are mostly useful for strategic level research decisions rather than operational level instructions. Therefore, following the "Three Cycles" tradition established by Hevner and his colleagues (A. Hevner \& Chatterjee, 2010; Alan R Hevner, 2007; Alan R. Hevner et al., 2004), we mapped out the strategic framework of the present DSR study in Figure 11 below. 


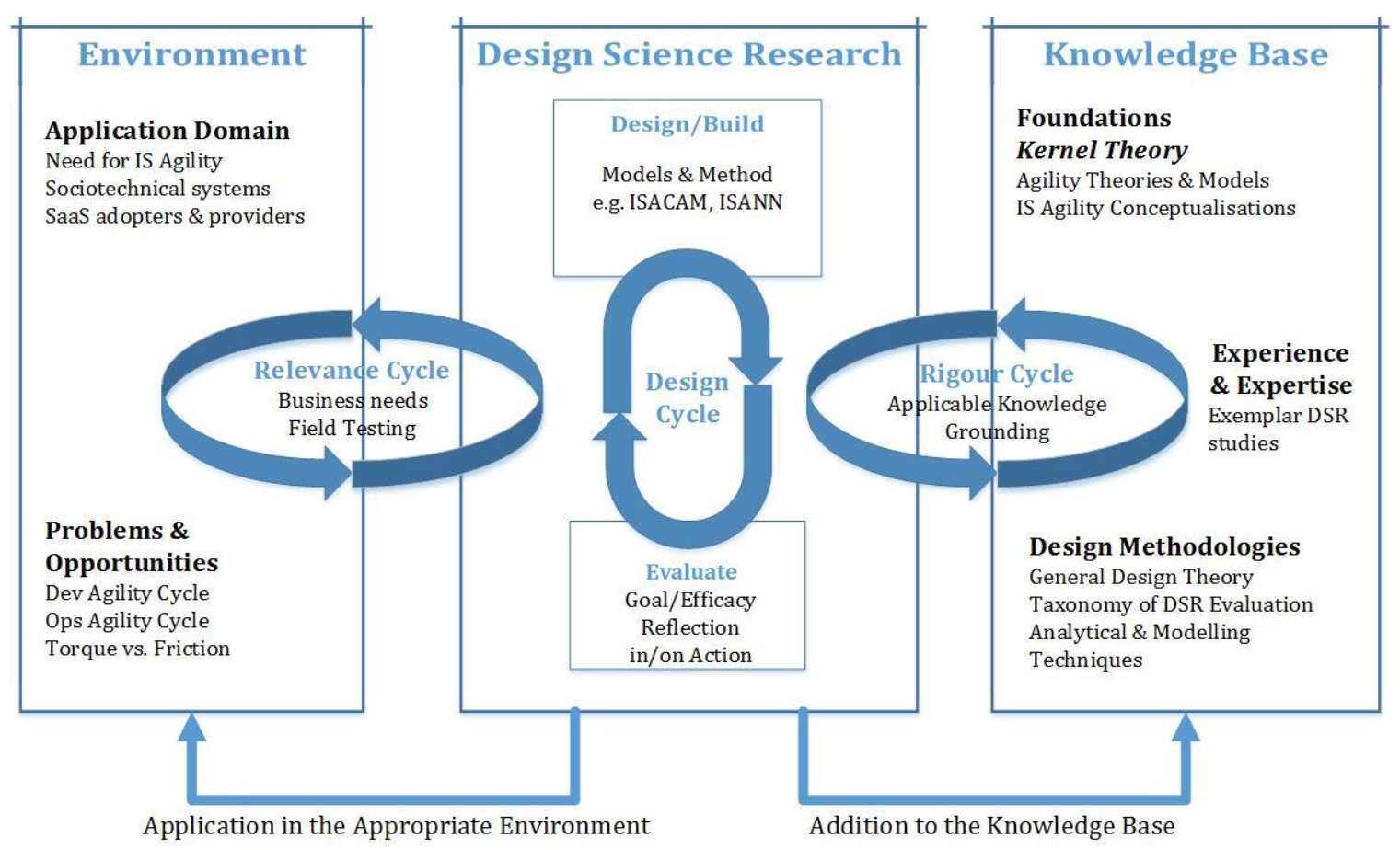

Figure 11 A Strategic Framework of the Present DSR

Adapted from: (Alan R Hevner, 2007; Alan R. Hevner et al., 2004)

Firstly, in the Relevance Cycle, we acknowledge the environment of the present study as contextualised particularly by the need for IS Agility. Without such a need this study would not be relevant or justifiable. At the centre of this environment are the sociotechnical systems to be investigated. The whole concept of IS Agility is built upon such systems involving both machine-focused technical component and human-focused business components. A purely technical system, such as a C++ compiler, would have little relevance to our conceptualisation of IS Agility. Next we identify the SaaS providers and adopters as key agents interacting in this environment. Such a feature is not necessarily a unique attribute of IS Agility studies, but it is a convenient enabler to the current study. With access to the intensive interactions between SaaS providers and adopters in the real world, it is much easier to find and engage with IS Agility issues associated with the same sociotechnical system. This way the environment is more controlled because all 
adopters are sharing the same SaaS system. Such an arrangement helps us reduce the complication of having to compare IS Agility issues with system $A B C$ and those with system XYZ. We can then focus on investigating the nature of the problems (e.g. Dev Agility Cycle having low torque vs. high friction) rather than the different features and functionalities of the systems.

Secondly, in the Rigour Cycle, as shown in Figure 11 above, we recognise the knowledge base of this study should provide the "Kernel Theory" about IS Agility as a specialisation of a more generic concept of Agility. This is done in Chapter 2 through reviewing and synthesising concepts and models from a broad range of literature across multiple disciplines. The result of such an exercise is the first artefact developed, namely, ISANN. Next we searched the knowledge base for exemplar DSR studies published on key IS journals such as (Abbasi, Albrecht, Vance, \& Hansen, 2012; Markus, Majchrzak, \& Gasser, 2002) to gain inspirations and practical guidance. Furthermore, we also drew upon the knowledge base of design engineering (Takeda, Veerkamp, \& Yoshikawa, 1990) and analytical modelling (Kimball \& Ross, 2013) (Diaper \& Stanton, 2003) to choose theories and techniques that can facilitate the design and development of our artefacts.

Last but not the least, in the Design Cycle, artefacts (e.g. ISACAM) are developed and tested using mixed styles and techniques. This is done through iteratively drawing upon the knowledge base for guidance and inspirations, applying knowledge-driven designs in the DSR environment, reflecting on the efficacy of such applications, and improving the designs for better outcomes. Reflection in/on action techniques are used to assess and learn from the experiences. New knowledge being generated is then added back to the knowledge base (e.g. through peer-reviewed publications). More details about the Design Cycle are discussed in the following sections. 


\subsubsection{The Choice of Design Methods}

Our goal in the Design Cycle, is to develop a systematic method for solving IS Agility problems. We have consulted the knowledge base and created ISANN - a unified conceptualisation of IS Agility. We plan to use ISANN as a conceptual framework to construct the problem space and scope the initial elements needed for the method being designed (i.e. ISACAM).

Moreover, to develop a problem-solving method, we need to explicitly identify what are the key requirements for "problem solving". In mathematical terms, problem solving fundamentally involves "operations" on "numbers" (Schoenfeld, 2014). Of course, the sequence and combination of operations need to be correct in order to solve a problem. However, IS Agility problems are sociotechnical in nature thus we do not expect solutions to be generated purely by using quantitative methods. For this reason, we decide to use "task and data" instead of "operation and number" to represent the key requirements underpinning our problem solving method. Such a choice allows not just quantitative approaches but also qualitative ones. Similar to mathematical problem solving, the right sequence and combination of tasks are important to success.

Next, we need to find a reliable approach to map ISANN into a "task and data" driven problem-solving method. As mentioned previously, the IS literature tends to offer generic guidelines and stay at an abstract level regarding how the Design Cycle should be executed. Leaving too much unspecified at design and development phase may risk the reproducibility and reliability of the design processes and the resulting artefacts. Researchers may be allowed to use their creativity and imagination but can also make immature or improvised design decisions based on intuition. This can present a deviation from the intended scientific research/design approach and a shift more towards an artistic design practice.

To mitigate these risks, we decided to look for support from a broader knowledge base kept by other reference disciplines with strong design culture such as 
Engineering and Computer Science. The objective is to identify relevant operational level guidelines and techniques for the design and development of "task and data" based ISACAM artefact. We have found two techniques most suitable: Dimensional Modelling (Kimball \& Ross, 2013) for the development of a data model, and Hierarchical Task Analysis (Diaper \& Stanton, 2003) for the development of a task model. We believe having a data model and a task model developed at the same time will enable other researchers to further design software instantiation.

\section{Dimensional Modelling}

So far, all the artefacts created in the previous stages of study are relational in nature. For example, ISANN in Chapter 2, the operational view of Dev vs. Ops Agility in Chapter 3, are all artefacts intending to describe relationships among the elements contributing to IS Agility. Such relationships can be order (i.e. SenseDiagnose-Select-Execute), or dependency (i.e. Torque to speed up the cycle vs. Friction to slow down), or simply part-to-whole (i.e. Dev Agility vs. Ops Agility, Spatial Uncertainty and Temporal Uncertainty). All these elements and relationships need to be captured in appropriate data structure and format to enable effective and efficient investigation and problem-solving efforts.

We have found Dimensional Modelling method (Kimball \& Ross, 2013) most suitable for designing data models needed for ISACAM. Dimensional Modelling techniques focus on mapping relational data into dimensional structure for more effective and flexible analysis which matches the intended analytical nature of ISACAM. Facts, Dimensions, and Hierarchies are three essential concepts in Dimensional Modelling. In ISACAM, "Facts" can be used to capture the key metrics of the IS Agility problem. "Dimensions" and "Hierarchies" can be used to represent the relationships between all those elements identified in ISANN that are contributing to the IS Agility problem. Moreover, dimensional data models can be easily extended to incorporate new relationships or elements emerged during the study. We decided to use the UML diagramming style to draw the data models for ISACAM, as this style 
has been widely accepted as a standard approach for modelling IS artefacts, data models, logic sequence, programming units such as classes, and so on (Booch, 2005). A series of dimensional models are presented in the next chapter illustrating the evolution of ISACAM.

\section{Hierarchical Task Analysis}

ISACAM is to be used for investigating and solving IS Agility problems. Such a method should prescribe certain tasks and activities in the right sequence for users to follow. This way ISACAM can minimise ad-hoc processes and make the investigation and problem-solving exercise systematic, consistent and rigorous. Given the already ambiguous nature of IS Agility and the absence of an established method to solve IS Agility problems, it is critical to provide step-by-step instructions to ISACAM users to ensure all key aspects, elements, and relationships of IS Agility are considered and analysed so that optimised solution can be generated.

We have found Hierarchical Task Analysis (HTA) (Diaper \& Stanton, 2003) a powerful method for developing the procedure of ISACAM. HTA is based on the theory of human performance and often being used in HCI (Human Computer Interaction) studies. It was originally built for decomposing and studying individual elements of a task. HTA offers a great way of depicting a system containing goals and sub-goals with feedback loops in a nested hierarchy. Investigating IS Agility problems involves tasks and goals that can break down into multiple hierarchies of subunits. HTA offers versatile and flexible techniques for capturing how tasks are performed in a systematic and structured manner. It can be used to describe both human tasks and system tasks (Diaper \& Stanton, 2003). All these features of HTA make it an excellent candidate for developing the task model of ISACAM. The next chapter will present a series of HTA based task models to demonstrate the development of ISACAM. 


\section{Technological Rules}

Clearly the notion "task and data" was inspired by the "operation and number" style of problem solving in mathematics. We call such type of problem solving "systematic" as it must have a set of rules established in advance and apply them strictly through the problem-solving tasks. Mathematical problem solving heavily relies on existing theorems. Such theorems are widely tested and accepted for us to follow and rationally apply on new problems in new settings.

Besides this "systematic" style of problem solving, the other style - we call it "intuitive" - is more common in real life. When no strict rules or principles are established, one has to begin investigating the problem at hand based on his/her own life experience and intuition to discover clues and patterns that are perceived reliable enough to further the reasoning process. An example of such an approach being used is when a new manager is trying to resolve undesirable, counterproductive office politics.

The creation of ISACAM is essentially trying to trigger a shift from the traditional "intuitive" ad-hoc way of solving IS Agility problems to a rule-driven, theoretically grounded, "systematic" way. To generate successful solutions using the "intuitive" way may require high level of expertise and experiences from the problem solver. However, following a "systematic" method with prescribed rules, we believe even novice problem solvers can produce effective solutions.

The rules we produce in this study are called "technological rules". Technological rules are important products of DSR. A technological rule is defined as " $a$ chunk of general knowledge, linking an intervention or artefact with a desired outcome or performance in a certain field of application" (Aken, 2004) (p.228). To solve the "serious utilisation problem" faced by business research, more prescription-driven research should be conducted with the aim to produce technological rules with highly practical relevance (Aken, 2004). 
Table 18 below provides a summary of the key components of ISACAM discussed above.

Table 18: Key Components of ISACAM and Design Methods used

\begin{tabular}{|c|c|c|c|}
\hline & Data Model & Task Model & Technological Rules \\
\hline 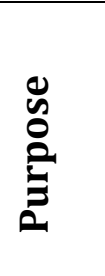 & $\begin{array}{l}\text { To ensure critical data is } \\
\text { captured for investigating } \\
\text { and solving IS Agility } \\
\text { problems }\end{array}$ & $\begin{array}{l}\text { To establish a } \\
\text { consistent and } \\
\text { repeatable procedure } \\
\text { for investigating and } \\
\text { solving IS Agility } \\
\text { problems }\end{array}$ & $\begin{array}{l}\text { To provide guidance for } \\
\text { ISACAM users to judge } \\
\text { and decide solutions }\end{array}$ \\
\hline : & $\begin{array}{l}\text { The model needs to } \\
\text { capture all attributes and } \\
\text { relationships identified in } \\
\text { ISANN and have the } \\
\text { extensibility to } \\
\text { incorporate new ones } \\
\text { emerged during the study. }\end{array}$ & $\begin{array}{l}\text { The model needs to } \\
\text { provide step-by-step } \\
\text { instructions and } \\
\text { prescribe what need to } \\
\text { be done to } \\
\text { systematically } \\
\text { investigate and solve IS } \\
\text { Agility problems }\end{array}$ & $\begin{array}{l}\text { The rules need to be } \\
\text { generic enough for } \\
\text { ISACAM users to apply } \\
\text { in their specific contexts }\end{array}$ \\
\hline 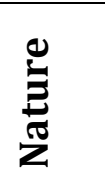 & Definition of data structure & Sequence of activities & Chain of judgements \\
\hline 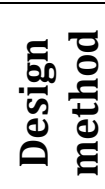 & $\begin{array}{l}\text { UML, Dimensional } \\
\text { Modelling }\end{array}$ & $\begin{array}{l}\text { Hierarchical Task } \\
\text { Analysis }\end{array}$ & $\begin{array}{l}\text { IF-THEN rule } \\
\text { specification }\end{array}$ \\
\hline
\end{tabular}

Prior to this study, no technological rules were found guiding our investigation of IS Agility problems. Such an absence of systematic problem solving was one of the study motivations. Given the novelty of the IS Agility problem-solving method (i.e. ISACAM) being developed in this study, we expected that a full set of rules will not be formulated at the beginning of the journey. During the Design Cycle of ISACAM through applying it on real-world problems, several technological rules have been observed and tested which are presented in the next chapter. Technological rules should not be a specific prescription to a specific situation, rather, it should be a 
general prescription for a class of problems (Aken, 2004). The rules we prescribe are based on the generic concepts and elements derived from ISANN which are not specific to any individual sociotechnical systems. We expect these rules to help IS developer, researchers, and users to make better decisions on solutions for solving IS Agility problems.

Further review of Design Engineering literature has provided more support to our decisions on design methods. Particularly the General Design Theory (GDT) proposed by Hiroyuki Yoshikawa and colleagues (Takeda et al., 1990; Yoshikawa, 1979). GDT was originally developed mathematically to support the initial building of Computer Aid Design (CAD) software tools which should facilitate both design activities and objects. As shown in Figure 12 below, with GDT, design is defined as "mapping from function space to attribute space" (Takeda et al., 1990). Function space is defined as "the entity concept set with a topology of functions", and attribute space is "the one with a topology of attributes" (P.38)(Takeda et al., 1990).

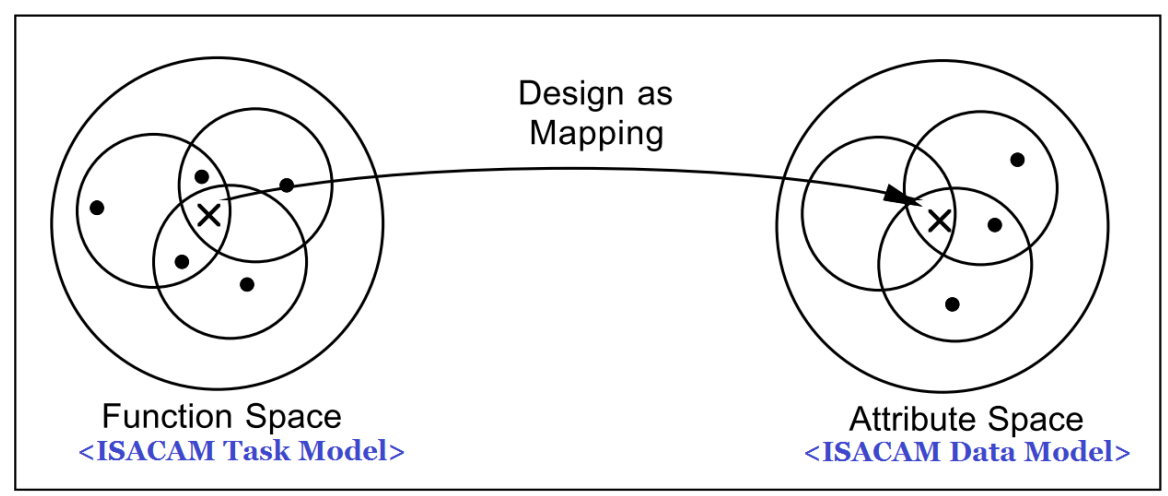

Figure 12 Design Process in General Design Theory

Source: Adapted from (Takeda et al., 1990)

Although GDT was criticised for being too mathematically restrictive, it is recommended to be used as a model to direct the design thinking rather than a 
precise guideline for design creations (Reich, 1995). Thinking design as a mapping exercise from functionalities to attributes is a useful tactic and aligns with our decisions on developing a task model (containing functions needed to perform ISACAM) and a data model (containing attributes captured and analysed for generating solutions) simultaneously for ISACAM. We can iteratively map the emerging tasks needed to solve IS Agility problems into the data model of ISACAM until no more new tasks can be identified. Moreover, GDT prescribes that function space and attribute space are built on the same entity concept set (Takeda et al., 1990)(p.39). This is exactly how our task and data model are built as both are derived from ISANN thus share the same set of entity concepts.

\subsubsection{The Choice of Evaluation Methods}

Contradicting opinions can be observed in the DSR literature regarding the necessity of evaluation. Such contradiction can be found among different researchers. For instance, in a MISQ paper, Hevner et al. (2004) stated "evaluation is a crucial component of the research process" (p.85), whereas some other researchers suggest that "acceptable research need not extend to evaluation if the design solution is particularly novel." (Alturki et al., 2011; March \& Smith, 1995). The contraction can even be observed in the same article of the same authors. For example, Hevner et al. (2004), on page 97, while assessing another DSR study done by (Markus et al., 2002), noted "no formal evaluation was attempted in the sense of comparison with other artefacts. This is not surprising, nor is it a criticism of this work. There simply are no existing artefacts that address the same problem."

I was baffled at the beginning by such contradicting statements but soon realised they can be reconciled if I dug deeper into the next level of granularity regarding the concept "evaluation". I have found the FEDS (Framework for Evaluation in Design Science) published on the EJIS (European Journal of Information Systems) particularly helpful (Venable, Pries-Heje, \& Baskerville, 2016). As shown in Figure 
13 below, Venable and the colleagues have proposed a much more detailed view of DSR evaluation by positioning four different strategies (Human Risk \& Effectiveness, Quick \& Simple, Technical Risk \& Efficacy, and Purely Technical) into a twodimensional framework. According to Venable et al. (2016), the black triangles represent "evaluation episodes, yet the number and placement of them are indicative only and can vary depending on the needs of a particular DSR project".

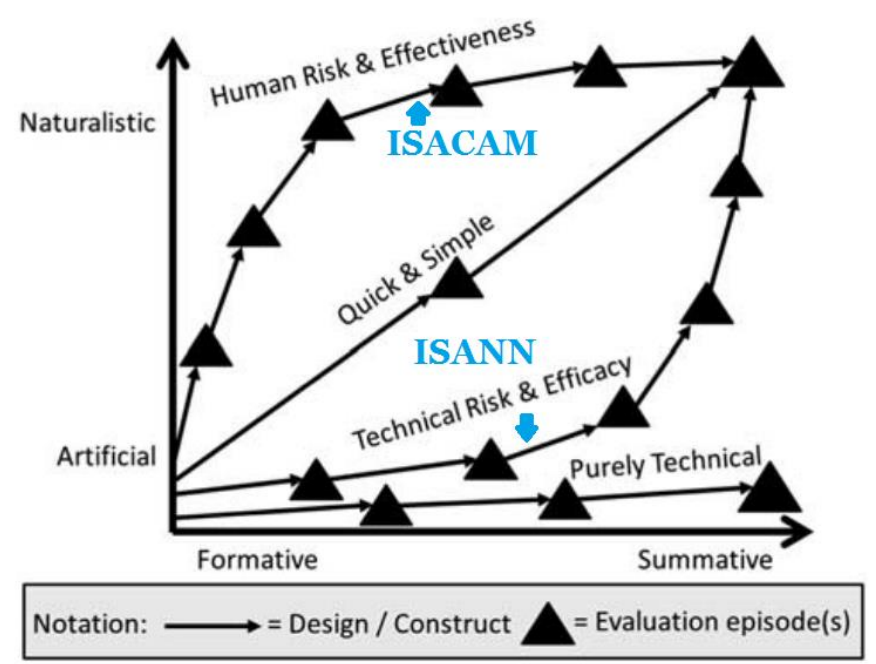

Figure 13 FEDS Evaluation Strategies

Source: (Venable et al., 2016)

The Naturalistic vs. Artificial dimension represents a paradigm shift from evaluating artefacts in the real-world (e.g. real people, real systems, and real settings) to more controlled environments. Naturalistic evaluations are typically empirical and "embrace all the complexities of human practice in real organisations" (Venable et al., 2016). Methods used for naturalistic evaluations can include case studies, surveys, field experiments, and ethnography (Venable, Pries-Heje, \& Baskerville, 2012). On the other hand, artificial evaluations are allowed to test imaginary scenarios on students rather than real cases on business users. Artificial evaluations can be empirical with a data-collection exercise or non-empirical purely though logical/rhetorical analysis (Venable et al., 2016). Methods used for artificial 
evaluations can include laboratory experiments, simulations, criteria-based analysis, theoretical arguments, and mathematical proofs (Venable et al., 2012).

The Formative vs. Summative dimension represents a transition in "functional purposes" of DSR evaluations. This dimension of evaluation was originated in education programmes but later brought into the IS literature by Dan Remenyi and Michael Sherwood-Smith (Remenyi \& Sherwood-Smith, 1999). The differences between summative and formative evaluations are subtler. Venable et al. argued that "the distinction does not arise in the innate qualities of the evaluation process, but rather inhabits the functional purpose of the evaluation" (Venable et al., 2016).

The purpose of formative evaluations is to improve the evaluand (the artefact being evaluated) thus such evaluations can and should be applied multiple times in a DSR study to encourage continuous improvements of the design (Venable et al., 2016). In fact, Remenyi and Sherwood-Smith (1999) argued that formative evaluations are inherently part of the artefact design and analysis processes, even though such evaluations are often not articulated. On the contrary, the purpose of summative evaluations is to decide if the evaluand is the right choice for certain applications. Therefore such evaluations, if needed, would most often take place at the end of a project (Venable et al., 2016). In other words, we consider formative evaluations are developmental in nature, whereas summative evaluations are more judgemental.

The FEDS brings greater insights into the nature and purpose of DSR evaluation. It helps us reconcile the seemingly contradicting opinions listed at the beginning of this section. We can now see that the contradiction and confusion were caused by the lack of specification in those statements. For instance, when Hevner et al. (2004) first stated "evaluation is crucial components of the research process" and later assessed the DSR study done by Markus et al. (2002) as "no formal evaluation was attempted...this is not...a criticism", they would not appear contradicting if more specific characteristics of evaluations were provided. According to Remenyi and Sherwood-Smith (1999), formative evaluations are not only crucial, but an integral 
part of IS artefact design and analysis. We believe that a designer simply cannot improve her designed artefacts without some form of formative evaluations. In fact, Markus et al. (2002) did evaluated their DSR artefact "TOP Modeler" in a naturalistic and formative fashion. They just didn't organise summative evaluation at the end of the project, which was noted by Hevner et al. (2004) as "no formal evaluation". However, Markus et al. (2002) called for future research to accumulate empirical evidence to establish the validity of their generalizability argument.

In the same vein, if specific characteristics are being assigned to the word "evaluation", the statements by other researchers such as "acceptable research need not extend to evaluation if the design solution is particularly novel." (Alturki et al., 2011; March \& Smith, 1995) may not appear contradicting to Hevner et al. (2004) in terms of the importance of "formative evolution" and their tolerance to the absence of formal "summative evaluation". Alturki et al. (2011) in their DSR roadmap argued that a DSR study can follow a construction-focused theme without formal evaluation or evaluation-focused theme without formal construction of artefacts. However, again these authors didn't differentiate the types of evaluations ${ }^{13}$. Therefore, our interpretation to both Hevner et al. (2004) and Alturki et al. (2011), based on FEDS, is that formative evaluation is a necessity and inherently part of the design process, while summative evaluation may not be necessary if a designed artefact is novel or first of its own kind.

Both ISANN and ISACAM developed in this study are novel artefacts hence formative evaluations are considered sufficient. The strategies prescribed by FEDS also suggest the same choice on the "functional purpose" dimension as our evaluations is developmental, not judgemental. However, ISANN and ISACAM have different design/evaluation goals thus need different treatments. The evaluation of ISANN

13 The same authors in a later publication have started differentiating formative evaluations from summative ones (Alturki, Gable, \& Bandara, 2013) . 
should focus on the efficacy of this conceptual framework with regard to describing and decomposing IS Agility phenomena (demonstrated in Chapter 2 and 3 through illustrative scenarios and descriptive analysis). The evaluation of ISACAM should aim to assess its effectiveness in investigating and solving IS Agility problems (demonstrated in Chapter 5 through a series of design/evaluation episodes).

According to FEDS, as shown in Figure 13, for ISACAM we should take the Human Risks \& Effectiveness strategy as the critical goal of the evaluation is to establish that "the utility/benefit will continue in real situation and over the long run" (Venable et al., 2016). Not to mention it is not costly to evaluate ISACAM with real problems as my day job was about solving problems for our SaaS adopters. Therefore, a Naturalistic \& Formative evaluation approach is justifiable and affordable.

On the other hand, for ISANN we should take the Technical Risk \& Efficacy strategy, as illustrated in Figure 13. Unlike ISACAM, ISANN was not built to solve real-world problems thus naturalistic evaluations are unjustifiable. Rather, the creation of ISANN is to help structuring our study and analysis of IS Agility. As such, demonstrating the structure and clarity provided by ISANN through illustrative scenarios, publishing ISANN-based structured analysis in academic outlets for feedback (Yang et al., 2016) (Yang et al., 2013), are considered sufficient as Artificial $\&$ Formative evaluations.

The formative evaluations demonstrated in this study are "goal-seeking" in nature, namely, to assess if the designed artefacts have achieved the design goals. Goal based artefact evaluation is still the first choice among DSR researchers. Prat et al. (2015) conducted a methodological analysis on 121 DSR papers published in eight key IS journals within the "AIS Senior Scholars basket" (including MISQ, EJIS, ISJ, ISR, JIT, JMIS, JSIS, JAIS) from 2004 to 2014. They have found that over $80 \%$ of these DSR studies have used goal based criteria for the evaluation of artefacts (Prat, ComynWattiau, \& Akoka, 2015). 
Following the same tradition recommended by Prat et al. (2015), we have chosen efficacy as the criterion for artificial evaluations and effectiveness for naturalistic evaluations. Efficacy is defined as "the degree to which the artefact achieves its goal considered narrowly, without addressing situational concerns", whereas effectiveness is defined as "the degree to which the artefact achieves its goal in a real situation" (Prat et al., 2015). These two criteria are commonly used by DSR methodologists as well. For instance, Peffers et al. demonstrated the efficacy of their artefact by using it to retroactively analysing and decomposing four already published IS research projects (Peffers et al., 2007). Hevner et al. (2004) evaluated their artefact (i.e. the IS Research Framework) in the same fashion. That's why they made the "no formal evaluation was attempted" comment on the "TOP Modeler" study done by Markus et al. (2002). In this thesis, the efficacy of ISANN has been demonstrated in a similar way through illustrative scenarios and descriptive analysis presented in Chapter 2 and 3 , as well as through peer-reviewed publications. The effectiveness of ISACAM is demonstrated through three design/evaluation episodes solving real problems in the real-world.

Table 19 below provides a summary of the evaluation methods applied on the key design artefacts produced in this study.

Table 19: The Key Artefacts and Evaluation Methods

\begin{tabular}{|c|c|c|c|}
\hline Artefacts & Evaluation Style & Metrics & Feedback \\
\hline $\begin{array}{c}\text { The Operational } \\
\text { view of Dev Agility } \\
\text { vs. Ops Agility }\end{array}$ & $\begin{array}{c}\text { Formative \& Artificial } \\
\text { Descriptive/Illustrative } \\
\text { Scenarios }\end{array}$ & Goal/Efficacy & $\begin{array}{c}\text { Peer-reviewed } \\
\text { publication } \\
\text { Consensus among } \\
\text { experts }\end{array}$ \\
\hline ISACAM & Formative \& & Goal/Effectiveness & $\begin{array}{c}\text { Real-world problem } \\
\text { Nolving in the form of } \\
\text { evaluation episodes } \\
\end{array}$ \\
& Observational or & & $\begin{array}{c}\text { Performance } \\
\text { Participatory }\end{array}$ \\
& & & \\
\hline
\end{tabular}




\subsection{Challenges of Design Science Research}

\subsubsection{Danger of Self-Referential Paradox}

Researchers may argue that the DSR process is inherently self-referential and circular in nature (Glanville, 1999; Rohde, Brödner, Stevens, Betz, \& Wulf, 2017). Through design, researchers are effectively engaging with the materials of a problematic situation in a "reflective conversation" (Schön, 1992). Following Schön (1992), the design researcher needs to "construct the design world within which he/she sets dimensions of his/her problem space, and invents the moves by which he/she attempts to find solutions" (p.11). Engaging a reflective conversation means that one needs to self-evaluate his/her own premature designs, learn from unexpected results, adjust, and sometimes even reconstruct the artefact, iteratively until the design reaches a satisfactory condition. Such a self-referential process allows continuous "simplification and pattern finding" reflections promoting modification, extension, and unification of understandings (Glanville, 1999). Some pioneer thinkers have even requested that the artefact produced by a DSR, e.g. a design theory, should be self-referential as well, meaning it should explain its own emergence (Jonas, 2007).

Although being acknowledged and embraced by design researchers, the notion of "self-referential", if unexamined, can become problematic and even paradoxical. Senior theorists have warned that extra care needs to be taken when constructing self-referential logic such as "using the logic to test a claim that is the same as the logic used to create it in the first place" (Argyris, 2003)(p.1184). Self-referential statements and claims in mathematics and logic studies has traditionally been considered sceptical and may cause illogical inferences (e.g. Russell's paradox in Set Theory) (Friedman \& Sheard, 1987; Yanofsky, 2003). An obvious self-referential semantic paradox can be illustrated by the statement "This sentence is not true." One can assume this statement to be either true or false, it will always contradict to itself. 
Unsurprisingly, philosophers have already offered a deeper elaboration on selfreferential logic and pointed out the crux of those paradoxes. Philosophical studies are frequently concerned with naturally self-referential "vertical theories" about the general nature of theories (Fitch, 1946). For instance, Whitehead's doctrine reported in the book Process and Reality is a vertical theory of all theories including itself (Whitehead \& Sherburne, 1957). Self-referential theories can be safe, as long as the logic is self-referentially consistent (Fitch, 1946). Self-referentially inconsistent logic, however, can cause "vicious circularity" and result in paradox that contradicts itself. In fact, identifying self-referential inconsistency in a philosophical view is a standard method for philosophers to refute such a view (Fitch, 1946). Along the same line, self-referential statements can be as consistent as "Homological is a homological word", or as inconsistent as "Hierological is a hierological word". The former is sound and meaningful while the latter is paradoxical.

Self-referential design patterns are more often practised in Computer Science than in the IS field. For instance, Figure 14 below demonstrates a classic Python example of recursive function calculating the factorial of natural numbers. The function factorial() calls itself inside its own definition to repetitively multiply the input number by the next smaller number till 1 is arrived. Such a self-referencing method is highly effective when a same logic/operation needs to be applied on a dataset over and over again. 


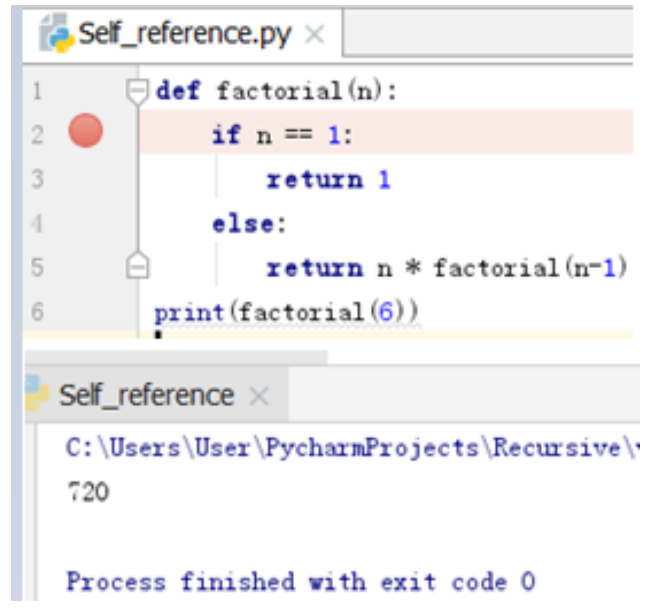

Figure 14: A Recursive Function in Python

However, if the logic is flawed in a way that is inconsistent to the original design (e.g. change " $n-1$ " to " $n+1$ " in the Python code above), such a self-referential function can cause "vicious circularity" and let the operation repeat infinitely. This may cause the host computer to run out of memory and crash, commonly known as "stack overflow". To prevent such an undesirable event, Python has a default value of 1000 as the "maximum recursion depth" meaning even an ill-defined self-referential function can only execute itself 1000 times at the max.

Figure 15 below illustrates another self-referential design pattern widely used in database systems. In such a table structure, each row of record contains reference to its parent (e.g. record id=71 "Fixed Wing" has parent_id=70 pointing to "Aircraft") which allows representation of technically unlimited levels of hierarchical relationship among these records. To display these records in a visually more recognisable hierarchical structure, we will need to write a self-join SQL query to match the parents with the children (see Figure 16 for the query and result). 


\begin{tabular}{|c|c|c|c|}
\hline & id & name & parent_id \\
\hline 1 & 71 & Fixed Wing & 70 \\
\hline 2 & 72 & Helicopter & 70 \\
\hline 3 & 739 & Car/Ute/Wagon & 93 \\
\hline 4 & 735 & $4 W D$ & 93 \\
\hline 5 & 736 & Quad & 93 \\
\hline 6 & 737 & Gator/Argo & 93 \\
\hline 7 & 738 & Motorbike & 93 \\
\hline 8 & 740 & Trailer & 93 \\
\hline 9 & 1131 & Tractor & 93 \\
\hline 10 & 1132 & Truck & 93 \\
\hline 11 & 1133 & Other & 93 \\
\hline 12 & 1516 & Terrain/bush & 100 \\
\hline 13 & 724 & Rock Fall & 100 \\
\hline 14 & 726 & Snow/lce & 100 \\
\hline 15 & 728 & Wind/Storm & 100 \\
\hline 16 & 1130 & Sun/Heat & 100 \\
\hline 17 & 671 & Equake/Tsunami/Volc. & 100 \\
\hline 18 & 725 & Flood/Rain & 100 \\
\hline 19 & 70 & Aircraft & 3726 \\
\hline 20 & 93 & Vehicles & 3726 \\
\hline 21 & 100 & Natural Event & 3726 \\
\hline
\end{tabular}

\section{Figure 15 A Self-Referencing Table Structure}

In this example, both the table structure and the query are self-referential by design. Such a design is beneficial in several ways including saving the need for creating multiple data tables to represent multiple levels of hierarchical relationship. This in turn allows dynamic increase and decrease in levels of hierarchies through simple data inputs from end user applications (e.g. a new grandchild level can be added easily by a user entering a new record "Scooter" with parent_id=738 pointing to "Motorbike"). On the other hand, without the self-referential design, adding a new level of hierarchy may mean creating a new table in the database which often requires intervention from IS specialists as such an operation cannot be done directly by end users in any serious business database systems. 


\begin{tabular}{|c|c|c|c|c|}
\hline $\begin{array}{l}\text { SEL } \\
\text { RC: } \\
\text { RC: } \\
\text { RC: } \\
\text { RC: } \\
\text { FRC } \\
\text { LEF } \\
\text { ON } \\
\text { WH: } \\
\text { ORL }\end{array}$ & $\begin{array}{l}\text { id } \\
\text { hame AS Par } \\
\text { id AS Chi } \\
\text { hame AS } \\
\text { RiskClas } \\
\text { JOIN Ris } \\
\text { RC1.id = } \\
\text { RC2.par } \\
\text { BY RC1. }\end{array}$ & $\begin{array}{l}\text { ntID, } \\
\text { arentwame, } \\
\text { IdID, } \\
\text { ildName } \\
\text { AS RC1 } \\
\text { KClass AS RC2 } \\
\text { RC2.parent_id } \\
\text { id;_id IN (70 }\end{array}$ & $\begin{array}{l}\text { - perf } \\
, 93,100\end{array}$ & raing self-join \\
\hline & ParentiD & ParentName & ChildiD & ChildName \\
\hline 1 & 70 & Aircraft & 71 & Foced Wing \\
\hline 2 & 70 & Aircraft & 72 & Helicopter \\
\hline 3 & 93 & Vehicles & 739 & Car/Ute/Wagon \\
\hline 4 & 93 & Vehicles & 735 & $4 W D$ \\
\hline 5 & 93 & Vehicles & 736 & Quad \\
\hline 6 & 93 & Vehicles & 737 & Gator/Argo \\
\hline 7 & 93 & Vehicles & 738 & Motorbike \\
\hline 8 & 93 & Vehicles & 740 & Trailer \\
\hline 9 & 93 & Vehicles & 1131 & Tractor \\
\hline 10 & 93 & Vehicles & 1132 & Truck \\
\hline 11 & 93 & Vehicles & 1133 & Other \\
\hline 12 & 100 & Notural Event & 1516 & Terrain/bush \\
\hline 13 & 100 & Natural Event & 725 & Flood/Rain \\
\hline 14 & 100 & Natural Event & 724 & Rock Fall \\
\hline 15 & 100 & Natural Event & 726 & Snow/lce \\
\hline 16 & 100 & Natural Event & 728 & Wind/Storm \\
\hline 17 & 100 & Natural Event & 1130 & Sun/Heat \\
\hline 18 & 100 & Natural Event & 671 & Equake/Tsunami/Volc. \\
\hline
\end{tabular}

Figure 16 Result of a Self-Join Query

However, such a self-referential table structure, if not controlled, may create paradoxical situations, namely, the parent_id of a record can be pointed at itself. This is inconsistent to the original design's logic and should be prevented. With modern database systems such as Microsoft SQL Server and IBM DB2 we can set up a CHECK constraint on the table to ensure new records added by user applications comply with an "id <> parent_id" rule.

In this study, we are fully aware of the self-referential nature of DSR and paid special attention to the research design to prevent paradoxical situations. We appreciate the danger of self-referential inconsistency and have identified the potential "vicious circularity" this study might enter, if uncontrolled. Two potentially paradoxical situations were recognised and controlled. 
The first one is at the kernel theory level, we have made a statement at the beginning of the thesis that "Agility is a confusing concept in the IS literature". Therefore, in Chapter 2, it will become self-referentially inconsistent if we only examine the IS literature in order to clarify the conceptual confusion. To prevent such a paradoxical situation, our control method is to extend the scope of literature review to a much broader range of disciplines such as sports science and military research. This was an effective approach that not only fends off the possible paradox, but also leads to a much higher conceptual clarity of Agility.

The second one resides in the design and evaluation cycle of this study, particularly on the judgement on ISACAM artefact. We believe that the designer and the judge should not be the same person(s) otherwise there will be a risk of self-referential paradox. Summative evaluations are judgemental in nature and could determine the fate of the designed artefact thus should better not be conducted by the designer herself. Formative evaluations are developmental in nature and used to improve the designed artefacts thus are self referentially consistent with the design effort.

In this study, to avoid being self-referentially inconsistent, we do not make judgemental claims such as ISACAM is universally applicable or generalizable to all possible environments. ISACAM was developed based on ISANN and evolved through solving real-world problems in a SaaS environment. This environment, denoted by Env1, is the context we are placed in to conduct our formative evaluations to improve the effectiveness of ISACAM. Metaphorically, Env1 is the place where ISACAM was grown up and trained. The positive feedback received, and performance improvement observed in Env1 during the problem solving episodes can be considered justification of the design of ISACAM, not evidence for generalisation. The effectiveness of ISACAM has limited generalizability due to the fact that all formative evaluations were done in the same Env1. To make a valid generalizability argument, ISACAM will need to be taken out of Env1 and applied in different environments, probably with some form of summative evaluations. Of 
course, we believe that to improve the scientific rigour of DSR, summative evaluations should be performed by someone else, not the designer(s), and in environments that differ from where the artefact was originally designed.

\subsection{Chapter Summary}

This chapter discusses the methodological aspect of the present study. It explains the choice of Design Science Research, the philosophical stance and the importance of DSR to the IS field. It elaborates on the design and evaluation of artefacts in terms of strategic intention and operational techniques. Explanation has been provided regarding why and how certain methods and techniques were chosen for designing and evaluating the intended artefacts. Next chapter will discuss details regarding the design and evaluation of ISACAM. 


\section{Chapter 5 : The Creation of ISACAM}

\subsection{Introduction}

The ISANN was developed extensively based on literature analysis and logical reasoning. The key concepts and relationships identified in the ISANN have been evaluated through illustrative scenarios and descriptive analysis in Chapter 2 and 3. With rationally selected design methods discussed in Chapter 4, we are now ready to use the ISANN as a conceptual framework to create the initial version of ISACAM (version 1.0) - an analytical method for systematically investigating and solving IS Agility problems. Next, through applying the ISACAM on real-world problems, we are enabled to explore new elements and factors necessitated from the environment, but not discovered in the original knowledge base. Iterative applications of the ISACAM helped us identifying what other new data features should be considered, quantitatively or qualitatively, besides those already described in the ISANN. In other words, the evolution of ISACAM is a process of absorbing new knowledge from the research environment. Such knowledge is then presented in the form of a more complete structure of the ISACAM - from the early version 1.0 to the latest version 2.0 .

\subsection{The Evolution of ISACAM}

As discussed in Section 4.5.2, we have developed two types of operational level models based on the ISANN. These include a series of data models and task models which were constructed using Dimensional Modelling and Hierarchical Task Analysis methods. The data and task models are the integral parts of ISACAM and were developed with an intention to enable future development of software instantiations. 
As illustrated in Section 4.5.1, the real-world setting used to design and evaluate the ISACAM, or the DSR "environment" according to (Alan R. Hevner et al., 2004), is consist of a SaaS platform, a SaaS provider and a group of adopters. The ISACAM evolves through iteratively being applied to analyse and solve real-world problems raised by those SaaS adopters. Those problems were particularly driven by the need for IS Agility in IS-supported operations. Through the applications on real-world problems, the ISACAM has been able to evolve significantly and absorb new features for effective problem analysis and solution design.

\subsubsection{The DSR Environment}

The DSR environment essentially is the ecosystem of a cloud-based SaaS provider (hereafter called The NOHARM Cloud). The NOHARM Cloud is a professional service firm specialised in safety risk management and has been one of the leading service providers in New Zealand for years. The SaaS solution provided by The NOHARM Cloud is a highly modularised software information system built upon a multitenant architecture. The IS (hereafter called NOHARM) has been evolving over a decade with incremental changes in functionalities and steady increase of the client base. After years of client-driven development, NOHARM has now expanded to a much larger system containing ten major modules, hundreds of explicit or implicit subsystems, over 2,000 web pages and scripts, and over 200 database tables.

By 2016, over 80 NZ based medium and large sized organisations have subscribed to the NOHARM service and been actively using the system to manage their operational safety risks, hazards and incidents etc. These organisations are demographically diverse, some are as large as having over ten thousand employees, while others are smaller entities with hundreds of staff members. Many of these organisations are NZ's iconic businesses operating in high-risk industries such as oil \& gas, forestry, transportation, construction, dairy \& farming, etc. These organisations use NOHARM to carry out activities including reporting incidents, 
conducting investigations, identifying hazards, assessing/controlling risks, analysing root causes, planning/tracking corrective actions, implementing audit programs, and so on.

Safety management was traditionally seen as a compliance-oriented practice relying heavily on the obedience to organisational policies and procedures. However, compliance-focused approaches are proven to be, at best, maintaining the status quo, instead of continuously improving safety performance. Modern businesses are operating in fast changing environments where continual improvement becomes essential. Today, many new safety programs are developed based on risk management frameworks (e.g. ISO 31000) with which organisations identify, assess, treat, and control safety risks through continuous reflections and adjustments on reactive measures such as incidents and near misses, as well as on proactive measures such as risks controls, audits, and safety plans.

Safety risk management has always been an important topic. In New Zealand, this topic has recently become far more critical than ever to businesses. In the wake of Pike River disaster (Pike_River_Royal_Commission, 2010), New Zealand government has determined to transform safety management practice in this country. WorkSafe New Zealand, a new government agency, acting as a workplace health and safety regulator, has been launched on 16 th December 2013 (WorkSafe, 2013). New legislation changes (e.g. WorkSafe New Zealand Act 201314) have been proposed and debated thoroughly in the public eye. Resultantly, the new Health and Safety (H\&S) at Work Act finally came into effect in April 2016. As part of the government's overhaul of NZ's occupational H\&S framework.

The Act introduces a range of new due diligence obligations specifically on Officers (termed as PCBU - The Person Conducting a Business or Undertaking). These

\footnotetext{
${ }^{14} \mathrm{http}: / /$ www.legislation.govt.nz/act/public/2013/0094/latest/DLM5302019.html?src=qs
} 
obligations explicitly require the PCBU to understand operations and their associated risks; to ensure the organisation has established processes to receive and respond to information regarding incidents, hazards, and risks; and to provide appropriate resources and practical steps for incident prevention. Failed to do so, in the face of incidents, can result in harsh penalties including hefty fines and years of imprisonment (Worksafe, 2015).

Such a drastic regulation change and associated serious penalties have driven New Zealand organisations to change their behaviours significantly and rapidly. CEOs and boards of directors are now legally accountable for actively managing safety related risks (in the past these were mostly dealt with by H\&S managers and advisors) thus are in need to make their organisations sensitive and responsive to workplace safety risks. Agility suddenly becomes a popular concept to safety risk management. To be more agile and legally responsible in the safety space, specialised information systems are deemed to be essential (Department of Labour, 2011). As recommended by ACC (Accident Compensation Corporation), to implement a safe workplace, organisations need to establish information systems that can ensure "employees are informed about and understand the risks of hazards with which they work" (ACC, 2016) (pp.38).

All the aforementioned changes have made safety risk management IS a great context to apply the ISACAM and study IS Agility problems. Such systems were often designed without agility in mind originally but now are expected to deliver it to users. The NOHARM ecosystem, is an ideal test bed for ISACAM. With its multitenancy nature, NOHARM offers a diverse sample set of user groups faced by various IS Agility problems. Users from different client organisations often try to develop their own solutions to solve these problems using their knowledge and experiences in the H\&S work domain. However, often their solutions are limited by their mental models grounded in their specific subjects. Such limitations pose a 
severe challenge when users are attempting to leverage the IS to sense and respond to safety risks effectively and efficiently.

The situation that NOHARM users are facing is another proof of the Dev Agility vs. Ops Agility dichotomy. The NOHARM development team, has been practising agile methods for many years. Following the Scrum methodology, the team has managed to reach the 150th Sprint in Q1 of 2016. The team in general has been responsive to system changes requested by client users with a discipline of executing biweekly Sprints and releasing new features monthly. However, as discussed in previous chapters, agility in system development process differs from agility in the resulting system. The former doesn't necessarily lead to the latter (Haberfellner and Weck, 2005). Given the intrinsic limitations of their work domain, the changes or solutions requested by client users are often not effective in altering the behaviours of the system and of themselves to work together seamlessly to sense and respond to safety risks. According to NOHARM users, although the NOHARM development team, as the SaaS provider, is agile in responding to their requests for system changes, they still, from time to time, find themselves not handling safety related tasks in a timely manner. For instance, users may misuse the NOHARM system by inappropriately configuring key parameters and classifying information. They may see themselves receiving too much data, or too little, meaning they become cognitively overloaded, or underloaded, either way, they cannot efficiently derive actionable information, which then leads to uncertainty with the situation and delay in decisions and responses.

In a nutshell, the NOHARM system and its client base, represent a fertile test bed for applying the ISACAM and assessing results against conventional wisdom. Given the legislation changes happening in New Zealand's workplace safety, organisations are becoming increasingly intolerant to delay and inaccuracy in safety data and information processing. They are now requesting more agility in there is to support the sudden change in risk appetite. Safety risk management systems, such as 
NOHARM, are now facing the challenge and demanded to empower users to sense and respond to safety risks effectively and efficiently.

In the following sections, the application, evolution, and evaluation of ISACAM is reported in the form of three episodes. These episodes are all derived from representative cases based on the real-world problems faced by NOHARM clients. They are presented and elaborated to demonstrate the effectiveness of ISACAM, the rationale of its evolution, and the limitations imposed by client users own work domains.

\subsubsection{Episode One - A "Sensing" Problem}

\subsubsection{The Problem and Context}

Episode One was derived from a problem-solving case for a major forestry and manufacturing company (hereafter named the E1 Company) who is an active client with over five thousand users accessing NOHARM on a regular basis. Episode One was chosen to be reported in this thesis for two reasons: firstly, it represents a typical IS Agility problem where the SDSE cycle of the agent had lost Synchronicity due to the lack of "sensing" ability which in turn caused insufficient data flowing towards the agent (in this episode, H\&S managers and advisors at the E1 Company) and resulted in indecision and inaction; secondly, this episode enabled us to reflect and evolve ISACAM to the next level (from version 1.0 to 1.1) with the inclusion of new elements (e.g. Torque Booster and Friction Reducer as two key solution types for increasing IS Agility which will be discussed in the following sections).

The E1 Company had long been experiencing unacceptably low "Near Miss" reporting rate. In an average month, the whole organisation could only gather 30 to 40 Near Miss data points. Such a number is far too low for a large organisation like E1 Company with a dozen of major reporting lines and each has hundreds of employees. 
Near Misses, or Close Calls, are terms used in safety management practice to describe "unplanned events occurred that did not result in injury, illness or damage, but had the potential to do so"15. History has suggested that many serious and catastrophic incidents were preceded by warnings and Near Miss events.

The absence of negative impact has made gathering Near Miss data points a challenging task to organisations. With incidents, workers cannot avoid reporting due to the actual consequences associated, e.g. injured persons, damaged properties. But Near Misses don't cause any real harm thus people can turn a blind eye and don't bother telling anyone.

To H\&S managers, Near Misses are valuable data points where organisations can learn from "narrowly escaped" events without paying the penalty - as there was no harm done. Trends and patterns may be found proactively through analysing Near Miss data at the early stage before risks manifest in the form of loss-producing incidents. In short, quality Near Miss data is critical to proactive incident prevention. Near Misses, especially those with high potential consequences, should be collected and analysed in a timely manner to identify weakness of the existing operational processes and safety programs for continual improvements.

Without sufficient Near Miss data points, the E1 Company could not determine if their safety program was truly effective. They had to rely on actual injury incidents to gain insights which often come with a high price and painful penalty (i.e. loss of production time, damage of assets, fines, legal cost, etc.). On the other hand, when there was a low injury rate for a period, the company could not tell if it was just pure luck or a major injury was about to occur.

15 Source: Fact sheet from OSHA and the National Safety Council -

http://www.nsc.org/WorkplaceTrainingDocuments/Near-Miss-Reporting-Systems.pdf 
Not only the absolute number of reported Near Misses matters, in fact the ratio between Near Misses and Minor Injuries (injuries require only first aid or simple medical treatment but no days off from work) is considered more important to injury prevention. For instance, the Heinrich's Safety Triangle, adopted by some safety practitioners, suggests that naturally for every Minor Injury, there ought to be ten Near Misses. Figure 17 shows an adjusted version of Heinrich's Triangle with a finer breakdown to Serious Injury, Fatality, and Catastrophe.

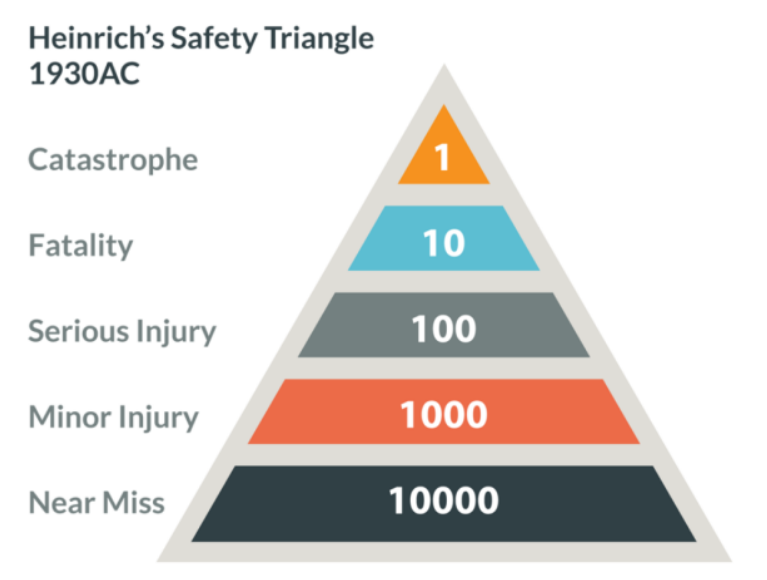

Figure 17: The Heinrich's Safety Triangle

Source: The Creative Works Group ${ }^{16}$

Some organisations may create their own versions of safety triangle adjusting the ratios to either higher or lower, based on the nature of their operations. The E1 Company and many other businesses in the same industry adopted the default 10:1 ratio to gauge the performance of Near Miss reporting. However, prior to 2011, the E1 Company was performing way below expectations using their paper-based

${ }^{16}$ http://creativeworksgroup.com.au/home/heinrichs-triangle-should-be-followed/ 
Incident and Near Miss reporting systems and processes with the ratio between Near Miss and Minor Injury being somewhere between 2:1 to 3:1.

The E1 Company have modernised their safety management systems by adopting NOHARM in early 2011 with the hope to improve the safety data and information flow between frontline workers and management level decision makers. Before the implementation of NOHARM system, reporting Near Misses and Incidents would require frontline workers at the E1 Company to fill out paper forms and hand them in to the managers or safety advisors before their offices during work hours. With the NOHARM, employees now can directly access the web-based IS anywhere with a computer and an Internet connection. They can now fill out electronic forms online anytime they want without the limitation of office hours. Therefore, the E1 Company was expecting a significant increase in Near Miss reporting rate.

After the implementation of NOHARM in early 2011, employees and contractors did seem to report more Near Misses in the system. As shown in Table 20 below, according to data kept in the NOHARM system, from the first quarter of 2011 to the fourth, the number of Near Misses reported increased from 211 to 358. Such an increase was then observed in early 2012 with the number rising up to 513 but then dropping down to 410 . 
Table 20: Near Miss to Minor Injury Ration at E1 Company 2011 Q1 to 2012 Q2

\begin{tabular}{|l|c|c|c|}
\hline Year Quarter & Near Miss Count & Minor Injuries & \multicolumn{2}{|c|}{$\begin{array}{l}\text { NM/Minor Injury } \\
\text { Ratio }\end{array}$} \\
\hline 2011-Q1 & 211 & 55 & 3.8 \\
\hline 2011-Q2 & 140 & 59 & 2.4 \\
\hline 2011-Q3 & 279 & 77 & 3.6 \\
\hline 2011-Q4 & 358 & 99 & 3.6 \\
\hline 2012-Q1 & 513 & 132 & 3.9 \\
\hline 2012-Q2 & 410 & 113 & 3.6 \\
\hline
\end{tabular}

Data Source: The NOHARM System (Visualised in Microsoft SSRS 2014)

Nevertheless, managers at the E1 Company were not satisfied. Because the ratio between Near Misses and Minor Injuries was almost staying the same for six quarters, fluctuating slightly but consistently remaining below 4:1 which is a slight improvement compared to previous years when the old paper-based system was used but still far away from the expected 10:1 ratio. The number of Minor Injuries was increasing almost in proportion to that of Near Misses. This was deemed to be merely a result of the increased number of operations caused by the expansion of business and workforce at the E1 Company, plus the convenience of having the NOHARM system to report everything about safety risks, not just Near Misses.

In short after the implementation of the NOHARM system, frontline workers at the E1 Company did seem to be reporting more Near Misses than they were before. However, what the E1 Company didn't want to see was the proportioned increase of Minor Injuries. This means their safety program and risk management practice were not being improved. A true improvement should result in an increased ratio between Near Misses and Minor Injuries with Near Misses trending upwards while Minor Injuries trending downwards.

The E1 Company felt uneasy to be stuck for six quarters at the below 4:1 ratio. They started to look for means to improve the data collection capability or the "signal 
detection" (a metaphor used by one of the managers) of their safety IS in order to respond to changes in their operational risks in a timely and effective manner.

\subsubsection{The Initial User-Driven Solution and Results}

To solve the problem, the H\&S advisors and managers at the E1 Company analysed the situation and worked out a solution. Their processes of problem analysis and solution design were predominately based on their expertise in the safety risk management work domain and their understandings of the NOHARM system. Such

processes can be effectively summarised in an Abstraction Decomposition Space (ADS) illustrated in Table 21. 
Table 21: ADS Problem Solving of Episode One

\begin{tabular}{|c|c|c|c|c|}
\hline & $\begin{array}{c}\text { System } \\
\text { (Whole SaaS solution } \\
\text { containing multiple } \\
\text { modules) }\end{array}$ & $\begin{array}{c}\text { Unit } \\
\text { (Incident } \\
\text { management } \\
\text { Module) }\end{array}$ & $\begin{array}{l}\text { Component } \\
\text { (Company Near } \\
\text { Miss reporting } \\
\text { process) }\end{array}$ & $\begin{array}{l}\text { Part } \\
\text { (Online forms for } \\
\text { Near Miss } \\
\text { reporting) }\end{array}$ \\
\hline $\begin{array}{l}\text { Purpose \& } \\
\text { Meaning }\end{array}$ & $\begin{array}{l}\text { Improve workplace } \\
\text { safety, reduce } \\
\text { injuries/harms, and } \\
\text { control risks }\end{array}$ & & & \\
\hline $\begin{array}{l}\text { Domain Values } \\
\text { \& Priorities }\end{array}$ & & $\begin{array}{l}\text { Analyse and learn } \\
\text { from Near Misses to } \\
\text { prevent injuries and } \\
\text { incidents }\end{array}$ & & \\
\hline $\begin{array}{l}\text { Domain } \\
\text { Functions }\end{array}$ & & & $\begin{array}{l}\text { Collect Near } \\
\text { Misses data points } \\
\text { as many as } \\
\text { possible for } \\
\text { analysis }\end{array}$ & \\
\hline $\begin{array}{l}\text { Technical } \\
\text { Functions }\end{array}$ & & & & $\begin{array}{l}\text { Frontline workers } \\
\text { to report Near } \\
\text { Misses in a timely } \\
\text { manner }\end{array}$ \\
\hline $\begin{array}{l}\text { Physical Form } \\
\text { (bottleneck lies } \\
\text { at this level) }\end{array}$ & & & & $\begin{array}{l}\text { Internet } \\
\text { connection is not } \\
\text { readily available } \\
\text { but should be } \\
\text { ensured through } \\
\text { mobile devices } \\
\text { with } 3 \mathrm{G} / 4 \mathrm{G} \\
\text { coverage }\end{array}$ \\
\hline
\end{tabular}


After discussions with frontline workers, as well as articulating the purpose, values, and functions of the NOHARM system/components (see in Table 21), the H\&S advisors at the E1 Company concluded, that the key reason for the lack of significant increase in Near Miss reporting rate after implementing a web-based IS was because of the system's dependence on computer and Internet connection (i.e. "Physical form" in Table 21) when submitting online forms (i.e. "Part" in Table 21). To the E1 Company, there seemed to be no problem at the "Domain function" and "Technical function" levels of the NOHARM ecosystem. They deemed the lack of mobile computing device and Internet connection, or in the ADS terminology, the "Physical form", was the key issue.

Frontline workers did not carry computers with them when they were out working in the fields or operating machinery on the factory floor. When a Near Miss event occurred, they would need to remember it, sometimes by jotting it down on a piece of paper if the Near Miss was indeed mentally disturbing, and then went back to the office or home (wherever a computer and Internet connection are available) after finished the day's work and enter the Near Miss data into the NOHARM system.

However, by the time workers finished their work of the day, the vividness of the event could fade away enough that they tended to forget reporting the Near Miss at all. Either it was inattention or tiredness, many would not bother sitting in front of a computer or logging into the system merely to type up the whole story of an event that didn't hurt anyone. In fact, if there were multiple Near Misses happened during the day, much of the details would be lost by the time a worker tries to recall these events.

At the E1 Company, the solution then became straightforward: to issue a mobile device (with 3G/4G technology) to each group of frontline workers so they can record Near Misses into the NOHARM right after the occurrence of such events without having to look around for a computer or wait till the end of a work day. 
Table 22: Near Miss to Minor Injury Ratio at E1 Company 2011 Q1 to 2012 Q4

\begin{tabular}{|c|c|c|c|}
\hline Year Quarter & Near Miss Count & Minor Injuries & $\begin{array}{l}\text { NM/Minor Injury } \\
\text { Ratio }\end{array}$ \\
\hline 2011-Q1 & 211 & 55 & 3.8 \\
\hline 2011-Q2 & 140 & 59 & 2.4 \\
\hline 2011-Q3 & 279 & 77 & 3.6 \\
\hline 2011-Q4 & 358 & 99 & 3.6 \\
\hline 2012-Q1 & 513 & 132 & 3.9 \\
\hline 2012-Q2 & 410 & 113 & 3.6 \\
\hline 2012-Q3 & 796 & 224 & 3.6 \\
\hline 2012-Q4 & 927 & 277 & 3.3 \\
\hline
\end{tabular}

Data Source: The NOHARM System (Visualised in Microsoft SSRS 2014)

\section{Results:}

Within a month, every work group received an Android tablet with 3G connection provided by a leading telecommunication company who has the best coverage across New Zealand. The workers were happy to take their nifty gadgets with them. For the first couple of months, the Near Miss reporting rate had a clear increase with the number went up from 410 to 796. However, as shown in Table 22, three months on, the increase started to fade away. Worse still, the Near Miss to Minor Injury ratio remained at below $4: 1$ and started to show a sign of dropping (i.e. from $3.6: 1$ to $3.3: 1)$.

\subsubsection{Problem Space Analysis based on ISACAM}

Under the pressure of missing opportunities for incident prevention due to inadequate Near Miss data, the E1 Company decided to consult with the NOHARM team, namely the system developer and service provider, for a more effective solution by potentially making changes on the system side. Given my in-depth involvement in both the technological details of the NOHARM system and the common safety risk management frameworks in general, I was requested to help frame the problem and propose potential solutions. 
Instead of following the same work domain-based approaches used by the E1 Company, we examined the problem from an IS Agility standpoint. We used the ISANN as a starting point to construct the problem space. Initially, the ISANN was too conceptual to be applied directly as an analytical method, thus we mapped it into two operational level models (data vs. task) that can systematically guide through the analytical processes as well as to capture relevant data needed for problem investigation. These models then became the fundamental structure of ISACAM.

The initial ISACAM (Ver 1.0) was relatively primitive but it consisted of the key elements of ISANN. The first operational model of ISACAM, see Figure 18, is essentially a data model developed using the Dimensional Modelling method (explained in Chapter 4) to map out the key factors and relationships needed to be captured for analysing and solving IS Agility problems. The second model, see Figure 19, is a task model developed using the Hierarchical Task Analysis method to plan out the main steps needed to go through in order to analyse and solve IS Agility problems. In short, the data model ensures that data essential to IS Agility is collected and documented in a structured and systematic way. The task model articulates a step-by-step instruction to collect data, analyse problems, and design solutions.

After iterations of problem solving applications and evolution of ISACAM, we also developed a set of "technological rules" to guide the judgement and design decisions while using the ISACAM to solve problems. These technological rules are documented at the end of this chapter as they were synthesized at a later stage of the evolution journey of ISACAM. 


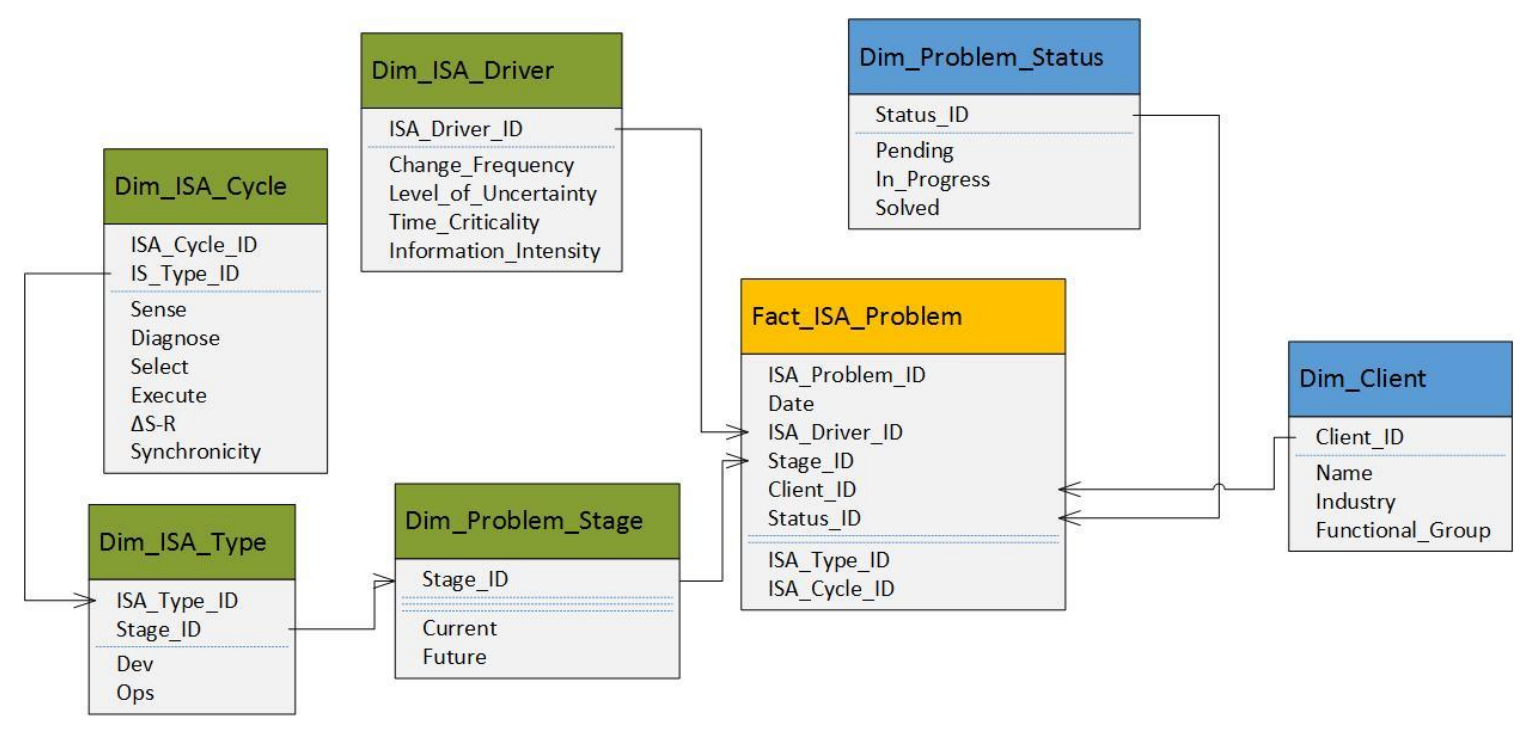

Figure 18: The Initial Data Model of ISACAM Ver 1.0

As shown in Figure 18 above, we developed the data model with two intentions. Firstly, it is to illustrate what data and relationships need to be captured to enable a systematic analysis of IS Agility problem. Secondly, it is to provide a data model design for the future development of a web-based tool to support ISACAM processes. Following the Dimensional Modelling terminology, the orange table represents the "Facts" capturing the essence of IS Agility problems (e.g. date, client, status, etc.). The other tables are all "Dimensions" used to define and classify the "Facts". The green tables are "Dimensions" representing relationships concerned with the key elements of IS Agility (derived from ISANN). They are the elements needed to be explicitly identified and analysed during the investigation of IS Agility problems thus are critical to the construction of the problem space and the creation of solutions. The blue tables, on the other hand, are more focused on the demographical aspects of the IS Agility problems through recording general information such as who encountered problems and when. The "Facts" and "Dimensions" have been expanding along with the progress of my study while new elements, hierarchies, and relationships emerging during my real-world problemsolving exercises. 
Following the data model and task model (see Figure 19 below) defined in ISACAM ver1.0, we first identified E1 Company's problem space as having high "Change Frequency" - Near Misses occurred frequently in E1 Company's high risk industry especially when working in the field falling trees and operating in the sawmill cutting timber.

Next, we identified high level of uncertainty in both spatial and temporal dimensions. Frontline workers didn't know and couldn't anticipate when a Near Miss would occur and didn't know how much time should be spent on reporting Near Misses, thus the temporal uncertainty. When a Near Miss did occur, workers in the work group didn't have a clear direction to follow, hence the spatial uncertainty. Workers had to discuss and decide if the event was worth reporting, who should be logging it in to the NOHARM system, and when. Although the E1 Company had issued a mobile device to individual workgroups, there was no dedicated person in a workgroup looking after the mobile device and to log Near Miss events. Not to mention workers could change workgroup from time to time almost everyone had excuses for forgetting to report Near Misses occurred within one group. 


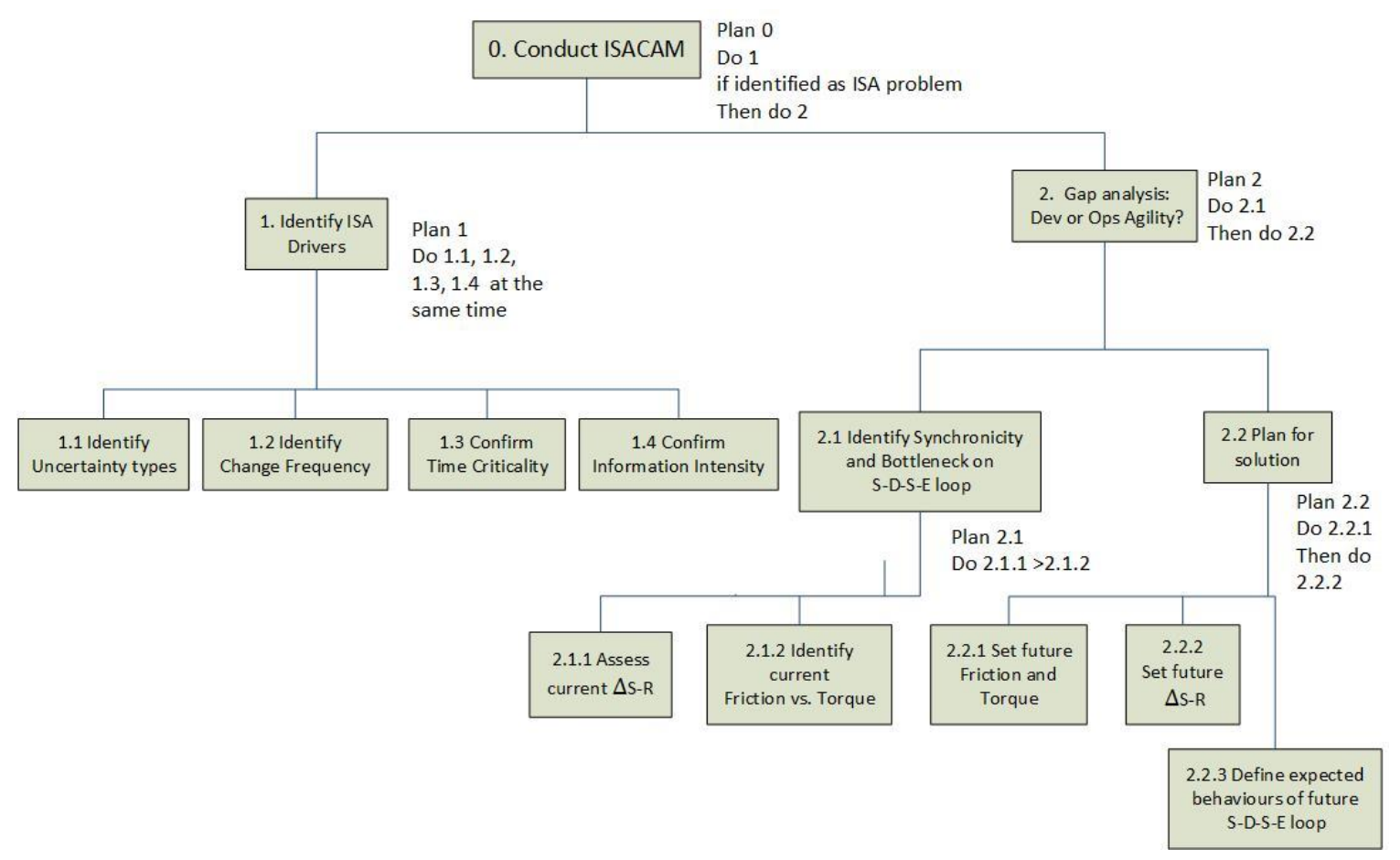

\section{Figure 19: The Task Model of ISACAM Ver 1.0}

Time Criticality was rated high as timely data was needed to suggest issues in business operation and improvements in the safety program. The earlier issues can be discovered, the more effective prevention will become. Information Intensity was considered high as the E1 Company can now accumulate some 300 Near Miss records in NOHARM in an average month. But the E1 Company was expecting to increase the Near Miss to Minor Injury ratio to three times more.

Next, we identified the problem was mostly on the Ops Agility side instead of the Dev Agility cycle. We clarified that the issue was not about how sensitive and responsive our IS development team was, but more about the operations of users. System users were not sensitive and responsive to signals in their environment. Qw saw the inadequate Near Miss reporting as a hindered "sensing" capability which then caused the suffering of those subsequent "diagnose" "select" and "execute" phases of the Ops Agility cycle of the H\&S managers and advisors at the E1 Company. 
We requested the E1 Company to set the expected $\Delta S-R$ value in terms of their regular data analysis, decision making, and action taking processes (together with the Near Miss reporting these steps manifested a typical Ops Agility cycle) on Near Miss events. The $\Delta S-R$ needed to be clearly defined instead of vaguely described as "ASAP" or "as soon as you can". The expected $\Delta S$ - $R$ for sensing and responding to Near Misses at the management level was then decided to be five work days, meaning weekly.

At the end of 2012, H\&S advisers and managers at the E1 Company were still unable to go through the "sense and respond" cycle on a weekly basis because in some weeks there were just no sufficient Near Miss data points to diagnose and respond to. For instance, in the fourth quarter of 2012, although a historically highest number, 927 Near Misses were reported in NOHARM, once breaking down the number into 13 weeks and then into the 12 main reporting lines, on average a reporting line will have less than 6 Near Misses for the line managers and safety advisors to review. The $\Delta S-R$ in practice was actually a month. Only after a month of accumulation, the E1 Company could then perform a more meaningful analysis of Near Miss data at the individual reporting line level${ }^{17}$. A month is considered too long of a "sense and respond" cycle at the E1 Company. Not to mention the number of Minor Injuries had gone up to 277, a historically highest number.

${ }^{17}$ Analysing Near Miss data at the individual reporting line level is critical as the E1 Company has multiple lines of business operations with each faced by different sets of risks. For instance, risks identified from Near Misses reported in a logging site will not necessarily be relevant to operations in a timber-treatment factory, yet both are the core businesses of the E1 Company. 
Low Synchronicity

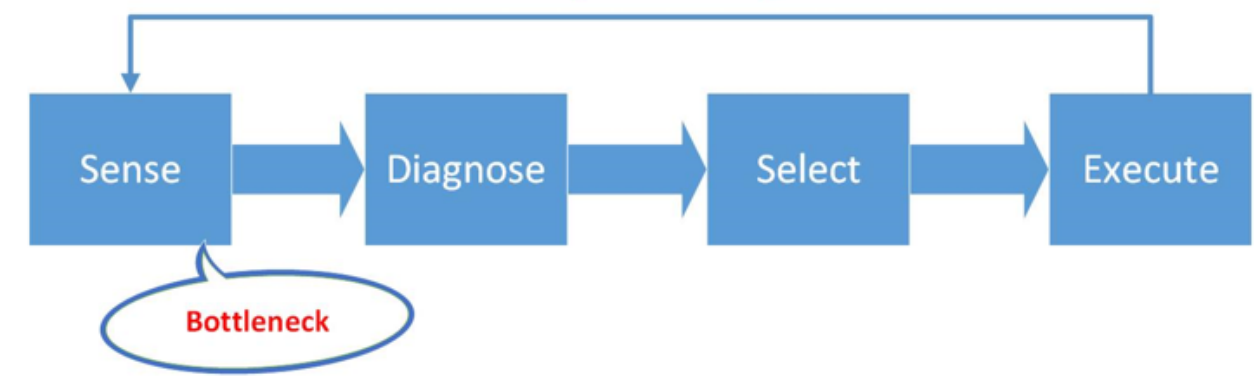

\begin{tabular}{|c|c|c|c|c|}
\hline $\begin{array}{l}\text { Tasks } \\
\text { and } \\
\text { Outcomes }\end{array}$ & $\begin{array}{l}\text { Collecting sufficient Near } \\
\text { Miss data points }\end{array}$ & $\begin{array}{l}\text { Identifying patterns and } \\
\text { trends, gaining insights } \\
\text { into the effectiveness of } \\
\text { risk controls }\end{array}$ & $\begin{array}{l}\text { Deciding new or } \\
\text { adjusted risk control } \\
\text { measures }\end{array}$ & $\begin{array}{l}\text { Implementing } \\
\text { upgraded risk control } \\
\text { measures }\end{array}$ \\
\hline $\begin{array}{l}\text { Functional } \\
\text { Group } \\
\text { (User Roles) }\end{array}$ & Frontline Workers & $\begin{array}{l}\text { Safety Advisors and } \\
\text { Analysts }\end{array}$ & $\begin{array}{l}\text { Safety Advisors and Line } \\
\text { Managers }\end{array}$ & $\begin{array}{l}\text { Line managers and } \\
\text { Frontline workers }\end{array}$ \\
\hline
\end{tabular}

Figure 20: The SDSE Mapping Table for Episode One

As shown in Figure 20, the "sensing" part of the Ops Agility cycle was highlighted as the main bottleneck slowing down the whole "sense and respond" cycle. The H\&S advisors and managers at the E1 Company could efficiently and effectively process the Near Miss data sensed but they had to wait four times longer than expected for more signals being collected in order to make insightful diagnosis and confident decisions. Consequently, new corrective actions would have to be delayed further which could leave too much room for recurrence of safety events.

\subsubsection{The Final ISACAM-Driven Solution and Results}

Following the ISACAM terminology, the "Current Friction" was found to be high in the Ops Agility Cycle. This was mostly from workers' concerns regarding distraction, loss of production time, and delay in work progress caused by having to report Near 
Misses on a worksite using mobile devices. An average worker would have to spend 15 to 20 minutes on the mobile device to record a Near Miss as the form contains some 20 textboxes and dropdown lists to be filled out.

To solve this problem, we needed to introduce "Friction Reducers" to eliminate or minimise the concerns of frontline workers. This could be done either through human procedural changes by formally setting aside some time a day for each workgroup to operate the NOHARM on their mobile devices, or via system functional changes by making the Near Miss reporting form in the NOHARM system intelligent enough to automatically populate some of the form elements (e.g. location, reporting line, date, owner, etc.). The E1 Company accepted both approaches.

We then identified the "Current Torque" was low and there was a lack of recognition for workers who reported Near Misses. There was especially little motivation for a worker to report Near Misses caused by a team mate. Near Misses were seen by some workers as "mistakes" made by individuals thus exposing them to managers may cause conflicts or resentment from co-workers. In short, reporting Near Miss was still considered by many a "favour" to the organisation's management team with no direct benefit to the frontline workers.

To solve this problem, we decided to create "Torque Boosters" to change the image of Near Miss reporting inside the E1 Company. This could be done by proactively promoting a "no blame" policy so those who caused and reported Near Misses were not to be ashamed, and/or by recognising those who actively reporting Near Misses with non-monetary incentives. The E1 Company agreed to implement both approaches.

To help identifying who were the most active "Near Miss reporters", we created new data queries and visualisations using Microsoft SQL Server Reporting Service (SSRS) for the E1 Company to rank the top 20 individuals who have reported most Near 
Misses on monthly and year-to-date bases. Names appearing on this list can be seen by all users (including workers and managers) after logging into the NOHARM and were also praised in a monthly safety newsletter inside the E1 Company.

Finally, to maximise the results, I proposed to let the frontline workers gain more "temporal confidence" and "spatial confidence". As mentioned earlier, the E1 Company agreed to establish a fixed time (up to one hour a day for each workgroup) for Near Miss discussion and reporting which could reduce the temporal uncertainty effectively. The spatial uncertainty, could be controlled by explicitly assigning one person to dedicate that one hour for operating NOHARM on the mobile device and collecting data from other co-workers inside the his/her workgroup (Note: the person operating NOHARM is not necessarily the one who spotted/reported a Near Miss).

\section{Results}

In early 2013, the E1 Company started implementing the agreed procedural changes, i.e. the aforementioned "Torque Boosters" and "Friction Reducers". The bottleneck at the "sense" phase started to be resolved. The safety advisors began to receive much more Near Miss data which enabled them to perform meaningful diagnosis more frequently. Their Ops Agility cycle started to run with a higher level of Synchronicity.

As shown in Table 23, according to data kept in the NOHARM system, by the end of the first quarter, the number of Near Misses reported in NOHARM raised from 927 to 1,388 , with Minor Injuries remaining almost the same level to the previous quarter from 277 to 279 . Such a change made a noticeable difference in the ratio between Near Misses and Minor Injuries which now raised, for the first time in many years, from the stubborn "below 4:1" to the new historical record 5:1. 
In the following two quarters, the E1 Company experienced a dramatic change in their "Near Miss vs. Minor Injury" performance. The Near Misses reported kept climbing from 1,388, to 2,026, then to 2,319. In the meantime, the Minor Injuries started to drop from 279 to 215 , then to 213. Such a drastic change resulted in an accelerated increase of the "Near Miss vs. Minor Injury" ratio which raised from 5:1 to $9.4: 1$, then 10.9:1.

Such a fast and significant change in safety performance was beyond the expectation of the H\&S managers and advisors at the E1 Company. They were able to review and amend their existing risk control measures and safety processes on a weekly basis based on the data collected. They acknowledged those top "Near Miss Reporters" formally according to the visualised "ranking report" we developed. In the next two quarters, both Near Misses and Minor Injuries started to drop after the new risk control measures and safety plans being implemented. The Near Miss to Minor Injury ratio remained at above 10:1 which is in alignment with the Heinrich's Safety Triangle discussed previously. 
Table 23: Near Miss to Minor Injury Ratio at E1 Company 2011 Q1 to 2014 Q1

\begin{tabular}{|c|c|c|c|}
\hline Year Quarter & Near Miss Count & Minor Injuries & $\begin{array}{l}\text { NM/Minor Injury } \\
\text { Ratio }\end{array}$ \\
\hline 2011-Q1 & 211 & 55 & \begin{tabular}{|l|l|} 
& 3.8
\end{tabular} \\
\hline 2011-Q2 & 140 & 59 & 2.4 \\
\hline 2011-Q3 & 279 & 77 & 3.6 \\
\hline 2011-Q4 & 358 & 99 & 3.6 \\
\hline 2012-Q1 & 513 & 132 & 3.9 \\
\hline 2012-Q2 & 410 & 113 & 3.6 \\
\hline 2012-Q3 & 796 & 224 & 3.6 \\
\hline 2012-Q4 & 927 & 277 & 3.3 \\
\hline 2013-Q1 & 1388 & 279 & 5.0 \\
\hline 2013-Q2 & 2026 & 215 & 9.4 \\
\hline 2013-Q3 & 2319 & 213 & 10.9 \\
\hline 2013-Q4 & 1710 & 168 & 10.2 \\
\hline 2014-Q1 & 1814 & 172 & 10.5 \\
\hline Total & 12891 & 2083 & \\
\hline
\end{tabular}

Data Source: The NOHARM System (Visualised in Microsoft SSRS 2014)

\subsubsection{Episode Summary and Reflection in Action}

Table 24 below summarises the key points of Episode One. Such a table has been used as a record keeping tool to document the key findings, solutions, and results of each problem-solving practice using ISACAM. Of course, the layout of this table has been evolving along with the upgrading journey of ISACAM itself.

Table 24: A Brief Summary of Episode One

\begin{tabular}{|c|c|}
\hline Functional Gro & Ip: Frontline workers - from the E1 Company \\
\hline Episode One - & nacceptable Near Miss reporting rate \\
\hline The original so & ution - summarised in Abstraction Decomposition Space(par \\
\hline $\begin{array}{l}\text { System } \\
\text { Purpose } \\
\end{array}$ & Improve workplace safety, reduce injuries, and control risks \\
\hline Domain Values & $\begin{array}{l}\text { Analyse and learn from Near Misses to prevent injuries and } \\
\text { incidents }\end{array}$ \\
\hline$\frac{\text { Domain }}{\text { Functions }}$ & $\begin{array}{l}\text { Sense changes in risk profile through timely Near Miss data } \\
\text { collection - sufficient data points are needed for further }\end{array}$ \\
\hline
\end{tabular}




\begin{tabular}{|c|c|}
\hline & diagnose \\
\hline$\frac{\text { Technical }}{\text { Functions }}$ & $\begin{array}{l}\text { Frontline workers to report Near Misses through a web- } \\
\text { based IS in a timely manner }\end{array}$ \\
\hline $\begin{array}{l}\text { Physical } \\
\text { Resources \& } \\
\text { Material } \\
\text { Configuration }\end{array}$ & $\begin{array}{l}\text { Initial User Driven Solution: Each workgroup received a } \\
3 \mathrm{G} / 4 \mathrm{G} \text { tablet with reliable Internet connection for accessing } \\
\text { the information system to logging Near Miss events. }\end{array}$ \\
\hline Results & $\begin{array}{l}\text { The following two quarters had seen noticeable increase in } \\
\text { the absolute number of Near Misses being reported. } \\
\text { However the Near Miss to Minor Injury ratio remained } \\
\text { below } 4: 1 \text { and was trending downwards. }\end{array}$ \\
\hline \multicolumn{2}{|c|}{ ISACAM (V1.0) based Problem Space Analysis } \\
\hline \multicolumn{2}{|c|}{$\begin{array}{l}\text { Change Frequency: High Uncertainty: High Information Intensity: High } \\
\text { Time Criticality: High } \\
\text { Problem lies on Ops Agility Cycle: Yes Dev Agility Cycle: No } \\
\Delta \text { S-R: Currently a month, expected to be a week }\end{array}$} \\
\hline Symptoms & $\begin{array}{l}\text { Near Miss events were being under reported thus } \\
\text { insufficient data for managers and advisors to diagnose and } \\
\text { decide changes in risk control measures in a timely manner. } \\
\text { Near Miss to Minor Injury ratio was as low as below } 4: 1 \text { but } \\
\text { expected to be } 10: 1 \text {. }\end{array}$ \\
\hline$\underline{\text { Root Causes }}$ & $\begin{array}{l}\text { Frontline workers were concerned by the productive time } \\
\text { lost on operating mobile devices as well as by potential } \\
\text { conflicts involved when reporting Near Misses caused by } \\
\text { co-workers. Uncertainty played a key role as workers didn't } \\
\text { know how much time they should spend on reporting Near } \\
\text { Misses using mobile devices, and who in the workgroup } \\
\text { should do it. }\end{array}$ \\
\hline \multicolumn{2}{|c|}{ ISACAM based Solution Design } \\
\hline$\frac{\text { Torque }}{\text { Booster }}$ & $\begin{array}{l}\text { To establish "spatial confidence" by promoting Near Miss } \\
\text { reporting as a lead indicator. To develop visualised } \\
\text { analytics for identifying and praising top Near Miss } \\
\text { reporters. To nominate a worker in each group to operate } \\
\text { the mobile device on a daily basis. }\end{array}$ \\
\hline
\end{tabular}




\begin{tabular}{|l|l|l|}
\hline$\underline{\text { Friction }}$ & $\begin{array}{l}\text { To establish "temporal confidence" by allowing one hour a } \\
\text { day for each group to operate the mobile device to access } \\
\text { the IS. To implement intelligent online forms to save time } \\
\text { needed for reporting Near Misses by automatically filing out } \\
\text { data fields that can be derived from user's login details. }\end{array}$ & $\begin{array}{l}\text { The following three quarters had seen a dramatic increase } \\
\text { in both the absolute number of Near Misses being reported } \\
\text { as well as its ratio to Minor Injuries. Such ratio reached over } \\
10: 1 \text { at the end of the third quarter which was beyond } \\
\text { expectation. Near Miss data analysis could be done weekly } \\
\text { instead of monthly. }\end{array}$ \\
\hline $\begin{array}{l}\text { Results } \\
\text { Evolution of ISACAM }\end{array}$ & $\begin{array}{l}\text { Uimension for solution design. } \\
\text { for problem analysis as well as solution design. }\end{array}$ \\
\hline
\end{tabular}

The outcome of Episode One improved the "sensing" capability of the Ops Agility cycle at the E1 Company with regard to detecting Near Miss "signals". Such agility cycle is crucial to safety managers and advisors who need to make effective responses to changes in their safety risk profile. When under time pressure, poor sensing performance demonstrated by the frontline workers can doom the efforts on the subsequence diagnose, select, and execute activities which are the primary responsibilities of the safety managers and advisors at the E1 Company.

The "sensors" in this episode were essentially human agents. To improve the "sensing" performance of the frontline workers, purely adding more technologies or devices into the equation was not enough. The bottlenecks identified were sitting more on the human side, whereas issues with systems and technologies were more of an excuse. Once the E1 Company provided more certainty to the workforce by formally setting time aside for Near Miss reporting, dedicating human resource, and recognising high performers, Near Misses reporting rates went up dramatically. 
On reflection, the system side improvements were also effective. New features such as shortening the time needed for reporting a Near Miss by introducing better intelligence into the data entry form and providing real-time visualised analytics for managers and workers to recognise top Near Miss reporters were well received by the E1 Company. However, my understanding is that if the company did not make changes on the human side, these improvements on the system side alone probably would not succeed.

Furthermore, Episode One helped me to further develop ISACAM by introducing two additional dimensions: "Uncertainty Type" and "Solution Type" into the later version 1.1. The "uncertainty" dimensions revealed its importance for identifying root causes on the human side, that is, frontline workers were uncertain on both "spatial" and "temporal" dimensions thus they tend to put off Near Miss reporting. The articulation of uncertainty dimensions also played a role when designing effective solutions. The E1 Company was able to explicitly improve workers' confidence on both dimensions which in turn drastically changed their Near Miss reporting behaviour.

The dichotomy of "Friction Reducer" vs. "Torque Booster" offered a great clarity to the solution design. I could explicitly examine what would drive forward the Ops Agility cycle and what would slow it down. By applying improvements on both dimensions optimal results were experienced. Therefore a "Solution Type" dimension has been formally introduced to the ISACAM models as an additional dimension dedicated for designing solutions to solve IS Agility problems. 


\subsubsection{Episode Two - A "Diagnosing" Problem}

\subsubsection{The Problem and Context}

Episode Two was based on another problem-solving case for a major energy company (hereafter named the E2 Company) who has almost two thousands of users accessing NOHARM on a regular basis. Episode Two was chosen for two reasons: firstly, it represents a typical IS Agility problem with which the agent had lost Synchronicity in its SDSE cycle due to the lack of "diagnosing" ability. This in turn led to unresponsive or even paralysed agent (in this episode, safety managers and advisors at the E2 Company) which then resulted in chronically delayed decisions and actions; secondly, this episode allowed me to reflect and evolve ISACAM to a fuller version (from version 1.1 to 1.2 ) with the inclusion of new elements (e.g. Human vs. Machine as two main Control Types for solution design which will be discussed in the following sections).

The E2 Company is one of the main fuel providers in New Zealand with storage tanks, retail sites, and logistic network all over the nation. The environmental and safety risks posed by the nature of operation in this industry, i.e. storing and distributing inflammable and explosive substance, are considerably high and require significant efforts to control. Since 2011, the E2 Company has been actively using the NOHARM system to support its safety risk management practice with the intention of leveraging technologies to gain agility in operations, e.g. making effective and timely responses to safety events (i.e. Incidents occurred, Hazards identified, Near Misses observed) through initiating appropriate investigations and issuing corrective actions.

The adoption of NOHARM has clearly improved the "sensing" ability of the E2 Company which resulted in a steady and significant increase in the number of safety events being reported and recorded. As shown in Table 25 below, according to data stored in the NOHARM system, in 2012 alone, 2,610 records were entered in the NOHARM system, climbing from 510 in Q1 to 851 in Q4. In 2013 the number was 
then almost doubled at 5,040. Although many of the safety events didn't result in severe consequences, they can provide valuable data points for generating insights into the effectiveness of safety management program and operational risk controls. The E2 Company was pleased to be able to collect data of higher volume and better quality.

Table 25: Number of Safety Events reported between 2012 Q1 and 2014 Q3

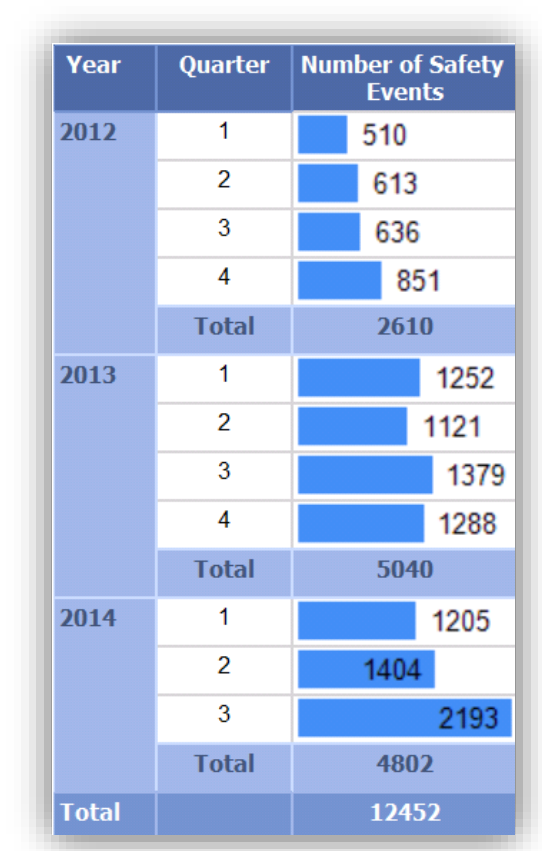

Data Source: The NOHARM System (Visualised in Microsoft SSRS 2014)

However, the "diagnosing" ability at the E2 Company, on the other hand, was unable to catch up with the pace of increase in the volume of data. Safety advisors found themselves swamped by event analysis tasks and could barely make timely responses. In safety risk management, a standard practice for diagnosing safety events, is to first classify them into event categories (some are common e.g. Fire/Explosions, Motor vehicle accident, while others are more specific depending on the nature of business e.g. Robberies, Vapour leaks/Emissions to air); next identify the hazard sources that caused the events (e.g. Electricity, Chemicals, 
Ergonomics, Psychological, Structural stability, Temperature etc.); and then assess the level of associated risks by estimating likelihood of recurrence and consequences. Subsequently, the persons processing the information need to decide if further detective work is needed, in the form of full investigation or simple investigation. If an investigation is initiated, the investigator, based on the findings, will issue corrective actions to make changes in either the business operation or the safety management practice.

For each occurrence, the whole "diagnosing" process of analysing a safety event to decide if further investigation is needed may take from as little as 30 minutes to as much as several hours, depending on how much is known about the associated risks and hazard sources, how well the event details are documented, and how efficient and effective the person is while conducting such processes. The NOHARM system has been designed to support the whole process through configurable workflow with which relevant roles will be notified via emails at different stages of the process.

At the E2 Company, for many years prior to the implementation of NOHARM system, the average time needed to analyse a safety event was about two hours. In most of the times, when an event was reported to the safety management office, officers needed to interview the key people involved either through phone call or in person and then document all the details they gathered to make decisions on appropriate investigations.

After the implementation of NOHARM, the average time needed for analysing safety events and deciding investigations has been reduced significantly to merely an hour. As people who report safety events now can write up detailed descriptions \& comments, attach documents and photos in NOHARM, safety advisors have found it much easier to make judgements and draw conclusions based on the first hand information directly available to them in the system. 
Although NOHARM has successfully helped the E2 Company to reduce some $50 \%$ of the average time needed for analysing a safety event, safety managers and advisors did not see themselves as responsive as they wanted to be hence were still requesting higher level of agility. They were more concerned with the delay in taking corrective actions after safety events being investigated. As shown in Table 26 , throughout the whole year of 2012, the average days between events being reported in the NOHARM system and corrective actions being issued was about 30 days.

Table 26: The Average Days Taken to Issue Corrective Actions 2012 Q1 to 2013 Q2

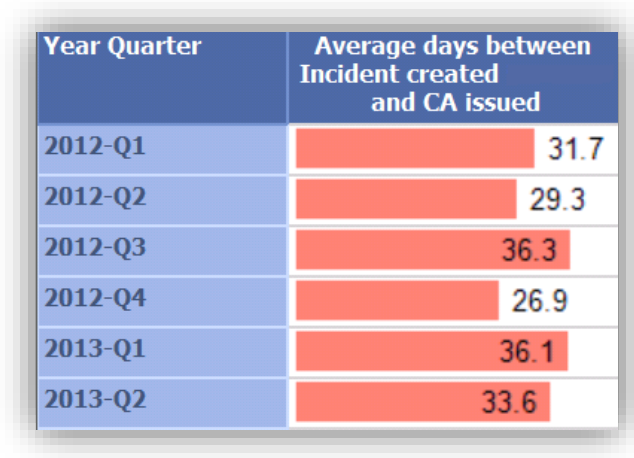

Data Source: The NOHARM System (Visualised in Microsoft SSRS 2014)

Waiting for 30 days to issue corrective actions was unacceptable to the E2 Company and is generally considered a slow response in safety management. The longer the lead time is before new actions are taken to rectify the situation, the more room left for the reoccurrence of safety events with undesirable consequences, and of course, the longer the wait to assess the effectiveness of the corrective actions.

In Q2 2013, the E2 Company conducted a major review on its safety risk management process and gave clear instructions to the safety managers and advisors that they needed to "shorten the cycle" and make the workflow more "agile, simple, and quick". One of the key targets was to reduce the lead time for issuing 
corrective actions from 30 days to 20 days in three months, and then down to 15 days in the following quarter. This way, the E2 Company would have a twice faster operational cycle for sensing, and diagnosing safety events, as well as making proper responses to prevent future occurrence.

\subsubsection{The Initial User-Driven Solution and Results}

At the E2 Company, the original setup in NOHARM, before Q2 2013, was to trigger an email alert for every single safety event occurred and send to one of the two safety advisors based in the head office. Once received an email alert, a safety advisor would log in to the NOHARM system and read the event details following the hyperlink in the email. Depending on the details reported, the safety advisor would decide if it was necessary to contact the key people involved and the line manager for further information. If the event caused no harm and was deemed of low risk, the safety advisor could take a "fast track" to close the event and initiate no investigations meaning no corrective actions were required. Such a fast track, may take anywhere between 20 minutes to an hour. However, if the event caused serious harm and/or was deemed of high risk, the safety advisor would need to interview the key people involved (can easily take several hours or a day) to decide if a fullscale investigation was necessary. A full investigation would take several days (or over a week) and would result in a series of corrective actions to improve the situation by better controlling the operational risks involved. For events falling in between, a shorter form investigation (one day only) would be initiated and corrective actions would also be issued in most of the cases.

As mentioned in the previous section, with the support of NOHARM, the E2 Company has managed to reduce the average diagnosing time of individual safety event from two hours to one hour. However, with such a performance increase, the average days taken to issue corrective actions almost remained the same, that is, 30 days more or less, for six quarters after the implementation of NOHARM. Given the targets set by the E2 Company's management team in Q2 2013, namely, reducing 
the 30-day delay to 20 days and then to 15 days, the safety managers started to review the event diagnosing process used by the safety advisors with an intention to identify the bottlenecks that were causing the delay. They estimated that to achieve the "15 day" target, a safety event must be diagnosed, with investigations issued (if needed) within 5 working days after the occurrence. Back in Q1 2013, it was common to see a safety event only got processed three weeks after it entered the NOHARM system. Yet there was a long queue of events from earlier time waiting to be diagnosed.

Based on their understandings towards safety event diagnosis and the NOHARM system processes, the safety managers identified the bottleneck for the delay was the capacity of the two safety advisors processing safety events. They believed the two safety advisors had done their best to keep up with the drastically increasing number of safety events which raised over 200\% from Q1 2012 to Q1 2013. As at Q1 2013 , for every quarter there were over 1,000 safety events being reported in the NOHARM system and each on average took one hour to process, meaning the two safety advisors had to put in over 75 hours of work every single week merely to go through the events and initiate investigations. This means, to be able to complete event diagnosis within 5 days after they occur was next to impossible. The two safety advisors could not afford working full time on the NOHARM system just for processing safety events. Each of them could only dedicate 15 hours per week on this matter as they both had other commitments and responsibilities (e.g. following up on corrective actions, assessing organisational hazards, producing/reviewing reports, training staff members, visiting high-risk sites, etc.). In total, the two safety advisors could spend 30 hours every week in total on diagnosing safety events which means a "45 hours" gap was left unattended on a weekly basis. Such a discovery effectively explained the 30-day lag in issuing corrective actions and the long queue of historical events not being processed for weeks, if not months. 
Similar to Episode One, the whole processes of problem solving can be briefly summarised in an ADS as a work domain analysis, see Table 27 in the next page.

Table 27: ADS Problem Solving of Episode Two

\begin{tabular}{|c|c|c|c|c|}
\hline & $\begin{array}{c}\text { System } \\
\text { (Whole SaaS } \\
\text { solution containing } \\
\text { multiple modules) }\end{array}$ & $\begin{array}{c}\text { Unit } \\
\text { (Incident } \\
\text { management } \\
\text { Module) }\end{array}$ & $\begin{array}{l}\text { Component } \\
\text { (Company } \\
\text { workflow } \\
\text { configuration) }\end{array}$ & $\begin{array}{c}\text { Part } \\
\text { (Email alerts for } \\
\text { assessment) }\end{array}$ \\
\hline $\begin{array}{l}\text { Purpose \& } \\
\text { Meaning }\end{array}$ & $\begin{array}{l}\text { Improve workplace } \\
\text { safety, reduce } \\
\text { injuries/harms, and } \\
\text { control risks }\end{array}$ & & & \\
\hline $\begin{array}{l}\text { Domain } \\
\text { Values \& } \\
\text { Priorities }\end{array}$ & & $\begin{array}{r}\text { Make prompt and } \\
\text { effective responses } \\
\text { to safety incidents } \\
\text { to prevent future } \\
\text { occurrence }\end{array}$ & & \\
\hline $\begin{array}{l}\text { Domain } \\
\text { Functions }\end{array}$ & & & $\begin{array}{r}\text { Assess safety } \\
\text { incidents to } \\
\text { initiate } \\
\text { investigations } \\
\text { and corrective } \\
\begin{array}{r}\text { actions }\end{array}\end{array}$ & \\
\hline $\begin{array}{l}\text { Technical } \\
\text { Functions } \\
\text { (bottleneck } \\
\text { lies at this } \\
\text { level) }\end{array}$ & & & & $\begin{array}{r}\text { Safety advisors } \\
\text { receive email } \\
\text { notifications for } \\
\text { diagnosing events } \\
\text { but cannot catch } \\
\text { up with the pace }\end{array}$ \\
\hline Physical Form & & & & $\begin{array}{l}\text { Internet } \\
\text { connection,y } \\
\text { Computers, } \\
\text { Phones, Servers } \\
\text { are all readily } \\
\text { accessible }\end{array}$ \\
\hline
\end{tabular}


In short, the E2 Company found no issue with the top layers of abstraction such as purposes, priorities, and domain functions in the work domain setup. The NOHARM was performing well as per its design at the system, unit, and component level of decomposition. Both advisors operating the NOHARM were highly functional and held values and beliefs consistent to the organisation's safety management framework. They had no problem with their physical equipment or devices thus could technically function well in the NOHARM system and any other systems they needed to work on.

However, the only problem, deemed by the E2 Company, was the limited capacity of the safety advisory team. Such a limitation led to the undesirably low throughput the technical function level where tasks had been left unattended on a regular basis. Resultantly, the solution approved at the E2 Company was to bring another full time safety advisor on board to improve the capacity. To fill up the " 45 hours" gap, this new advisor would dedicate all her work hours on the NOHARM system to diagnose safety events in a timely manner, namely, within a week after they occur.

\section{Results}

In Q3 2013, soon after the new safety advisor, Agent B was recruited and trained up to speed with the NOHARM system regarding the processes of diagnosing safety events, the E2 Company started to see a significant increase in event diagnosing speed. The "30-day lag" was reduced to 20.7 days in Q3 2013 for the first time (see Table 28). With the new advisor putting in 40 hours work on diagnosing safety events in the NOHARM system on a weekly basis, the queue of historical events began to shrink.

However, four months after the new safety advisor's appointment, one of the two original advisors, the most senior one (hereafter referred to as Agent $\mathrm{A}$ ), , sent in his resignation and accepted a new job offer from another company. It was said that Agent $\mathrm{A}$, as the virtual leader of the advisory team, had to work extra hours to 
supervise and review the new safety advisor's diagnosis and decisions. He was able to rectify several safety events that did require full investigations yet were assessed by the new advisor as "no investigation needed".

Table 28: The Average Days Taken to Issue Corrective Actions after Safety Incidents - 2012 Q1 to 2013 Q4

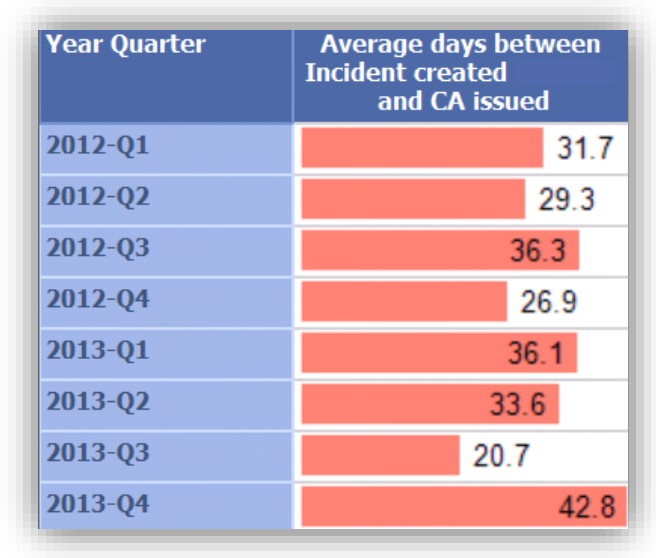

Data Source: The NOHARM System (Visualised in Microsoft SSRS 2014)

The E2 Company wasn't totally unprepared for the departure of Agent A. Another advisor, Agent $\mathrm{C}$ was appointed immediately to minimise disruption to the safety business. Nevertheless, Agent $\mathrm{C}$ wasn't regarded as artful and knowledgeable as Agent A, especially on diagnosing safety events in the NOHARM environment. From time to time, Agent $\mathrm{C}$ was challenged by line managers regarding his decisions on more frequent full-scale investigations and demanding corrective actions. Together with other existing commitments, Agent C couldn't clear up his queue of safety events as fast as expected.

To make the situation more difficult, relationships between the three safety advisors became a bit complicated. Missing Agent A's leadership and seeing Agent C's undesirable performance, the other two advisors were competing to be recognised as the new leading person in the team. All these human factors, compounded with the ongoing increase of safety events reported in the NOHARM system, in Q4 2013, 
the lag in issuing corrective actions had bounced back up to and gone far beyond an acceptable level, that is, 42.8 days (see Table 28), a historically highest point in the last two years after the NOHARM implementation.

\subsubsection{Problem Space Analysis based on ISACAM}

Frustrated by the unpleasing results, the E2 Company decided to seek improvements in the NOHARM system to increase speed and quality of responses to safety events, as well as to reduce dependency on human agents. Such responses, at the E2 Company, had been depending heavily on human factors, e.g. capability and capacity of individual safety advisors, perceived safety justice by line managers, etc. The E2 Company was hoping to enhance its NOHARM implementation at engineering level to reduce influence from human factors and to produce agile responses in a consistent manner.

At the beginning of 2014, The E2 Company approached the NOHARM team for a system-driven solution to make its safety event management process more agile. Given the clear instructions from the E2 Company on increasing agility and "shorten the cycle" and my previous success with addressing IS Agility problems, I had the opportunity to analyse the problem and propose solutions. I used ISACAM (an updated version 1.1 as shown in Figure 21 and Figure 22 below) to construct the problem space and to design NOHARM based solutions for better performance from an IS Agility point of view. 


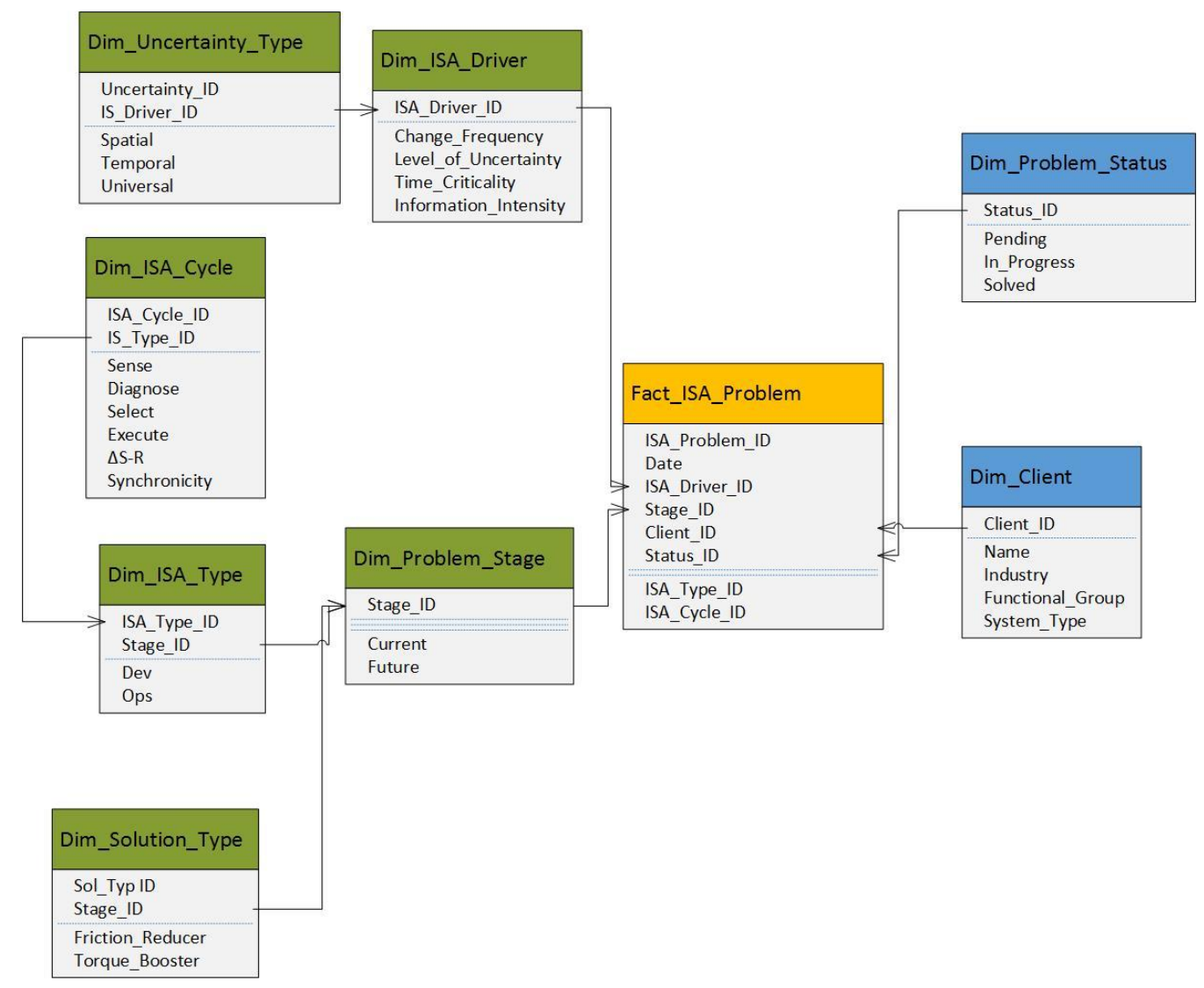

Figure 21: The Data Model of ISACAM Ver 1.1

Equipped with the upgraded data model and task model defined in ISACAM Ver 1.1, we first identified that all four IS Agility drivers had strong presence in the problem space. "Change Frequency" was high as the E2 Company was experiencing hundreds of safety events every month which were expected to alter its course of action in safety risk management. "Information Intensity" was high as the sheer amount of data collected from safety events on a weekly basis had already gone beyond human cognitive processing which had left the three safety advisors overwhelmed on a weekly basis. "Time Criticality" was a significant issue as the main trouble faced by the E2 Company was the inability to produce timely responses (in the form of corrective actions) to the ever-accumulating safety events. In the energy industry that never lacks high risk operations, an overlooked minor safety event could lead to a major blow-up if no effective changes were made in time. 


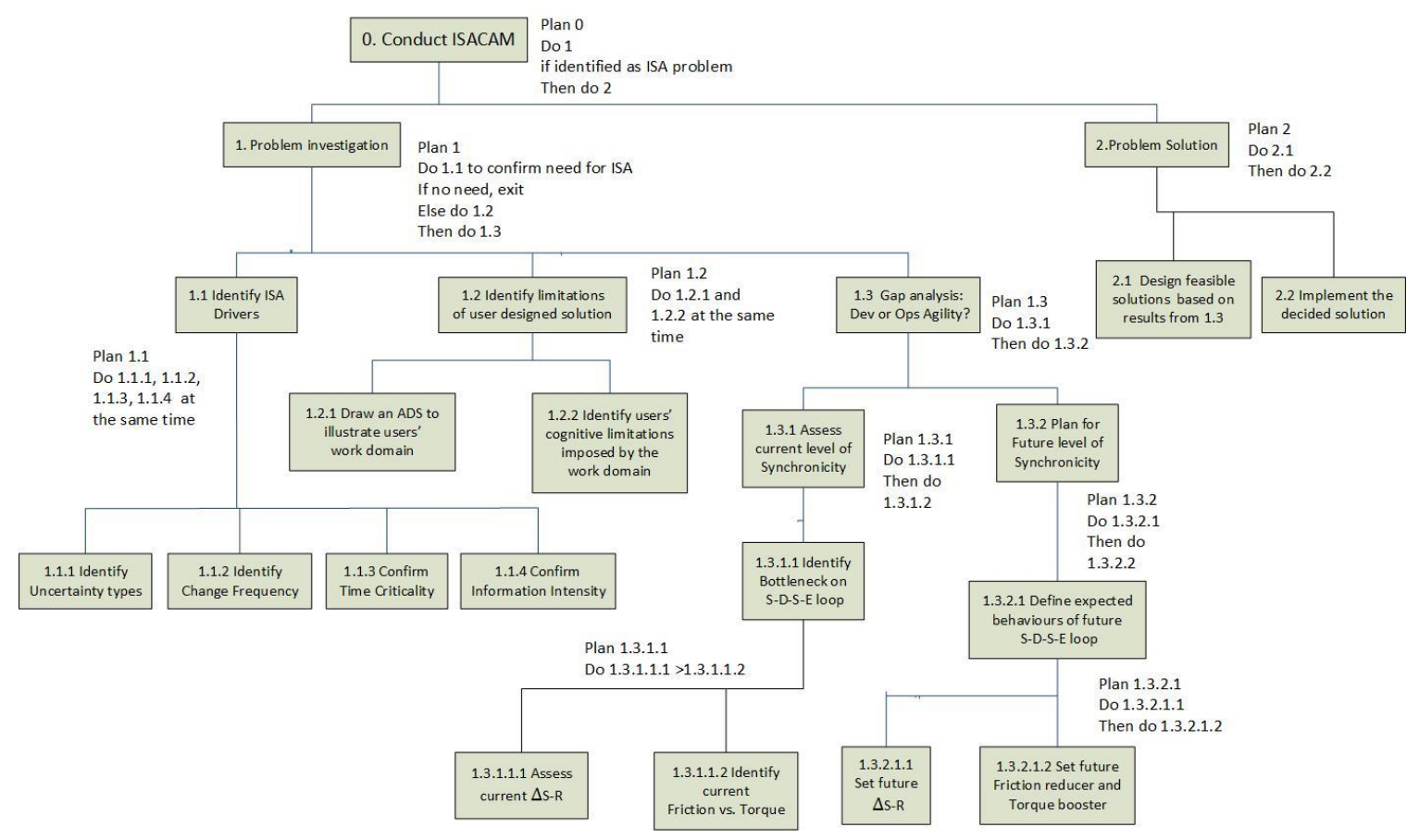

Figure 22: The Task Model of ISACAM Ver 1.1

Following the steps illustrated in Figure 22, we next identified that "uncertainty" was clearly an issue not being managed well thus preventing the agent (in this case, the safety advisors) from generating agile responses. In fact, we recognised that unmanaged uncertainty was more of a problem than the high information intensity in terms of slowing down the cycle of safety event processing.

Temporal uncertainty was apparent as safety advisors couldn't anticipate when a safety event would occur. For every notifiable safety event, the NOHARM system would send an email notification to the advisors as an alert for further diagnosis. Due to the increase in safety events reporting, throughout the year of 2013, in an average week, almost a hundred email notifications would be sent to the safety advisors. The E2 Company didn't set a certain time frame for safety advisors to address those email alerts. Therefore, as a natural practice, whenever it's possible, those advisors would immediately read and click through every single email alert 
right after it arrived in their mailboxes. Such a practice, on the surface, was to ensure every safety event gets attention from the safety advisors as soon as possible. However, the result was far from satisfying as each email alert could cause a considerable interruption and distract a safety advisor from the task he or she was working on. Some a hundred interruptions at random times during an average week on a regular basis could easily break people's concentration and cognitively overload the safety advisory team, which in turn deteriorated their performance and job satisfaction in general (part of the reason for Agent A's resignation).

Spatial uncertainty was apparent and not controlled formally in this problem space. Safety advisors didn't have explicit guideline to follow when diagnosing safety events. They had to interpret and analyse the safety events one by one using their own experience and expertise. No standard or predefined rules for advisors to rely on when deciding if an event will require full investigation, short investigation, or no investigation. Most of the judgements and decisions were based on tacit knowledge communicated among safety team members. Although in many cases when the risks associated with the safety events were obviously insignificant, the process would run relatively smoothly as agreement could be promptly reached between safety advisors, in other cases, especially with medium to high risk events, conflicting opinions often appeared and required much more time to reconcile. Furthermore, without a certain set of rules to decide types of investigations, the decisions of a safety advisor, particularly when suggesting full scale investigations (often require significant effort and resource from the manager in charge) in the reporting lines where safety events occurred, tended to invite challenges from the line managers who considered initiating full investigations a "overkill" given their circumstances (line managers' resistance to Agent C's decisions on full investigations was an example).

Next, we identified that the E2 Company was mostly attempting to improve its Ops Agility cycle in terms of processing and responding to safety events. Dev Agility was 
not a real concern as the E2 Company was focusing on addressing the "information intensity" issue by adding more human safety advisors into the cycle and didn't envisage any system development effort from the NOHARM team. Essentially, speaking the IS Agility language developed in this thesis, the problem faced by the E2 Company was not about how fast and well the IS development team could act upon changing system requirements, rather, it was that the IS users were swamped by the data/information collected and performed poorly at the "diagnosis" stage thus could not cycle through the whole process in a timely manner with acceptable quality.

\section{Low Synchronicity}

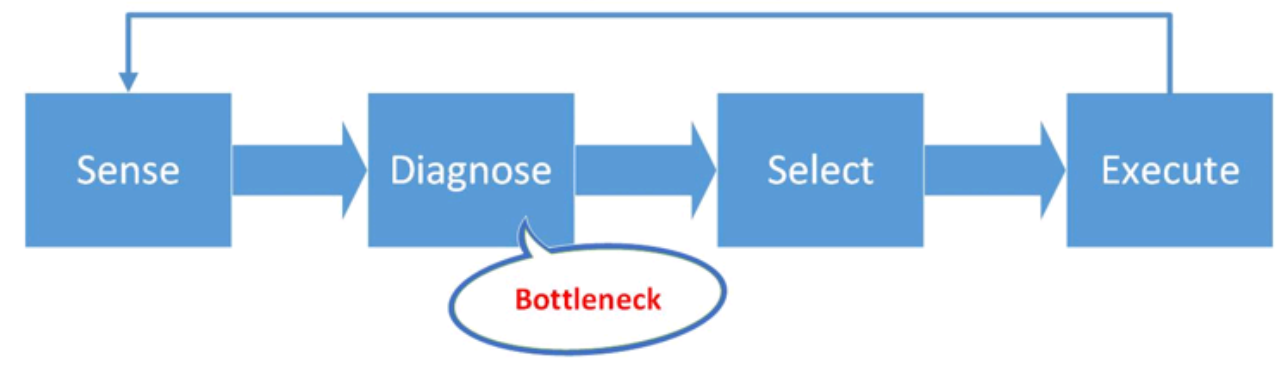

\begin{tabular}{l|l|l|l|l}
$\begin{array}{l}\text { Tasks } \\
\text { and } \\
\text { Outcomes }\end{array}$ & $\begin{array}{l}\text { Collecting safety events } \\
\text { data points }\end{array}$ & $\begin{array}{l}\text { Classifying and analyse } \\
\text { safety events to initiate } \\
\text { investigations }\end{array}$ & $\begin{array}{l}\text { Deciding on corrective } \\
\text { actions to rectify issues } \\
\text { in business operations } \\
\text { and/or safety processes }\end{array}$ & $\begin{array}{l}\text { Carrying out } \\
\text { corrective actions }\end{array}$ \\
\hline $\begin{array}{l}\text { Functional } \\
\text { Group } \\
\text { (User Roles) }\end{array}$ & Frontline Workers & Safety Advisors & $\begin{array}{l}\text { Investigators and safety } \\
\text { advisors }\end{array}$ & $\begin{array}{l}\text { Line managers and } \\
\text { Frontline workers }\end{array}$ \\
\hline $\begin{array}{l}\text { Traditional } \\
\text { Time frame } \\
\text { ( } \begin{array}{l}\text { S-R }=\text { a } \\
\text { month) }\end{array}\end{array}$ & $\begin{array}{l}\text { Mostly on the same day of } \\
\text { (Satisfactory) }\end{array}$ & $\begin{array}{l}\text { Close to a month with a } \\
\text { long queue of events } \\
\text { waiting to be diagnosed } \\
\text { (Unsatisfactory) }\end{array}$ & $\begin{array}{l}\text { Normally within five } \\
\text { work days depending on } \\
\text { the type of } \\
\text { investigations } \\
\text { (Satisfactory) }\end{array}$ & $\begin{array}{l}\text { Depending on the } \\
\text { assigned due date for } \\
\text { actions. Mostly on } \\
\text { time. } \\
\text { (Satisfactory) }\end{array}$ \\
\hline $\begin{array}{l}\text { Targeted } \\
\text { Time frame } \\
\text { ( } \begin{array}{l}\text { SS-R }=\text { two } \\
\text { weeks) }\end{array}\end{array}$ & Maintain the same & $\begin{array}{l}\text { Five work days after the } \\
\text { events entered the system }\end{array}$ & Remain the same & Remain the same \\
\end{tabular}

Figure 23: The SDSE Mapping Table for Episode Two 
In summary, as shown in Figure 23 above, "diagnosis" was identified as the bottleneck of the Ops Agility cycle at the E2 Company in terms of safety events processing. With the support of NOHARM, the E2 Company's "sense" performance was increased drastically thus collected large amount of data that overwhelmed the "diagnosis" capability (limited by the capacity of the safety advisory team). However, through analysing the investigation processes at the E2 Company, once an event was diagnosed and investigation initiated, the "select" phase would run smoothly by deciding what corrective actions should be issued. Next, the "execute" phase, according to historical data, did also perform well in terms of the actual execution and completion of corrective actions.

The current value of $\Delta S-R$ and its expected future value were already identified at the E2 Company with the former being some "30 day delay" in issuing corrective actions (bounced back from 20.7 in Q3 2013 to 42.8 in Q4 2013 as shown in Table 28 ) and the latter being "15 days". The desirable outcome would be to first clean up the historical backlog (as at Q1 2014 some 80 safety events were still left not diagnosed) and then set up a new event processing mechanism that can diagnose at least 200 safety events on a fortnightly basis. 200 was a relatively conservative number calculated based on the past data thus the E2 Company was expecting to see a higher number in the following months.

\subsubsection{The Final ISACAM-Driven Solution and Results}

Proceeding with ISACAM, the "Current Friction" was seen as high and largely due to the "Spatial Uncertainty" caused by the lack of explicitly articulated criteria for assessing the necessity of full scale investigations vs. short investigations. Without an officially defined standard, every event was an uncertain situation that required ad-hoc analysis. The safety advisors had to rely on their own discretion in initiating investigations through reviewing every individual event one after another. This meant the judgements made would not be always consistent across events and between advisors which would leave much room for line managers to challenge. 
Launching a full-scale investigation is generally demanding in human resource and often cause interruption to business operation of the reporting line being investigated. Therefore, line managers have a natural tendency to resist, sometimes even make counter-offers to full investigations in their lines of business. In contrast, short investigations are less unpleasant to line managers. Of course, "no investigations needed" is most desirable from a business operation standpoint but not necessarily from a safety risk management perspective. In short, the "Spatial Uncertainty" is fuelled up with the interpersonal Friction inside the safety advisory team as well as between the safety advisors and line managers. Such a Friction was mostly a result of inconsistency caused by the missing of a commonly-agreed explicitly-defined basis for initiating investigations.

To create a "Friction Reducer" in the E2 Company situation, certain degree of "Spatial Confidence" needed to be established. The E2 Company was recommended to institute an organisational standard set of criteria for deciding "definitely requiring full investigation", "definitely requiring short investigation" and "definitely not requiring investigation". A set of formally prescribed criteria can help minimise unnecessary disagreements and conflicts which had been slowing down the event diagnosing process (the identified bottleneck of the Ops Agility cycle in this Episode). The safety advisors originally doubted the possibility of articulating an explicit set of criteria for such a purpose as the decisions on investigations can be influenced by many factors including event type, incident categories, product type, parties/people involved, actual consequence, and potential consequence etc. However, I argued that there was no need for the initial set of criteria to be perfect and achieve $100 \%$ accuracy, rather, a set of criteria that were good enough to perform $80 \%$ of the time would be sufficient as a starting point for batch processing safety events. For those $20 \%$ safety events that could not meet any of the defined criteria, ad-hoc analysis would be carried out to help refine the initial set of criteria. 
Soon in February 2014, the E2 Company organised a full day workshop including the whole safety advisory team, safety managers and several representative line managers to define the criteria. Based on the historical data, they defined nine types of safety events (e.g. Spills to water, Spills to ground, Process safety incident, Robberies, Fuel quality, etc.) that would definitely require investigations. The choice between a full-scale investigation and a short version would be decided by other factors including parties/people involved, product type, and consequences, etc. With no intention to generate a perfect algorithm in the first place, the previously deemed impossible task of articulating a set of explicit criteria for initiating investigations was completed without a problem.

Following the ISACAM process, the "Current Torque" was recognised as very low. The safety advisors were the only drivers to move forward the Ops Agility cycle by manually diagnosing safety events and initiating investigations. To make their performance worse, the advisors were following the lead of email alerts generated by the NOHARM system to attend safety events one by one in a piecemeal by piecemeal manner which caused significant interruptions to their concentration. They were struggling to keep up with the increasing number of safety events entered into the NOHARM system while working on other responsibilities. To improve the "Torque", the E2 Company had already increased the number of safety advisors in the cycle, however the resulting performance was unstable and not sustainable if the number of safety events kept rising.

Therefore, a "Torque Booster" should be designed from the software system side, rather than from the system user side. Such a recognition later led to the formal inclusion of a new dimension "Control Type (Human vs. Machine)" in the ISACAM. We started to evaluate the feasibility of replacing "human controlled processes" with "machine-controlled processes" through automation and the potential improvement in agility performance. Given the safety event processing capability at 
the E2 Company was mostly depending on human agents and their knowledge, We believed major breakthrough could be made via extracting the tacit knowledge from the safety advisors and automating their event diagnosis processes.

After reviewing historical data to analyse the outcomes from past two years of safety event processing, I was able to see a clear trend that although the total number of safety events had been increasing, the percentage of events requiring investigations had been dropping significantly from 2012 to 2013. As shown in Table 29 below, according to the data kept in the NOHARM system, the percentage of events requiring full scale investigations had been gradually trending downwards from above 5\% in Q1 2012 to below 1\% in Q4 2013. The percentage of events initiated short investigations was receding from some $29 \%$ to slightly above $7 \%$ during the same period. In the meantime, the percentage of events resulted in no investigations had raised from some $65 \%$ to over $90 \%$.

Table 29: Number of Safety Events by Investigation types 2012-2013

\begin{tabular}{|c|c|c|c|c|c|c|c|c|}
\hline Incident Year & Quarter & Full Investigation & & No Investigation & & Simple I & & Total \\
\hline \multirow[t]{4}{*}{2012} & 1 & 28 & $5.49 \%$ & 333 & $65.29 \%$ & 149 & $29.22 \%$ & 510 \\
\hline & 2 & 32 & $5.22 \%$ & 458 & $74.71 \%$ & 123 & $20.07 \%$ & 613 \\
\hline & 3 & 29 & $4.56 \%$ & 486 & $76.42 \%$ & 121 & $19.03 \%$ & 636 \\
\hline & 4 & 19 & $2.24 \%$ & 684 & $80.47 \%$ & 147 & $17.29 \%$ & 850 \\
\hline \multirow[t]{4}{*}{2013} & 1 & 23 & $1.84 \%$ & 1131 & $90.34 \%$ & 98 & $7.83 \%$ & 1252 \\
\hline & 2 & 13 & $1.16 \%$ & 1020 & $90.99 \%$ & 88 & $7.85 \%$ & 1121 \\
\hline & 3 & 13 & $0.95 \%$ & 1247 & $90.76 \%$ & 114 & $8.30 \%$ & 1374 \\
\hline & 4 & 11 & $0.86 \%$ & 1180 & $91.83 \%$ & 94 & $7.32 \%$ & 1285 \\
\hline Total & & 168 & & 6539 & & & & 7641 \\
\hline
\end{tabular}

Data Source: The NOHARM System (Visualised in Microsoft SSRS 2014)

The review of historical investigation data (shown in Table 29) gave me enough confidence that if a machine-based agent could be designed to automatically pick out those safety events definitely requiring "no investigations", we could effectively remove up to some $90 \%$ of the workload from those struggling human agents, i.e. 
the safety advisors. We could then leave the $10 \%$ safety events that potentially require investigations for human agents to scrutinize and decide if a "full scale" or a "short form" investigation was necessary.

After the E2 Company formally established a set of criteria for initiating investigations in February 2014, we, as the NOHARM development team and service provider, within two sprints (meaning four weeks), were able to design and implement a system-driven "Torque Booster" through an automated event classification algorithm, later called the "auto-triaging" function by the E2 Company internally. Such a function was based on the NOHARM workflow configuration thus the safety advisors could set up the criteria themselves for machine-driven automated event processing. In this fashion, safety events were classified into three groups:

Group One was the most information intensive group and contained the majority of safety events (up to $90 \%$ according the historical data shown in Table 29) that were "definitely not requiring investigations" (i.e. customers dialling on mobile phones while filling cars with petrol at the forecourts of service stations ). This group of events would be automatically forwarded to relevant line managers to review and close without further investigations. In other words, these events were to be automatically triaged by the NOHARM system itself without sending email alerts to safety advisors. Of course, if a line manager believed investigation was needed while reviewing the events forwarded by the NOHARM, he/she could assign the event back to a safety advisor and request a "human-driven" diagnosis. As at Q1 2014, there were about 180 line managers of all levels at the E2 Company, each could easily spare fifteen to twenty minutes every week to review a couple of safety events (may well be none, depending how risky their lines of operation were) classified by the NOHARM system as "no investigations required". 
Group Two contained those events that met the criteria for "definitely require investigations". For this group, the company maintained the conventional approach by sending email notifications to the safety advisory team directly to invite further detective work. However, the number of email alerts sent by the NOHARM system to the advisors were expected to reduce by $90 \%$ from the past due to the "autotriaging" function started processing some 90\% of the events (Group One) automatically without sending emails to safety advisors. In fact, to further reduce temporal uncertainty and minimise interruptions to safety advisors, a summary report was developed using Microsoft SSRS to list all the Group Two safety incidents occurred during the day that require attention from the advisors. This report was then scheduled to send to safety advisors once a day to eliminate the need for frequently checking emails for updates.

Group Three consisted of safety events that didn't meet the criteria of the previous two groups. This group, would represent a smaller number of events and was expected to shrink over time. The events falling in this group would be sent to safety advisors to analyse and help refine the established criteria for the previous two groups. Through continuous learning and adjusting the criteria, the accuracy of the auto-triaging function would improve and the number of events falling in Group Three should drop, ideally, to zero. However, even if Group Three could never be eliminated, it should only represent a slightly extra workload on top of Group Two which was easily affordable to the safety advisory team.

Essentially, the approach to diagnose Group One was the main component of the "Torque Booster". Such an approach completely changed the nature of safety event processing at the E2 Company from the original "human-driven" manual analysis that was heavily limited by the capacity of the safety advisory team, to a "machinedriven" classification (the "auto-triaging") mechanism coupled with a "quasicrowdsourcing" feedback system (over 180 line managers to provide feedback for 
the classification results done by machines). Since the implementation of this "Torque Booster", the event processing speed and capacity were no longer depleting the cognitive horsepower of the safety advisory team. In other words, the "bottleneck" at the "diagnosis" phase of the Ops Agility cycle in this Episode could be effectively resolved. We were expecting the $\Delta$ S-R to begin reducing in Q2 2014.

\section{Results}

After the full implementation of the "Torque Booster" and the "Friction Reducer" in March 2014, the E2 Company started to experience significantly improved performance in safety events processing. The Ops Agility cycle began to run much more synchronically as the bottleneck at the "diagnose" phase was resolved by the boosted processing capacity generated from the auto-triaging function in the NOHARM system. As shown in Table 30 below, the average days taken to issue corrective actions dropped to a historical low number at 16.7 in Q2 2014 and then to 12.7 Q3 2014. The E2 Company was reassured and contented to see its safety risk management system become much more responsive to safety events with a decent level of accuracy in initiating appropriate investigations. 
Table 30: The Average Days Taken to Issue Corrective Actions 2012 Q1 to 2014 Q3

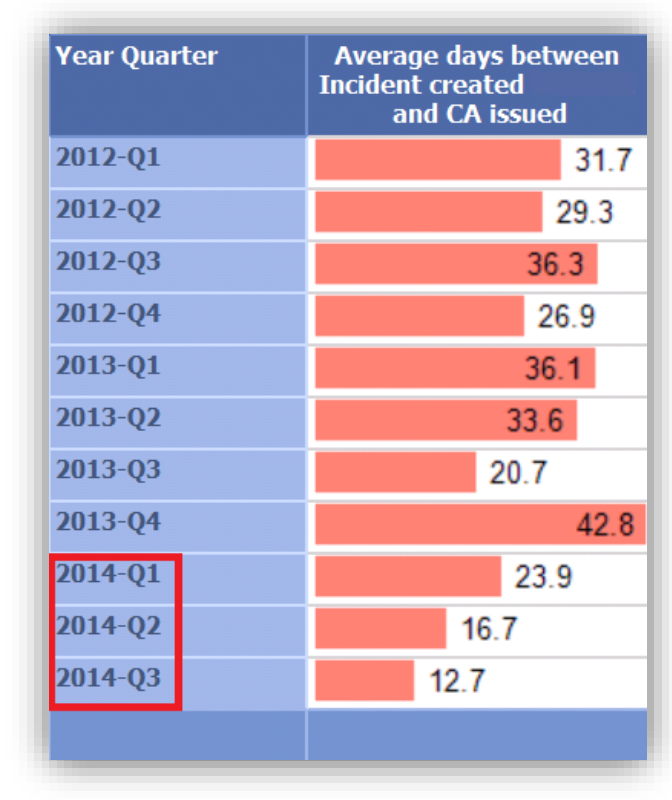

Data Source: The NOHARM System (Visualised in Microsoft SSRS 2014)

\subsubsection{Episode Summary and Reflection in Action}

Table 31 below summarises the key points of Episode Two. This episode was about improving the "diagnosing" capability of the Ops Agility cycle at the E2 Company regarding interpreting safety incidents and classifying them into appropriate investigations. Such "diagnosing" effort was originally purely relying on human agents who could only analyse safety incident one by one on an ad-hoc basis. When the increasing number of incidents caused a much higher level of information intensity that overwhelmed the human agents, delay would inevitably occur, which prevented the E2 Company from performing timely investigations and taking effective corrective actions. 
Table 31: A Brief Summary of Episode Two

\begin{tabular}{|c|c|}
\hline Functiona & : Safety Advisors - from the E2 Company \\
\hline Episode Two - & Excessive delay in safety events assessment \\
\hline The original so & ution - summarised in Abstraction Decomposition Space(par \\
\hline $\begin{array}{l}\text { System } \\
\text { Purpose }\end{array}$ & Improve workplace safety, reduce injuries, and control risks \\
\hline Domain Values & $\begin{array}{l}\text { Make prompt and effective responses to safety incidents to } \\
\text { prevent future occurrence }\end{array}$ \\
\hline $\begin{array}{l}\text { Domain } \\
\text { Functions }\end{array}$ & $\begin{array}{l}\text { Diagnose safety events to initiate investigations and } \\
\text { corrective actions }\end{array}$ \\
\hline$\frac{\text { Technical }}{\text { Functions }}$ & $\begin{array}{l}\text { Initial User Driven Solution: Added more safety advisors } \\
\text { to speed up the process of analysing details of incidents and } \\
\text { assigning appropriate investigations }\end{array}$ \\
\hline $\begin{array}{l}\text { Physical } \\
\text { Resources \& } \\
\text { Material } \\
\text { Configuration }\end{array}$ & $\begin{array}{l}\text { Each safety advisor had reliable Internet connection for } \\
\text { accessing the incident data stored in the information system }\end{array}$ \\
\hline$\underline{\text { Results }}$ & $\begin{array}{l}\text { The following quarter had seen noticeable drop (from } 33.6 \\
\text { days to } 20.7 \text { days) in the delay between safety incident and } \\
\text { corrective actions. However, the next quarter had } \\
\text { experienced a far greater delay (from } 20.7 \text { days to } 42.8 \\
\text { days) caused by staff turnover in the safety advisory team. }\end{array}$ \\
\hline ISACAM (Ver & based Problem Analysis \\
\hline $\begin{array}{l}\text { Change Freque } \\
\text { Time Criticality } \\
\text { Problem lies or } \\
\Delta \text { S-R: Currently }\end{array}$ & $\begin{array}{l}\text { Acy: High Uncertainty: High Information Intensity: High } \\
\text { High } \\
\text { Ops Agility Cycle: Yes Dev Agility Cycle: No } \\
\text { month, expected to be two weeks }\end{array}$ \\
\hline Symptoms & $\begin{array}{l}\text { Many safety incidents were not diagnosed as soon as they } \\
\text { occurred, rather, they had accumulated in a long queue to } \\
\text { be processed by safety advisors in an ad-hoc manner. The } \\
\text { average delay between safety incidents and necessary } \\
\text { corrective actions had been over } 30 \text { days which was }\end{array}$ \\
\hline
\end{tabular}




\begin{tabular}{|c|c|}
\hline & expected to be reduced to half. \\
\hline$\underline{\text { Root Causes }}$ & $\begin{array}{l}\text { Safety advisors were the only agents responsible for } \\
\text { scanning and assessing safety incidents to initiate } \\
\text { investigations. The quarterly number of safety incidents } \\
\text { had doubled which overwhelmed those advisors. Spatial } \\
\text { uncertainly was high as no explicitly defined criteria were } \\
\text { used when diagnosing incidents thus the quality of } \\
\text { diagnosis depended solely on the experience and } \\
\text { knowledge of the safety advisors. Temporal uncertainty was } \\
\text { high as email alerts could be sent to safety advisors and } \\
\text { interrupt their work anytime during the day. }\end{array}$ \\
\hline \multicolumn{2}{|c|}{ ISACAM based Solution Design } \\
\hline $\begin{array}{l}\text { Torque } \\
\text { Booster }\end{array}$ & $\begin{array}{l}\text { Based on predefined criteria, to design a machine-driven } \\
\text { auto-triaging function to automatically pick out those } \\
\text { incidents needing no investigations vs. definitely requiring } \\
\text { investigations. }\end{array}$ \\
\hline $\begin{array}{l}\text { Friction } \\
\text { Reducer }\end{array}$ & $\begin{array}{l}\text { To reduce "spatial uncertainty" by extracting a set of } \\
\text { explicitly defined criteria for assessing investigation needs. } \\
\text { To reduce "temporal uncertainty" by summarising incidents } \\
\text { needing human attention into a daily report automatically } \\
\text { sent to safety advisors for review. }\end{array}$ \\
\hline$\underline{\text { Results }}$ & $\begin{array}{l}\text { The following three quarters had seen a continuous drop in } \\
\text { the delay between safety incidents and necessary corrective } \\
\text { actions (from } 23.9 \text { days to } 12.7 \text { days). }\end{array}$ \\
\hline \multicolumn{2}{|c|}{ Evolution of ISACAM } \\
\hline \multicolumn{2}{|c|}{$\begin{array}{l}\text { Control_Type (Human Control vs. Machine Control) was added as a new } \\
\text { dimension for solution design to explicitly define the level of automation can } \\
\text { be achieved. }\end{array}$} \\
\hline
\end{tabular}

When faced with drastically increasing information intensity, it is natural to design some automated procedures to leverage the computational power of machines. However, such a design needs to be grounded in the specific context with an indepth understanding of the business problems in question. It is essential to 
articulate patterns and trends suggesting what happened in the past, what is the problem at the present, what is intended to be achieved in the future.

To boost the "diagnosing" performance, a machine-driven and rule-based "autotriaging" function was designed and implemented in the NOHARM system to help the E2 Company automatically filter out safety events that were "definitely not requiring investigations. This solution was successful mostly due to the fact that almost $90 \%$ of the safety events reported at the E2 Company indeed did not require investigations. Without the upfront data analysis revealing the $90 \%$ figure, the solution probably would be designed in a different way.

Uncertainty, again, played a critical role in slowing down the agility cycle of human agents. Either spatial uncertainty or temporal uncertainty is enough to compromise performance of people. Both together, fuelled with excessive information intensity, can make human agents procrastinate on decisions and actions, if not paralysed.

I have found that improvement can be gained through merely establishing some form of confidence or assurance on either "spatial" or "temporal" dimensions, or even better, on both. For instance, in Episode Two, having an explicitly defined set of criteria, even though not perfectly exhaustive, for classifying safety incident into types of investigations, clearly improved "spatial confidence" and speeded up the incident investigation process by minimising the case-by-case judgements from different safety advisors and line managers. By summarising all Group Two incidents into one single report and sending it out once a day, the safety advisors established more "temporal confidence" knowing they would not miss any incidents needing their attention, without having to check their emails frequently throughout the day.

In addition, as a result from Episode Two, I extended ISACAM models by including an extra dimension called "Control Type" to enforce explicit assessment and 
articulation of the trade-offs between "Human Control" and "Machine Control" while designing solutions for improving agility.

\subsubsection{Episode Three - A "Selecting" Problem}

\subsubsection{The Problem and Context}

Episode Three was based on a problem-solving case for another major energy company (hereafter named the E3 Company) who has over two thousand active users accessing the NOHARM system on a regular basis. Episode Three was chosen to be reported for two reasons: firstly, it represents an IS Agility problem where the weak "selecting" ability caused delay in deciding responses to the identified changes (in this episode, many corrective actions were not issued in a timely manner through the safety auditing processes at the E3 Company); secondly, this episode helped me to reflect and evolve ISACAM to an even fuller version (from version 1.1 to 1.2) with the inclusion of an important dimension, i.e. the DIKW (DataInformation-Knowledge-Wisdom) cognitive hierarchy which will be reflected on at the end of this episode.

The E3 Company is one of the leading gas and electricity providers in New Zealand with power lines and gas network supporting some half million homes, businesses and organisations across the nation. The E3 Company acknowledges the high level of safety risks faced in its daily operations and has been dedicated to continuous improvements in its safety practice. Instead of the traditional, reactive, incident/injury-driven approaches (i.e. learn from hindsight), the E3 Company has taken a more proactive stance by conducting comprehensive safety audits across high risk business areas all year round.

The whole audit-based safety risk management approach works in a cyclic manner which allows it to be neatly mapped into the Agility Cycle. Besides the scheduled regular auditing (monthly and quarterly) in high risk areas, the E3 Company has 
been continuously "sensing" changes in its incident frequency rate, risk profile and obligation requirements in order to identify operational areas for ad-hoc auditing. Those audits themselves serve as a "diagnosis" tool for the company to understand gaps and issues between the expected performance and the practice in reality. Every audit consists of several "elements" within each a list of questions are examined. A reporting line being audited will receive a final score based on its rating against each audit questions. Once an audit is completed, the auditor then needs to "select" necessary responses based on the results. At the E3 Company, if an audit resulted in a score lower than $100 \%$, corrective actions need to be issued in a timely manner to make remedies and/or improvements in the affected business areas. Of course, these corrective actions, once accepted, should be "executed" within the scheduled time frame.

Since April 2013, The E3 Company has started using the NOHARM system to track their safety audits which were originally recorded in Excel spreadsheets. The NOHARM system has improved the "sensing" ability of the E3 Company by collecting safety events and observations with larger quantity and higher quality. Safety advisors have become more efficient and effective in terms of detecting where and when audits are needed. They began to directly prescribe audits in the NOHARM system which can send email reminders to designated auditors. The auditors, in general, are requested to start audits on scheduled dates and enter audit results into the NOHARM system within 24 hours after completion. The intention was to establish a real-time view of changes occurring in the safety practice and the business environment of the E3 Company so that effective and efficient responses could be made.

Such a real-time requirement demands high "diagnose" capability from the auditors which has been drastically improved by the NOHARM system. Audit templates have been created, maintained and shared in the system and can be modified and tailored on the fly to meet the purposes of any particular audits. This "open source" style 
management of audit templates has boosted the efficiency and speed of auditors as it allows immediate adaptation of auditing processes to fit the business areas being audited. Moreover, with the support of the NOHARM system, auditors can easily access historical incident data and previous auditing results of the business areas being audited which make their "diagnosis" a lot more effective and accurate.

Because of the improved "sense" and "diagnose" capabilities, the E3 Company has been able to organise large number of audits. In nine months, from April to December 2013, the E3 Company had started 1,278 safety audits among which failed audits had resulted in 587 corrective actions (shown in Table 32 below). These two figures were significantly high, in fact, over ten times higher than the average in the same industry where many companies were still following the traditional reactive method relying on post-incident investigations to diagnose causes and control safety risks. The E3 Company's belief has been that through its proactive auditing approach, gaps and issues in safety practice would be revealed earlier before they lead to incidents of personal injuries and financial losses.

Table 32: Number of Audits Started and Corrective Actions Issued at E3 in 2013

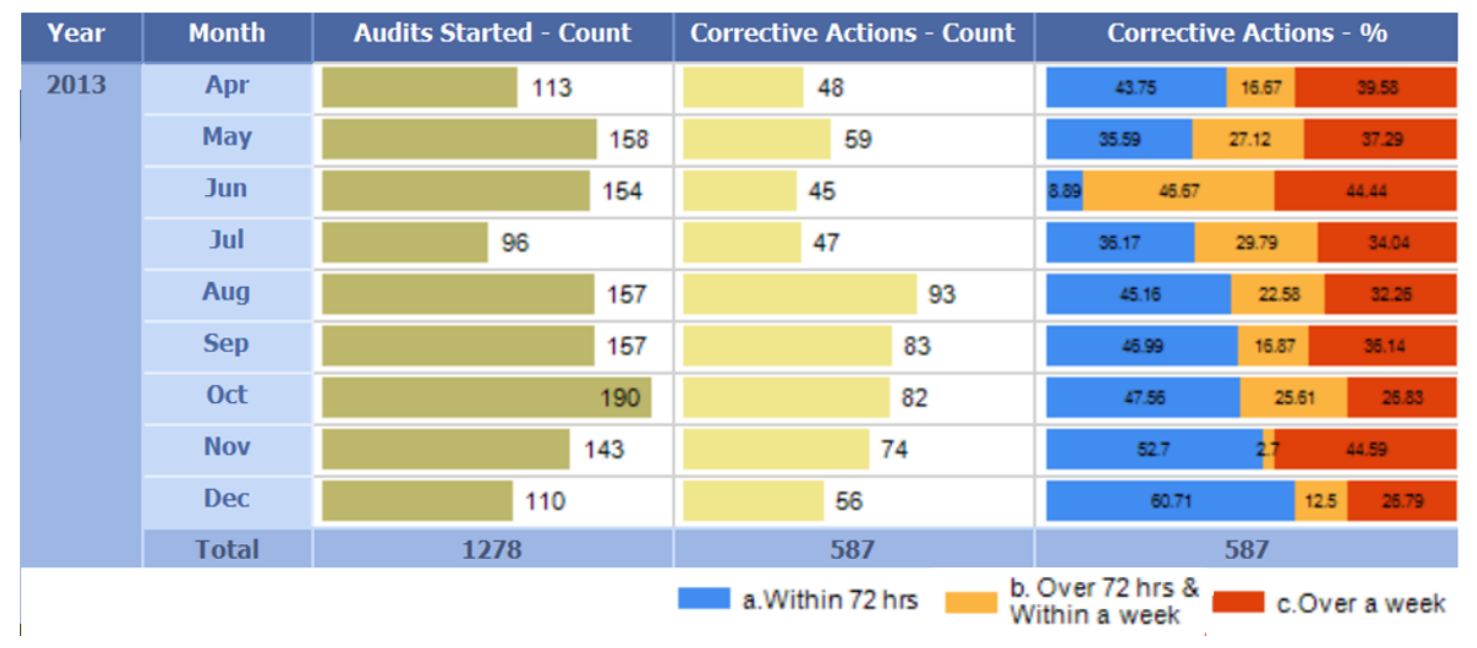

Data Source: The NOHARM System (Visualised in Microsoft SSRS 2014) 
To be proactive and able to prevent future incidents, strong performance in "sense" and "diagnose" is only the half way. Being able to "select" and "execute" effective responses within a required time frame is the other half. At the E3 Company, the corrective actions have been expected to be issued as soon as possible against business areas or processes that didn't pass their audits. After all, timeliness of audit-driven corrective actions is crucial to proactive safety management. As it will be pointless to spend extensive amount of time and effort on detecting gaps and issues yet then delay actions to rectify and improve.

Even though the auditors managed to pull through over 140 audits and issued over 60 corrective actions in an average month in 2013, the E3 Company was not satisfied. The dissatisfaction largely came from the delay in issuing corrective actions subsequent to failed audits. As shown in the last column in Table 32 above, on average, only some $41.7 \%$ of corrective actions were issued within 72 hours after the completion of audits. 72 hours are more or less acceptable at the E3 Company, however, still some $35.4 \%$ of corrective actions were issued over a week after failed audits. Such a performance was undesirable.

In December 2013, after the establishment of the WorkSafe New Zealand which caused a sudden surge in demand for higher safety performance, the E3 Company has launched a slogan called "building agility and increasing insights" across the whole organisation as a sign of determination to become faster in making insightful responses to changes in its business and environment. One of the objectives was to reduce the delay in issuing corrective actions after failed audits. This means to maximise the percentage of corrective actions issued within 72 hours while minimising those issued later than a week. It is deemed that the earlier actions are taken to correct issues identified during the auditing process, the lower the operational risk and the safer the workforce. 


\subsubsection{The Initial User-Driven Solution and Results}

In contrast to other companies following reactive approaches and having only one or two safety advisors looking after safety audits as part-time assignments, the E3 Company has been keeping dedicated auditors to facilitate its proactive safety risk management approach. Throughout the whole year of 2013, there were four fulltime safety auditors available in any given month for conducting audits and issuing corrective actions. Nevertheless, these auditors, even well trained in diagnosing issues and identifying gaps in safety practice, were still swamped by the large number of safety audits scheduled each month (on average over some 35 audits per auditor per month), especially struggling to decide on the resulting corrective actions within a desirable time frame.

At the E3 Company, the original process for issuing corrective actions after failed audits was that auditors needed to first discuss with the safety advisors (through phone calls or emails) of the reporting lines with failed audits. This step allowed room for negotiation to ensure the corrective actions planned are "feasible and practical" to the targeted reporting lines. Such a "negotiation" phase was designed to avoid mismatches that corrective actions issued by auditors are simply not executable given the circumstances of the reporting lines being audited. Once both parties can agree on a list of corrective actions, the auditors then would go ahead and schedule them in the NOHARM system and assign to relevant line managers.

Before the end of 2013, the E3 Company reviewed its auditing processes (both in its business process and in the setup of the NOHARM system), listened to feedback from auditors, and decided to alter the approach for issuing corrective actions. The change was straightforward and to grant full authority to auditors for making decisions on the nature and timeframe of corrective actions. Essentially, such a change was to simplify the process by removing the "negotiation" step between auditors and line-level safety advisors. 
As mapped out in Table 33 in the next page, within the work domain of proactive safety auditing, the E3 Company deemed that the "negotiation" step was the key bottleneck slowing down the decisions on corrective actions. This step was seen as an obsolete "reassurance" function performed between auditors and line-level safety advisors manually outside the processes set up in the NOHARM system. It was difficult and sometimes frustrating for both parties to find time for meaningful "negotiations" based on thorough understanding of objective facts instead of subjective opinions. As auditors were always busy with audits in the field, they found it hard to chase up line-level safety advisors for comments on the practicality and feasibility of their planned corrective actions. Moreover, operational level details could be lost in email and phone conversations which in turn lead to miscommunications.

The E3 Company believed that auditors, over time, had accumulated enough data in the NOHARM system and sufficient experience through months of intensive safety auditing. They should be well equipped to make decisions on their own regarding the practicality and feasibility of corrective actions. Therefore auditors, starting from January 2014, should issue corrective actions directly to line managers to execute without having to consult with line-level safety advisors. This way they can save considerable time and effort which should lead to quicker decisions on corrective actions. After all, safety advisors at the E3 Company were already very busy people, as only eleven of them needed to look after all aspects of safety management (e.g. safety plans, personal protective equipment, access permit, and regulatory requirements) across 93 reporting lines. 
Table 33: ADS Problem Solving of Episode Three

\begin{tabular}{|c|c|c|c|c|}
\hline & $\begin{array}{c}\text { System } \\
\text { (Whole SaaS } \\
\text { solution containing } \\
\text { multiple modules) }\end{array}$ & $\begin{array}{c}\text { Unit } \\
\text { (Audit Management } \\
\text { Module) }\end{array}$ & $\begin{array}{l}\text { Component } \\
\text { (Record audit } \\
\text { results and Issue } \\
\text { Corrective } \\
\text { Actions) }\end{array}$ & $\begin{array}{c}\text { Part } \\
\text { (Email reminders, } \\
\text { Audit templates, } \\
\text { Action scheduler) }\end{array}$ \\
\hline $\begin{array}{l}\text { Purpose \& } \\
\text { Meaning }\end{array}$ & $\begin{array}{l}\text { Improve workplace } \\
\text { safety, reduce } \\
\text { injuries/harms, and } \\
\text { control operational } \\
\text { risks }\end{array}$ & & & \\
\hline $\begin{array}{l}\text { Domain } \\
\text { Values \& } \\
\text { Priorities }\end{array}$ & & $\begin{array}{l}\text { Proactively identify } \\
\text { safety issues to } \\
\text { correct and improve } \\
\text { through intensive }\end{array}$ & & \\
\hline $\begin{array}{l}\text { Domain } \\
\text { Functions }\end{array}$ & & & $\begin{array}{r}\text { Conduct audits at } \\
\text { defined time and } \\
\text { places and issue } \\
\text { corrective actions } \\
\text { against failed } \\
\text { audits }\end{array}$ & \\
\hline $\begin{array}{l}\text { Technical } \\
\text { Functions } \\
\text { (bottleneck } \\
\text { lies at this } \\
\text { level) }\end{array}$ & & & $\begin{array}{r}\text { Auditors swamped } \\
\text { by audits and } \\
\text { delayed } \\
\text { negotiations with } \\
\text { pafety advisors on } \\
\text { corrective actions }\end{array}$ & \\
\hline Physical Form & & & & $\begin{array}{r}\text { Internet connection, } \\
\text { Computers, Phones, } \\
\text { Servers are all } \\
\text { readily accessible }\end{array}$ \\
\hline
\end{tabular}


In the same fashion to previous episodes, the ADS above (see Table 33) summarises the problem-solving processes at the E3 Company in a work domain analysis style. No issues were found at the top levels of abstractions, i.e. purposes, priorities, and domain functions. The bottleneck was found at the technical level where the "negotiation" between audits and safety advisors could delay the process of issuing corrective actions for failed audits. The NOHARM system was performing well at all levels of decomposition, i.e. system, unit, component, and part. However, the "negotiation" process was not integrated in the NOHARM as a component of the system, rather, it was done by human agents outside the NOHARM system via emails or phone calls. In general, no problems were found at the physical form level as all parties had access to technologies and devices they needed to perform their tasks. The part level decomposition had seen no issues as well, as all parts existing in the NOHARM were performing as they were designed for.

\section{Results}

Started from the beginning of 2014, auditors were granted full authority to decide on corrective actions without discussing with line-level safety advisors. However, instead of the expected faster turnover, the E3 Company had seen a clear deterioration in the performance of auditors in terms of issusing corrective actions after failed audits. As shwon in Table 34 below, from January to March 2014, on average some $51.9 \%$ of corrective actions were issued later than a week (worse than the average $35.4 \%$ in 2013). On the other hand, only an average $31.7 \%$ of corrective actions were issued within 72 hours which indicated a sharp drop from the average $41.7 \%$ in 2013. 


\section{Table 34: Number of Audits Started and Corrective Actions Issued at E3 Company From April 2013 to March 2014}

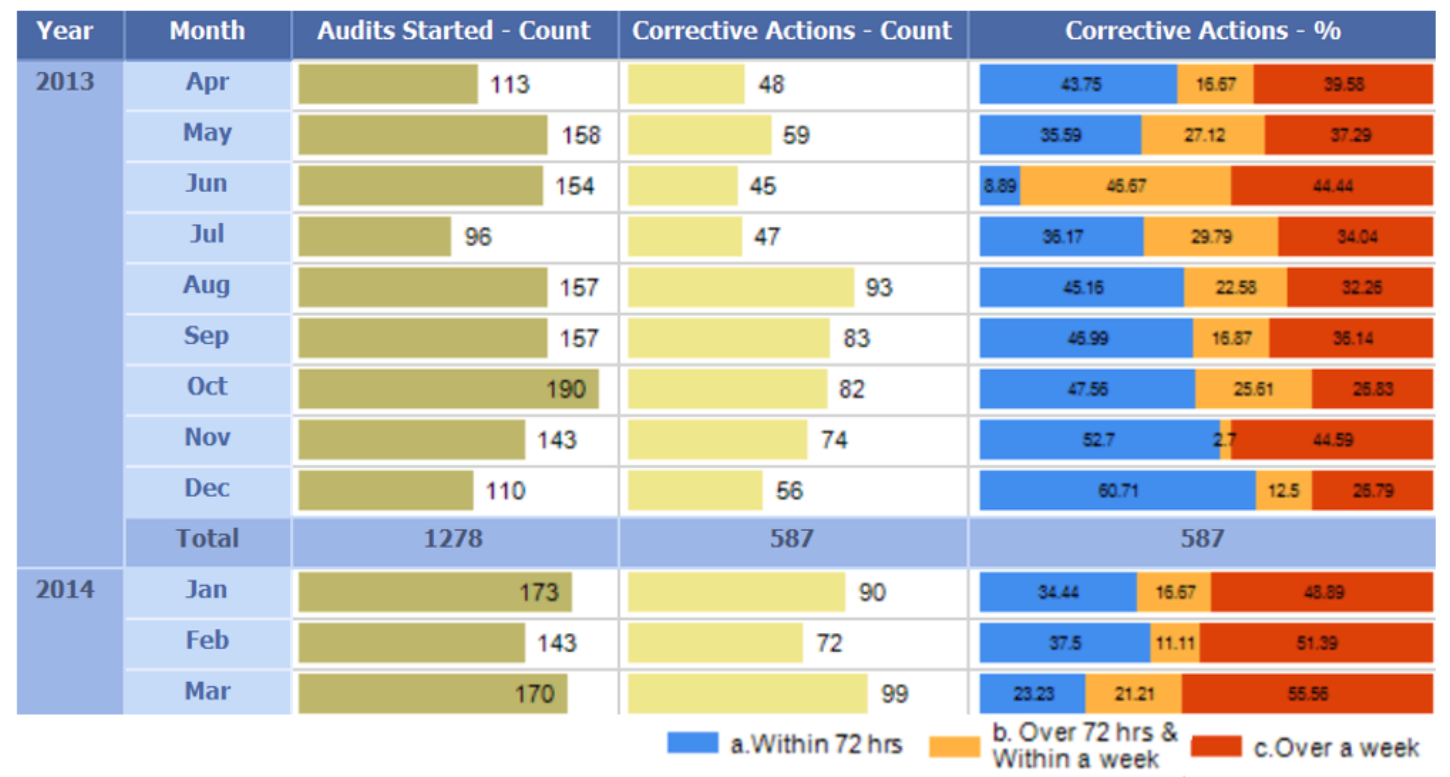

Data Source: The NOHARM System (Visualised in Microsoft SSRS 2014)

The unexpected decrease in performance caused unease at the E3 Company. The senior management team became more concerned than before, especially when auditors complained that their stress level and workload went up significantly, yet the speed of decision making on corrective actions plummeted. Clearly, such a result from the newly implemted auditing approach was nowhere resonating with the company-wide slogan "building agility and increasing insights". Unsatisfied with the human-driven decision making performance on issuing corrective actions, the E3 Company turned to the NOHARM provider and started to look for system-driven solutions for boosting the agility in their auditing processes, particulary the process related to selecting corrective actions . 


\subsubsection{Problem Space Analysis based on ISACAM}

In February 2014, the E3 Company initiated a discussion with the NOHARM provider to explore innovative system functionalities that can provide stronger support to their auditors to process through the particular "from failing audits to issuing corrective actions" phase faster. Such type of discussion was considered beyond the scope of the generic SLAs offered by a SaaS provider thus was treated as a consulting project.

Given the main motivation of the E3 Company was to speed up the cycle from audits to corrective actions through potential enhancement in the IS functionalities and processes, I was assigned to this project to analyse the problem from an IS Agility perspective and to propose effective yet economical solutions to both parties. This meant the solution needed to involve minimal modifications of the NOHARM system and have minimal impact on other clients sharing the system, yet still could shorten the decision cycle of the auditors and maximise the percentage of corrective actions issued within a desirable timeframe (i.e. 72 hours after failed audits).

To optimise the understanding towards the problem and propose convincing solutions, we reused my systematic method for IS Agility analysis - now described as ISACAM ver1.2, which involved more dimensions in the data model (see Figure 24 below) and more detailed steps in the task model (see Figure 25 below). Evolved from previous versions, ISACAM ver 1.2 became further structured to allow finergrained analysis of the problem space. However, we still experienced some challenges in assessing trade-offs between the promptness of rule-based machinedriven decisions and the prudence of collaborative decision-making based on human knowledge and wisdom. I will discuss this more in detail at the end of this section. 


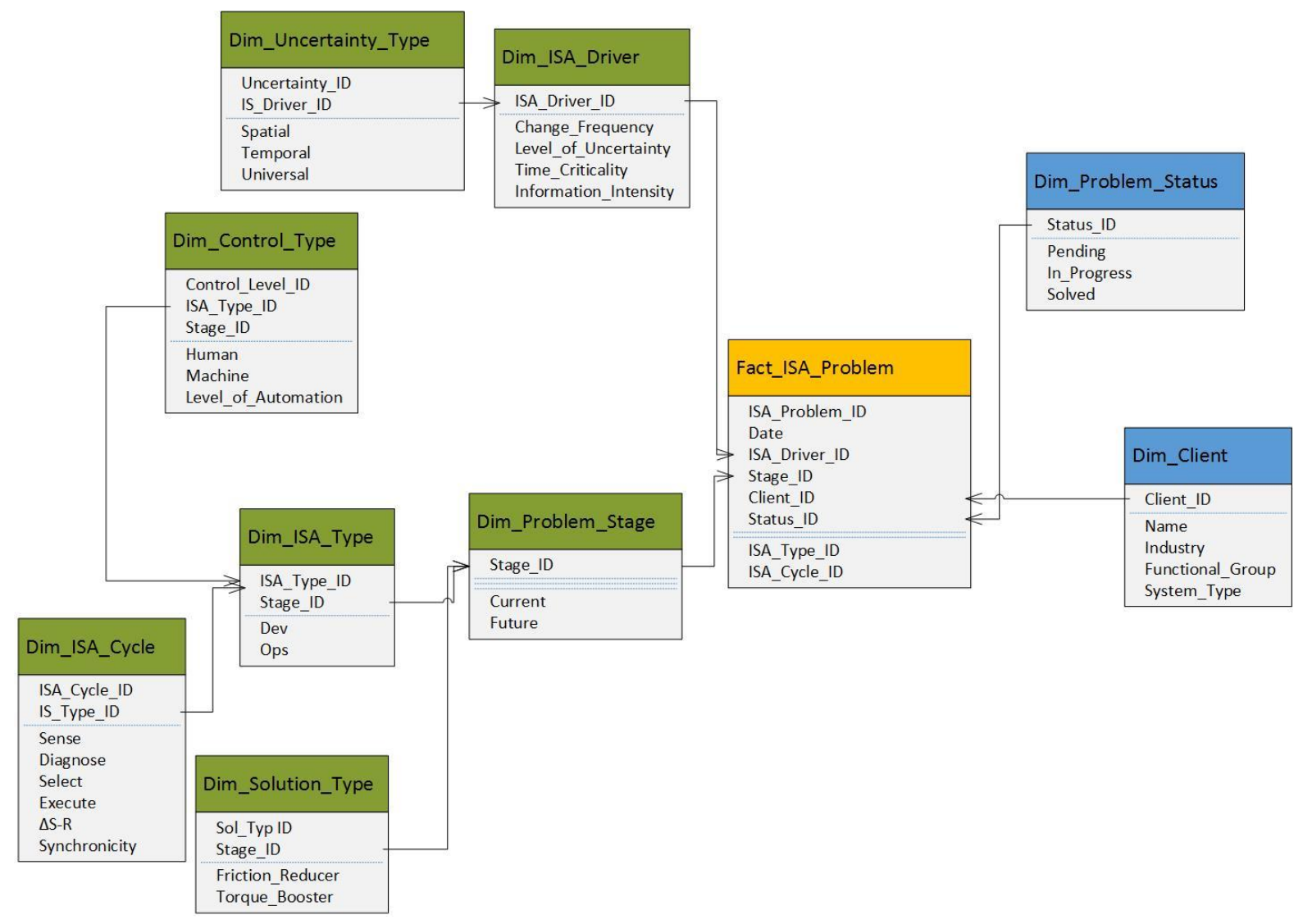

Figure 24: The Data Model of ISACAM Ver 1.2

Following the steps summarised in the task model (see Figure 25), I moved on to construct the problem space based on the data model illustrated in Figure 24. The starting point was to focus on the drivers for IS Agility in the auditing process of the E3 Company.

"Change Frequency" was high as in an average month, the E3 Company was conducting over 140 audits and issuing over 70 corrective actions across 93 reporting lines. All these activities were intended to detect changes in the business operations and environments at the earliest time possible, so that prompt and effective responses can be made to mitigate safety risks and prevent incidents/injuries. The rationale behind these proactive and frequent auditing was that the E3 Company had been aggressively expanding its business across the nation and implementing new equipment, new technologies, plus recruiting new frontline 
workers/contractors which all contributed to a more turbulent operational environment.

"Information Intensity" was also high as the amount of data and information being collected and processed through intensive auditing could easily swamp and paralyse four full-time auditors if there was no computer-based IS to support them. In fact, without a modern web-based IS having functionalities specifically designed for safety auditing purposes, i.e. the NOHARM system, the E3 Company would not be able to initiate and follow through the large number of audits done in 2013.

"Time Criticality" was high as the earlier issues and gaps can be detected via safety audits and addressed through corrective actions, the lower the operational risks and the safer the workforce. Timeliness of corrective actions is critical. The E3 Company invested significant resource into proactive safety auditing not for merely knowing where problems were, but more importantly, to act on the problems and rectify errors before undesirable safety events occur. 


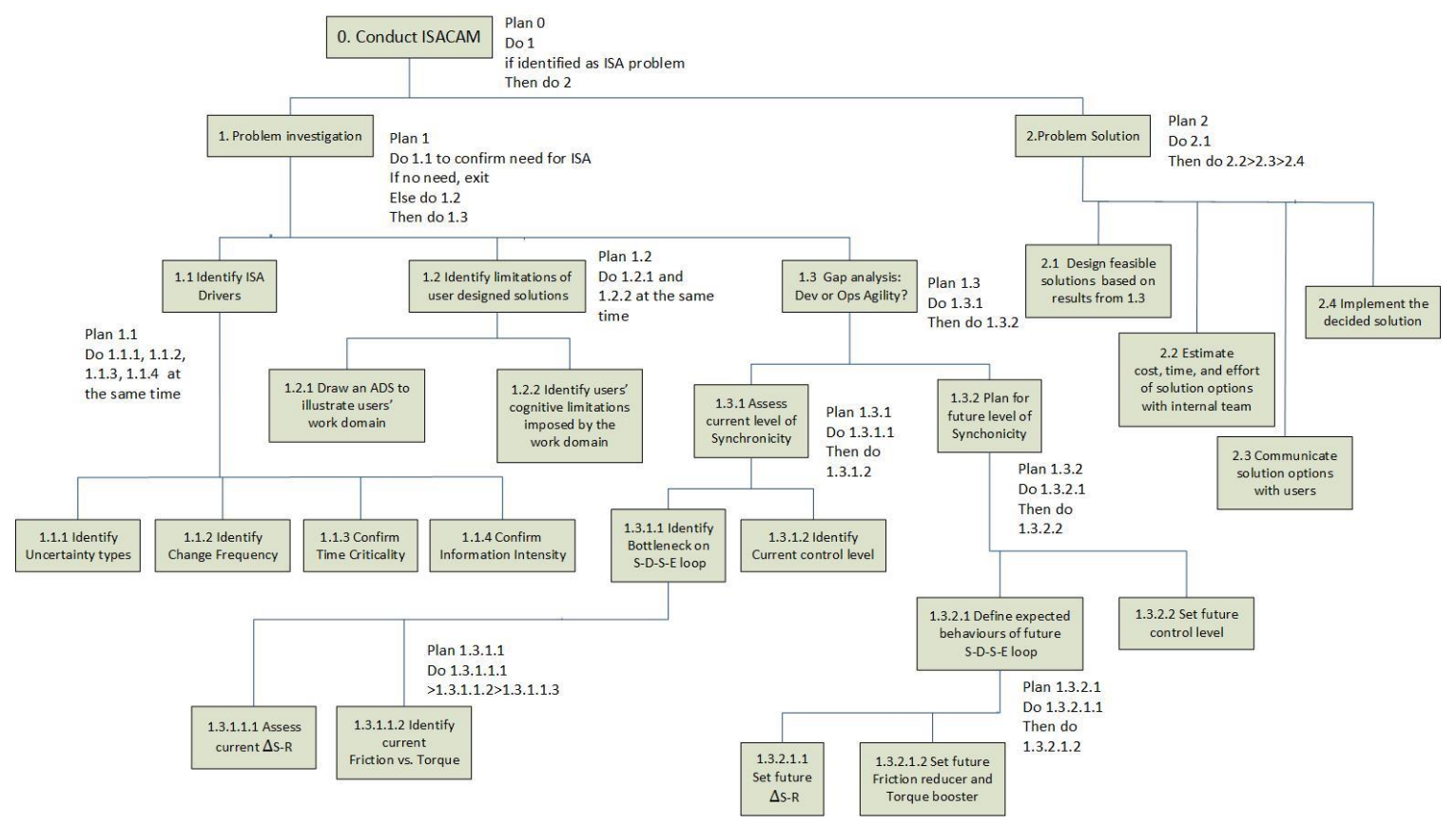

Figure 25: The Task Model of ISACAM Ver 1.2

Both "Spatial Uncertainty" and "Temporal Uncertainty" were found high which was affecting the performance of auditors in selecting corrective actions but not in conducting audits. As illustrated in Figure 26 below (mapped the auditing process to the SDSE model), after the E3 Company changed its process for issuing corrective actions, auditors alone were responsible for both conducting audits and deciding on corrective actions for reporting lines that failed their audits.

Conducting audits, or "diagnosing" as shown in Figure 26 below, was found to be the easier task by auditors as they had established confidence on both temporal and spatial dimensions. On the temporal dimension, auditors knew when they should conduct a particular audit on which reporting lines, as the safety advisors would create the schedule upfront in the NOHARM system. The system would then send email notifications to remind the auditors for upcoming audits. On the spatial dimension, auditors also knew what types of audits they should conduct, which audit templates should be used, and how to tailor the templates for the targeted 
reporting lines. In short, the level of uncertainty involved in conducting audits had been kept low through well-established processes and systems.

Nevertheless, issuing corrective actions, or "selecting" as shown in Figure 26, was a much more challenging task for auditors. Before the E3 Company decided to let auditors be the sole decision makers on corrective actions, line-level safety advisors were brought in to help on decisions. These safety advisors knew more details about the operations and resources regarding the business lines they were working in thus could help auditors to design feasible and practical corrective actions that would be willingly accepted and executed by the managers of these reporting lines. After the change in January 2014, line-level safety advisors were removed from the process of issuing corrective actions to save time for the auditors to make quicker decisions on what should be done in the reporting lines failed safety audits. The assumptions were that auditors should have accumulated enough experiences to make optimal decisions on their own with the support from historical data collected in the NOHARM system.

Such assumptions, however, didn't reflect the reality. When issuing corrective actions, auditors were faced with higher level of uncertainties at both temporal and spatial dimensions. The four auditors were responsible for over 140 audits spread across 93 reporting lines, every month. To maintain neutrality and avoid building reciprocity, auditors had been shuffled around on a weekly basis to audit safety practice in different reporting lines which often operate in very different business areas. This alone made it hard for auditors to retain in-depth knowledge of the operational level details at the reporting lines they audited. 


\section{Low Synchronicity}

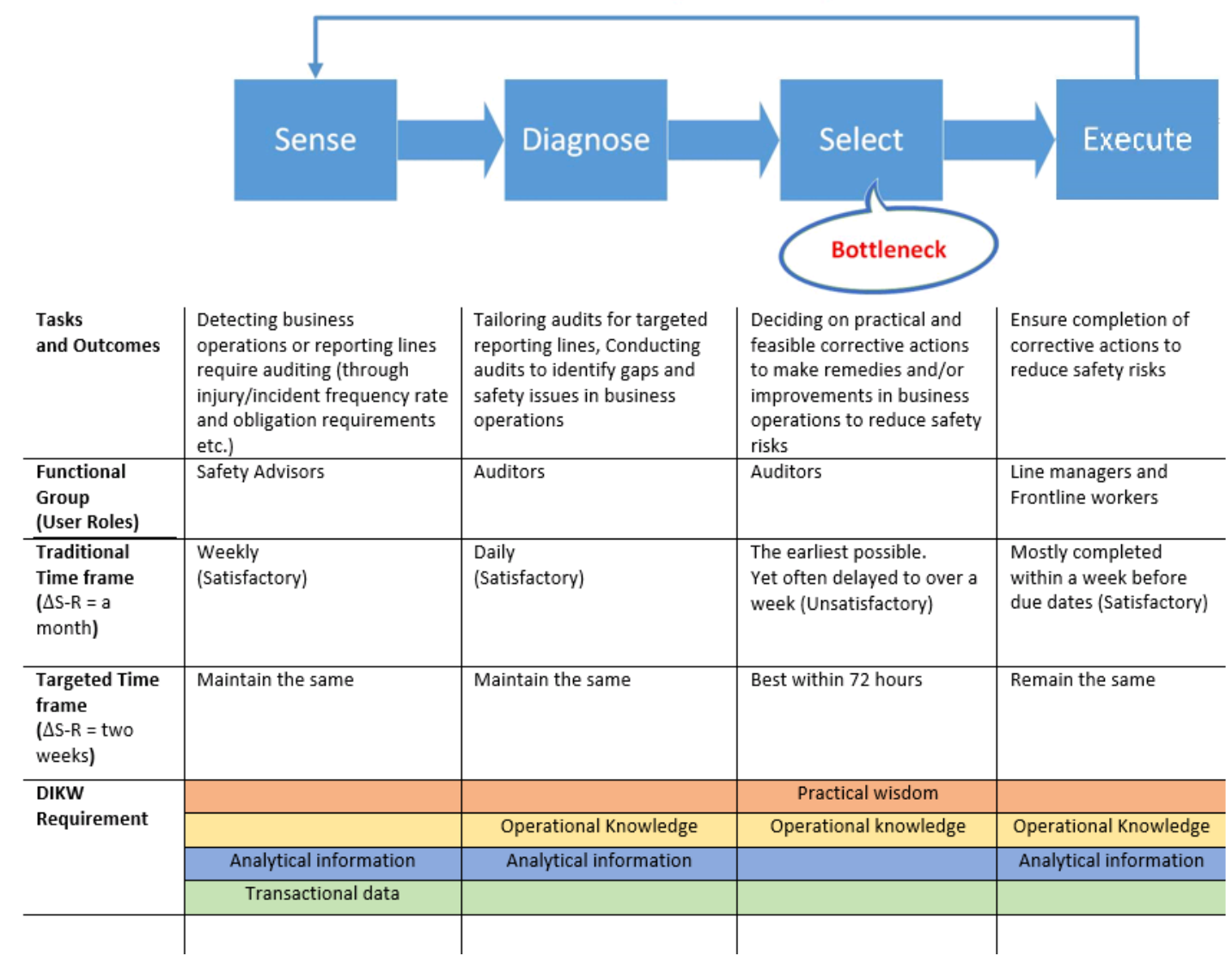

\section{Figure 26: The SDSE Mapping Table for Episode Three}

Consequently, on the spatial dimension, without the support from line-level safety advisors, auditors started to have more doubts about what should be considered feasible and practical actions for line managers to take on after failed certain audits. Not to mention novel issues came along with the introduction of new equipment and technologies boosted by the expansion of business operations. Safety auditors had to put in extra time to deliberately study the operational level details of reporting lines they intended to issue corrective actions.

Even after a deliberately designed corrective action was decided, an auditor could still have uncertainty on the temporal dimension meaning he/she could not be sure about the time needed for the action to be completed by the targeted reporting line. Experienced auditors would be very careful not setting unrealistic due dates for 
corrective actions as this would cause conflicts between safety auditing and business operation. Setting unrealistic due dates would later result in overdue actions, yet the number of corrective actions overdue vs. closed on time was one of the KPI measures for line-level safety performance.

This had long been a dilemma for safety auditors. Setting aggressive due dates on corrective actions would not only cause bad-looking safety performance stats with many overdue actions highlighted in red but disturb the priorities of line managers which would have a negative impact on business operation and production. On the other hand, conservative due dates would cause unnecessarily delay in corrective action. Such delay would result in safety issues not being fixed in time which then could lead to undesirable safety incidents (e.g. personal injuries or property damages).

As shown in Figure 26 above, after mapped the E3 Company's auditing process into the SDSE loop, the bottleneck was apparently at the "Select" phase where auditors got stuck and slowed down. The issue was not much on the Dev Agility from the IS development side, but mostly focused on Ops Agility where IS users couldn't get enough support to go through the SDSE loop with a desirable level of Synchronicity.

As discussed in Chapter 2, the "Select" phase is mainly about making trade-offs between possible responses through assessing each one available. Dove's four metrics - time, cost, predictability, and scope - sum up the common criteria employed by decision makers (either implicitly or explicitly) during such an assessment (Dove \& LaBarge, 2014). At the E3 Company, auditors clearly had to compromise on the "time" metric but not others. They were not comfortable with issuing "quick patch jobs" that were not thought over carefully which could portray a negative image of the auditing team. The auditors were put in a difficult position as they could not effectively and efficiently assess all four metrics of the corrective actions on their own. After all, line mangers knew best about priorities, resource and time available in their own reporting lines thus they were in a better position 
than safety auditors to tell if corrective actions were feasible and practical according to local circumstances.

Figure 26 also introduced the DIKW (Data-Information-Knowledge-Wisdom) cognitive hierarchy (Rowley, 2007) which helped me to understand and articulate why the "Select" phase went out of Synchronicity. The DIKW hierarchy has been widely cited in various contexts as a classification scheme for of human cognition. For instance, the DIKW hierarchy has been an often recommended theoretical model for knowledge management in the ITIL (Information Technology Infrastructure Library) training courses. More practically, some thoughtful software engineers have adopted the DIKW hierarchy in their requirement engineering 18 process to clarify the level of cognitive support a system could provide to human agents.

As an IS designer myself, I have found the DIKW hierarchy useful for analysing the "supply and demand" relationship between IS and IS users. For the purpose of solving this particular problem in the auditing process faced by the E3 Company, I termed the four levels of DIKW as "Transactional data - Analytical information Operational knowledge - Practical wisdom". I coloured each level to represent its supply in the IS against the demand from IS users. Red means "not available", Orange "little if not no", Blue "sufficient", and Green "abundant".

As shown in Figure 26 , at the E3 Company, particularly in the safety auditing process, the "Sense" phase was done by safety advisors who needed to access "transactional data" and "analytical information" which were strongly supported by the IS, i.e. the NOHARM system, thus they could complete their tasks within a satisfactory timeframe. The "Diagnose" phase was done by auditors who mostly needed "operational knowledge" of how to conduct safety audits, and "analytical

\footnotetext{
${ }^{18}$ http://mitosystems.com/how-to-write-requirements/
} 
information" of how the reporting lines being audited were tracking against safety performance targets. The need for "analytical information" was directly satisfied by the NOHARM system, whereas the need for "operational knowledge" was satisfied by the auditors themselves as they were all competent and well-trained safety auditors. Therefore the "Diagnose" phase had no trouble to be completed in time.

Nevertheless, the "Select" phase, as shown in Figure 26 above, required "operational knowledge" and "practical wisdom" regarding the operations and resources at the reporting lines being audited. The knowledge and wisdom needed was clearly out of reach to an "information" system (i.e. the NOHARM) yet was not possessed by the human agents (i.e. the safety auditors) who were assigned to be the sole performer of the "Select" task and to decide on corrective actions. Such knowledge and wisdom was more accessible to line managers, yet they were not involved in the "Select" phase at all. The line managers only got called in at the "Execute" phase to allocate resources and supervise the execution of corrective actions prudently evaluated and decided by safety auditors at the "Select" phase. Following the same logic, unsurprisingly the E3 Company had no issue at the "Execute" phase because as long as the corrective action selected were practical and feasible, line managers with abundant "operational knowledge" supported by the NOHARM system providing sufficient "analytical information", would execute them within a desirable time frame.

Through the above structured analysis, it became clear that the "Torque" at the "Select" phase was too low to drive the auditing process forward in Synchronicity with other phases of the Ops Agility cycle, i.e. "failing audit and issuing corrective actions". The auditors were the only driver pushing through the decision process, yet they often did not have immediate access to the operational knowledge and practical wisdom needed for the decisions. Not to mention that the auditors were already swamped and interrupted on a regular basis as they needed to travel from one site to another to conduct scheduled safety audits. 
On the other hand, the "Friction" was high enough to keep the agent (i.e. safety auditors) from choosing responses in a timely manner (i.e. prompt decisions on corrective actions). The practicality and feasibility of the decided corrective actions seemed to be commonly associated to the reputation and authority of auditors. Auditors were openly concerned that corrective actions with poor practicality and feasibility would cause complaints or even rejections from line managers due to the potential interruptions on business operations.

Resultantly, although the E3 Company had expected a shorter $\Delta \mathrm{S}-\mathrm{R}$ by demanding a "less than 72 hours" response time between "failing audits" and "issuing corrective actions", all four auditors found it difficult to achieve. They would not risk issuing corrective actions that potentially could be considered "impractical" or "unfeasible", rather, they would deliberately spend more time and effort on ensuring the quality, not the speed, of their decisions.

\subsubsection{The Final ISACAM-Driven Solution and Results}

Through ISACAM problem space analysis, it became clear that to bring Synchronicity into the SDSE cycle of the auditing function at the E3 Company, the key was to improve the performance at the "Select" phase. In this auditing scenario, such a "Select" phase required operational knowledge and practical wisdom which were not directly accessible to the sole performer (i.e. the auditors) of this phase. Other human agents (i.e. line managers) who possessed these knowledge and wisdom were left out from the "Select" phase.

Consequently, the auditors were unable to make prompt and confident decisions on corrective actions. In other words, the auditors were stuck in the deliberative mode, not moving to the implemental mode (Gollwitzer, Heckhausen, \& Steller, 1990), and kept elaborating on the correctivness of their decisions before issusing them. Given the large amount of cognition-consuming activities (i.e. safety audits) they needed to perform on a daily basis at the E3 Company, the auditors could frequently reach a 
state of decision fatigue where deciding on corrective actions involving a high level of uncertainty became annoying or even interminating.

From an IS designer's point of view, an effective solution to the problem at the E3 Company should improve the "Torque" and reduce "Friction" by feeding the "Select" phase with the needed knowledge and wisdom. Following this logic, we proposed two approaches to achieve this goal. The first one was to somehow extract the knowledge and wisdom from the line managers and store them in the NOHARM system for auditors to access when needed. The second one was to bring line managers into the "Select" phase and make them a part of the decision-making process for issuing corrective actions.

The first approach was considered too costly and risky thus rejected. Firstly, the operational knowledge and practical wisdom needed at the "Select" phase were predominately tacit in nature thus systemically capturing them in an IS could be extremely difficult. Not to mention there were 93 line managers at the E3 Company meaning the knowledge and wisdom capturing effort could take excessive amount of time. Secondly, the NOHARM system was designed to be a workflow-driven IS to facilitate flexible processes and collect data/information generated through the processes, instead of an intelligent decision system designed to make optimal selection of corrective actions based various factors and variables needing human knowledge/wisdom. Therefore, the E3 Company should expect the knowledge and wisdom needed for selecting corrective actions to come from human agents, not the IS.

The second approach was deemed practical and implementable. To bring the line managers into the decision-making process for issuing corrective actions, it was to remove the cognitive burden from safety auditors. To achieve this, a system modification was proposed to automatically create a corrective action for each failed audit questions and assign to the line manager responsible. If an auditor failed a reporting line on a particular safety audit (normally containing 30 to 40 audit 
questions), the specific questions failed would be used as default titles for corrective actions. These tentative corrective actions were meant to be reviewed and adjusted by the line managers in charge thus the default due dates would be set as three days (72 hours) initially. The line managers would receive email notifications from the NOHARM system indicating new corrective actions had been created and needed to be reviewed and accepted. They then would assess the feasibility and practicality of the auto-generated corrective actions to their own reporting lines within the given 72 hours. Next the line managers would add their comments/reasons and choose to modify, accept, or close the auto-generated actions. Corrective actions with similar requirements could be merged into one. Generic actions should be localised and specified in the business context of the targeted reporting lines. Line managers were in a far better position to do these than safety auditors. Once a line manager accepted a corrective action, he/she needed to assign a new achievable due date for the action to be executed and completed.

This "auto-suggestion" approach let the IS (i.e. the NOHARM system) decide on corrective actions which then reviewed and accepted by relevant line managers. Auditors no longer needed to be concerned with optimising corrective actions to acknowledge line level operational and contextual details. This approach was both a "Torque Booster" and a "Friction Reducer". It created ultimate "Torque" to move the "Select" phase forward by allowing the IS to take control and generate corrective actions immediately after failed audits. The system-generated corrective actions were intended to be primitive compared to those prudently designed by human auditors. However, they would become highly practical and feasible as line managers were called in by the IS automatically to review, adjust, and accept those actions within 72 hours. This approach minimised the original "Friction" by reducing the cognitive load and concerns of auditors. In fact, auditors no longer needed to gather, remember, and recall operational details of reporting lines failed their audits. They would just focus on conducting high quality safety audits and not 
be slowed down by having to find time for deciding on the optimal corrective actions.

\section{Results}

The "auto-suggestion" solution was technically straightforward and implemented directly in the following sprint in April 2014. The NOHARM system started to autonomously issue corrective actions and send email notification to line managers whenever their reporting lines failed safety audits. The line managers were informed by the system to review, modify, and accept these actions in 72 hours. Once a corrective action was accepted by the relevant line manager, it was considered "issued successfully".

Table 35: Number of Audits Started and Corrective Actions Issued at E3 Company From April 2013 to August 2014

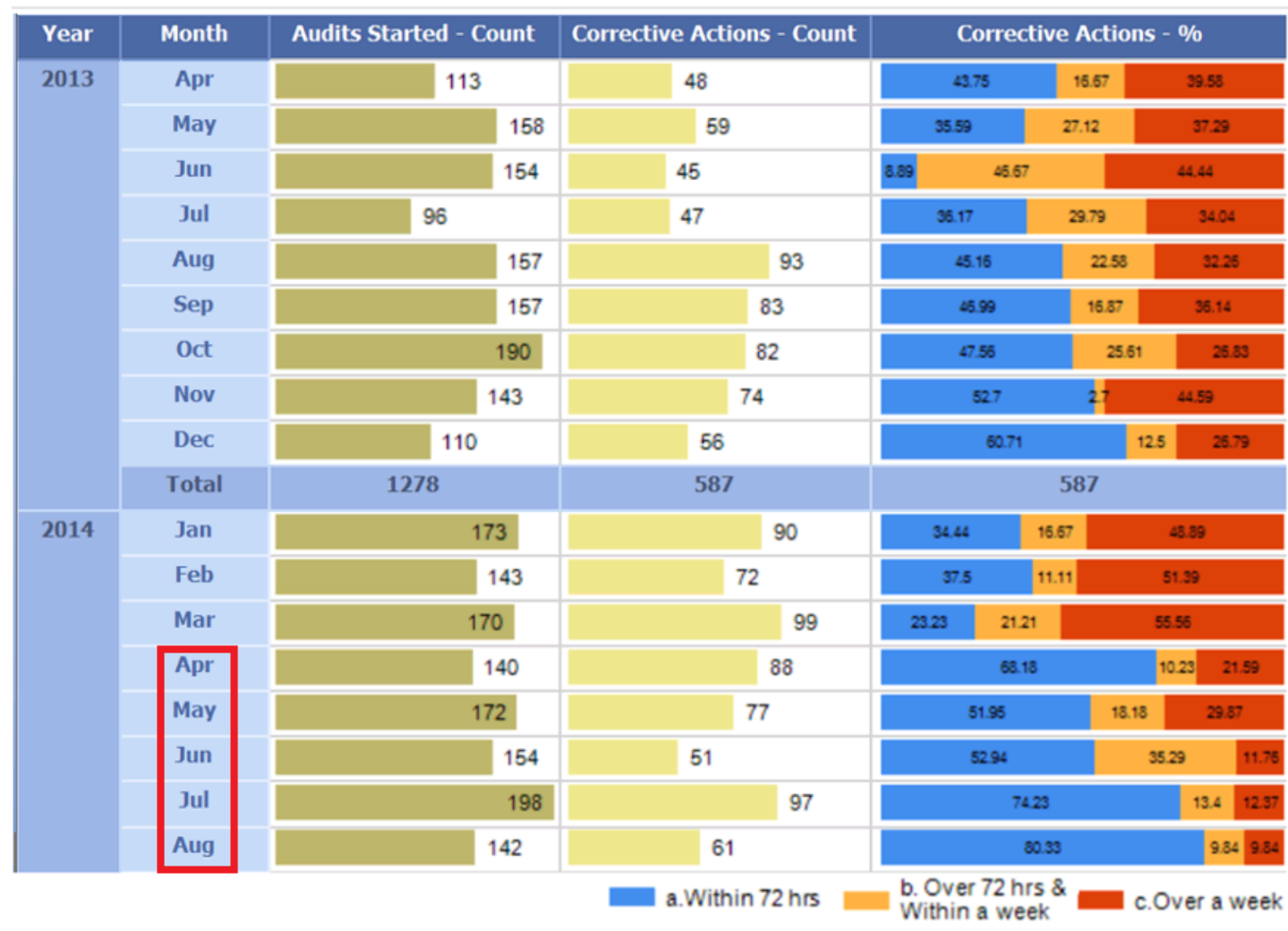

Data Source: The NOHARM System (Visualised in Microsoft SSRS 2014) 
Such a system-driven "Select" phase freed up safety auditors from difficult decisionmaking efforts, as well as enforced a shorter time frame for issuing corrective actions after failed audits. The E3 Company began to see clear improvement in performance and a sharp drop in the percentage of delayed corrective actions. As shown in Table 35 above, the percentage of corrective actions issued over a week after failed audits had dropped from the original over $50 \%$ on average in the first three months of 2014 , to some $20 \%$ and then $10 \%$ in the following months. The percentage of corrective actions issued within 72 hours continued to climb up from as low as $23.23 \%$ in March 2014 to as high as $80.33 \%$ in August 2014.

\subsubsection{Episode Summary and Reflection in Action}

Episode Three was focused on improving the "Select" capability to bring "Synchronicity" back into the Ops Agility cycle of the safety auditing process. This episode led me to examine the need for articulating the limitations of IS in terms of supporting cognitive activities of human users. Being able to illustrate on the cognitive hierarchy to articulate what an IS can/cannot support could help users to understand their choices and why one solution is considered over another.

In reality, improving agility in operational processes sometimes can be as simple as having the IS to drive the right persons to do the right tasks. This is especially practical and feasible when it is unbearably expensive and risky to make attempts of replacing the right persons with machines/algorithms by extracting and consolidating the operational knowledge and practical wisdom needed from those highly skilled human agents.

The NOHARM system was able to generate enough "Torque" to speed up the "Sense" and "Diagnose" phases by providing strong support to safety advisors and auditors regarding transactional data and analytical information. However, at the "Select"

phase, what needed the most were operational knowledge and practical wisdom, which were clearly not possessed within a process-oriented workflow-driven IS. In fact, I suspect any contemporary business IS could claim optimal support at 
knowledge and wisdom levels of the cognitive hierarchy. After all, the term IS stands for "Information Systems" which are specialised in certain business operations and management such as ERP, CRM, SCM, and so on. These types of systems are designed to facilitate and supervise business processes and workflows. Their fundamental promise is to capture and process business data and information, not to guarantee the provision of knowledge and wisdom.

On reflection, the ineffectiveness of E3 Company's initial solution (i.e. letting safety advisors alone to decide corrective actions) could also be explained through the levels of cognitive hierarchy supported by the IS (i.e. the NOHARM system). The E3 Company was hoping data collected and information produced in an IS could enable their auditors to make prompt yet optimal decisions on matters that clearly require operational knowledge and practical wisdom from outside the IS. To these safety auditors, acquiring enough knowledge and wisdom needed would involve predominately manual effort which they could hardly afford.

The machine-driven automation created in Episode Three was not designed to outsmart human decision makers. Rather, it was to minimise human-entailed procrastination and anxiety. We humans, when faced with important decisions, tend to think long and deep, especially when the outcomes of these decisions may induce challenges from other human counterparts. The safety auditors at the E3 Company were in the position to decide on corrective actions without enough understanding of the changing business operations and resource allocation in the reporting lines having to execute these actions. Concerned with causing conflicts or challenges from line managers, those auditors were anxious about the potential of issuing impractical/unfeasible actions. In the meantime, safety auditors had always got their own excuses (i.e. already busying with traveling between sites to conduct safety audits) to procrastinate on making the hard decisions.

In the same manner to previous episodes, Table 36 below summarises the main points of Episode Three. In this episode, the decisions made by machines (i.e. the IS) 
automatically were simple and sometimes naïve yet could pull the human counterparts into the cycle to contribute. In the new process of issuing corrective actions after failed audits, no human agents would be held accountable for the decisions made by machines. Instead, safety advisors became free from having to make these decisions they were struggling with, while line managers only needed to look after those machine-generated corrective actions assigned to their own lines of business (could be only a handful for each line every week). A line manager would possess relevant operational knowledge and practical wisdom to review and consolidate the machine-generated corrective actions into feasible and practical ones and set realistic expectations for his/her staff members to execute in the shortest time frame reasonable. Of course, a line manager could demonstrate that his/her intelligence is superior to the machines without hurting the feelings of anyone.

Table 36: A Brief Summary of Episode Three

\begin{tabular}{|c|c|c|}
\hline \multicolumn{3}{|c|}{ Functional Group: Safety Auditors - from the E3 Company } \\
\hline \multicolumn{3}{|c|}{$\begin{array}{l}\text { Episode Three - Excessive delay in issuing corrective actions after failed safety } \\
\text { audits }\end{array}$} \\
\hline \multicolumn{3}{|c|}{ The original solution - summarised in Abstraction Decomposition Space(partial) } \\
\hline $\begin{array}{l}\text { System } \\
\text { Purpose }\end{array}$ & Improve workplace safety, reduce injuries, and control risks & \\
\hline Domain Values & $\begin{array}{l}\text { Proactively identify safety issues to correct and improve } \\
\text { through intensive auditing }\end{array}$ & \\
\hline $\begin{array}{l}\text { Domain } \\
\text { Functions }\end{array}$ & $\begin{array}{l}\text { Conduct audits at defined time and places and Select } \\
\text { corrective actions for failed audits }\end{array}$ & \\
\hline$\frac{\text { Technical }}{\text { Functions }}$ & $\begin{array}{l}\text { Initial User Driven Solution: Granted safety auditors full } \\
\text { authority to decide on corrective actions independently } \\
\text { from other parties }\end{array}$ & \\
\hline $\begin{array}{l}\text { Physical } \\
\text { Resources \& } \\
\text { Material } \\
\end{array}$ & $\begin{array}{l}\text { Each safety auditor had reliable Internet connection for } \\
\text { accessing the audit templates, incident records, and action }\end{array}$ & \\
\hline
\end{tabular}




\begin{tabular}{|l|l|l|}
\hline$\underline{\text { Configuration }}$ & scheduler provided in the web-based information system & \\
\hline$\underline{\text { Results }}$ & & \\
\hline
\end{tabular}

ISACAM (V1.2) based Problem Analysis

Change Frequency: High Uncertainty: High Information Intensity: High

Time Criticality: High

Problem lies on Ops Agility Cycle: Yes Dev Agility Cycle: No

$\Delta S$-R: Currently a month, expected to be two weeks

\begin{tabular}{|l|l|}
\hline Symptoms & $\begin{array}{l}\text { Many corrective actions were not issued within a desirable } \\
\text { timeframe (72 hours) after failed safety audits. Instead, a } \\
\text { large percentage of them were issued later than a week } \\
\text { after the completion of audits. }\end{array}$ \\
\hline Root Causes & $\begin{array}{l}\text { Safety auditors were the only agents responsible for } \\
\text { deciding corrective actions after failed audits, yet they did } \\
\text { not possess the operational knowledge and practical } \\
\text { wisdom needed to make optimal decisions. Spatial } \\
\text { uncertainly was high as safety advisors were unsure what } \\
\text { would make a corrective action practical and feasible to a } \\
\text { particular reporting line. Temporal uncertainty was high as } \\
\text { safety advisors could not estimate the time and effort } \\
\text { needed to complete the corrective actions in a targeted } \\
\text { reporting line. Moreover, the safety advisors were already } \\
\text { busy with conducting safety audits on a daily basis thus } \\
\text { they tended to wait and elaborate to seek prudent decisions } \\
\text { on corrective actions that would not endanger their } \\
\text { authority and reputation. }\end{array}$ \\
\hline ISACAM based Solution Design \\
\hline $\begin{array}{l}\text { Torque } \\
\text { Booster }\end{array}$ & $\begin{array}{l}\text { A new machine-driven function was created to } \\
\text { automatically generate a corrective action right after a } \\
\text { failed safety audit question and immediately assign this } \\
\text { action to line manager in charge to review and accept } \\
\text { within 72 hours. }\end{array}$ \\
\hline$\underline{\text { Friction }}$ & $\begin{array}{l}\text { Same as above. Due to the original struggling human } \\
\text { decision maker (i.e. safety advisors) being removed from } \\
\text { the process, the initial Friction caused by human-entailed } \\
\text { procrastination and anxiety disappeared. The new decision } \\
\text { reviewers (i.e. line managers) were more efficient and }\end{array}$ \\
\hline
\end{tabular}




\begin{tabular}{|l|l|l|}
\hline Results & $\begin{array}{l}\text { pragmatic as they had the knowledge and wisdom to ensure } \\
\text { the feasibility and practicality of corrective actions by not } \\
\text { challenging any human counterparts any more but merely } \\
\text { decisions made by the information system. }\end{array}$ & $\begin{array}{l}\text { In the following five months, the percentage of corrective } \\
\text { actions issued over a week after failed audits had dropped } \\
\text { from the previous 55.56\% to a historical low 9.84\%. The } \\
\text { percentage of corrective actions issued within 72 hours } \\
\text { continued to climb up from as low as 23.23\% in March } 2014 \\
\text { to as high as 80.33\% in August 2014. }\end{array}$ \\
\hline Evolution of ISACAM & $\begin{array}{l}\text { Cognitive_Hierarchy (Data - Information - Knowledge - Wisdom) was added } \\
\text { as a new dimension for solution design to explicitly identify level of cognitive } \\
\text { support that can be provided to users by an IS. }\end{array}$ \\
\hline
\end{tabular}

Uncertainty was playing a critical role in Episode Three, yet it was minimised when the new ISACAM based solution was implemented. Spatial uncertainty was high as safety advisors were unsure what should be the optimal decisions on corrective actions. Temporal uncertainty was high as the auditors also could not estimate how much time should be allowed for completing corrective actions assigned to a targeted reporting line. However, these uncertainties and the associated anxiety were removed from the process after the NOHARM system started to issue corrective actions directly to line managers without interventions from safety advisors. Line managers were best informed to estimate time and effort thus they were the right persons to assess whether corrective actions were feasible and practical to their lines of business. In fact, given line managers began to assign due dates to their own corrective actions, they were more motivated and bound to complete the actions on time. 


\subsection{Ladders of Reflection}

\subsubsection{Reflection on Action - Some General Observations}

The three episodes reported in this chapter were exemplar applications of "reflection in action" which led to the development of ISACAM as an analytical method. Such a method was then evaluated through solving real-world IS Agility problems. The resulting success was beyond expectation yet was a testament of continuous "ladders of reflections" (Schön, 1983). As discussed in Chapter 4, Schön, in his classic 1983 "The Reflective Practitioner" book, argued that action, and reflection on action make a ladder where every action is followed by reflection and every reflection is followed by action in a recursive manner. "Doing extends thinking in the tests, moves, and probes of experimental action, and reflection feeds on doing and its results" (Schön, 1983)(p.280). Possible objects of reflection, according to Schön, can vary depending on the phenomena of interest and the knowledge of the reflective practitioner. One can reflect through a more theoretical lens on objects such as "the tacit norms and appreciations which underlie a judgement" and "strategies and theories implicit in a pattern of behaviour", or from a more practical perspective on objects such as "feeling for a situation led to adopt a particular course of action", "the way in which he has framed the problem he is trying to solve" and "the role he has constructed for himself within a larger institutional context" (Schön, 1983) (p.62).

My role as the reflective practitioner in this research project, can also be seen as a reporter attempting to explicitly articulate "situated cognition" and "situated action" associated with problem-solving activities (Young \& McNeese, 1995) in a systematic and replicable manner, and in the form of ISACAM. As a SaaS provider who is trying to accommodate different organisations from various industries, using a multitenant architecture based on the same source code and data structure, the IS development team I have been working with often receive various change requests from client organisations. However, many changes or solutions proposed by clients 
are ad-hoc, and far from systematic with a strong sense of avocation. As Schön (1983, p.22) cited from Wilbert Moore that "avocation is the antithesis to a profession...is based upon customary activities and modified by the trial and error of individual practice". Such a sense of avocation can be felt stronger while clients are requesting a significant system change to accommodate their own improvised solution in order to solve a minor problem that will not even exist if their business operations were optimised.

Unlike traditional on-premises IS which are often dedicated to only one organisation or business function, with the SaaS model, a service provider cannot tolerate much of the "avocation" style solutions from clients for two reasons. Firstly, the sustainability and profitability of a SaaS business is relying on its multi-tenant model, meaning all clients are sharing the same system design, database structure, source code, and infrastructure. Changes beneficial to only one SaaS client or just a small group of clients may not be useful to the rest of the client base. Moreover, functional changes made for only one client may cause disruption in the system that could bring negative impact on the operations of other clients. Secondly, the number of SaaS clients will continue to grow unless the provider is out of business, meaning change requests will keep increasing especially when new clients are subscribing to the SaaS. Without a systematic means to filter out "avocation" style solutions requested by clients, a SaaS provider can be swamped quickly and end up being less responsive or even paralysed. Consequently, failures to meet the SLAs (Service Level Agreements) may occur on a regular basis.

In retrospect, I have realised that the reasoning behind "avocation" style client solutions is mostly based on the narrow views they hold towards certain parts of the system relevant to their own work domain. In other words, client users are confined by their own work domain knowledge and practices, thus often do not think beyond the common and familiar processes they have been following for years. Instead of consciously constructing a "problem space" to incorporate all the issues 
they have experienced using the NOHARM system to manage their safety risks, client users tend to see problems as individual occurrences to be addressed one after another. Furthermore, SaaS users often do not have time and energy to analyse IS Agility related problems deeply enough to identify the root causes. After all, they are professionals specialised in their own work domain (i.e. safety and risk) who would rather spend their efforts on analysing problems directly within their domain (e.g. the effectiveness of control measures to certain safety risks).

In contrast to client users, designing, developing, and implementing multi-tenant IS for large number of clients is our profession as SaaS providers. However, in the IT industry, we do not seem to have an established, "profession" style method to handle IS Agility problems raised by clients using our systems and services. Many SaaS providers remain in the same tradition to offer online help, support desk, user training, and etc. These are all classic approaches but not directly helpful to clients who are faced with IS Agility problems. Again Schön (1983, p.22) cited from Wilbert Moore, noted that "profession involves the application of general principles to specific problems, and it is a feature of modern societies that such general principles are abundant and growing". Ironically, the lack of a "profession" style solution to IS Agility problems is common among "IS professional" and "IS researchers". A key reason to such a common weakness is that agility is a complex concept thus it has been very difficult to construct a "problem space" for IS Agility problems. The dimensions of such a problem space are either missing or only incomplete in the existing literature (as discussed in Chapter 2). The "general principles" for solving IS Agility problem, therefore, do not exist in the literature.

During my PhD journey and my tenure with the NOHARM SaaS provider, one interesting phenomenon is that the IS Agility problems encountered have been predominately on the Ops Agility cycle, namely, from the IS user side, rather than on the IS developer side. On reflection, I have observed an obvious power imbalance between the IS users and IS developers, particularly in the SaaS context. With the 
SaaS delivery model, one business IS provider needs to directly serve hundreds, if not thousands, of client organisations in real-time. These SaaS clients can come from different industries with distinct business operations. To be able to handle new requirements and change requests from such a client base, SaaS providers have to seek every means to stay agile in system development and deployment to survive and thrive.

For instance, the NOHARM development team has adopted one of the proven agile methodologies, Scrum, to manage ever-changing client requirements and organise short iterative software development cycles (represented as "Agile SystemDevelopment" in the IS Agility Pyramid from Chapter 2). The NOHARM system has been designed in a modular manner following the SOA principles and implemented as a cluster of independent web services (represented as "Agile-System Architecture" in the IS Agility Pyramid). Furthermore, an intelligent code generator and a version control server have been extensively utilised to improve speed and quality of programming in order to catch up with the fast iterations defined by the Scrum methodology. In short, as a SaaS provider, the NOHARM development team need to and must prepare themselves for optimal Dev Agility to be able to withstand changes initiated from the increasing client base and the "globally wired" competitors.

On the other hand, SaaS users (e.g. the NOHARM client base) often are not prepared or equipped with the knowledge and skills to configure and operate their IS for optimal Ops Agility. Even though users have the demand to improve agility, there is just little if no reference and guidance for them to do so. Unlike the plethora of academic studies and industry white papers focusing specifically on the IS developer side of Dev Agility (e.g. Agile Methodologies and SOA), the user side of Ops Agility had not even been clearly defined prior to this study. The lack of systematic approaches to improve Ops Agility and solve associated problems indicates a clear knowledge gap in both the academia and the industry. However 
there seems to be an optimistic hope that those more strategy-oriented studies on "Organisational Agility" might somehow stretch far enough to fill this gap. But this is apparently not happening in any near future.

Another interesting experience is that in all these years, there were barely any "executing" problems raised by the NOHARM clients. I have seen all sorts of issues raised by users relating to "sensing", "diagnosing", and "selecting" phases of the agility cycle, yet it seems every client has been satisfied by their "execute" capabilities supported by the NOHARM system. In the context of the NOHARM system, the "execute" phase is mostly instantiated as the completion of "corrective actions". These corrective actions could be generated from incident investigations, failed safety audits, hazard identifications and so on. These actions are all critical tasks and need to be executed promptly and carefully to rectify errors, fix issues, isolate hazards, or in general, minimise safety risks. In safety risk management, once a corrective action is created, a "due date" and a "person responsible" will be assigned. In the NOHARM system, as an extra caution, we allow users to assign a second person to the action as "person to close" the action and a "priority" to be set by the line manager in charge. All NOHARM clients treat "overdue" actions seriously and many set the percentage of overdue actions as a lag indicator for safety performance. To help NOHARM users keep actions completed on time, we have developed an analytical dashboard for all client organisations to visually track their progress on actions, as well as a to-do list style operational dashboard to remind individual users regarding the open actions assigned to them.

My reflection on the lack of "executing" problems, even though a positive one, is that the two agility drivers "Information Intensity" and "Uncertainty" often reduce their effect at the "execute" phase. This might be a curious case of the particular NOHARM system but could still be true in the context of IS designed for other purposes. My observation is that the actions created in the NOHARM system contain very specific information prescribing who to execute, when to execute, what to do, where to do, 
etc. Such an approach provides just enough, not excessive, information to execute the actions, and allows little uncertainty to the persons being assigned to those actions. This way the person responsible could drive straight into an "implemental mode" without getting stuck at a "deliberative mode" (Gollwitzer et al., 1990).

\subsubsection{Reflection on Technological Rules and ISACAM Artefacts}

Through my problem-solving practice in the above episodes and other unreported, less intensive experiences, I began to observe common patterns in the successful solutions. These patterns are summarised in Table 37 as "technological rules" to be considered while using ISACAM to solve IS Agility problems. Technological rules are typically heuristic rules generated through prescription-driven design science research (Aken, 2004). According to Aken (2004), heuristic rules are indeterminate in nature, thus are to be used in an instrumental way. They are not specific prescription for a specific setting, rather, are general principles to a class of problems. Aken (2004) further argued that "A practitioner has to design his/her own intervention or system, on the one hand based on his/her experience, creativity and deep understanding of his/her local setting, and on the other (hand) on the knowledge of the appreciate technological rules of their generative mechanisms and of their supporting evidence" (Aken 2004, P.238). 


\section{Table 37: ISACAM Technological Rules}

\begin{tabular}{|c|c|}
\hline & ISACAM-driven Technological Rules \\
\hline TR1 & $\begin{array}{l}\text { IF need to improve the overall IS Agility in a business area, first differentiate Ops } \\
\text { Agility cycle from Dev Agility and identify which cycle(s) the problem lies. }\end{array}$ \\
\hline TR2 & $\begin{array}{l}\text { IF need to improve the performance of a particular agility cycle (Ops or Dev), first } \\
\text { define a measurable target } \Delta S-R \text { value and then measure the current } \Delta S-R \text { value, } \\
\text { next identify where the bottleneck is in the SDSE loop, and then design Torque } \\
\text { Booster and Friction Reducer to resolve it. }\end{array}$ \\
\hline TR3 & $\begin{array}{l}\text { IF need to design a Torque Booster or a Friction Reducer, a starting point is to } \\
\text { control the level of uncertainties by explicitly establishing order and confidence in } \\
\text { either spatial or temporal dimension. }\end{array}$ \\
\hline TR4 & $\begin{array}{l}\text { IF need to increase Torque and reduce Friction for an SDSE loop and the targeted } \\
\text { processes only require data and information accessible to the IS in question, modify } \\
\text { the IS to automate the processes and maximise machine control. }\end{array}$ \\
\hline TR5 & $\begin{array}{l}\text { IF need to increase Torque and reduce Friction for an SDSE loop and the targeted } \\
\text { processes require knowledge and wisdom inaccessible to the IS in question, modify } \\
\text { the IS to solicit contribution from the right human agents who possess such } \\
\text { knowledge and wisdom. }\end{array}$ \\
\hline
\end{tabular}

As shown in Table 37 above, these heuristic "technological rules" are summarised using the terminology created in ISANN. These rules do not cover all aspects of ISANN, but only focus on those factors that enabled me to create effective solutions to IS Agility problems. Unlike prescriptions found in Heathrow-literature, the rules here are grounded in academic theories analysed in Chapter 2 and have justification from the effectiveness of their real-life implementations reported in the three episodes at the beginning of this chapter.

TR1: IF you want to improve the overall IS Agility in a business area, first differentiate Ops Agility cycle from Dev Agility and identify which cycle(s) the problem lies.

This rule is critical to the success of solution design to solve IS Agility problems. When agility problem is raised in the IT space, service providers or software vendors tend to jump directly into the Dev Agility realm and start preaching Agile 
Software Development Methodology (hereafter "agile methods"). Users, on the other hand, tend to have little choice but believe in that agile methods would deliver the agility they are after. However, adopting agile methods, although can improve responsiveness and throughput of an IS development team to handle changing user requirements, itself alone is not the cure to Ops Agility problems.

In all the three episodes reported previously, the SaaS clients had no complaints towards the Dev Agility of our development team at all. Rather, they were puzzled by the gap between their expected improvement in operational performance and the actual reality. The IS users simply did not know how to leverage the IS to optimise their performance in the business areas they intend to excel. In such a scenario, agile methods adopted by the IS development team would not solve the Ops Agility problems faced by the IS users. Being able to explicitly identify and articulate which agility cycle needs improvement is the crucial first step towards effective solutions.

TR2: IF you want to improve the performance of a particular agility cycle (Ops or Dev), first define a measurable target $\Delta S-R$ value and then measure the current $\Delta S$ - $R$ value, next identify where the bottleneck is in the SDSE loop and then design Torque Booster and Friction Reducer to resolve it.

This rule brings clarity to the problematic situation and sets up realistic expectations (i.e. a measurable and justifiable target $\Delta S$ - $R$ value). It forces the problem solver to be disciplined by mapping the whole chain of activities suffering from the lack of agility, into the SDSE loop recommended in this thesis. Through examining the performance of each of the four phases (i.e. Sense, Diagnose, Select, and Execute), the problem solver will discover which phase is out of Synchronicity and becomes a bottleneck to the rest. In this thesis, such an exercise is visualised in a SDSE mapping table (see Figure 27 below taken from Episode Three). Next, the problem solver should aim at optimising the most constrained area to improve the performance of the whole SDSE loop. Such an approach has been described as 
"Theory of Constraints", which is another widely cited "technological rule" designed by (Goldratt, 1990) for maximising the output of a factory.

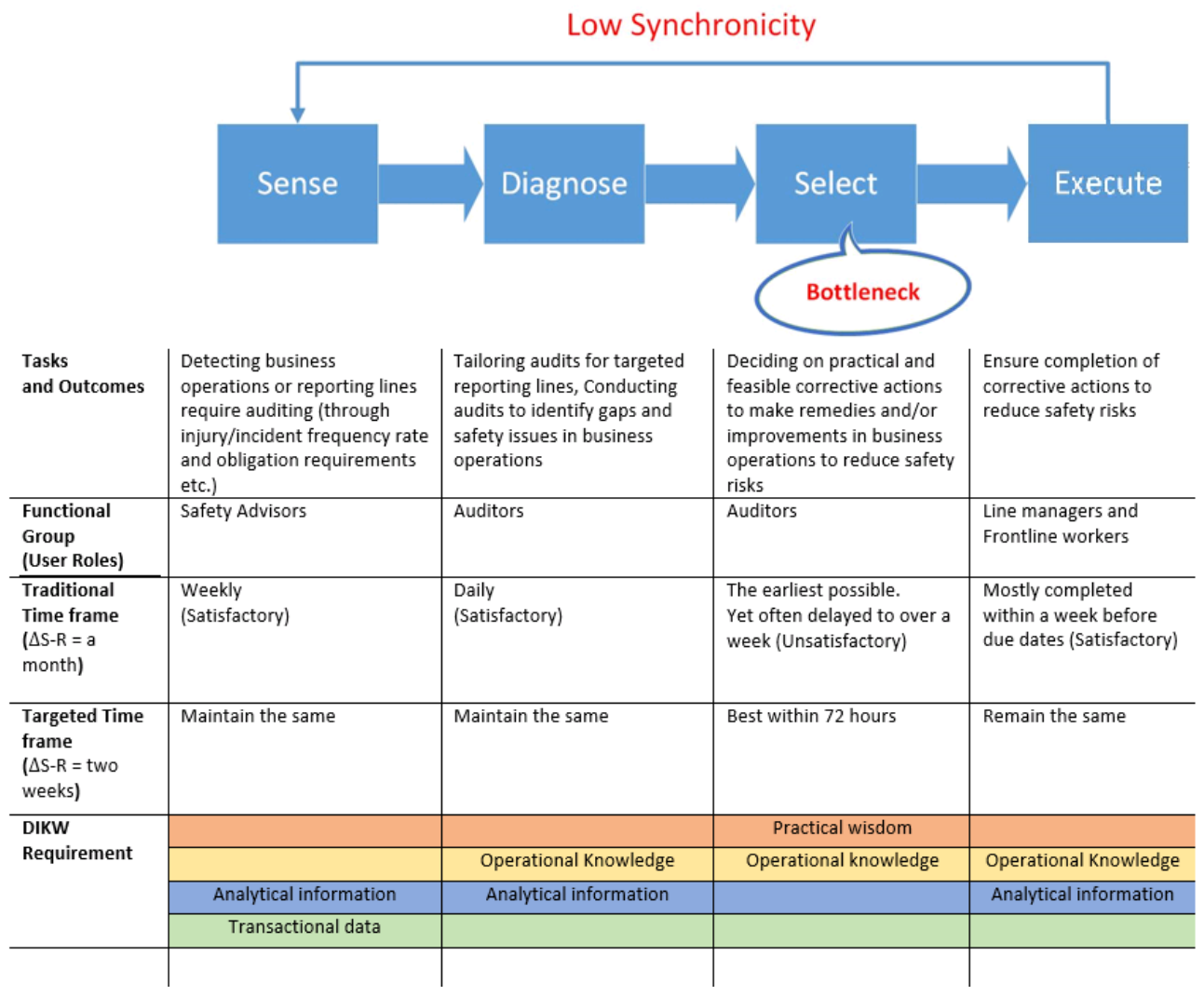

Figure 27: Recap The SDSE Mapping Table

The problem solver needs to identify who and what are responsible to each phase of the SDSE loop (illustrated in Figure 27 above as "Functional Group" and later added "DIKW requirement"), and to recognise the Torque vs. Friction dynamics as the driving and blocking mechanisms. As demonstrated in all the three Episodes, Torque Booster and Friction Reducer need to be explicitly defined and implemented for optimal results. The design of these mechanisms is to be guided by the next three rules below.

TR3: IF you want to design a Torque Booster or a Friction Reducer, first try to control the level of uncertainties by explicitly establishing order and confidence in either spatial or temporal dimension. 
This rule acknowledges the critical role of uncertainty plays in any agility problems. Uncertainty is often associated with some level of unpredictability on either temporal or spatial dimension (adopted from sports science, see Chapter 2 for detailed discussion). In this thesis, temporal uncertainty means that an agent can predict the possible changes needed in the future, but cannot predict when these changes will happen and in what sequence. Spatial uncertainty means an agent can predict when changes are going to happen, but just do not know what these changes are and what to do with them.

Depending on the nature of the operation, uncontrolled uncertainties in either spatial or temporal dimension can cause delay, especially for human agents, in making decisions and producing actions. Unlike machines, we humans have psychological reactions to uncertainties such as concerns and doubts. When high level of uncertainty present in the spatial dimension, the human agent is unsure about what to do and who should do it. Procrastination, avoidance, or even conflicts can quickly appear. Unless some level of assurance is given to establish a sense of order and confidence in the process, the situation could become chaotic and reactive fire-fighting. In such a situation, it is unrealistic to expect improvements or modifications in IS, or in other words, smarter machines, could alone solve the problem.

Therefore, the solution designed in Episode One, was to first change the human-side policy and procedure to ensure frontline workers confidently knew what the right things to do when a Near Miss event occurred, and who should be doing it on what equipment. The IS was modified to merely reinforce the spatial confidence by identifying and prompting desirable behaviours from human agents. In Episode Two, the spatial uncertainty was mitigated by first explicitly defining a set of criteria to diagnose if a safety event required further investigation. The IS was then enhanced to automatically pick out those safety events do not meet the criteria. Such automation effectively drove the SDSE loop forward. In Episode Three, it was 
unfeasible to extract a set of criteria to control spatial uncertainty faced by those safety auditors, thus the solution was to use the IS as a process management tool to solicit contribution from the line managers who perceived much less spatial uncertainty in deciding on corrective actions.

On the other hand, when uncertainties present in the temporal dimension, the human agents know what changes are going to happen and what to do when they happen, but he/she does not know when these will happen and in what sequence, thus has to stay alert and diagnose relevant signals to decide if the changes are coming. In military operations, such a daunting situation is often handled by dedicated and well-trained guards or scouts with specialised skills and knowledge. In the business environment, however, a human agent acting as a guard or a scout tend to have other duties at the same time, which means him/her can be frequently distracted and have difficulties to concentrate.

In Episode One, the solution to control temporal uncertainty was straightforward by officially allowing one frontline worker of each workgroup to spend up to one hour a day dedicated on operating the IS and recording Near Miss events. In Episode Two, the safety advisors were receiving over 100 email alerts every week and became overwhelmed due to the need for diagnosing every single alert whenever it came in. The IS was then modified to filter out some $90 \%$ of the noise. The email alerts were also converted into one single report and sent to the safety advisory team only once a day, which minimised interruptions originally caused by those scattered alerts coming in at random time during the day. In Episode Three, temporal uncertainty was controlled by using the IS to automatically issue corrective actions immediately after failed safety audits and assign a tentative due date for the human agents to follow up. The new agents called in by the IS (i.e. the line managers) perceived less temporal uncertainty (e.g. realistically when a corrective action can be completed) compared the previous agents (i.e. safety auditors). 
TR4: IF your need to increase Torque and reduce Friction for an SDSE loop and the targeted processes only require data, information, and knowledge accessible to the IS in question, try modifying the IS to automate the processes and maximise machine control.

TR5: IF you need to increase Torque and reduce Friction for an SDSE loop and the targeted processes require knowledge and wisdom inaccessible to the IS in question, try modifying the IS to solicit contribution from the right human agents who possess such knowledge and wisdom.

These two rules recognise the interplay between IS requirements on cognitive support and level of machine-controlled automation in business processes. If a process only requires data, information, or certain level of knowledge that is directly accessible to the IS, then full automation should be considered to improve effectiveness and efficiency. In Episode Two, to "diagnose" whether or not further investigation is needed for a safety event, the data (e.g. details of the safety event including when, who, what, how, etc.), the information (e.g. the classification and categorization of the safety event), and some simple knowledge (e.g. a set of criteria to articulate which classes and categories of safety events definitely do not need investigations) were all made accessible to the IS to perform the "diagnose" process without human intervention. Of course, line mangers were requested to review the "no investigation needed" type of safety events automatically picked out by the IS and provide feedback to improve the knowledge for better accuracy.

On the other hand, if a process heavily depends on complex knowledge (i.e. tacit knowledge that cannot be adequately articulated as a set of criteria) and even certain level of wisdom that only human agents have access to (e.g. organisational culture, office politics), then automation may be infeasible, let alone resulting in desirable outcomes. In Episode Three, to "select" a practical and feasible corrective actions after failed safety audits, both the knowledge (e.g. resource availability, task priority, effectiveness of similar actions from previous audits) and the wisdom (e.g. 
potential resistance from frontline workers, potential impact on KPIs) were not accessible to the IS and even to the human agents who were requested to perform the "select" process alone. Such knowledge and wisdom at the line level were only accessible to the line managers themselves. However, it was apparent that the knowledge and wisdom were too complex to be elicited and engineered into the IS in a timely manner, thus we could not give full control to the machines as the final authority to "select" corrective actions. Instead, the IS was used more as a workflow supervisor to take input from one group of human agents (i.e. auditors who failed reporting lines for not meeting the requirements of safety audits) and then trigger responses from another group of human agents (i.e. the line managers who failed safety audits).

Some may argue that the recent advancement in the Artificial Intelligence (AI) field may pose a challenge to the two above rules. However, my observation is, even with the most advanced deep learning technologies, automated decisions can only be as good as the training data sets used and the feedback systems deployed. In some business applications, such a training data set may not be readily available, or may be available but unusable due to data quality issues. Not to mention the feedback systems may not be in place at all. In Episode Three, the desired result, i.e. a practical and feasible corrective action, is far more complicated than a "successful purchase transaction in the web store". The latter is a typical result used to train the machine learning based "recommendation engine" at Amazon.com where billions of transactions have been recorded every year which provides immediate feedback to the algorithm if the recommendations generated are successful. The reality is, however, in many systems such as the NOHARM, the results to be achieved are highly intangible and feedback is often not directly available at the time when needed.

Having said that, I still believe in using machines to automate business processes for the sake of agility. Machines do not have emotions when making decisions and 
producing actions. They should be used when human emotions become a Friction (not a Torque) to the business processes. Such Friction can come from uncertainties with the tasks themselves, or with the personal consequences involved in the tasks such as accountability and reputation. Machines have no sense of fear and ego, thus can be programmed to produce immediate but maybe naïve responses. However such responses can promptly trigger subsequent human activities that can improve the situation. In Episode Three, the IS was programmed to generate "tentative" corrective actions directly after failed safety audits. This approach saved the previously struggling human agents (i.e. the safety auditors) from spending excessive amount of time and effort pondering on optimal solutions. Instead, the IS directly kicked the ball to line managers who were most capable of deciding on the feasibility and practicality of corrective actions. In short, from an IS Agility perspective, automation does not necessarily mean super intelligence, rather, it requires a great level of coordination to ensure that the right agents (be it humans or machines) are operating on the right processes at the right time which then lead to a seamless flow on the SDSE loop with a high level of Synchronicity.

On further reflection, the models of ISACAM have been updated to include those most essential data and processes discovered in this thesis for solving IS Agility problems. As shown in Figure 28, since the initial version 1.0, three additional dimensions have been added to the data model to help articulate and construct a IS Agility problem space for investigation and solution design. These dimensions are "Solution Type" from Episode One, "Control Type" from Episode Two, and "Cognitive Hierarchy" from Episode Three. 


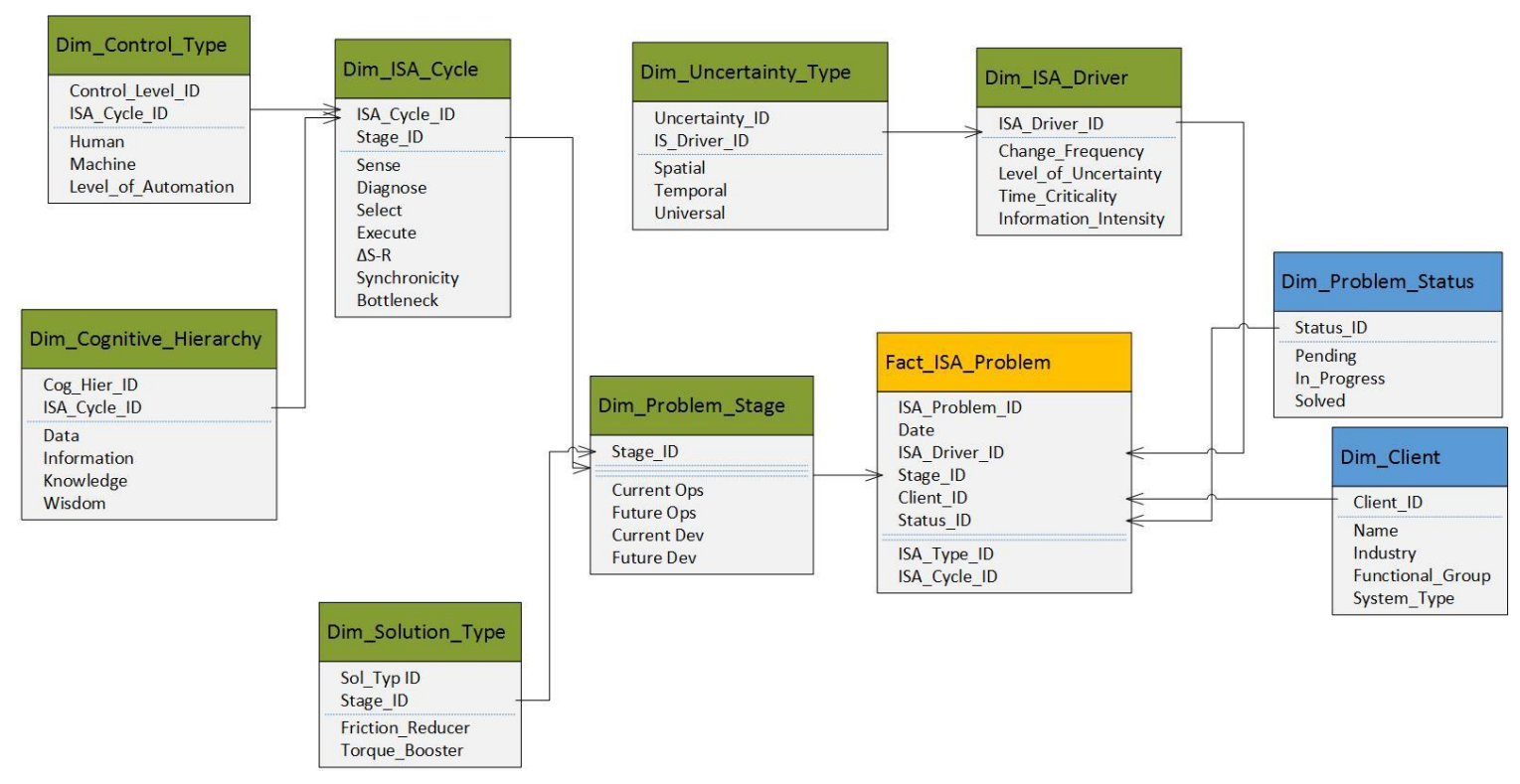

Figure 28: The Data Model of ISACAM Ver. 1.3

The HTA based process map (shown in Figure 29 below) has also been updated to include more detailed instructions to guide the problem solvers through the essential steps for IS Agility problem investigation and solution creation. Once again, the very first steps are to identify the "IS Agility drivers". This is important to the success of the following steps. If the Level of Uncertainty, Change Frequency, Time Criticality, and Information Intensity of a problem space are all rated high by the stakeholders, then using ISACAM to solve the problem is appropriate. However, for the reasons discussed in Chapter 2, if any of these four drivers did not present in the problem space, sub-optimal result may be expected as the stakeholders may not see the benefits or feel the pressure to commit to the solutions generated through ISACAM. 


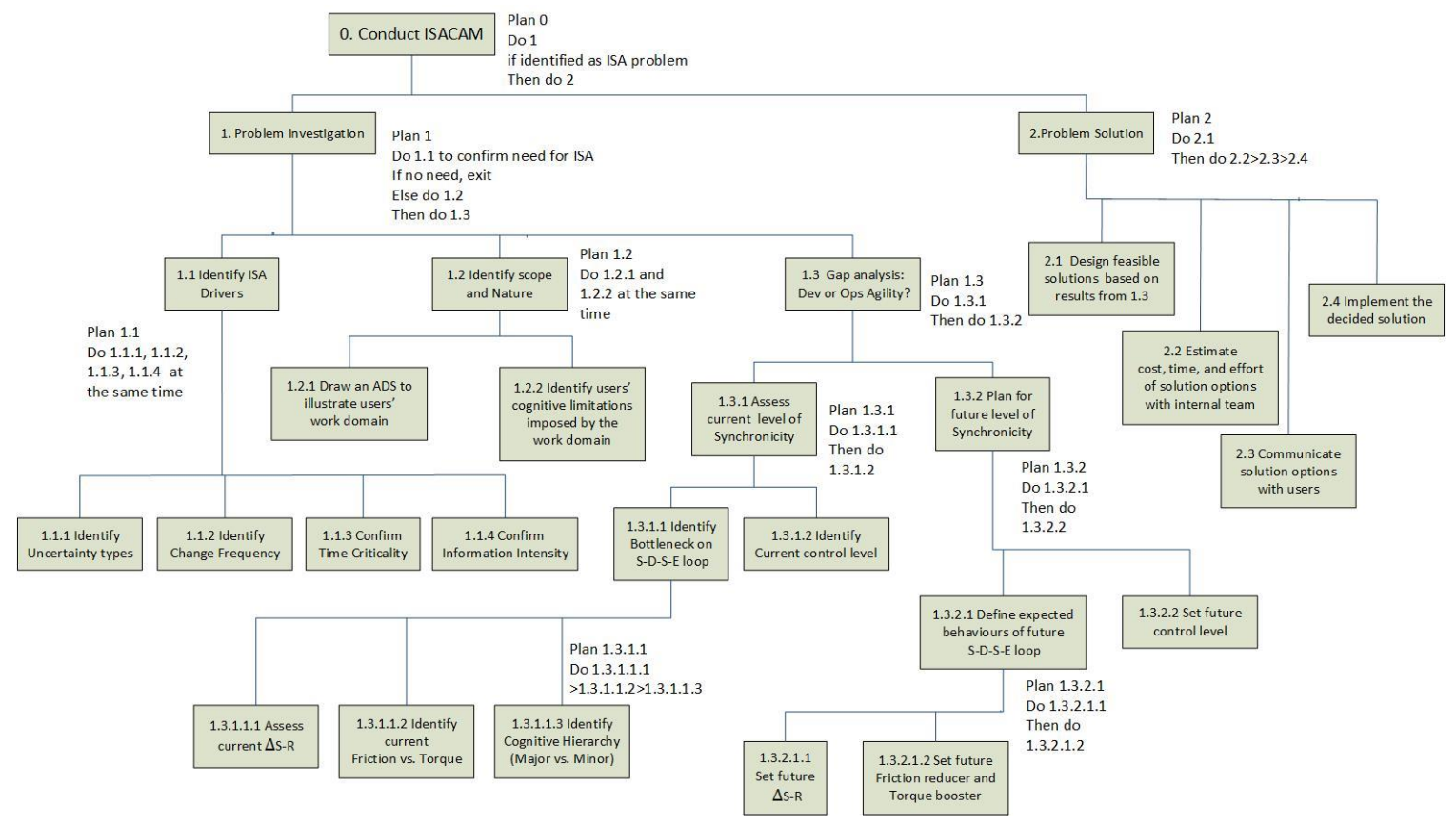

Figure 29: The Task Model of ISACAM Ver. 1.3

The data model (Figure 28), process map (Figure 29), SDSE mapping table (Figure 27) and the technological rules (Table 37) are the main artefacts created through the development, application, and evaluation of ISACAM. They are not perfect but can effectively help problem solvers to slice and dice IS Agility issues for improvements. ISACAM, as the first of its own kind, will no doubt keep evolving in the future through applications in different IS environments other than the NOHARM SaaS ecosystem. One possible scenario is to develop a web-based tool to integrate all the aforementioned artefacts and give access to organisations that are suffering from IS Agility problems. Problem solvers from these organisations can follow the processes listed in Figure 29, break down their problems using Figure 27, record their analysis data in a database derived from Figure 28, and design solutions through instantiating the technological rules (Table 37) in their own business contexts. 


\subsubsection{Reflection on the Success of "Agile Methodologies"}

In retrospect, the lack of Dev Agility problems in the NOHARM SaaS environment should not be a surprise. Since the inception of the Agile Alliance and its Manifesto for Agile Software Development ${ }^{19}$, the success stories of those "agile methods" (e.g. Scrum, XP) have been widely observed and reported in both academic literature and industry whitepapers.

As another means of evaluation, I am making an attempt here to analyse and explain the success of agile methods using ISACAM. I have previously studied agile methods and their differences from the conventional system development approaches (Yang et al., 2009). Now when speaking in the ISACAM language, in a typical scenario faced by an web-based IS development team adopted one or more of the agile methods, say Scrum for instance (the most commonly applied agile method in the industry ${ }^{20}$ ), all the four drivers for IS Agility would be rated as high.

Change Frequency is high as user requirements are simply evolving quickly all the time in the context of web-based applications, not to mention that some disruptive changes needed to drive innovations and survive competitions. Level of Uncertainty is high as the development team cannot predict what will be changed (spatial dimension) and when (temporal dimension). Time Criticality is high due to the strong urge of increasing "speed to market" as well as being the earlier movers in a globally-wired competition. Many software vendors have development teams operating simultaneously on different continents just to ensure a 24-hour non-stop development cycle. Information Intensity is high, which is already an undoubted fact in the software development practice. With the cloud-based SaaS delivery model, the intensity of information the development team needs to handle only gets higher.

\footnotetext{
19 http://agilemanifesto.org/

20 http://blogs.forrester.com/tom_grant/09-04-17-extended_family_agile
} 
I have found that ISACAM can clearly and logically explain the reasons why agile methods can successfully improve Dev Agility. Although not being explicitly described in the literature, those successful agile methods, e.g. Scrum, tend to have their own specific solutions to address the issues and follow the technological rules articulated in ISACAM. Take Scrum as an example, this method creates a set of artefacts - purposely designed meetings, filing systems, roles and schedules etc. - to manage frequent changes in user requirements, high demands on speed to market, high volume of information, and high level of uncertainties.

\section{SCRUMM}

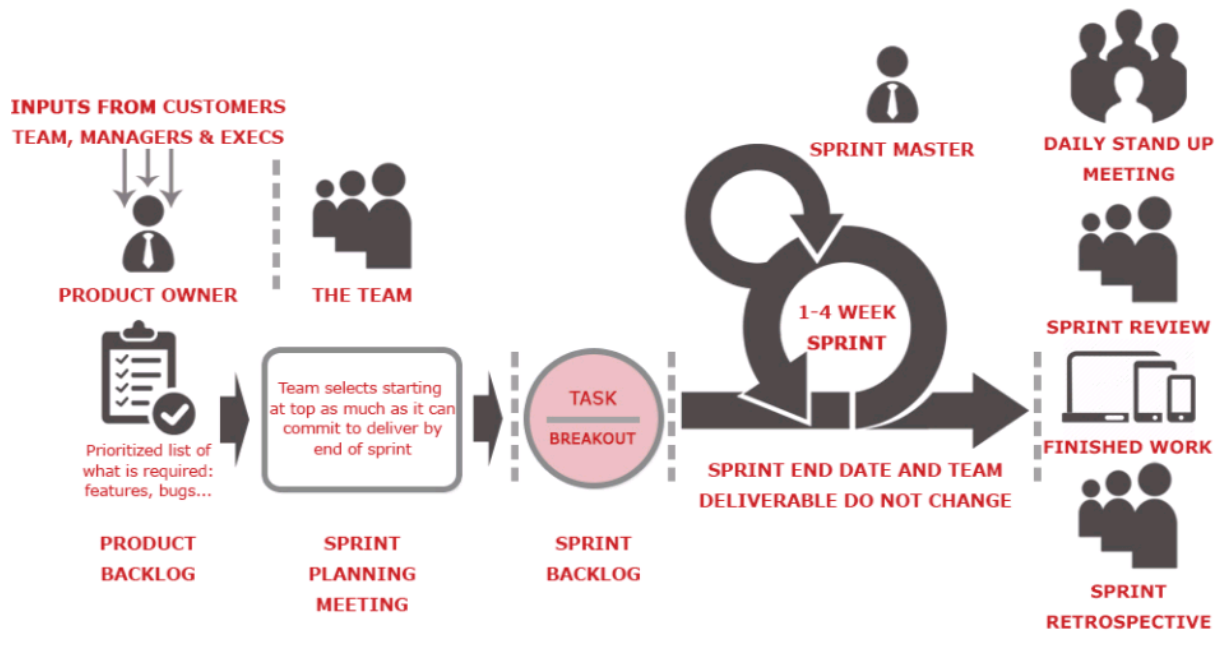

Figure 30: Scrum Software Development Process

Source: adopted from The Zenyth Group ${ }^{21}$

As shown in Figure 30 above, the Scrum methodology echoes with the second technological rule (TR2) prescribed in the previous section (see 5.3.2) by setting up a measurable $\Delta S-R$ in advance. Scrum defines a Sprint as a regular, short but iterative system development cycle. Such a cycle is recommended to be completed in one to four weeks, but very often set as two weeks in actual practice. For instance,

\footnotetext{
21 http://www.zenythgroup.com/wp-content/uploads/2015/12/Scrum-Process-Software-Development-LifeCycle.jpg
} 
the NOHARM development team and many agile development teams which I worked with during one of my previous research projects (Yang et al., 2009), followed a two-week sprint schedule. More detailed discussions regarding the Scrum process can be found in Chapter 3 (section 3.2.1). The focus here is on analysing and explaining the Scrum methodology using ISACAM.

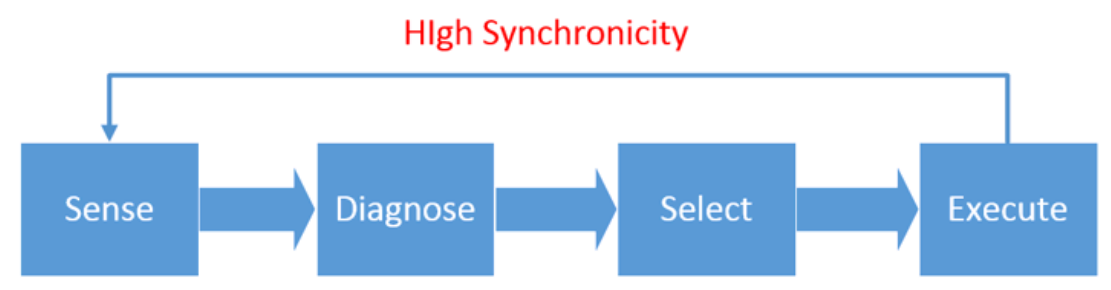

\begin{tabular}{|c|c|c|c|c|}
\hline $\begin{array}{l}\text { Tasks } \\
\text { and Outcomes }\end{array}$ & $\begin{array}{l}\text { Detecting changes in user } \\
\text { requirements and reporting } \\
\text { bugs in system, and recording } \\
\text { them in the product backlog; } \\
\text { Also detecting issues and } \\
\text { roadblocks in development } \\
\text { (Daily Scrum/Stand-up } \\
\text { Meeting - } 15 \text { minutes) }\end{array}$ & $\begin{array}{l}\text { Analysing product backlog to } \\
\text { estimate effort and sort the } \\
\text { items in terms of priority and } \\
\text { story point } \\
\text { (Backlog Grooming Session - } \\
2 \text { or } 3 \text { hours) }\end{array}$ & $\begin{array}{l}\text { Deciding on which items to } \\
\text { be taken into the next } \\
\text { sprint } \\
\text { (Sprint Planning Meeting - } \\
3 \text { or } 4 \text { hours) }\end{array}$ & $\begin{array}{l}\text { Completing the } \\
\text { development work } \\
\text { needed to implement } \\
\text { the sprint items } \\
\text { (New features are } \\
\text { demonstrated at Sprint } \\
\text { Review Meeting - } 2 \text { to } \\
4 \text { hours - at the end of } \\
\text { each sprint) }\end{array}$ \\
\hline $\begin{array}{l}\text { Functional } \\
\text { Group (Roles) }\end{array}$ & $\begin{array}{l}\text { Product Owner } \\
\text { Stakeholders (users) } \\
\text { Development Team } \\
\text { Scrum Master }\end{array}$ & $\begin{array}{l}\text { Product Owner } \\
\text { Development Team }\end{array}$ & $\begin{array}{l}\text { Product Owner } \\
\text { Scrum Master } \\
\text { Development Team }\end{array}$ & $\begin{array}{l}\text { Development Team } \\
\text { Scrum Master }\end{array}$ \\
\hline $\begin{array}{l}\text { Time frame } \\
\text { ( } \Delta S-R=\text { two } \\
\text { weeks) }\end{array}$ & Daily & weekly & Biweekly & Daily \\
\hline \multirow{4}{*}{$\begin{array}{l}\text { DIKW } \\
\text { Requirement }\end{array}$} & & Practical wisdom & Practical wisdom & Practical wisdom \\
\hline & Operational knowledge & Operational knowledge & Operational knowledge & Operational knowledge \\
\hline & Analytical information & Analytical information & Analytical information & Analytical information \\
\hline & Transactional data & & & Transactional data \\
\hline
\end{tabular}

\section{Figure 31: The SDSE Mapping Table for Scrum Methodology}

As mapped out in Figure 31 above, the Scrum process can fit in the SDSE loop neatly. Operating on two-week sprints to develop new features and fix bugs has been seen as able to maintain a desirable tempo $(\Delta S-R)$ to handle the high time criticality and high change frequency entailed by IS providers. Product Backlog and Sprint Backlog are the filing systems used to record and track requirement changes and development plans. These backlogs are effective ways for the team members to 
sense and diagnose changes in the development environment, and manage intensive information associated with these changes. In the NOHARM development environment, these backlogs were hosted on a web-based case tracking system that every team member can access and review.

The Scrum methodology also resonates with the third technological rule (TR3) prescribed in the previous section (see 5.3.2) by establishing order and confidence in the face of spatial and temporal uncertainties. The development team cannot predict what changes in requirements will be (spatial uncertainty) and when they will need to happen (temporal uncertainty). To avoid chaotic situations, Scrum creates meetings such as Daily Stand-up (strictly 15 minutes), Sprint Planning (3-4 hours), and Sprint Review (2-3 hours) etc. which are all purposefully designed events to take place on certain days (temporal order and confidence) during a sprint. At each meeting, participants will perform predefined tasks (spatial order and confidence) such as estimating and prioritising user stories at the biweekly Sprint Planning Meeting, reporting on progress and roadblocks at the daily Stand-up Meeting. All these predefined time and activities help mitigate the sense of uncertainty perceived by team members. Even when they cannot predict what changes are coming next, they can still operate with confidence and much reduced anxiety knowing what should be done for the current sprint and when.

Last but not the least, the Scrum methodology meets the conditions of the fourth and fifth technological rules (TR4 and TR5) prescribed in the previous section (see 5.3.2). Product Owner, Scrum Master (or Sprint Master), The Development Team (or The Team) and Stakeholders are the roles defined in the Scrum process to clarify responsibilities. Such a role-play approach, with clear instructions on who should attend which meetings and work on which processes, can effectively bring the needed data, information, knowledge, and wisdom into the right places when needed. In the case of the NOHARM development team, transactional data (e.g. user stories) and analytical information (e.g. priorities, estimated story points) are all 
recorded in a web-based case tracking system. Many of the tasks involved in processing these data and information have been automated and controlled by machines (e.g. automatically classifying incoming user stories into pre-defined categories, sending reminders to the relevant team members, monitoring development progress and time spent on sprint items). Those operational knowledge (e.g. which clients are more positive than others with the new features developed in the current sprint?) and practical wisdom (e.g. should the team release some new features to certain clients for UAT?) commonly possessed by human agents (e.g. The Product Owner, Stakeholders) can all be readily accessible at the regular meetings in each sprint.

In short, using ISACAM to analyse the Scrum process brings a great level of clarify and valuable insights into the success of this agile method. Such an analysis also helps to evaluate the usefulness of ISACAM as a tool to analyse and solve IS Agility problems. Moreover, the discipline enforced by the Scrum methodology echoes with the desired state portrayed in ISACAM, which explains the lack of Dev Agility related problems in the NOHARM environment.

\subsection{Chapter Summary}

Chapter 5 reported the major evolutions of ISACAM through three real-world episodes. Each episode recorded a problem-solving practice focused on improving one blocked phase of the SDSE loop (e.g. "Sense" in Episode One, "Diagnose" in Episode Two). During these episodes, new elements have emerged, and new insights have been discovered towards systematically constructing a problem space for solving IS Agility problems. The interplay between the elements in an IS Agility problem space have been explored and examined (e.g. dimensions of uncertainty, cognitive hierarchy, machine driven automation, etc.). The effectiveness of ISACAM on solving IS Agility problems has been demonstrated in the results of those episodes. 
Following the tradition of "reflective practice" (Schön, 1983), I further refined those ISACAM artefacts (i.e. the data model, the task model, and the SDSE mapping table). Next, I synthesized patterns found in those ISACAM-driven solutions into five technological rules and explained each in detail. These rules were then found to be able to provide powerful explanations to the success of the Scrum methodology. All these artefacts and findings can be of good use for problem solvers to design rigours analysis on IS Agility problems and to create effective solutions. Next chapter will be the conclusion of this thesis. 


\section{Chapter 6 : Conclusion}

\subsection{Achieved Objectives}

At the beginning of this thesis we have set five objectives. Now we can conclude that all of them have been achieved. Achieving these objectives has effectively fulfilled the two main goals of this study (see Table 38 below for a summary). Table 1 in Chapter 1 has already provided another summary of the research problems and questions being addressed by this study, thus Table 38 is only focusing on the goals and objectives fulfilled.

Table 38: Achieved Research Objectives

\begin{tabular}{|c|c|c|}
\hline Research Goals & Objectives & Achieved by \\
\hline \multirow{3}{*}{$\begin{array}{l}\text { A. To generate a } \\
\text { unified and holistic } \\
\text { conceptualisation of IS } \\
\text { Agility so that both } \\
\text { researchers and } \\
\text { practitioners can } \\
\text { understand and utilise } \\
\text { in their own specific } \\
\text { contexts with clarity } \\
\text { and consistency; }\end{array}$} & $\begin{array}{l}\text { a. To examine, synthesise, and } \\
\text { refine existing theories/models } \\
\text { of agility published in a broad } \\
\text { yet practical range of literature }\end{array}$ & $\begin{array}{l}\text { Chapter 2: } \\
\text { Literature review and analysis }\end{array}$ \\
\hline & $\begin{array}{l}\text { b. To create a unified } \\
\text { conceptualisation that explains } \\
\text { why IS Agility is needed and } \\
\text { how it can be achieved }\end{array}$ & $\begin{array}{l}\text { Chapter 2: } \\
\text { The creation of ISANN (IS Agility } \\
\text { Drivers and Dev vs. Ops Agility } \\
\text { cycles, etc.). } \\
\text { Peer-reviewed publication }\end{array}$ \\
\hline & $\begin{array}{l}\text { c. To evaluate and improve the } \\
\text { efficacy of this unified } \\
\text { conceptualisation and } \\
\text { associated models through } \\
\text { peer-review processes and/or } \\
\text { scenario-based illustrations }\end{array}$ & $\begin{array}{l}\text { Chapter 3: } \\
\text { ISANN based illustrative scenarios } \\
\text { and structured analysis of Cloud } \\
\text { Computing services } \\
\text { Peer-reviewed publication }\end{array}$ \\
\hline \multirow{2}{*}{$\begin{array}{l}\text { B. To design and } \\
\text { develop a systematic } \\
\text { method for } \\
\text { investigating and } \\
\text { solving IS Agility } \\
\text { problems with which } \\
\text { people can follow } \\
\text { prescriptive steps and } \\
\text { rules to implement } \\
\text { with clarity and } \\
\text { consistency. }\end{array}$} & $\begin{array}{l}\text { d. Based on the improved } \\
\text { conceptualisation of IS Agility, } \\
\text { to create a method for analysing } \\
\text { and designing solution for IS } \\
\text { Agility problems }\end{array}$ & $\begin{array}{l}\text { Chapter 5: } \\
\text { ISACAM (data and task models, and } \\
\text { technological rules) }\end{array}$ \\
\hline & $\begin{array}{l}\text { e. To evaluate and improve } \\
\text { relevance and effectiveness of } \\
\text { ISACAM through real-world } \\
\text { applications }\end{array}$ & $\begin{array}{l}\text { Chapter 5: } \\
\text { Formative evaluations via the three } \\
\text { episodes and an ISACAM based } \\
\text { analysis of the Scrum methodology }\end{array}$ \\
\hline
\end{tabular}


IS Agility is a critical ability to modern and Internet-connected businesses, and an important concept to the advancement of IS and business research. However, prior to this study, the understanding towards IS Agility was limited and obscure in both academic and practitioner literature, probably due to the tangled nature of this concept. The missing of a unified conceptualisation made studying IS Agility a challenging and sometimes frustrating endeavour.

The present study has accomplished its first goal by establishing ISANN (in Chapter 2) as a holistic and unified conceptualisation for dissecting and researching IS Agility problems. The graphical ISANN ensures a much higher clarity and consistency than the scattered semantic definitions of IS Agility found in the existing literature. This study then moved on and fulfilled the second goal through designing/developing the ISACAM, which offers operational level prescription for practitioners and researchers to analyse and solve IS Agility problems. The ISACAM consists of a series of theory-grained and practice-grounded artefacts including the data mode, the task model, five technological rules, and the SDSE mapping table. The effectiveness of these artefacts has been demonstrated in real-world applications documented in the form of three episodes in Chapter 5.

\subsection{Main Contributions}

The first contribution of this study, is the graphically rich ISANN which brings the long-missing conceptual clarity and structural integrity to the complicated concept of IS Agility. It does so by synthesising related theoretical and conceptual elements into a unified problem space, which offers a previously non-existing vantage point for researchers and practitioners to acquire a holistic view of IS Agility, as well as to understand the relationships between the contributing factors.

The second contribution is the ISACAM, which offers a theory-ingrained yet highly practical approach to investigate and solve IS Agility problems. Such an approach is 
prescription-driven and has produced positive results in real-world problemsolving situations. The creation of ISACAM provides a practical alternative to the adhoc approach used by practitioners to address IS Agility problems. Such problems, now, can be analysed and solved in a systematic and consistent manner. Moreover, the ISACAM is generic enough for adopters to interpret in their own specific contexts to design customised solutions that are most effective to their particular problems.

The third contribution is that the study itself provides an educational example of how to combine theoretical rigour and practical relevance, which has been often considered a major challenge to novice IS researchers. Striking the balance between rigour and relevance to produce "consumable" research, in fact, could even be a dilemma to senior IS and business researchers (Aken, 2004; Robey \& Markus, 1998). This study has demonstrated that a DSR project, with the application of "reflective practice" (Schön, 1983), is a great way for a PhD candidate to first intensively accumulate subject knowledge to lay a solid theoretical foundation, and then get immersed in a real-world context to develop and test artefacts derived from theories through iterations of reflections and design improvements.

The fourth contribution is that the thesis presents a viable path to place the IT artefact (e.g. an IS) at the centre of an IS phenomenon while generating unique knowledge distinct from other technology-centric disciplines such as Software Engineering and Computer Science. The academic legitimacy of the IS field has been criticised for having "nothing at the centre", namely, being a "market of ideas" without a central focus in the research literature and topics (Lyytinen \& King, 2004). Leading IS researchers have urged that the IT artefact should be the "core subject matter" of the IS field, however, it is often briefly mentioned or even not engaged at all in many IS studies (Wanda J Orlikowski \& Iacono, 2001). The present study set an example for novice IS researchers to design research strategies that can deeply engage the IT artefact (i.e. the NOHARM system) as well as ground their research 
inquiries into business theories (e.g. IS Agility models) to produce salient insights (e.g. ISANN and ISACAM) that can define the uniqueness of the IS field.

\subsection{Limitations}

This study has several limitations.

Firstly, it has limited generalizability. As already discussed in Section 4.6.1, we believe generalizability of DSR studies should come from summative evaluations performed in settings differ from those artefacts being designed in (e.g. new environments, new evaluators). Such type of evaluations may "require quite different expertise and entail substantial resources" thus has been suggested to be separated from a "construction theme" study (Alturki et al., 2011; Winter, 2008). Given the artefacts constructed in this study are novel in nature, utilising formative evaluation as a way to further develop and improve their design is justifiable and acceptable (see discussions in Section 4.5.3).

Secondly, personal biases may come from my strong interest in IS Agility, which might lead me to analyse many IS projects I have been involved only from an agility point of view. Such a tendency might create a "when you have a hammer everything looks like a nail" mentality. Since 2008, I, as an IS researcher, also as an IT practitioner, have been working closely with agile software development teams in different organisations in New Zealand. I have developed genuine interest towards the concept "agility" in an IS context and studied the differences between agile software development projects and traditional ones (Yang et al., 2009). 
As a reflective practitioner, I have experienced a state of "over-learned" 22 for a period but I was able to regulate my own thoughts and behaviours through continuous reflection. I then have become fully aware of the potential biases I may have during this research. Therefore, I have developed a set of criteria to filter out situations and problems that are not related to IS Agility. These criteria include Change Frequency, Level of Uncertainty, Time Criticality and Information Intensity which will be discussed in detail in Chapter 2 .

Thirdly, New Zealand is the only context in which the present study was conducted. This may seem to be purely a convenient and economic choice as I happened to be working in the IT industry in this country for many years. Having said that, New Zealand is a great place to study IS Agility in a cloud environment. The average size (by market capitalisation) of firms in New Zealand is much smaller than in many other countries (MED, 2009). Due to the smaller size and resource constrains, New Zealand firms often cannot afford the same level of stability compared to their global competitors. Companies here tend to adapt at a higher rate to survive, which leads them to a generally stronger desire for agility as a true competitive advantage. Unsurprisingly, adopting pay-per-use Cloud Computing services with light-weight implementation is naturally appealing to many New Zealand firms with tight IT budgets.

${ }^{22}$ Schön (1983) described "over-learned" as a mental state where a practitioner has become too good at what he does thus his practice starts to be more repetitive and routine. Such a mental state can manifest itself as a sense of boredom, inattention to new phenomena, or simply, narrowness and rigidity in practice. 


\subsection{Future Work}

Future research can extend the application of ISACAM in contexts other than a SaaS environment. For instance, researchers can apply the ISACAM to analyse and solve agility problems with on-premises enterprise systems (e.g. ERP, CRM, and SCM). The technological rules developed in this study are generic in nature thus can be tested in wider applications to examine their effectiveness, namely, to aim for a "horizontal expansion". On the other hand, researchers from different backgrounds may further develop more specific rules that give precise instructions only for particular industries or systems, in other words, to focus on a "vertical concentration".

We also envisage the future of ISACAM as a web-based application developed following the data and task models. Such an application can be made accessible to problem solvers from different backgrounds whoever need to solve IS Agility problems. The application should have a built-in evaluation feature with which users can provide feedback for improvements of the application itself as well as the problem-solving method. Data collected through such an application will be of great value. In the Appendix, several screenshots were taken from a proof-of-concept to illustrate the potential software instantiation. However, developing and evaluating a software instantiation is considered beyond the scope of the current study thus opportunities should be given to future projects.

Next, the ISACAM can be developed into a short online training course for IS practitioners to develop their abilities for continuous reflections and adjustments on their tactics and techniques to improve IS Agility in a business context. Such a course should follow the tradition of this thesis by requesting participants to bring in real-world IS Agility problems. These problems can be analysed and discussed more or less following the style of the three episodes reported in Chapter 5. With a web-based application and a training course, we can reach out to a broad range of potential users of ISACAM. Currently applying ISACAM on real-world problems is limited to a small group of people who have already possessed certain level of 
expertise in IS Agility. We hope future development will reduce the barrier to enable novice problem solvers or junior practitioners to apply the ISACAM in their daily work settings. 


\section{References}

Abbasi, A., Albrecht, C., Vance, A., \& Hansen, J. (2012). Metafraud: a meta-learning framework for detecting financial fraud. MIS Quarterly, 1293-1327.

ACC. (2016). How to implement safe workplace practices: a guide to workplace health and safety. Retrieved from http://www.acc.co.nz/PRD EXT CSMP/groups/external ip/documents/publication s_promotion/wcm000924.pdf

Acharya, A., \& Sidnal, N. S. (2016, 19-22 Dec. 2016). High Frequency Trading with Complex Event Processing. Paper presented at the 2016 IEEE 23rd International Conference on High Performance Computing Workshops (HiPCW).

Adams, M. (2010). Dynamic Workflow In A.H.M. ter Hofstede et al. (eds.) (Ed.), Modern Business Process Automation, . Verlag Berlin Heidelberg: Springer.

AgileAlliance. (2001). Manifesto for agile software development. Retrieved from http://www.agilemanifesto.org/

Aken, J. E. v. (2004). Management research based on the paradigm of the design sciences: the quest for field - tested and grounded technological rules. Journal of management studies, 41(2), 219-246.

Alter, M. J. (2004). Science of Flexibility (3rd ed.): Human Kinetics Publishers.

Alturki, A., Gable, G. G., \& Bandara, W. (2011). A Design Science Research Roadmap. In H. Jain, A. P. Sinha, \& P. Vitharana (Eds.), Service-Oriented Perspectives in Design Science Research: 6th International Conference, DESRIST 2011, Milwaukee, WI, USA, May 5-6, 2011. Proceedings (pp. 107-123). Berlin, Heidelberg: Springer Berlin Heidelberg.

Alturki, A., Gable, G. G., \& Bandara, W. (2013). The design science research roadmap: in progress evaluation. PACIS 2013 proceedings.

Ansoff, H. I. (1980). Strategic issue management. Strategic Management Journal, 1(2), 132148.

Antunes, P., Baloian, N., Zurita, G., \& Pino, J. A. (2018). Supporting People-Driven, Dynamic and Geo-Located Work Processes. Paper presented at the Proceedings of the 10th International Conference on Subject-Oriented Business Process Management.

Antunes, P., \& Mourão, H. (2011). Resilient business process management: Framework and services. Expert Systems with Applications, 38(2), 1241-1254.

Antunes, P., Simes, D., \& Pino, L. C. A. (2013). An end-user approach to business process modeling. J. Netw. Comput. Appl., 36(6), 1466-1479. doi:10.1016/j.jnca.2013.03.014

Archer, L. B. (1981). A view of the nature of design research. In J. R. \& P. J. (Eds.), Design:Science:Method. Guildford,UK: Westbury House.

Argyris, C. (2003). A life full of learning. Organization Studies, 24(7), 1178-1192.

Assy, N., \& Gaaloul, W. (2015). Extracting configuration guidance models from business process repositories. Paper presented at the International Conference on Business Process Management.

Babar, M. A., Brown, A. W., \& Mistrík, I. (2013). Agile Software Architecture: Aligning Agile Processes and Software Architectures: Newnes.

Babb, J., Hoda, R., \& Norbjerg, J. (2014). Embedding reflection and learning into agile software development. IEEE software, 31(4), 51-57.

Barki, H. (2008). Thar's gold in them thar constructs. ACM SIGMIS Database, 39(3).

Barki, H., Rivard, S., \& Talbot, J. (1993). A Keyword Classification Scheme for IS Research Literature: An Update. MIS Quarterly, June, 209-225. 
Barros, A., Decker, G., Dumas, M., \& Weber, F. (2007). Correlation patterns in service-oriented architectures. Paper presented at the International Conference on Fundamental Approaches to Software Engineering.

Barros, F. J. (2015). Aspect - oriented programming and pluggable software units: a comparison based on design patterns. Software: Practice and Experience, 45(3), 289314.

Baskerville, R., Mathiassen, L., \& Pries-Heje, J. (2005). Agility in Fours: IT Diffusion, IT Infrastructures, IT Development, and Business. In R. Baskerville, L. Mathiassen, J. Pries-Heje, \& J. DeGross (Eds.), Business Agility and Information Technology Diffusion (Vol. 180, pp. 3-10). Boston: Springer

Bhatt, G., Emdad, A., Roberts, N., \& Grover, V. (2010). Building and leveraging information in dynamic environments: The role of IT infrastructure flexibility as enabler of organizational responsiveness and competitive advantage. Information \& Management, 47(7-8).

Boehm, B., \& Turner, R. (2003). Balancing agility and discipline: A guide for the perplexed: Addison-Wesley Professional.

Böhm, M., Leimeister, S., Riedl, C., \& Krcmar, H. (2010). Cloud Computing - Outsourcing 2.0 or a new Business Model for IT Provisioning? . In F. Keuper, C. Oecking, \& A. Degenhardt (Eds.), Application Management Service Management und Service Creation (pp. 2-26): Gabler.

Booch, G. (2005). The unified modeling language user guide: Pearson Education India.

Boubaker, S., Mammar, A., Graiet, M., \& Gaaloul, W. (2016). A formal guidance approach for correct process configuration. Paper presented at the International Conference on Service-Oriented Computing.

Boyd, J. R. (1976). An Organic Design for Command and Control. Unpublished lecture notes. In Boyd, J.R. A Discourse on Winning and Losing.

Bradley, S., \& Hood, C. (2003). Delivering minimalist workplaces that improve corporate agility. Journal of Facilities Management, 2, 68.

Brown, J. L., \& Agnew, N. M. (1982). Corporate Agility. Business Horizons, 25(2), 29.

Cabitza, F., \& Simone, C. (2013). Computational Coordination Mechanisms: A tale of a struggle for flexibility. Comput. Supported Coop. Work, 22(4-6), 475-529. doi:10.1007/s10606-013-9187-5

Camarinha-Matos, L., Afsarmanesh, H., \& Rabelo, R. (2003). Infrastructure developments for agile virtual enterprises. International Journal of Computer Integrated Manufacturing, 16, 235.

Canter, J. (2000). An Agility Based 00DA Model for The e-Commerce/e-Business Enterprise. Retrieved from http://www.iohai.com/iohai-resources/agility-based-oodamodel.html

Caswell, N. S., \& Nigam, A. $(2005,19$ July 2005). Agility = change + coordination . Paper presented at the E-Commerce Technology Workshops, 2005. Seventh IEEE International Conference on.

Chang, M., He, J., \& Castro-Leon, E. (2006). Service-Orientation in the Computing Infrastructure. Paper presented at the IEEE International Symposium on ServiceOriented System Engineering.

Chow, T., \& Cao, D.-B. (2008). A survey study of critical success factors in agile software projects. The Journal of Systems and Software, 81, 961-971.

Cohen, W. M., \& Levinthal, D. A. (1990). Absorptive capacity: a new perspective on learning and innovation. Administrative Science Quarterly, 35(1), 128-152. 
Conboy, K. (2009). Agility from First Principles: Reconstructing the Concept of Agility in Information Systems Development. Info. Sys. Research, 20(3), 329-354. doi:http://dx.doi.org/10.1287/isre.1090.0236

Conboy, K., Coyle, S., Wang, X., \& Pikkarainen, M. (2011). People over Process: Key Challenges in Agile Development. IEEE Software, 28(4), 48.

Conboy, K., \& Fitzgerald, B. (2004). Toward a conceptual framework of agile methods: a study of agility in different disciplines. Paper presented at the Proceedings of the 2004 ACM workshop on Interdisciplinary software engineering research, Newport Beach, CA, USA.

Coram, M., \& Bohner, S. (2005). The impact of agile methods on software project management Paper presented at the 12th IEEE International Conference and Workshops on the Engineering of Computer-Based Systems, Greenbelt, MD USA

Coronado, M., Lyons, A. C., \& Kehoe, D. F. (2004). Assessing the value of information systems in supporting agility in high tech manufacturing enterprises. International journal Operations \& Production Management, 24(12).

Creswell, J. W. (2009). Research design: Qualitative, quantitative, and mixed methods approaches (3rd ed.). Thousand Oaks,CA: Sage Publications.

Cross, N. (1993). A history of design methodology, . In M. J. In de Vries, Cross, N. and Grant, D. P. (Eds.). (Ed.), Design Methodology and Relationships with Science . : Dordrecht: Kluwer Academic Publishers.

Denning, P. J. (2007). Mastering the mess. Communications of the ACM, 50(4), 21+.

Dennis, A. R., Fuller, R. M., \& Valacich, J. S. (2008). Media, tasks, and communication processes: a theory of media synchronicity. MIS Q., 32(3), 575-600.

Denzin, N. K., \& Lincoln, Y. S. (2005). The Discipline and Practice of Qualitative Research. In N. K. Denzin \& Y. S. Lincoln (Eds.), The Sage Handbook of Qualitative Research (3 ed., pp. 1-32). CA:Thousand Oaks: Sage Publications.

Department of Labour, N. Z. (2011). Forestry sector action plan 2010-2013. Retrieved from http://www.worksafe.govt.nz/worksafe/about/who-we-work-with/action-agendaaction-plans/forestry-sector-action-plan-2010-13/forestry-action-plan.pdf

Diaper, D., \& Stanton, N. (2003). The handbook of task analysis for human-computer interaction: CRC Press.

Dörbecker, R., \& Böhmann, T. (2015). Tackling the Granularity Problem in Service Modularization. Paper presented at the 21st Americas Conference on Information Systems Seattle, U.S.

Dove, R. (2001). Response ability: The language, structure and culture of the Agilie enterprise. New York: Wiley.

Dove, R., \& LaBarge, R. (2014). Fundamentals of Agile Systems Engineering-Part 1 and Part 2. Paper presented at the Int. Counc. Syst. Eng. Int. Symp.

Dunkel, J., Fernández, A., Ortiz, R., \& Ossowski, S. (2011). Event-driven architecture for decision support in traffic management systems. Expert Systems with Applications, 38(6), 6530-6539. doi:http://dx.doi.org/10.1016/j.eswa.2010.11.087

Eder, W. E. (2011). Engineering design science and theory of technical systems: Legacy of Vladimir Hubka. Journal of Engineering Design, 22(5), 361-385.

Ellis, T. J., \& Levy, Y. (2010). A guide for novice researchers: Design and development research methods. Paper presented at the Proceedings of Informing Science \& IT Education Conference, InSITE.

Erich, F., Amrit, C., \& Daneva, M. (2014). Cooperation between information system development and operations: a literature review. Paper presented at the In 
Proceedings of the 8th ACM/IEEE International Symposium on Empirical Software Engineering and Measurement. ACM.

http://doi.acm.org/10.1145/2652524.2652598

Fernandez-del-Rincon, A., Garcia, P., Diez-Ibarbia, A., de-Juan, A., Iglesias, M., \& Viadero, F. (2017). Enhanced model of gear transmission dynamics for condition monitoring applications: Effects of torque, friction and bearing clearance. Mechanical Systems and Signal Processing, 85, 445-467. doi:https://doi.org/10.1016/i.ymssp.2016.08.031

Ferris, D. L., \& Smith, G. A. (1978). U.S. Patent No. 4,105,365 A. P. a. T. Office.

Fink, L., \& Neumann, S. (2007). Gaining Agility through IT Personnel Capabilities: The Mediating Role of IT Infrastructure Capabilities *. Journal of the Association for Information Systems, 8, 440.

Fink, L., \& Neumann, S. (2009). Exploring the perceived business value of the flexibility enabled by information technology infrastructure. Information \& Management, 46(2), 90-99.

Fitch, F. B. (1946). Self-reference in philosophy. Mind, 55(217), 64-73.

Foster, I., Yong, Z., Raicu, I., \& Lu, S. (2008 ). Cloud Computing and Grid Computing 360Degree Compared. Paper presented at the Grid Computing Environments Workshop, 2008. GCE '08.

Friedman, H., \& Sheard, M. (1987). An axiomatic approach to self-referential truth. Annals of Pure and Applied Logic, 33, 1-21.

Fullerton, T., \& Ness, L. R. (2010). Information Technology Flexibility: A synthesized model from existing literature. Journal of Information Technology Management, XXI(3), 5159.

Gallagher, K., \& Worrell, J. (2008). Organizing IT to promote agility. Information Technology and Management, 9, 71.

Gebauer, J., \& Schober, F. (2006). Information System Flexibility and the Cost Efficiency of Business Processes. Journal of the Association for Information Systems, 7(3), Article 8.

Glanville, R. (1999). Researching design and designing research. Design Issues, 15(2), 80-91.

Gleasure, R. (2015). When is a problem a design science problem? Systems, Signs \& Actions, 9(1), 9-25.

Goldman, S., Nagel, R., \& Preiss, K. (1995). Agile Competitors and Virtual Organizations. New York: Van Nostrand Reinhold.

Goldman, S., Preiss, K., Nagel, R., \& Dove, R. (1991). 21st century manufacturing enterprise strategy: An Industry-Led View. Bethlehem,PA: Iacocca Institute,Lehigh University.

Goldratt, E. M. (1990). What is this thing called the Theory of Constraints? . Croton-onHudson, NY. : North River Press,.

Gollwitzer, P. M., Heckhausen, H., \& Steller, B. (1990). Deliberative and implemental mindsets: Cognitive tuning toward congruous thoughts and information. Journal of Personality and Social Psychology, 59(6), 1119.

Gong, Y., \& Janssen, M. (2010). Measuring process flexibility and agility. Paper presented at the Proceedings of the 4th International Conference on Theory and Practice of Electronic Governance, Beijing, China.

Goodhue, D. L., Chen, D. Q., Boudreau, M. C., Davis, A., \& Cochran, J. D. (2009). Addressing Business Agility Challenges With Enterprise Systems. MIS Quarterly Executive, 8(2), 73-87.

Grant, T., \& Kooter, B. (2005). Comparing OODA \& other models as Operational View C2 Architecture Topic: C4ISR/C2 Architecture. ICCRTS2005, Jun. 
Guba, E. G., \& Lincoln, Y. S. (2005). Paradigmatic Controversies, Contradictions, and Emerging Confluences. In N. K. Denzin \& Y. S. Lincoln (Eds.), The Sage Handbook of Qualitative Research (3 ed., pp. 191-215). CA:Thousand Oaks: Sage Publications.

Haberfellner, R., \& Weck, O. d. (2005). Agile SYSTEMS ENGINEERING versus AGILE SYSTEMS engineering. Fifteenth Annual International Symposium of the Internation Council On System Engineering (INCOSE).

Haeckel, S. H., \& Nolan, R. L. (1996). Managing By Wire: Using I/T to Transform a Business From "Make-and-Sell" to "Sense-and-Respond". In J. N. Luftman. (Ed.), COMPETING IN THE INFORMATION AGE: STRATEGIC ALIGNMENT IN PRACTICE, : Oxford University Press, Inc.

Hancock, P. A., Jagacinski, R. J., Parasuraman, R., Wickens, C. D., Wilson, G. F., \& Kaber, D. B. (2013). Human-automation interaction research: Past, present, and future. ergonomics in design, 21(2), 9-14.

Hevner, A., \& Chatterjee, S. (2010). Design science research in information systems: Springer.

Hevner, A. R. (2007). A three cycle view of design science research. Scandinavian journal of information systems, 19(2), 4.

Hevner, A. R., March, S. T., Park, J., \& Ram, S. (2004). Design science in information systems research. MISQ, 28(1), 75-105.

Hobbs, G., \& Scheepers, R. (2010). Agility in Information Systems:Enabling Capabilities for the IT Function. Pacific Asia Journal of the Association for Information Systems, 2(4), Article 2.

HP. (2011). Does IT Deliver Business Agility? Retrieved from http://h10131.www1.hp.com/downloads/does-it-deliver-agility.pdf

Huang, C.-Y., \& Nof, S. Y. (1999). Enterprise agility: a view from the PRISM lab. International Journal of Agile Management Systems, 1(1), 51.

Huang, P.-Y., Pan, S. L., \& Ouyang, T. H. (2014). Developing information processing capability for operational agility: implications from a Chinese manufacturer. European Journal of Information Systems, 23(4), 462-480.

Hubka, V., \& Eder, W. E. (1987). A scientific approach to engineering design. Design Studies, $8(3), 123-137$.

Hubka, V., \& Eder, W. E. (2012). Design science: introduction to the needs, scope and organization of engineering design knowledge: Springer Science \& Business Media.

Huff, S. L., Munro, M. C., \& Martin, B. H. (1988). Growth stages of end user computing. Commun. ACM, 31(5), 542-550. doi:http://doi.acm.org/10.1145/42411.42417

Hugos, M. (2010). Business Strategy based on Cloud Computing and Agility. CIO. Retrieved from

http://advice.cio.com/michael hugos/14230/business strategy based on cloud co mputing and agility

Hugoson, M.-A., Magoulas, T., \& Pessi, K. (2009). Architectural Principles for Alignment Within the Context of Agile Enterprises. Paper presented at the Proceedings of the European Conference on Information Management \& Evaluation.

Iivari, J. (2007). A paradigmatic analysis of information systems as a design science. Scandinavian journal of information systems, 19(2), 5.

IT_Governance_Institute. (2007). COBIT 4.1: Framework, Control Objectives, Management Guidelines, Maturity Models. Rolling Meadows IL: IT Governance Institute.

Izza, S., Imache, R., Vincent, L., \& Lounis, Y. (2008). An Approach for the Evaluation of the Agility in the Context of Enterprise Interoperability. In K. Mertins, R. Ruggaber, K. 
Popplewell, \& X. Xu (Eds.), Enterprise Interoperability III - New Challenges and Industrial Approaches (pp. 3-14): Springer London.

Jonas, W. (2007). Design Research and its Meaning to the Methodological Development of the Discipline. Design research now, 187-206.

Kappelman, L., McLean, E., Johnson, V., \& Gerhart, N. (2014). The 2014 SIM IT key issues and trends study. MIS Quarterly Executive, 13(4), 237-263.

Katz, R. H. (2009). Tech Titans Building Boom. IEEE Spectrum, 46(2), 40.

Keen, P. (1980). MIS research: Reference disciplines and a cumulative tradition. Paper presented at the Proceedings of the First International Conference on Information Systems Philadelphia, December 1980.

Kimball, R., \& Ross, M. (2013). The Data Warehouse Toolkit: The Definitive Guide to Dimensional Modeling: Wiley Publishing.

Knabke, T., \& Olbrich, S. (2013, 7-10 Jan. 2013). Understanding Information System Agility -The Example of Business Intelligence. Paper presented at the System Sciences (HICSS), 2013 46th Hawaii International Conference on.

Kuechler, B., \& Vaishnavi, V. (2008). On theory development in design science research: anatomy of a research project. European Journal of Information Systems, 17, 489504.

Lanz, A., Weber, B., \& Reichert, M. (2010). Workflow time patterns for process-aware information systems. In Enterprise, Business-Process and Information Systems Modeling (pp. 94-107): Springer.

Lawson, J. (1981). Command control as a process. IEEE Control Systems Magazine, 1(1), 511.

Lawton, G. (2008). Developing Software Online With Platform-as-a-Service Technology. Computer, 41(6), 13-15.

Leavitt, N. (2009 ). Is Cloud Computing Really Ready for Prime Time? Computer, 42(1), 1520.

Lee, A. (2010). Retrospect and prospect: information systems research in the last and next 25 years. Journal of Information Technology. doi:citeulike-article-id:8392856doi: $10.1057 /$ jit.2010.24

Lee, A. S. (1991). Integrating Positivist and Interpretivist Approaches to Organizational Research. Organization Science, 2(4), 342-365.

Lee, G., \& Xia, W. (2010). Toward Agile: An Integrated Analysis of Quantitative and Qualitative Field Data on Software Development Agility. MIS Quarterly, 34, 87-114.

Levy, R. (1985). Science, Technology and Design. Design Studies, 6(1), 66-72.

Liu, S., Spencer, B., Yong, L., Bo, X., Libo, Z., \& Brooks, M. (2007, 24-27 July 2007). Towards an Agile Infrastructure to Provision Devices, Applications, and Networks: A Serviceoriented Approach. Paper presented at the Computer Software and Applications Conference, 2007. COMPSAC 2007. 31st Annual International.

Luftman, J., \& Ben-Zvi, T. (2010). Key Issues for IT Executives 2009: Difficult Economy's Impact on IT. MIS Quarterly Executive, 9(1), 46-59.

Lunsford, D. (2009). Virtualization Technologies in Information Systems Education. Journal of Information Systems Education, 20, 339.

Lyytinen, K., \& King, J. L. (2004). Nothing at the center?: Academic legitimacy in the information systems field. Journal of the Association for Information Systems, 5(6), 8.

Lyytinen, K., \& Rose, G. M. (2006). Information system development agility as organizational learning. Eur J Inf Syst, 15(2), 183-199. 
MacCormack, A. (2008). Building the Agile Enterprise: Myths, Perceptions, and Reality. Cutter Benchmark Review, 8(4), 5-13.

March, S. T., \& Smith, G. F. (1995). Design and natural science research on information technology. Decision support systems, 15(4), 251-266.

Markus, M. L., Majchrzak, A., \& Gasser, L. (2002). A design theory for systems that support emergent knowledge processes. MIS Quarterly, 179-212.

Martensson, A. (2007). Producting and Consuming Agility. In K. C. Desouza (Ed.), Agile Information Systems:Conceptualizaion,Construction, and Management (pp. 41-51). Oxford: Butterworth Heinemann.

Mathiassen, L., \& Pries-Heje, J. (2006). Business agility and diffusion of information technology. Eur J Inf Syst, 15(2), 116-119.

Maurer, C., \& Goodhue, D. (2010). A Theoretical Model of the Enterprise System Agility LifeCycle. Paper presented at the AMCIS 2010 Proceedings. .

McKinsey. (2006). Building a nimble organization: A Mckinsey Global Survey. Retrieved from http://www.mckinseyquarterly.com/Building_a nimble organization A McKinsey Global Survey 1808

MED. (2009). The Structure and Ownership of New Zealand Companies. Retrieved from http://www.med.govt.nz/templates/MultipageDocumentTOC 42161.aspx

Mell, P., \& Grance, T. (2010). The NIST Definition of Cloud Computing. Association for Computing Machinery. Communications of the ACM, 53(6), 50.

Microsoft. (2010). Cloud Services. Retrieved from http://download.microsoft.com/download/7/0/B/70B05EA3-233E-4677-A921DA409B4EADF6/Microsoft CloudServices.pdf.

Mullins, R. (2010). Agility, Not Savings, May Be The True Value Of The Cloud. Network Computing. Retrieved from http://www.networkcomputing.com/datacenter/agility-not-savings-may-be-the-true-value-of-the-cloud.php

Myers, M. D. (1997). Qualitative Research in Information Systems. MIS Quarterly, 21(2), 241242.

Myers, M. D., \& Newman, M. (2007). The qualitative interview in IS research: Examing the craft. Information and Organization, 17, 2-26.

Nazir, S., \& Pinsonneault, A. (2008). The Role of Information Technology in Firm Agility: An Electronic Integration Perspective. AMCIS 2008 Proceedings.

Ngo-Ye, L., \& Ahsan, M. (2005). Enterprise IT Application Systems Agility and Organizational Agility. Paper presented at the AMCIS 2005.

Nguyen, T. M., Schiefer, J., \& Tjoa, A. M. (2005). Sense and response service architecture (SARESA): an approach towards a real-time business intelligence solution and its use for a fraud detection application. Paper presented at the Proceedings of the 8th ACM international workshop on Data warehousing and OLAP, Bremen, Germany.

Nguyen, T. M., Schiefer, J., \& Tjoa, A. M. (2007). ZELESSA: an enabler for real-time sensing, analysing and acting on continuous event streams. International Journal of Business Intelligence and Data Mining, 2(1), 105-141.

Nunamaker Jr, J. F., Chen, M., \& Purdin, T. D. M. (1990). Systems Development in Information Systems Research. Journal of Management Information Systems, 7(3), 89-106.

Offermann, P., Levina, O., Schnherr, M., \& Bub, U. (2009). Outline of a design science research process. Paper presented at the Proceedings of the 4th International Conference on Design Science Research in Information Systems and Technology, Philadelphia, Pennsylvania. 
Oosterhout, M., Waarts, E., \& Hillegersberg, J. V. (2006). Change factors requiring agility and implications for IT. Eur J Inf Syst, 15(2), 132-145.

Oracle. (2010). Increase Business Performance through IT Agility. Retrieved from https://landingpad.oracle.com/webapps/dialogue/ns/dlgwelcome.jsp?p ext=Y\&p $\underline{\mathrm{dlg} i \mathrm{id}=8920806 \& \mathrm{src}=7011677 \& A \mathrm{At}=8}$

Orlikowski, W. J., \& Baroudi, J. J. (1991). Studying Information Technology in Organizations: Research Approaches and Assumptions. Information Systems Research, 2(1), 1-28.

Orlikowski, W. J., \& Iacono, C. S. (2001). Research commentary: Desperately seeking the "IT" in IT research-A call to theorizing the IT artifact. Information Systems Research, 12(2), 121-134.

Osinga, F. (2005). Science, Strategy and War. Delft, The Netherlands, 6.

Overby, E., Bharadwaj, A., \& Sambamurthy, V. (2006). Enterprise agility and the enabling role of information technology. Eur J Inf Syst, 15(2), 120-131.

Pankaj. (2005). An analysis and exploration of the construct of information systems agility. (Ph.D.), Southern Illinois University at Carbondale, United States -- Illinois.

Retrieved from http://proquest.umi.com/pqdweb?did=921027641\&Fmt $=7 \&$ clientId $=7511 \&$ RQT $=3$ 09\&VName $=$ PQD

Pankaj, Hyde, M., Ramaprasad, A., \& Tadisina, S. K. (2009). Revisiting Agility to Conceptualize Information Systems Agility. In M. D. Lytras \& P. O. d. Pablos (Eds.), Emerging Topics and Technologies in Information Systems (pp. 19-54).

Parasuraman, R., Sheridan, T. B., \& Wickens, C. D. (2000). A model for types and levels of human interaction with automation. IEEE Transactions on systems, man, and cybernetics-Part A: Systems and Humans, 30(3), 286-297.

Paschke, A., Vincent, P., \& Springer, F. (2011). Standards for complex event processing and reaction rules. Paper presented at the Proceedings of the 5 th international conference on Rule-based modeling and computing on the semantic web, Ft. Lauderdale, FL, USA.

Pavlou, P. A., \& El Sawy, O. A. (2010). The "Third Hand": IT-Enabled Competitive Advantage in Turbulence Through Improvisational Capabilities. Information Systems Research, 21(3), 443-471.

Peffers, K., Tuunanen, T., Rothenberger, M. A., \& Chatterjee, S. (2007). A design science research methodology for information systems research. Journal of Management Information Systems, 24(3), 45-77.

Pierce, J. R. (2012). An introduction to information theory: symbols, signals and noise: Courier Corporation.

Pike_River_Royal_Commission. (2010). Commission's Report - Volume 1 - What happened at Pike River. Royal Commission on the Pike River Coal Mine Tragedy. Retrieved from http://pikeriver.royalcommission.govt.nz/Volume-One---What-Happened-at-PikeRiver

Pinsonneault, A., \& Kraemer, K. L. (1993). Survey research methodology in Management Information Systems: An Assessment. Journal of Management Information Systems, 10(2), 75-105.

Porter, M. E. (1996). What is strategy? Harvard Business Review, 74(6), 61-78.

Prat, N., Comyn-Wattiau, I., \& Akoka, J. (2015). A taxonomy of evaluation methods for information systems artifacts. Journal of Management Information Systems, 32(3), 229-267. 
Ramasesh, R., Kulkarni, S., \& Jayakumar, M. (2001). Agility in manufacturing systems: an exploratory modelling framework and simulation. . Integrated Manufacturing Systems, 12(6/7), 537-548.

Rasouli, M., Ghazanfari, M., \& Eshuis, H. (2017). A process aware information system to support agility in relief operations. Paper presented at the 13th International Conference on Industrial Engineering (IIEC 2017).

Reich, Y. (1995). A critical review of general design theory. Research in Engineering Design, $7(1), 1-18$.

Reichert, M., Rinderle-Ma, S., \& Dadam, P. (2009). Flexibility in Process-Aware Information Systems. In J. Kurt \& M. A. Wil (Eds.), Transactions on Petri Nets and Other Models of Concurrency II (pp. 115-135): Springer-Verlag.

Rekik, M., Boukadi, K., Assy, N., Gaaloul, W., \& Ben-Abdallah, H. (2016). A linear program for optimal configurable business processes deployment into cloud federation. Paper presented at the Services Computing (SCC), 2016 IEEE International Conference on.

Remenyi, D., \& Sherwood-Smith, M. (1999). Maximise information systems value by continuous participative evaluation. Logistics Information Management, 12(1/2), 1431.

Ren, M., \& Lyytinen, K. (2008). Building Enterprise Architecture Agility and Sustenance with SOA. Communications of AIS, 2008, 75-86.

Richard, B., \& Jan, P. H. (2004). Short cycle time systems development. Information Systems Journal, 14(3), 237-264. doi:doi:10.1111/j.1365-2575.2004.00171.x

Robey, F., \& Markus, M. L. (1998). Beyond rigor and relevance:Producing consumable research about information systems. Information Resources Management Journal, 11(1), 7-15.

Rohde, M., Brödner, P., Stevens, G., Betz, M., \& Wulf, V. (2017). Grounded Design-a praxeological IS research perspective. Journal of Information Technology, 32(2), 163179.

Rouse, W. B. (2007). Agile Information for Agile Decision Making. In K. C. Desouza (Ed.), Agile Information Systems:Conceptualization,Construction, and Management (pp. 1629). Oxford: Butterworth Heinemann.

Rowley, J. (2007). The wisdom hierarchy: representations of the DIKW hierarchy. Journal of Information Science, 33(2), 163-180. doi:doi:10.1177/0165551506070706

Saad, S., \& Arakaki, R. (2014). An event processing architecture for operational risk management in an industrial environment. Paper presented at the Proceedings of the 8th ACM International Conference on Distributed Event-Based Systems, Mumbai, India.

Salmela, H., Tapanainen, T., Baiyere, A., Hallanoro, M., \& Galliers, R. (2015). IS Agility Research: An Assessment and Future Directions. Paper presented at the Twenty-Third European Conference on Information Systems.

Sambamurthy, V., Bharadwaj, A., \& Grover, V. (2003). Shaping agility through digital options: Reconceptualizing the role of information technology in contemporary Firms. MIS Quarterly, 27(2), 237.

Sawas, M., \& Watfa, M. (2015). The impact of cloud computing on information systems agility. Australasian Journal of Information Systems, 19.

Schatten, A., \& Schiefer, J. (2007, 24-26 Oct. 2007). Agile Business Process Management with Sense and Respond. Paper presented at the e-Business Engineering, 2007. ICEBE 2007. IEEE International Conference on. 
Schiefer, J., Rozsnyai, S., Rauscher, C., \& Saurer, G. (2007). Event-driven rules for sensing and responding to business situations. Paper presented at the Proceedings of the 2007 inaugural international conference on Distributed event-based systems, Toronto, Ontario, Canada.

Schiefer, J., \& Seufert, A. (2005, 28-30 Nov. 2005). Management and Controlling of TimeSensitive Business Processes with Sense and Respond. Paper presented at the Computational Intelligence for Modelling, Control and Automation, 2005 and International Conference on Intelligent Agents, Web Technologies and Internet Commerce, International Conference on.

Schoenfeld, A. H. (2014). Mathematical problem solving: Elsevier.

Schön, D. A. (1983). The reflective practitioner - how professionals think in action.: Basic Books.

Schön, D. A. (1988). Designing: rules, types, and worlds. Design Studies, 9, 181-190.

Schön, D. A. (1992). Designing as reflective conversation with the materials of a design situation. Knowledge-Based Systems, 5(1), 3-14.

Sengupta, K., \& Masini, A. (2008). IT agility: striking the right balance. Business Strategy Review, 19(2), 42.

SEO, D., \& Paz, A. I. L. (2008). Exploring the Dark Side of IS in Achieving Organizational Aagility. Communications of the ACM, 51(11), 136-139.

Setia, P., Sambamurthy, V., \& Closs, D. (2008). Realizing business value of agile IT applications: antecedents in the supply chain networks. Information Technology and Management, 9, 5.

Shafer, R. A., Dyer, L., Kilty, J., Amos, J., \& Ericksen, J. (2001). Crafting a human resource strategy to foster organizational agility: A case study. Human Resource Management, 40(3), 197.

Shambour, Q., \& Lu, J. (2012). A trust-semantic fusion-based recommendation approach for e-business applications. Decision Support Systems, 54(1), 768-780. doi:https://doi.org/10.1016/j.dss.2012.09.005

Sharifi, H., \& Zhang, Z. (2000). A methodology for achieving agility in manufacturing organizations. International Journal of Operations \& Production Management, 20(4), 496-513.

Sharifi, H., \& Zhang, Z. (2001). Agile manufacturing in practice: Application of a methodology. International Journal of Operations \& Production Management, 21(5/6), 772.

Sheppard, J. M., \& Young, W. B. (2006). Agility Literature Review: Classification, Training, and Testing. Journal of Sports Science, 24(9), 919-932.

Silva, A. R., Meziani, R., Magalhaes, R., Martinho, D., Aguiar, A., \& Flores, N. (2009). AGILIPO: Embedding social software features into business process tools. Paper presented at the International Conference on Business Process Management.

Silver, N. (2012). The signal and the noise: why so many predictions fail--but some don't: Penguin.

Simon, H. A. (1996). The sciences of the artificial. (3rd Ed.): MIT press. Chicago

Singh, S., \& Chana, I. (2012). Enabling reusability in agile software development. arXiv preprint arXiv:1210.2506.

Slack, N. (1993). Flexibility as a Manufacturing Objective. International Journal of Operations \& Production Management, 3(3), 4-13.

Smith, R. K., \& Montgomery, M. T. (2015). Toward clarity on understanding tropical cyclone intensification. Journal of the Atmospheric Sciences, 72(8), 3020-3031. 
Snowden, D. J., \& Boone, M. E. (2007). A leader's framework for decision making. Harvard Business Review, 85(11), 68.

Solano, M. A., Ekwaro-Osire, S., \& Tanik, M. M. (2012). High-Level fusion for intelligence applications using Recombinant Cognition Synthesis. Information Fusion, 13(1), 7998.

Sommerville, I. (2010). Software Engineering: Addison-Wesley Publishing Company.

Sull, D. (2010). Competing through organizational agility. The McKinsey Quarterly, 48.

Takeda, H., Veerkamp, P., \& Yoshikawa, H. (1990). Modeling design process. AI magazine, 11(4), 37.

Tecce, D. J., Pisano, G., \& Shuen, A. (1997). Dynamic capabilities and strategic management. Strategic Management Journal, 18(7), 509-533.

Tiwana, A., \& Konsynski, B. (2010). Complementarities between organizational IT architecture and governance structure. Information Systems Research, 21(2), 288(217).

Trinh-Phuong, T., Molla, A., \& Peszynski, K. (2010). Enterprise Systems and Organisational Agility: Conceptualizing the Link. Paper presented at the ACIS 2010 Proceedings. .

Truong, D. (2010). How Cloud Computing Enhances Competitive Advantages: A Research Model for Small Businesses. The Business Review, Cambridge, 15, 59.

Van der Aalst, W. M. (2009). Process-aware information systems: Lessons to be learned from process mining. In Transactions on petri nets and other models of concurrency II (pp. 1-26): Springer.

Van der Aalst, W. M., Lohmann, N., \& La Rosa, M. (2012). Ensuring correctness during process configuration via partner synthesis. Information Systems, 37(6), 574-592.

Venable, J., Pries-Heje, J., \& Baskerville, R. (2012). A comprehensive framework for evaluation in design science research. Paper presented at the International Conference on Design Science Research in Information Systems.

Venable, J., Pries-Heje, J., \& Baskerville, R. (2016). FEDS: a framework for evaluation in design science research. European Journal of Information Systems, 25(1), 77-89.

VMware. (2011). Business Agility and the True Economics of Cloud Computing Retrieved from https://www.vmware.com/content/dam/digitalmarketing/vmware/en/pdf/VMwa re Business Agility and the True Economics of Cloud Computing White Paper.pdf

Von Foerster, H. (2003). Disorder/order: discovery or invention? In Understanding Understanding (pp. 273-282): Springer.

Walls, J. G., Widmeyer, G. R., \& El Sawy, O. A. (1992). Building an information system design theory for vigilant EIS. Information Systems Research, 3(1), 36-59.

Wang, L., Tao, J., Kunze, M., Castellanos, A. C., Kramer, D., \& Karl, W. (2008 ). Scientific Cloud Computing: Early Definition and Experience. Paper presented at the High Performance Computing and Communications, 2008. HPCC '08. 10th IEEE International Conference on.

Weber, B., Reichert, M., \& Rinderle-Ma, S. (2008). Change patterns and change support features-enhancing flexibility in process-aware information systems. Data \& knowledge engineering, 66(3), 438-466.

Weber, R. (2004). The Rhetoric of Positivisim vs. Interpretivism : A personal view. MIS Quarterly, 28(1), iii-xii.

Webster, J., \& Watson, R. T. (2002). Analyzing the past to prepare for the future: Writing a literature review. . MIS Quarterly, 26 (2), iii-xiii. 
Weill, P., Subramani, M., \& Broadbent, M. (2002). Building IT infrastructure for strategic agility. MIT Sloan Management Review, 44(1), 57.

Whitehead, A. N., \& Sherburne, D. W. (1957). Process and reality: Macmillan New York, NY.

Winter, R. (2008). Design science research in Europe. European Journal of Information Systems, 17(5), 470-475.

Wohl, J. G. (1981). Force Management Decision Requirements for Air Force Tactical Command and Control. Systems, Man and Cybernetics, IEEE Transactions on, 11(9), 618-639. doi:10.1109/TSMC.1981.4308760

WorkSafe. (2013). Retrieved from http://www.worksafe.govt.nz/worksafe/about

Worksafe. (2015). Offences and penalties under the Health and Safety at Work Act 2015. Retrieved from http://www.worksafe.govt.nz/worksafe/information-guidance/allguidance-items/hswa-fact-sheets/offences-and-penalties-under-the-health-andsafety-at-work-act-2015

Yang, H., Antunes, P., \& Tate, M. (2016). Towards a unified conceptualisation of IS Agility. Paper presented at the The 20th IEEE International Conference on Computer Supported Cooperative Work in Design (CSCWD) Nan Chang, China.

Yang, H., Huff, S., \& Strode, D. (2009). Leadership in Software Development: Comparing Perceptions of Agile and Traditional Project Managers. Paper presented at the AMCIS 2009 Proceedings., San Francisco, USA.

Yang, H., Huff, S. L., \& Tate, M. (2013). Managing the Cloud for Information Systems Agility. In A. Bento \& A.K.Aggarwal (Eds.), Cloud Computing Service and Deployment Models: Layers and Management (pp. 70-93). Hershey, PA, USA: IGI Global.

Yang, H., \& Tate, M. (2012). A Descriptive Literature Review and Classification of Cloud Computing Research. Communications of the Association for Information Systems, 31(1/2), 35-60.

Yanofsky, N. S. (2003). A universal approach to self-referential paradoxes, incompleteness and fixed points. Bulletin of Symbolic Logic, 9(3), 362-386.

Yoshikawa, H. (1979). Introduction to General Design Theory

subtitle_in_Japanese. Journal of the Japan Society of Precision Engineering, 45(536), 906-912. doi:10.2493/jjspe1933.45.906

Young, M., \& McNeese, M. (1995). A Situated Cognition Approach to Problem Solving. . In P. Hancock, J. Flach, J. Caid, \& K. V. (Eds.) (Eds.), Local Applications of the Ecological Approach to Human Machine Systems. (pp. (pp. 359-391).). NJ: Erlbaum.: Hillsdale,.

Yousif, M., \& Pessi, K. (2016). It Agility Research Review: Thematic Analysis and Categorization of literature. Paper presented at the PACIS.

Zain, M., Rose, R. C., Abdullah, I., \& Masrom, M. (2005). The relationship between information technology acceptance and organizational agility in Malaysia. Information \& Management, 42(6), 829-839.

Zappia, I., Paganelli, F., \& Parlanti, D. (2012). A lightweight and extensible Complex Event Processing system for sense and respond applications. Expert Systems with Applications, 39(12), 10408-10419. doi:http://dx.doi.org/10.1016/j.eswa.2012.01.197 


\section{Appendix}

\section{Illustrations of potential software instantiation - configuration pages and a data classification page}

\begin{tabular}{|c|c|c|c|c|c|c|c|}
\hline Configure & Delete & Field Name & Data Type & Description & Location & Orde & der \\
\hline 3 & Q & Client Company & Dropdown & Select one client organisation which raised the matter - faced by IS Agility problems. & Top & & $\mathbf{v}$ \\
\hline 2 & $\theta$ & $\begin{array}{l}\text { Functional } \\
\text { Group }\end{array}$ & Dropdown & $\begin{array}{l}\text { The group(s) of users involved in the business activities described in this case. If selected Don't know, please explain in } \\
\text { case diary. }\end{array}$ & Top & $\Delta$ & $\mathbf{v}$ \\
\hline 2 & $\theta$ & $\begin{array}{l}\text { Current ISA } \\
\text { cycle-Sensing } \\
\text { ability }\end{array}$ & Dropdown & $\begin{array}{l}\text { Do the business activities described in this case involve gathering and collecting data? If yes, how satisfactory are the } \\
\text { speed and quality? }\end{array}$ & Top & $\mathbf{A}$ & $\mathbf{v}$ \\
\hline Z & $\theta$ & $\begin{array}{l}\text { Current ISA } \\
\text { cycle- } \\
\text { Diagnosing } \\
\text { ability }\end{array}$ & Dropdown & $\begin{array}{l}\text { Do the business activities described in this case involve analysing and interpreting data? If yes, how satisfactory are the } \\
\text { speed and quality? }\end{array}$ & Top & $\Delta$ & $\boldsymbol{v}$ \\
\hline 2 & (2) & $\begin{array}{l}\text { Current ISA } \\
\text { cycle- } \\
\text { Selecting ability }\end{array}$ & Dropdown & $\begin{array}{l}\text { Do the business activities described in this case involve selecting from available options or choosing to create new } \\
\text { options in order to make a response? If yes, how satisfactory are the speed and quality? }\end{array}$ & Top & $\Delta$ & $\mathbf{v}$ \\
\hline G & (2) & $\begin{array}{l}\text { Current ISA } \\
\text { cycle - } \\
\text { Executing } \\
\text { ability }\end{array}$ & Dropdown & $\begin{array}{l}\text { Do the business activities described in this case involve executing actions to make a response? If yes, how satisfactory } \\
\text { are the speed and quality? }\end{array}$ & Top & $\Delta$ & $\mathbf{v}$ \\
\hline & $\theta$ & $\begin{array}{l}\text { Current Dev S- } \\
\text { R }\end{array}$ & Dropdown & $\begin{array}{l}\text { If the business activities described in this case involves IS development, please rate the level of satisfactory in terms o } \\
\text { speed and quality. Otherwise choose N/A. }\end{array}$ & Top & $\Delta$ & $\mathbf{v}$ \\
\hline & $\theta$ & $\begin{array}{l}\text { Current Ops S- } \\
\text { R }\end{array}$ & Dropdown & $\begin{array}{l}\text { If the business activities described in this case involves IS operation, please rate the level of satisfactory in terms o speed } \\
\text { and quality. Otherwise choose N/A. }\end{array}$ & Top & $\Delta$ & $\boldsymbol{\nabla}$ \\
\hline & $\theta$ & Current $\Delta S-R$ & Dropdown & $\Delta S-R=$ current response time once a change is sensed? If answered "Don't know', please explain in the case diary. & Top & $\Delta$ & $\mathbf{v}$ \\
\hline 2 & 웅 & Expected $\Delta S-R$ & Dropdown & $\begin{array}{l}\text { After resolving this case, what is the expected response time when a change is sensed in the same business activities } \\
\text { described in this case? If answered "Don't know", please explain in the case diary. }\end{array}$ & Top & $\mathbf{A}$ & $\mathbf{v}$ \\
\hline 2 & Q & $\begin{array}{l}\text { Spatial } \\
\text { Dimension }\end{array}$ & Dropdown & $\begin{array}{l}\text { If uncertain, then knowing the nature of changes involved in the business activities described in this case is not possible. } \\
\text { Thus no response can be prepared. On the opposite, if the nature is known, then confident. No matter which option is } \\
\text { selected, please explain in the case diary. }\end{array}$ & Top & $\Delta$ & $\mathbf{v}$ \\
\hline Z & Q & $\begin{array}{l}\text { Temporal } \\
\text { Dimension }\end{array}$ & Dropdown & $\begin{array}{l}\text { If uncertain, then the timing of changes in the business activities involved in this case cannot be known. On the opposite, } \\
\text { if timing can be known, then choose confident. Please explain in the case diary no matter which option is selected. }\end{array}$ & Top & $\Delta$ & $\mathbf{v}$ \\
\hline 3 & $\theta$ & $\begin{array}{l}\text { Current Friction } \\
\text { reducer }\end{array}$ & Dropdown & $\begin{array}{l}\text { Current approaches used to reduce matters that slow down IS agility cycles. Please explain in detail in the case diary no } \\
\text { matter which option you chose. }\end{array}$ & Top & $\Delta$ & $\nabla$ \\
\hline 2 & $\theta$ & $\begin{array}{l}\text { Current Torque } \\
\text { booster }\end{array}$ & Dropdown & $\begin{array}{l}\text { Current approaches used to increase matters that speed up IS agility cycles. Please explain in detail in the case diary no } \\
\text { matter which option you chose. }\end{array}$ & Top & $\Delta$ & 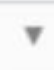 \\
\hline
\end{tabular}




\begin{tabular}{|c|c|c|c|c|c|c|c|}
\hline 2 & $\theta$ & $\begin{array}{l}\text { Current Control } \\
\text { Level }\end{array}$ & Dropdown & $\begin{array}{l}\text { What is the main party controlling the execution of business activities involved in this case? If answered "Don't know", } \\
\text { please explain in the case diary. }\end{array}$ & Top & $\Lambda$ & $\mathbf{\nabla}$ \\
\hline 2 & Q & $\begin{array}{l}\text { Expected } \\
\text { Control Level }\end{array}$ & Dropdown & $\begin{array}{l}\text { After resolving this case, what is the expected main party controlling the execution of business activities involved in this } \\
\text { case? If answered "Don't know", please explain in the case diary. }\end{array}$ & Top & $\Delta$ & $\mathbf{\nabla}$ \\
\hline 8 & (2) & $\begin{array}{l}\text { Nature of } \\
\text { situation }\end{array}$ & Dropdown & Is the situation described in this case a new or existing one? If answered "Don't know", please explain in the case diary. & Top & $\boldsymbol{\Lambda}$ & $\mathbf{\nabla}$ \\
\hline L & Q & $\begin{array}{l}\text { Change } \\
\text { Frequency }\end{array}$ & Dropdown & How often do changes occur regarding this matter. If answered "Don't know", please explain in the case diary. & Top & $\Delta$ & $\boldsymbol{\nabla}$ \\
\hline 2 & $\theta$ & Time Criticality & Dropdown & $\begin{array}{l}\text { How critical is it to sense and respond to this matter in a timely and accurate manner? If answered "Don't know", please } \\
\text { explain in the case diary. }\end{array}$ & Top & $\Lambda$ & $\boldsymbol{v}$ \\
\hline 2 & $\theta$ & $\begin{array}{l}\text { Information } \\
\text { Intensity }\end{array}$ & Dropdown & $\begin{array}{l}\text { How intensively is computer-supported information processing being used in sensing and responding to this matter? } \\
\text { Deciding a rough percentage of the chances when decisions and actions have to be based on results from computer- } \\
\text { supported information processing. If answered "Don't know", please explain in the case diary. }\end{array}$ & Top & $\boldsymbol{\Lambda}$ & \\
\hline 2 & Q & $\begin{array}{l}\text { Cognitive } \\
\text { Hierarchy Level } \\
1 \text { - Data }\end{array}$ & Dropdown & $\begin{array}{l}\text { Is data (collected raw, unprocessed) the priority for carrying out the business activities involved in this case? If answered } \\
\text { "Don't know", please explain in the case diary. }\end{array}$ & Left & & $\boldsymbol{\nabla}$ \\
\hline 2 & $\theta$ & $\begin{array}{l}\text { Cognitive } \\
\text { Hierarchy Level } \\
2 \text { - Information }\end{array}$ & Dropdown & $\begin{array}{l}\text { Is information (derived from processing raw data) the priority for carrying out the business activities involved in this case? } \\
\text { If answered "Don't know", please explain in the case diary. }\end{array}$ & Left & $\Lambda$ & $\boldsymbol{\nabla}$ \\
\hline 2 & 9 & $\begin{array}{l}\text { Cognitive } \\
\text { Hierarchy Level } \\
3-\text { Knowledge }\end{array}$ & Dropdown & $\begin{array}{l}\text { Is knowledge (derived from analysing information) the priority for carrying out the business activities involved in this } \\
\text { case? If answered "Don't know", please explain in the case diary. }\end{array}$ & Left & $A$ & $\mathbf{\nabla}$ \\
\hline 2 & 익 & $\begin{array}{l}\text { Cognitive } \\
\text { Hierarchy Level } \\
4 \text { - Wisdom }\end{array}$ & Dropdown & $\begin{array}{l}\text { Is wisdom (derived from understand knowledge) a priority for carrying out the key business activities involved in this } \\
\text { case? If answered "Don't know", please explain in the case diary. }\end{array}$ & Left & 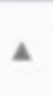 & $\boldsymbol{\nabla}$ \\
\hline
\end{tabular}




\begin{tabular}{|c|c|c|c|c|c|c|c|}
\hline 2 & $\theta$ & $\begin{array}{l}\text { Planned level of } \\
\text { automation }\end{array}$ & Dropdown & $\begin{array}{l}\text { After this case is resolved, to what degree the business activities described in this case will be automated? If selected } \\
\text { Don't know, please try explain in the case diary. }\end{array}$ & Left & $\Delta$ & $\mathbf{\nabla}$ \\
\hline 3 & (2) & $\begin{array}{l}\text { Current level of } \\
\text { automation }\end{array}$ & Dropdown & $\begin{array}{l}\text { How much the business activities described in this case are currently automated? If selected Don't know, please try } \\
\text { explain in the case diary. }\end{array}$ & Left & $\Delta$ & $\mathbf{\nabla}$ \\
\hline L & $\theta$ & $\begin{array}{l}\text { Planned } \\
\text { Friction reducer }\end{array}$ & Dropdown & $\begin{array}{l}\text { Planned approaches to be used to reduce matters that slow down IS agility cycles. Please explain in detail in the case } \\
\text { diary no matter which option you chose. }\end{array}$ & Left & $\Delta$ & $\mathbf{\nabla}$ \\
\hline 2 & (2) & $\begin{array}{l}\text { Planned Torque } \\
\text { booster }\end{array}$ & Dropdown & $\begin{array}{l}\text { Planned approaches to be used to increase matters that speed up IS agility cycles. Please explain in detail in the case } \\
\text { diary no matter which option you chose. }\end{array}$ & Left & $\Delta$ & $\mathbf{\nabla}$ \\
\hline 2 & (2) & $\begin{array}{l}\text { Modified ISA } \\
\text { cycle - Sensing } \\
\text { ability }\end{array}$ & Dropdown & To be rated by the whoever initiated this case after the implementation of the solution designed. & Left & $\Delta$ & $\mathbf{\nabla}$ \\
\hline 2 & (2) & $\begin{array}{l}\text { Modified ISA } \\
\text { cycle - } \\
\text { Diagnosing } \\
\text { ability }\end{array}$ & Dropdown & To be rated by the whoever initiated this case after the implementation of the solution designed. & Left & $\mathbf{\Delta}$ & $\mathbf{\nabla}$ \\
\hline 2 & $\theta$ & $\begin{array}{l}\text { Modified ISA } \\
\text { cycle - } \\
\text { Selecting ability }\end{array}$ & Dropdown & To be rated by the whoever initiated this case after the implementation of the solution designed. & Left & $\Delta$ & $\mathbf{\nabla}$ \\
\hline 2 & Q & $\begin{array}{l}\text { Current ISA } \\
\text { cycle - } \\
\text { Executing } \\
\text { ability }\end{array}$ & Dropdown & To be rated by the whoever initiated this case after the implementation of the solution designed. & Left & $\mathbf{\Delta}$ & \\
\hline+ & Add & w Custom Field & & & & & \\
\hline
\end{tabular}




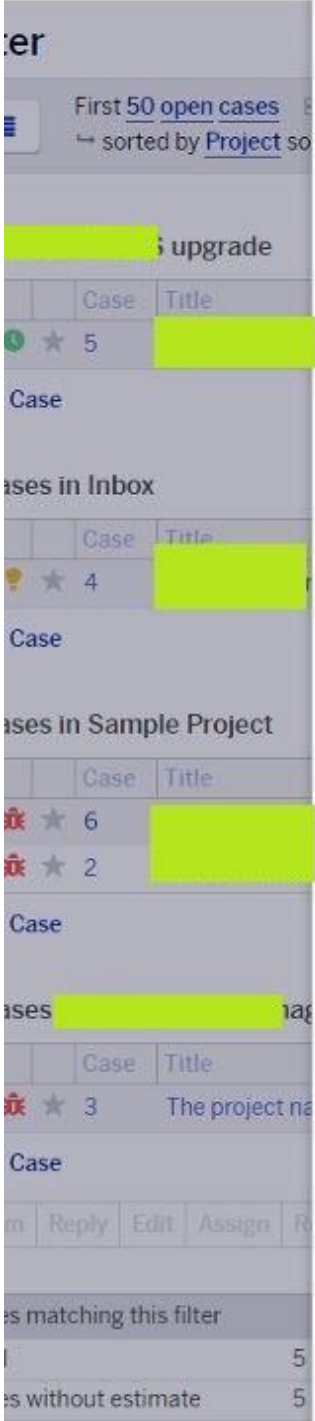

5

Active

as Priority

- 3-Must Fix 2 days

Release Notes

Add release note

Cognitive Hierarchy Level 1 - Data High priority

Cognitive Hierarchy Level 2 . Information

Essential

\begin{tabular}{|c|c|c|}
\hline Project: & Area: Misc & one: Undecided \\
\hline Client Company & $\begin{array}{l}\text { Functional Group } \\
\text { Senior Managers }\end{array}$ & $\begin{array}{l}\text { Current ISA cycle - Sensing ability } \\
\text { Very dissatisfied }\end{array}$ \\
\hline $\begin{array}{l}\text { Current ISA cycle - Diagnosing ability } \\
\text { Very dissatisfied }\end{array}$ & $\begin{array}{l}\text { Current ISA cycle - Selecting ability } \\
\text { Very dissatisfied }\end{array}$ & $\begin{array}{l}\text { Current ISA cycle - Executing ability } \\
\text { Very dissatisfied }\end{array}$ \\
\hline $\begin{array}{l}\text { Current Dev S-R } \\
\text { Very dissatisfied }\end{array}$ & $\begin{array}{l}\text { Current Ops S-R } \\
\text { Very dissatisfied }\end{array}$ & $\begin{array}{l}\text { Current } \Delta S-R \\
\text { Months }\end{array}$ \\
\hline $\begin{array}{l}\text { Expected } \Delta S-R \\
\text { Weeks }\end{array}$ & $\begin{array}{l}\text { Spatial Dimension } \\
\text { Uncertain }\end{array}$ & $\begin{array}{l}\text { Temporal Dimension } \\
\text { Uncertain }\end{array}$ \\
\hline $\begin{array}{l}\text { Current Friction reducer } \\
\text { None }\end{array}$ & $\begin{array}{l}\text { Current Torque booster } \\
\text { None }\end{array}$ & $\begin{array}{l}\text { Current Control Level } \\
\text { Mostly Human control }\end{array}$ \\
\hline $\begin{array}{l}\text { Expected Control Level } \\
\text { Mix (roughly 50/50) }\end{array}$ & $\begin{array}{l}\text { Nature of situation } \\
\text { Novel }\end{array}$ & $\begin{array}{l}\text { Change Frequency } \\
\text { Often }\end{array}$ \\
\hline $\begin{array}{l}\text { Time Criticality } \\
\text { Extremely important }\end{array}$ & $\begin{array}{l}\text { Information Intensity } \\
\text { High intensity over } 61-100 \%\end{array}$ & \\
\hline
\end{tabular}

\section{Tith Edited by}

Revised 10:27 PM entry from 09/17/2016

09/18/2016 9:47 PM

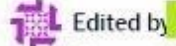

Current ISA cycle - Sensing ability changed from 'Not at all satisfied' to 'Very dissatisfied'.

Current ISA cycle - Diagnosing ability changed from 'Not at all satisfied' to 'Very dissatisfied'
Current ISA cycle - Selecting ability changed from 'Not at all satisfied' to 'Very dissatisfied'.

Current ISA cycle - Executing ability changed from 'Not at all satisfied' to 'Very dissatisfied'.

Current Dev S-R changed from 'Not at all satisfied' to 'Very dissatisfied'.

Current Ops S-R changed from 'Not at all satisfied' to 'Very dissatisfied'

Modified ISA cycle - Diagnosing ability changed from (No Value) to ' $N$ /A'

Modified ISA cycle - Selecting ability changed from (No Value) to 'N/A'.

Current ISA cycle - Executing ability changed from (No value) to 'N/A'

09/18/2016 9:46 PM 